Prepared for the U.S. Department of Energy

under Contract DE-AC05-76RL01830

\title{
Lateral Earth Pressure at Rest and Shear Modulus Measurements on Hanford Sludge Simulants
}
BE Wells
NN Bauman
JJ Jenks
AD Guzman
G Boeringa

Pacific Northwest National Laboratory

P Arduino

PJ Keller

University of Washington

September 2010

\section{Pacific Northwest}

NATIONAL LABORATORY

Proudly Operated by Baltelle Since 1965 


\title{
DISCLAIMER
}

This report was prepared as an account of work sponsored by an agency of the United States Government. Neither the United States Government nor any agency thereof, nor Battelle Memorial Institute, nor any of their employees, makes any warranty, express or implied, or assumes any legal liability or responsibility for the accuracy, completeness, or usefulness of any information, apparatus, product, or process disclosed, or represents that its use would not infringe privately owned rights. Reference herein to any specific commercial product, process, or service by trade name, trademark, manufacturer, or otherwise does not necessarily constitute or imply its endorsement, recommendation, or favoring by the United States Government or any agency thereof, or Battelle Memorial Institute. The views and opinions of authors expressed herein do not necessarily state or reflect those of the United States Government or any agency thereof.

\author{
PACIFIC NORTHWEST NATIONAL LABORATORY \\ operated by \\ BATTELLE \\ for the \\ UNITED STATES DEPARTMENT OF ENERGY \\ under Contract DE-ACO5-76RL01830
}

Printed in the United States of America
Available to DOE and DOE contractors from the
Office of Scientific and Technical Information,
P.O. Box 62, Oak Ridge, TN 37831-0062;
ph: (865) 576-8401
fax: (865) 5765728
email: reports@adonis.osti.gov

\author{
Available to the public from the National Technical Information Service, \\ U.S. Department of Commerce, 5285 Port Royal Rd., Springfield, VA 22161 \\ ph: (800) 553-6847 \\ fax: (703) 605-6900 \\ email: orders@nits.fedworld.gov \\ online ordering: http://www.ntis.gov/ordering.htm
}




\title{
Lateral Earth Pressure at Rest and Shear Modulus Measurements on Hanford Sludge Simulants
}

\author{
BE Wells NN Bauman \\ JJ Jenks \\ AD Guzman \\ G Boeringa \\ Pacific Northwest National Laboratory \\ P Arduino \\ PJ Keller \\ University of Washington
}

September 2010

Prepared for

the U.S. Department of Energy

under Contract DE-AC05-76RL01830

Pacific Northwest National Laboratory

Richland, Washington 



\section{Summary}

This report describes the equipment, techniques, and results of lateral earth pressure at rest and shear modulus measurements on kaolin clay as well as two chemical sludge simulants. The testing was performed in support of the problem of hydrogen gas retention and release encountered in the doubleshell tanks (DSTs) at the Hanford Site near Richland, Washington. Wastes from single-shell tanks (SSTs) are being transferred to double-shell tanks (DSTs) for safety reasons (some SSTs are leaking or are in danger of leaking), but the available DST space is limited.

The current System Plan for the Hanford Tank Farms (Rev. 4, Certa and Wells 2009) uses relaxed buoyant displacement gas release event (BDGRE) controls for deep sludge (i.e., high- level waste [HLW]) tanks, which allows the tank farms to use more storage space in some of the DSTs. The relaxed BDGRE controls are based on preliminary analysis of a gas release model from van Kessel and van Kesteren (2002). Applying the van Kessel and van Kesteren model requires parametric information for the sediment, including the lateral earth pressure at rest and shear modulus.

A device to concurrently measure the lateral earth pressure at rest $\left(\mathrm{k}_{0}\right)$ and shear modulus $\left(\mathrm{G}_{\max }\right)$, the " $\mathrm{k}_{0}$ consolidometer," was designed and produced. Independent measurements taken with reproductions of this device using kaolin clay slurries over a shear-strength range similar to that of Hanford sludge are shown to be in agreement with the literature.

The $\mathrm{k}_{0}$ consolidometer was used to measure the $\mathrm{k}_{0}$ and $\mathrm{G}_{\max }$ of chemical Simulants 1 and 2 of Wells et al. (2010), which have chemical and physical properties that match well with the Hanford sludge parameters considered. The lateral earth pressure at rest of the chemical simulants have nominally similar functionality with respect to their shear strength. Decreasing $\mathrm{k}_{0}$, described from the data by

$$
\mathrm{k}_{0}=0.5052 \tau^{-0.0927}
$$

with a variation of $\mathrm{k}_{0}=0.08$ [variation to encompass data spread, not uncertainty of Equation (S.1)] approximates both chemical simulants over the range of shear strength tested. Unique relations are described for $\mathrm{G}_{\max }$ as

$$
\mathrm{G}_{\max }=1232.2 \tau
$$

for Simulant 1 and

$$
\mathrm{G}_{\max }=264.6 \tau
$$

for Simulant 2.

No measurements of the lateral earth pressure at rest and shear modulus are currently available for actual Hanford sludge. Thus, it is not possible to establish that the lateral earth pressure at rest and shear modulus measured on the chemical simulants and the relationship to shear strength described by these 
measurements represent these parameters for actual Hanford sludge. Further, although the simulants are unique with respect to each other, they do not represent the possible range of actual Hanford sludge.

Recommendations are made addressing the enhancement and expansion of the simulant data set, the analysis of existing and future actual Hanford waste characterization data for insight into the shear modulus, and hot-cell testing of actual waste samples. 


\section{Acronyms and Abbreviations}

$\begin{array}{ll}\text { BBI } & \text { Best Basis Inventory } \\ \text { BDGRE } & \text { buoyant displacement gas release event } \\ \text { DST } & \text { double-shell tank } \\ \text { EQL } & \text { estimated quantification limit } \\ \text { ESP } & \text { Environmental Simulation Program } \\ \text { HLW } & \text { high-level waste } \\ \text { KOH } & \text { potassium hydroxide } \\ \text { MDL } & \text { method detection limit } \\ \text { PEP } & \text { Pretreatment Engineering Platform } \\ \text { PNNL } & \text { Pacific Northwest National Laboratory } \\ \text { PSD } & \text { particle-size distribution } \\ \text { PSDD } & \text { particle size and density distribution } \\ \text { REDOX } & \text { reduction oxidation } \\ \text { RPP } & \text { River Protection Project } \\ \text { SEM } & \text { scanning electron microscopy } \\ \text { SST } & \text { single-shell tank } \\ \text { TOC } & \text { total organic carbon } \\ \text { UDS } & \text { undissolved solids } \\ \text { WTP } & \text { Hanford Tank Waste Treatment and Immobilization Plant } \\ \text { XRD } & \text { X-ray diffraction }\end{array}$





\section{Contents}

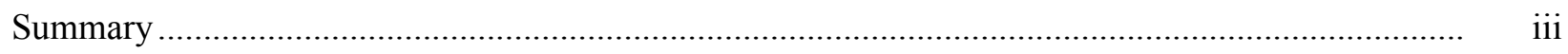

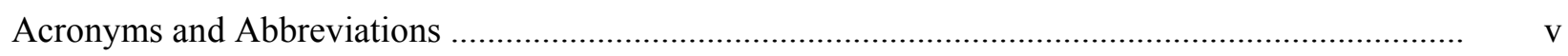

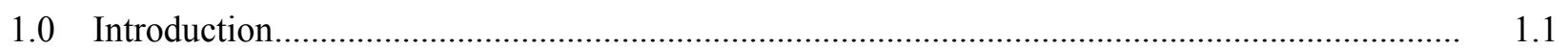

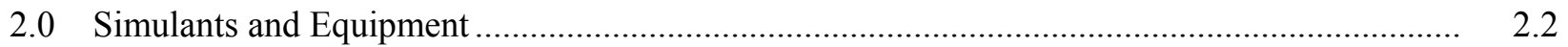

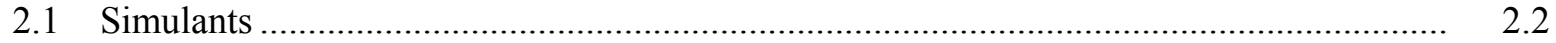

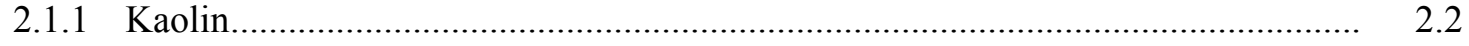

2.1.2 Chemical Simulants …................................................................................... 2.3

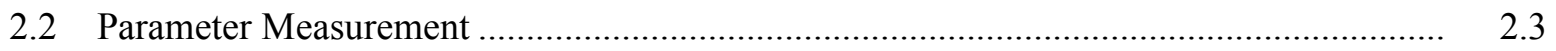

2.2.1 Lateral Earth Pressure at Rest ................................................................... 2.3

2.2.2 Shear Modulus ........................................................................................... 2.6

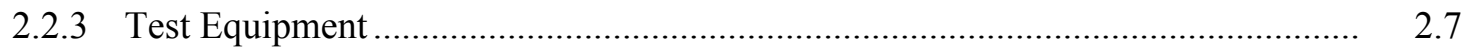

2.2.4 Parameter Calculation and Uncertainty ........................................................ 2.13

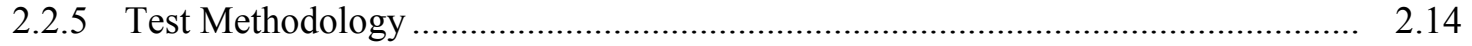

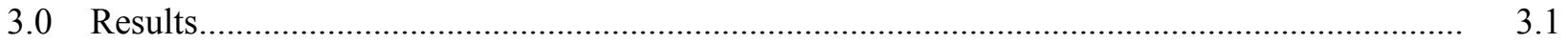

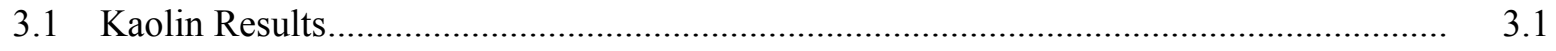

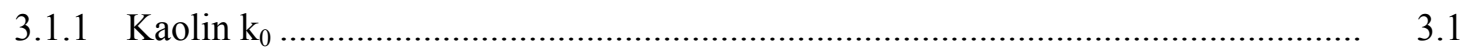

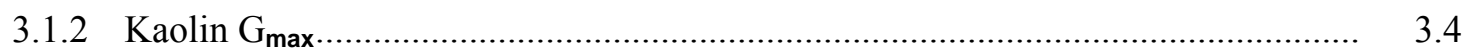

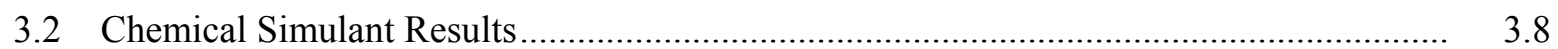

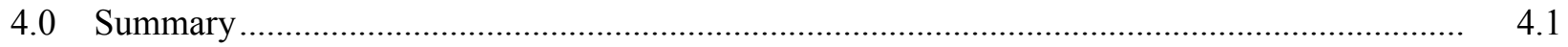

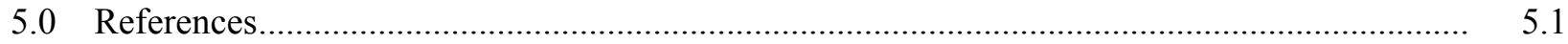

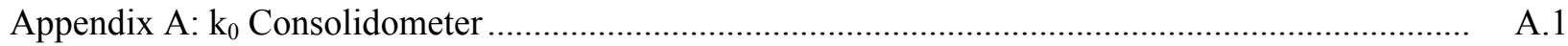

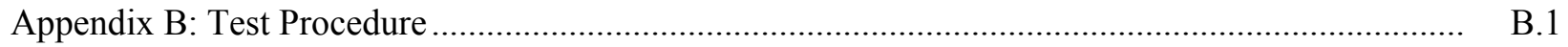

Appendix C: Kaolin Test Data ......................................................................................... C.1

Appendix D: Chemical Simulant Test Data ......................................................................... D. D. 


\section{Figures}

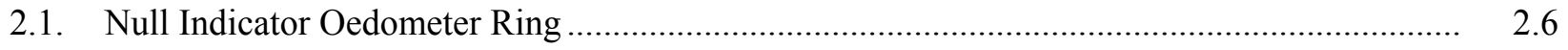

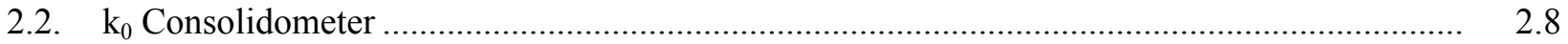

2.3. Consolidation Test Facility ......................................................................................... 2.9

2.4. $\mathrm{k}_{0}$ Consolidometer and Displacement Gauge ............................................................. 2.10

2.5. Consolidation Frame ….............................................................................................. 2.10

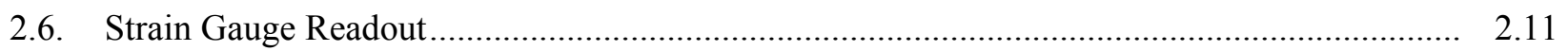

2.7. Air Pressure Pump and Pressure Gauge .............................................................................. 2.11

2.8. Bender Element System (a) with Signal Readout (b) ...................................................... 2.12

2.9. Example of Displacement as a Function of the Square Root of Displacement Time............... 2. 2.16

2.10. Example of Displacement as a Function of the Displacement Time ...................................... 2.16

2.11. Average Sleeve Strain Gauge Reading (readout value shown, 1.0 counts is 0.0001 on readout) as a Function of Outer Chamber Air Pressure ......................................................... 2.17

2.12. Bender Element Response Example, Single or Equal Peaks............................................... 2.. 2.18

2.13. Bender Element Response Example, Unequal Peaks ........................................................... 2.19

3.1. $\mathrm{k}_{0}$ as a Function of the Initial Mass Fraction of Kaolin .................................................... 3.3

3.2. $\mathrm{k}_{0}$ as a Function of the Kaolin Plasticity Index................................................................ 3.4

3.3. Shear Wave Velocity as a Function of the Time-of-Measurement Mass Fraction of Kaolin..... 3.7

3.4. Kaolin Shear Wave Velocity as a Function of Sample Shear Strength ................................... 3.7

3.5. Kaolin Shear Modulus as a Function of Sample Shear Strength ............................................ 3.8

3.6. Chemical Simulant $\mathrm{k}_{0}$ as a Function of Sample Shear Strength .......................................... 3.10

3.7. Chemical Simulant $\mathrm{k}_{0}$ as a Function of Sample Shear Strength, Linear Functionality ............. 3.12

3.8. Chemical Simulant $\mathrm{G}_{\max }$ as a Function of Sample Shear Strength ........................................ 3.12

3.9. Chemical Simulant; Comparison of Shear Modulus Methods ............................................. 3.13 


\section{Tables}

2.1. $\mathrm{k}_{0}$ Consolidometer As-Built Measurements ...................................................................... 2.9

2.2. Test Equipment Primary Components............................................................................... 2.13

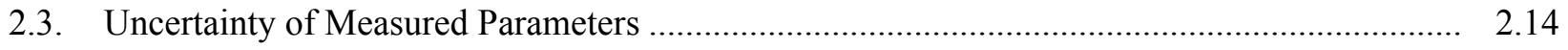

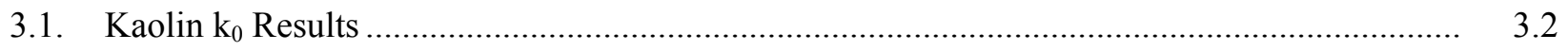

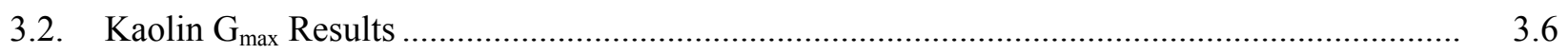

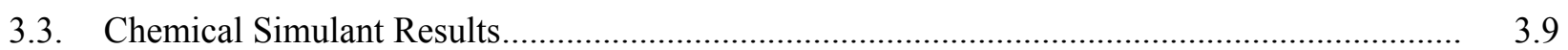





\subsection{Introduction}

Radioactive wastes composed of liquid (water and dissolved solids) and settled undissolved solids (UDS) are stored in 177 large underground storage tanks on the Hanford Site. The 177 storage tanks include 149 single shell tanks (SSTs) and 28 double shell tanks (DSTs). Waste will be retrieved from the SSTs to interim storage in the DSTs. Certa and Wells (2009) (System Plan, Rev. 4) report that the Baseline Case, which, in part, describes how the River Protection Project (RPP) mission ${ }^{(a)}$ could be achieved given an underlying set of assumptions, shows that there is adequate DST space to meet the near-term success criteria for specific SST retrieval. Subsequently, however, there will be minimal DST space available to proceed with additional SST retrievals. Management of DST space is thus a key issue.

The UDS management strategy in the previous System Plan (Rev. 3) followed the existing buoyant displacement gas release event (BDGRE) controls (Weber 2008). The depth of settled UDS or sediment accumulated in a DST, and therefore the inventory of UDS that may be stored in a DST, is limited by these controls. The current System Plan (Rev. 4, Certa and Wells 2009) uses relaxed BDGRE controls for deep sludge (i.e., high-level waste [HLW]) tanks, which allow the tank farms to use more storage space in some of the DSTs. The relaxed BDGRE controls are based on preliminary analysis of a gas release model from van Kessel and van Kesteren (2002).

The van Kessel and van Kesteren model requires parametric information for the sediment, including the lateral earth pressure at rest and shear modulus. No actual Hanford sludge measurements of these two parameters are currently available. The lateral earth pressure at rest and shear modulus are experimentally measured for the two Hanford sludge simulants that were intended specifically for this purpose (Wells et al. 2010). In Section 2, the sludge simulants and instrumentation are described. Test results are provided in Section 3, and a summary is provided in Section 4.

(a) The RPP mission is to retrieve and treat Hanford's tank waste and close the tank farms to protect the Columbia River. 


\subsection{Simulants and Equipment}

No measurements of the lateral earth pressure at rest and shear modulus are currently available for actual Hanford sludge. Although the lateral earth pressure at rest is a common measurement in soil mechanics, it is typically determined via an indirect method. Van Kessel and van Kesteren (2002) used a unique direct measurement method for the lateral earth pressure at rest. Thus, a direct measurement methodology for the lateral earth pressure at rest has been developed and employed, and a simulant (kaolin clay) with well-quantified lateral earth pressure at rest and shear modulus has been employed to develop the testing methodology and establish the validity of the measurement techniques.

Two chemical simulants were selected and developed in Wells et al. (2010) to be used to experimentally measure lateral earth pressure at rest and shear modulus representative of Hanford sludge sediment. The kaolin and chemical simulants are summarized in Section 2.1, and the parameter measurement is described in Section 2.2.

\subsection{Simulants}

As described in Section 2.1.1, kaolin clay was chosen as the simulant used to develop the testing methodology and establish the validity of the measurement techniques. The two chemical simulants representative of Hanford sludge sediment are summarized in Section 2.1.2.

\subsubsection{Kaolin}

EPK kaolin (Edgar Minerals Inc. Edgar, FL) was mixed with de-ionized water to provide slurries at various concentrations (i.e., mass of clay per total mass of slurry). Recent characterization of kaolin slurries is provided in Bontha et al. (2010) and Burns et al. (2010).

Numerous experimental studies related to the storage and retrieval of waste from the large underground Hanford storage tanks have employed clay slurries as simulants to represent the waste of interest. These studies have included investigations of gas retention and release (Gauglitz et al. 1994, 1995, 1996, Stewart et al. 1996, etc.), sediment mobilization (Powell et al. 1995, Enderlin et al. 2003, Bontha et al. 2005, Kurath et al. 2007, etc.), and slurry transport (Poloski et al. 2009, Bontha et al. 2010). Gauglitz and Aiken (1997) developed a method to obtain shear strength estimates for Hanford sediment via visual observation of waste core extrusion behavior in comparison to clay simulants.

The lateral earth pressure at rest of kaolin clay is established in the literature. Federico et al. (2008) provides a summary of experimental measurements on various kaolin clays from Poulos (1978) Abdelhamid and Krizek (1976), Edil and Dhowian (1981), Moore and Cole (1977), Perry and Wroth (1976), Sketchly and Bransby (1973), Burland (1967), and Singh (1971). The lateral earth pressure at rest of kaolin can also be determined from Prashant and Penumadu (2005). Although there are numerous references for the shear modulus of kaolin clay, only limited information was identified for the relatively low shear strength range of interest (Oh et al. 2008, Black 2009). ${ }^{\text {a) }}$

(a) The upper 95\% empirical limit for the shear strength of Hanford sludge is approximately 10,000 Pa (Wells et al. 2010). 
As established by the previously listed studies, kaolin clay has successfully been used as a Hanford waste simulant, and the lateral earth pressure at rest and shear modulus of kaolin slurries have been evaluated. In addition, kaolin is non-hazardous and readily available. Kaolin clay simulant is therefore used to develop the testing methodology and establish the validity of the measurement techniques.

\subsubsection{Chemical Simulants}

As described in Wells et al. (2010), the lateral earth pressure at rest and shear modulus are expected to be influenced by the chemical and physical properties of the sludge material. Chemical Simulants 1 and 2 of Wells et al. (2010) were shown to have chemical and physical properties that match well with all of the Hanford sludge parameters considered. The parameters considered were the chemical composition of the solid and liquid phases; the density, viscosity, and $\mathrm{pH}$ of the liquid; the solid particle size and shape, and the slurry rheology. The simulants are unique with respect to each other for some of the parameters considered and fall within the broad variation of Hanford waste.

Simulant 1, chosen from Hanford sludge simulants that have previously been produced and characterized, was selected to represent the Hanford sludge as a whole. Simulant 2 was developed in Wells et al. (2010) to represent the resultant sludge of a specific SST into a DST retrieval scenario (C-104, C-111, and C-112 retrieval into AN-101).

As specified, no measurements of the lateral earth pressure at rest and shear modulus are currently available for actual Hanford sludge. It is thus not possible to establish that the lateral earth pressure at rest and shear modulus measured on Simulants 1 and 2 actually represent these parameters for actual Hanford sludge. In addition, although the simulants are unique with respect to each other, they do not represent the possible range of actual Hanford sludge.

\subsection{Parameter Measurement}

The test equipment is designed to directly measure the lateral earth pressure at rest and shear modulus. Parameter definitions and equipment for these measurements are discussed in Section 2.2.1 and 2.2.2, and the employed test equipment is described in Section 2.2.3. The parameter calculations are listed in Section 2.2.4, and the test methodology is summarized in Section 2.2.5.

\subsubsection{Lateral Earth Pressure at Rest}

The lateral earth pressure at rest, $\mathrm{k}_{0}$, is the ratio of the lateral (horizontal) pressure to the vertical pressure when the lateral strain is zero (Craig 2004). Although $\mathrm{k}_{0}$ can be measured in situ (e.g., dilatometer test or borehole pressure meter test), the Hanford waste environment is such that applying in situ methodologies is challenging.

A common indirect methodology to determine the lateral earth pressure at rest uses the empirical relation of Jaky (1948), which uses the friction angle, itself affected by the material properties that affect stress. Although reasonable agreement in $\mathrm{k}_{0}$ is seen between the Jaky (1948) relation and actual experimental values (e.g., Federico et al. 2008), Michalowski (2005) suggests that reasonable predictions of the lateral earth pressure at rest made via indirect methods are somewhat coincidental. 
The evaluation of the lateral earth pressure coefficient at rest of soils has been an important topic of research for many years. There was an attempt in Sweden as early as 1936 to measure lateral stresses in the laboratory using a complicated three-dimensional mechanical pressure device (Kjellman 1936). Subsequently, more emphasis was placed on simulating the condition of a natural clayey material. Since natural clays are consolidated under conditions of zero lateral strain, it became important to develop testing equipment that could both measure three-dimensional, stress-strain-time relationships and maintain the constrained condition. A zero lateral strain condition is usually referred to as the at rest, or $\mathrm{k}_{0}$, condition, defined by

$$
\mathrm{k}_{0}=\frac{\sigma_{\mathrm{h}}^{\prime}}{\sigma_{\mathrm{v}}^{\prime}}
$$

where $\sigma_{\mathrm{h}}^{\prime}$ and $\sigma_{\mathrm{v}}^{\prime}$ are the horizontal and vertical effective stresses, respectively (e.g., Craig 2004).

Several unique pressure cells have been devised for the specific purpose of measuring lateral pressures under zero lateral strain conditions $\left(\mathrm{k}_{0}\right)$. The development of the cylindrical triaxial cell offered a new method to measure lateral stresses during consolidation. With the added capability of a lateral strain detector (Bishop and Henkel 1962), this device could be used to study fundamental consolidation behavior. Difficulty in maintaining a zero lateral strain condition in the triaxial cell, especially for soft or sensitive clayey material, prompted the use of electromechanical servo systems that automate the adjustment of lateral or cell pressure. These difficulties prompted many researchers to turn to specially modified oedometer rings where constrained conditions are less difficult and costly to maintain and conventional consolidation equipment (i.e., oedometers) can be used. Three basic oedometer ring designs have been employed (Duval 1994):

- the rigid cell

- the semi-rigid confining ring

- the null indicator.

The rigid cell or confining ring is a thick-walled cylinder that allows the measurement of strain or pressure at points around the diameter of the cell. The rigidity of the cell makes certain that the soil is in an at-rest condition. However, the value of $\mathrm{k}_{0}$ is determined from a single point and extrapolated for the whole sample.

The semi-rigid confining ring uses a thin wall with strain gauges or wires wrapped around the exterior. The device is calibrated to known lateral pressures and allows the correlation of strain to pressure. This calibration factor is then used to determine the pressure from the strain measurements. Unfortunately, lateral deformations are allowed to take place, raising questions about the validity of the at-rest condition in the specimen.

The null indicator ring is similar to the semi-rigid ring, except that the thin wall is part of a pressure chamber. The strain gauges measure any deflection of the thin wall. This deflection can be maintained at zero throughout the test by applying pressure to the thin-wall chamber. This allows the horizontal pressure to be directly measured at the at rest condition. 


\subsubsection{Oedometer Ring Design}

Due to its applicability and relative simplicity, the null indicator is used as a basis for designing a new oedometer ring for directly measuring $\mathrm{k}_{0}$. The null indicator offers continuous measurement about the periphery of the sample while avoiding the complicated calibration equations and procedures of other methodologies.

The mode of deformation of a null indicator ring associated with the imposed state of stress can be approximated using the following equations that are applicable to a non-compact section. This exercise demonstrates the viability of the measurement approach. Using elasticity theory, the stresses in a thinwalled pressure vessel subjected to a uniform pressure differential, $\Delta \mathrm{P}$, can be calculated. Assuming that the walls stretch as a membrane results in

$$
\sigma_{1}=\sigma_{\text {axial }}=\frac{\mathrm{r} \Delta \mathrm{P}}{2 \mathrm{t}}
$$

and

$$
\sigma 2=\sigma_{\text {hoop }}=\frac{\mathrm{r} \Delta \mathrm{P}}{\mathrm{t}}
$$

The deformation that results from this biaxial state of stress can be expressed in terms of elastic modulus and Poisson's ratio as

$$
\delta=\frac{\mathrm{r}^{2} \Delta \mathrm{P}(2-v)}{\mathrm{tE}}
$$

where $\quad r=$ radius of the oedometer ring

$\mathrm{t}=$ ring wall thickness

$\Delta \mathrm{P}=$ differential pressure

$\delta=$ deformation

$\mathrm{E}=$ elastic modulus

$v=$ Poisson's ratio.

The radius of the ring is chosen as 1.25 inches to conform to standard practice and to allow the ring to be used with available consolidation testing equipment. Poisson's ratio and Young's modulus will be dependent on the ring's material being considered. Yellow brass, used by Duval (1994), which generally consists of $70 \%$ copper and $30 \%$ tin, has $\mathrm{E}=15 \mathrm{E} 6$ psi and $v=0.3$. Using these parameters, the calculated strain levels for $\Delta \mathrm{P}=0.5 \mathrm{psi}$ (nominally $0.25 \mathrm{~m}$ of waste at $1.5 \mathrm{~g} / \mathrm{mL}$ ) and a wall thickness of 0.005 inch is $2 \mu \varepsilon$. For a wall thickness of 0.003 inch, the calculated strain level is $3 \mu \varepsilon$. For $\Delta \mathrm{P}=10 \mathrm{psi}$ (nominally $5 \mathrm{~m}$ of waste at $1.5 \mathrm{~g} / \mathrm{mL}$ ), the estimated strain levels are $45 \mu \varepsilon$ and $75 \mu \varepsilon$, respectively. Conventional strain gauges are capable of measuring strain levels on this range.

Figure 2.1 shows a schematic of Duval's (1994) yellow brass oedometer ring. A pressure chamber surrounds the inner sample-containing ring. General operation of the null indicator ring involves 1) applying a vertical load and measurement of the corresponding lateral deflection and 2) increasing the 
ring wall chamber pressure to maintain the deflection at zero. Maintaining the lateral deflection at zero throughout consolidation keeps the sample in an at-rest condition. At the end of primary consolidation, the lateral earth pressure at rest is, per Equation (2.1), the chamber pressure (horizontal pressure) divided by the vertical pressure (from the vertical load). The end of the primary consolidation condition is required such that the horizontal and vertical pressures are effective stresses.
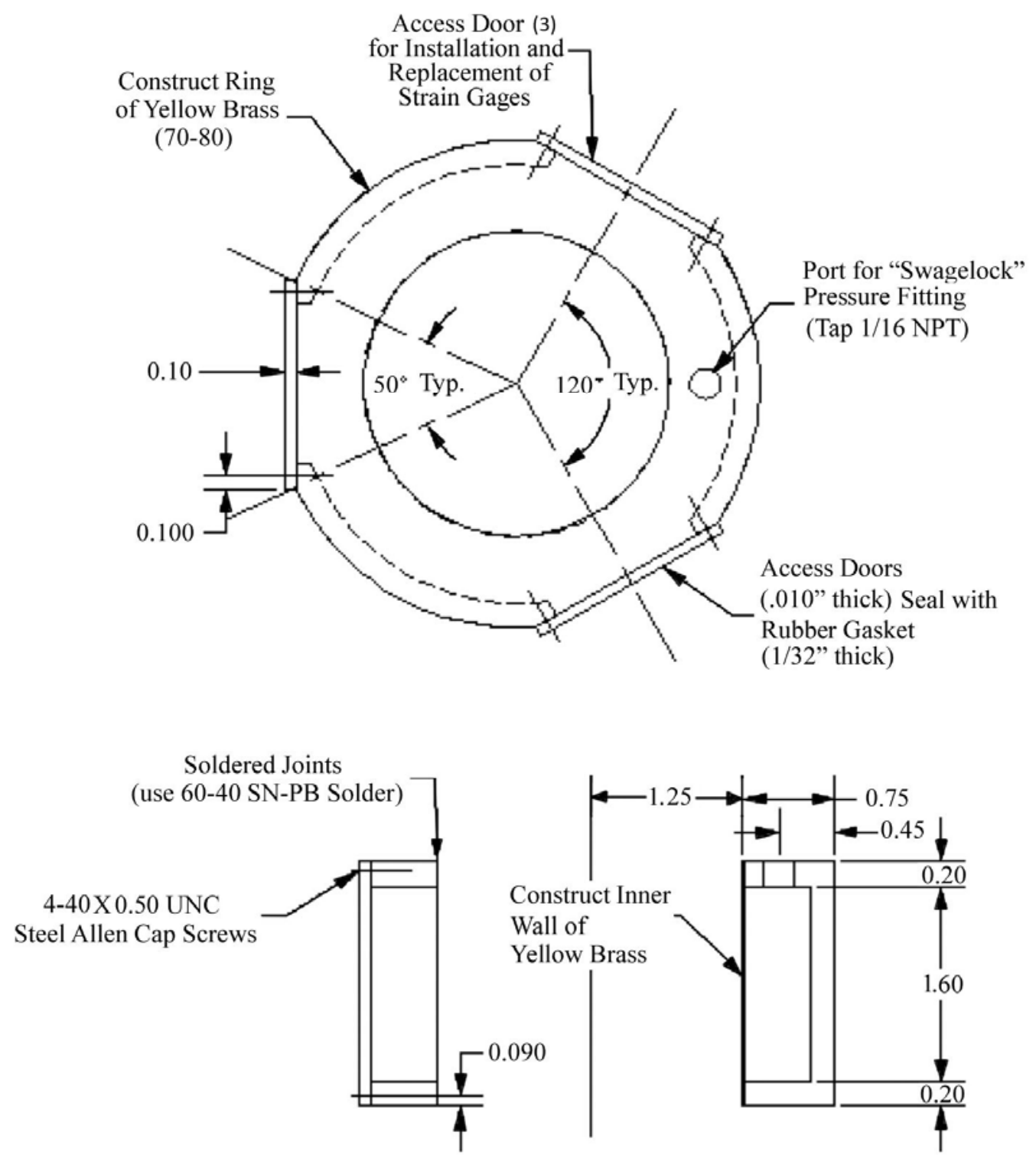

Figure 2.1. Null Indicator Oedometer Ring (Duval 1994)

\subsubsection{Shear Modulus}

The shear modulus is the slope of the initial linear portion of a shear-stress, shear-strain curve and is a measure of the material's stiffness in shear. Houlsby and Wroth (1991) describe three possible definitions of the shear modulus: 1) the initial gradient of the stress-strain curve, 2) the secant modulus to $50 \%$ of the failure stress (similar definitions for other proportions of the failure stress are also used), and 3) the 
unload-reload modulus. Dynamic tests (employing very small amplitude cycling) provide a further shear modulus, $G_{\max }$, which may be different than definition 1) above in certain circumstances. $G_{\max }$ is considered as representing most closely the actual elastic behavior of clay (Houlsby and Wroth 1991) and is the shear modulus considered for the current work.

As noted, there are no in situ data for the shear modulus of Hanford sediment. Although ultrasonic techniques can be used for in situ measurements, the Hanford waste environment typically precludes this type of approach. Methodologies do exist to determine the shear modulus from shear vane data (Alderman et al. 1991, Barnes and Nguyen 2001), and shear vane testing had been done on waste from 22 Hanford tanks (16 of which are sludge tanks, Gauglitz et al. 2009).

For the current testing, bender elements are used to determine the shear wave velocity of the material. The use of bender elements for shear wave velocity measurement is a technique that has been used successfully for over 20 years (Lee and Santamarina 2005).

Bender elements are piezoelectric elements that consist of a ceramic material sandwiched between layers of metal, and they bend when subjected to voltage and generate a voltage when bent. One element is used as a transmitter and another as a receiver. A signal pulse is input into the "transmitter" bender element, which translates it to a motion or shear wave in the soil. That shear wave travels through the soil and causes the "receiver" bender element to move, generating a voltage signal. The arrival time of a wave pulse sent through a sample from one to another bender element can be determined. The shear wave velocity, $\mathrm{V}_{\mathrm{S}}$, is calculated from the time and distance the wave travels. The shear modulus, $\mathrm{G}_{\max }$, can then be determined using the basic relationship

$$
\mathrm{G}_{\max }=\rho \mathrm{V}_{\mathrm{S}}^{2}
$$

where $\rho$ is the sample density.

\subsubsection{Test Equipment}

As described above, a null indicator oedometer ring and bender elements are used to measure the lateral earth pressure at rest and shear modulus, respectively. A null indicator ring, the " $\mathrm{k}_{0}$ consolidometer," was designed specifically for the current work.

The pHs of Simulants 1 and 2 (Section 2.1) are on the order of 13 and greater (Wells et al. 2010). These high pHs dictate the type of material that can be used for the oedometer, and 316 stainless steel was selected to replace the brass of the oedometer ring to address this issue. Although stainless steel is more resistant to deformation than the yellow brass of Duval (1994) for equivalent dimensions, measurable deflection was achieved (see Section 2.2.5.1). As described previously, the wall of the sample-containing ring is kept at zero deflection, so the actual magnitude of the deflection is not considered. The bender elements are located in the top and bottom of the oedometer ring.

The $\mathrm{k}_{0}$ consolidometer is shown in side view in Figure 2.2. The device is cylindrical as per the null indicator shown in Figure 2.1. Starting from the bottom of Figure 2.2, the lower platen serves to support the device in a consolidation frame and acts as the primary containment for the liquid drained from the sample during consolidation. The hole in the center of the lower platen is the mounting port for the 
bottom bender element. Two porous plates sit atop the lower platen, and the plates and consolidometer body are aligned in the lower platen via three locating pins, one of which is shown to the left of the device center. The bender element is shown extending through the porous plates and into the sample chamber. The $\mathrm{k}_{0}$ consolidometer body consists of the outer air-tight chamber and the inner sample chamber. The inner and outer chambers are separated by a stainless steel sleeve that is sealed to the top and bottom of the consolidometer body. One of the three access ports in the consolidometer body is depicted on the left side of the body. The upper platen and top porous plate are shown at the top of the sample chamber. The top bender element is mounted in the upper platen and extends down into the sample chamber through the top porous plate. Design drawings for the $\mathrm{k}_{0}$ consolidometer are provided in Appendix A.

The stainless steel sleeve that separates the inner sample and outer chambers has a wall thickness of 0.005 inches and as such is very responsive to displacement from the applied vertical and horizontal stresses. Three strain gauges are mounted at the vertical centerline at $120^{\circ}$ spacing on the sleeve wall inside the outer chamber. The gauges are oriented such that the longitudinal axis of each gauge is horizontal. Each individual gauge is capable of measuring the deformation because of lateral pressures, and having three gauges provides redundancy.

The inner sample chamber has a nominal diameter of 2.5 inches. For bender elements in an oedometer, the distance the wave travels depends on the sleeve height. Conventional oedometer equipment typically uses a ring height of 1 inch, but a ring height of 2 inches is used in the current work to facilitate the measurement of the shear modulus. As-built measurements pertinent to the determination of $\mathrm{k}_{0}$ and $\mathrm{G}_{\max }$ are provided in Table 2.1. The extended sample chamber height (i.e., greater than 2 inches; see Appendix A drawings) is a result of the complicated machining process required to achieve the 0.005 -inch sleeve wall thickness.

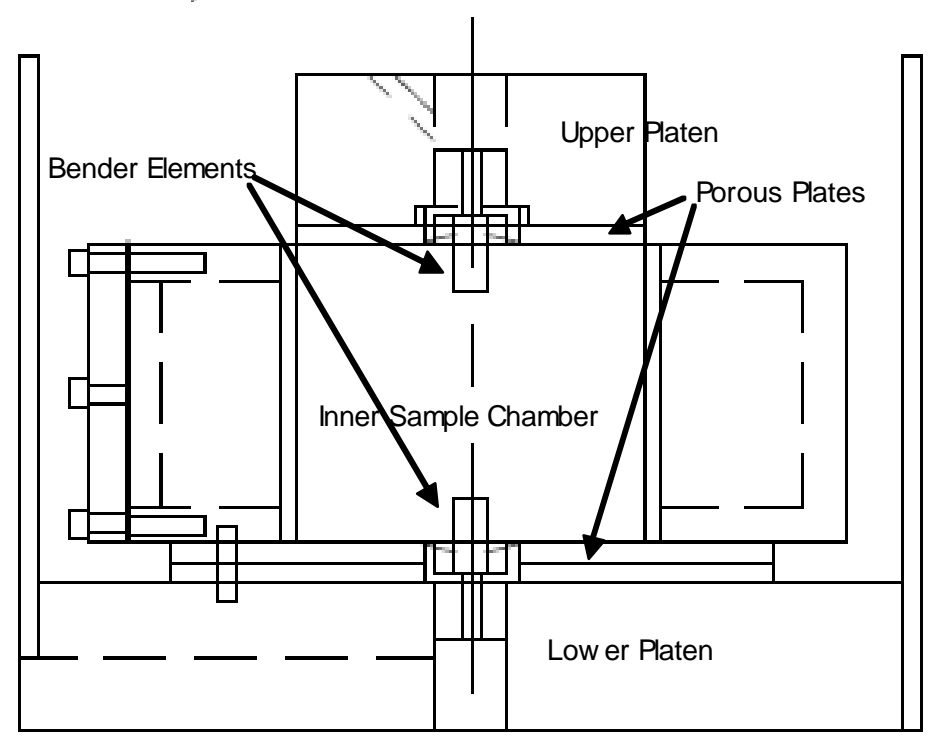

Figure 2.2. $\mathrm{k}_{0}$ Consolidometer

Pacific Northwest National Laboratory (PNNL) and The University of Washington (UW) concurrently tested kaolin clay. All of the salient components of the two systems, specifically including the $\mathrm{k}_{0}$ consolidometer and strain gauges, displacement gauge, consolidation frame, and bender elements, 
are exactly equivalent between the PNNL and UW tests. The specific equipment information (strain gauge readouts, signal generator, etc.) and images provided herein relate to the PNNL system.

Table 2.1. $\mathrm{k}_{0}$ Consolidometer As-Built Measurements

\begin{tabular}{lc}
\hline \multicolumn{1}{c}{ Measurement } & Length (inches) $^{(\mathrm{a})}$ \\
\hline Inner sample chamber diameter, $\mathrm{D}$ & 2.499 \\
Inner sample chamber height, $\mathrm{h}$ & 2.055 \\
Top stone thickness, $\mathrm{h}_{\mathrm{S}}$ & 0.125 \\
Height bottom bender element extends into inner sample chamber, $\mathrm{h}_{\mathrm{B}}$ & 0.234 \\
Height top bender element extends into inner sample chamber, $\mathrm{h}_{\mathrm{T}}$ & 0.219 \\
\hline
\end{tabular}

(a) Average of three measurements. Measurements taken with Electronic Digital Caliper, model G06083255, zeroed before each reading and checked for accuracy to a metal 6-inch ruler (The L.S Starrett Co., No. C604RE).

The consolidation test facility is shown in Figure 2.3. The system includes the consolidometer and displacement gauge (Figure 2.4), consolidation frame (Figure 2.5), strain gauge readout (Figure 2.6), air pressure pump (Figure 2.7), and bender elements with signal generator and amplifier (Figure 2.8). The primary components of the system are listed in Table 2.2 .

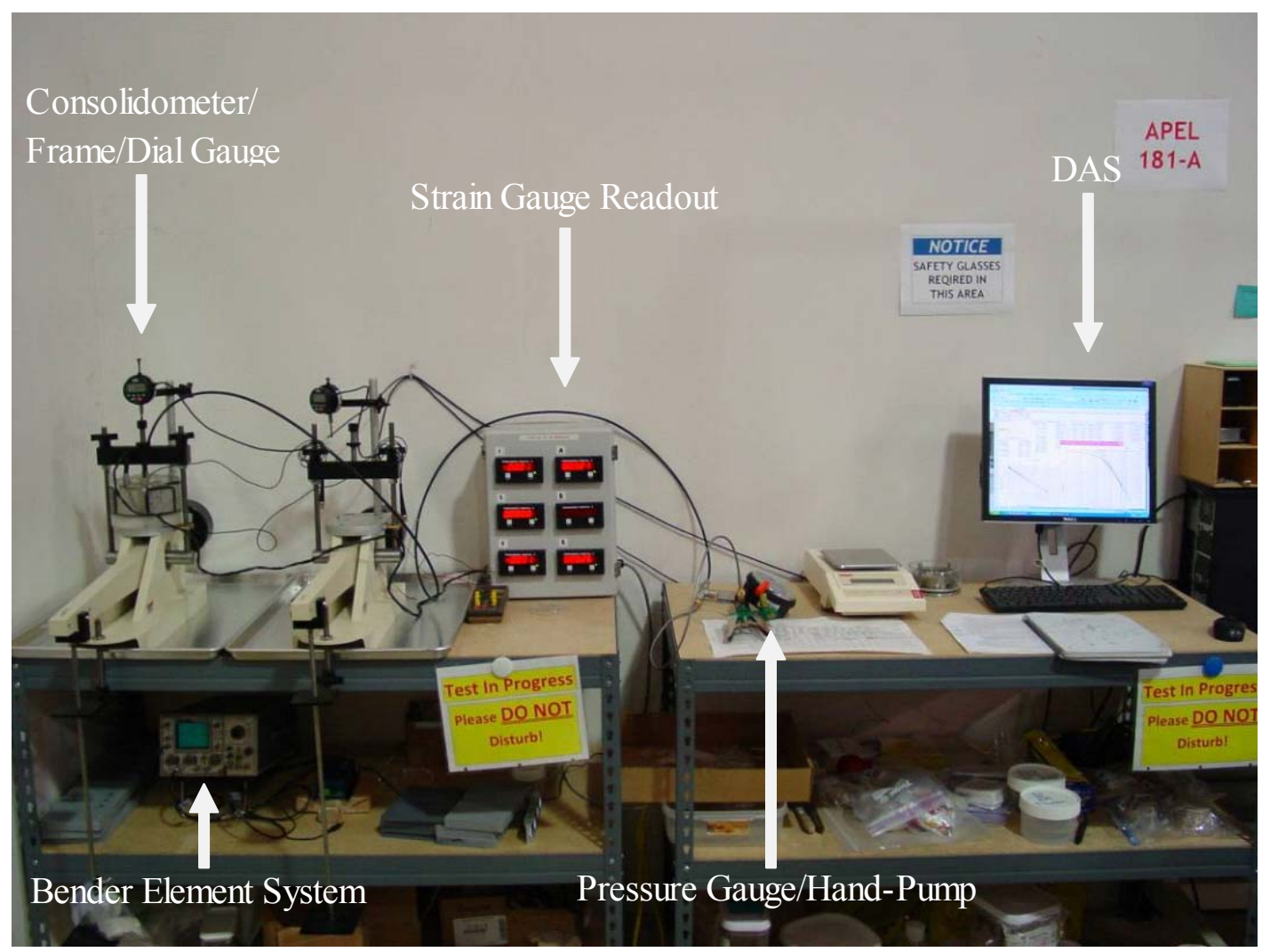

Figure 2.3. Consolidation Test Facility 


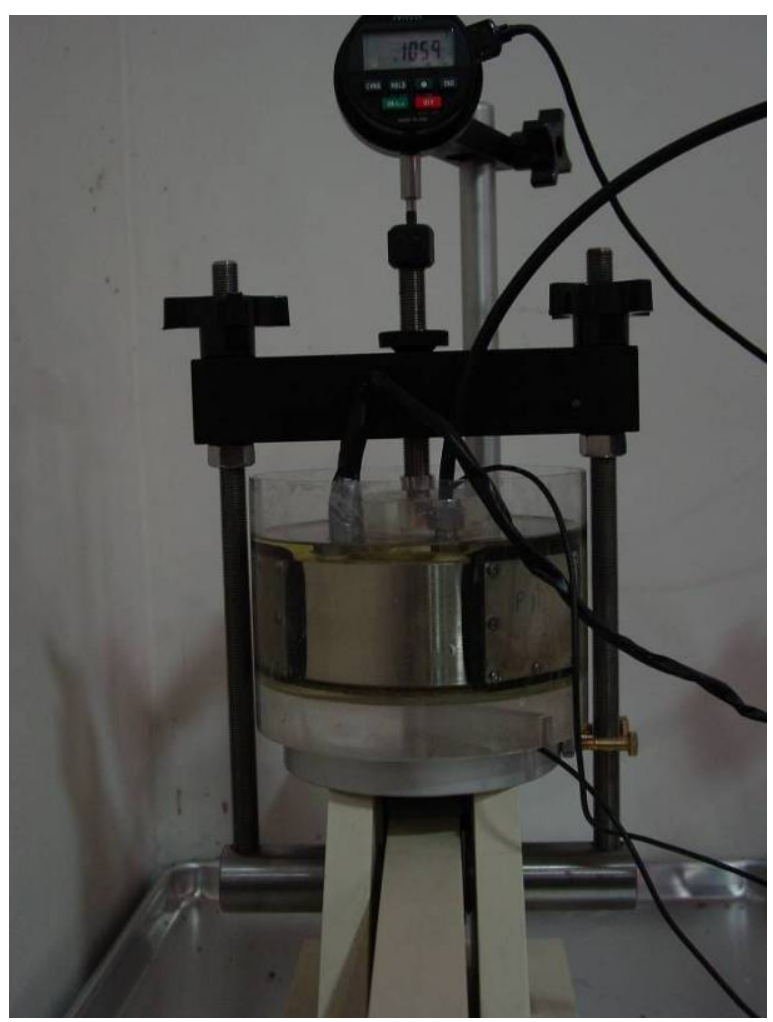

Figure 2.4. $\mathrm{k}_{0}$ Consolidometer and Displacement Gauge

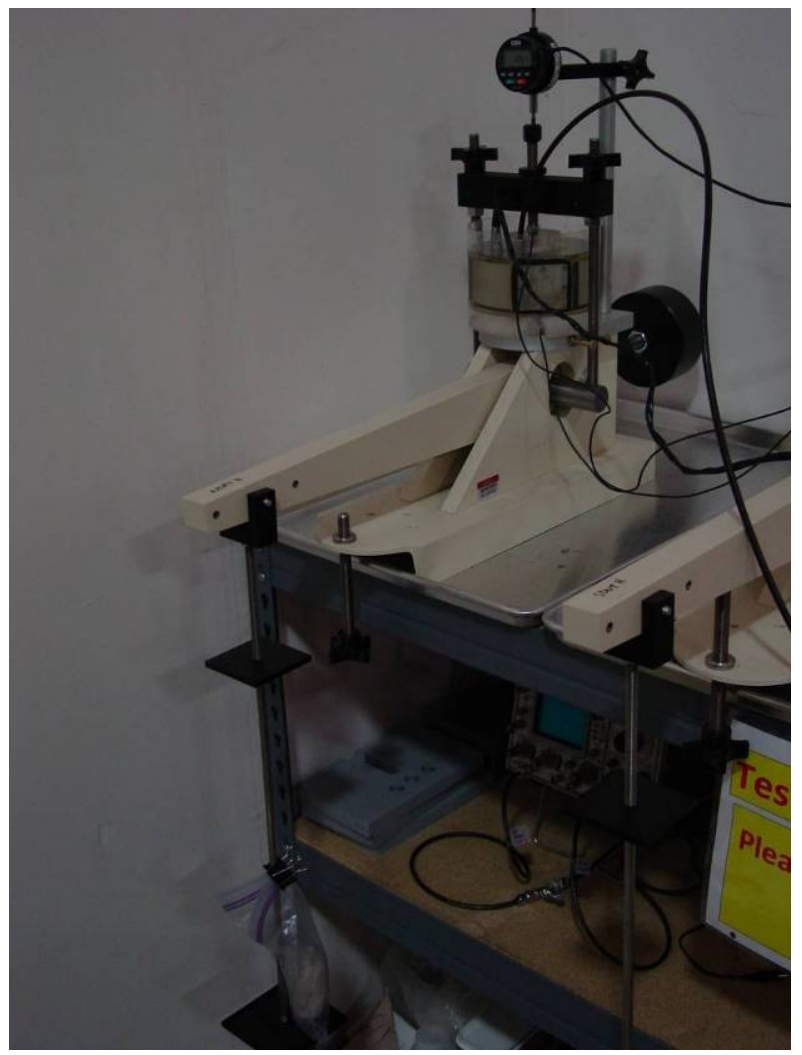

Figure 2.5. Consolidation Frame 


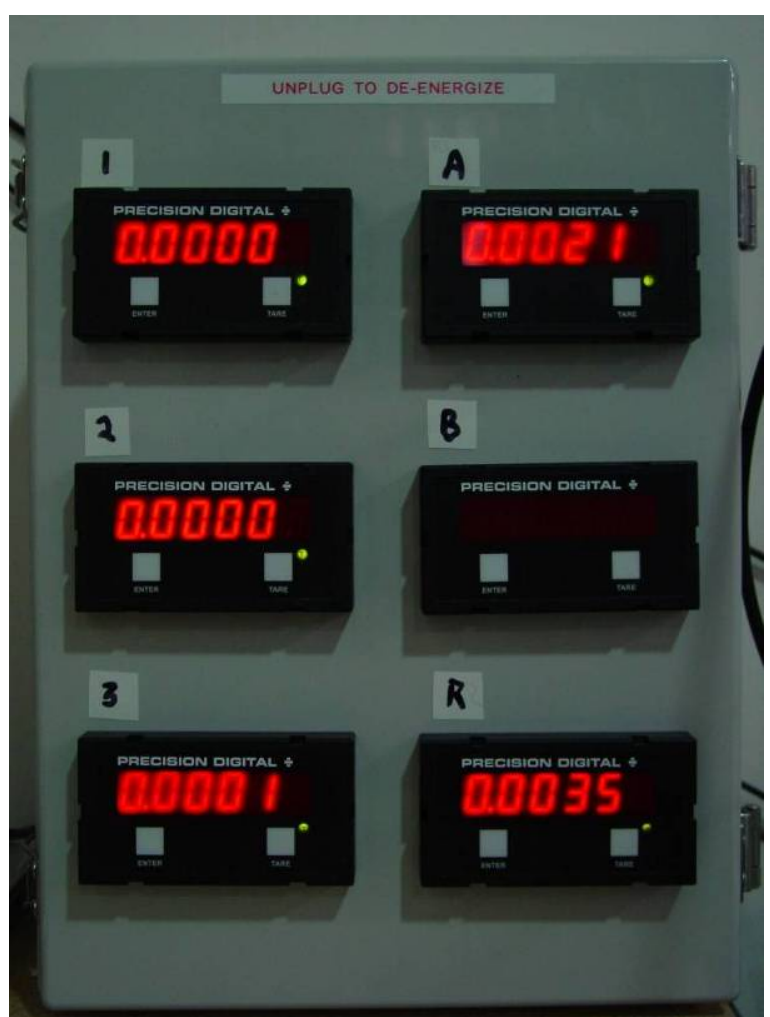

Figure 2.6. Strain Gauge Readout

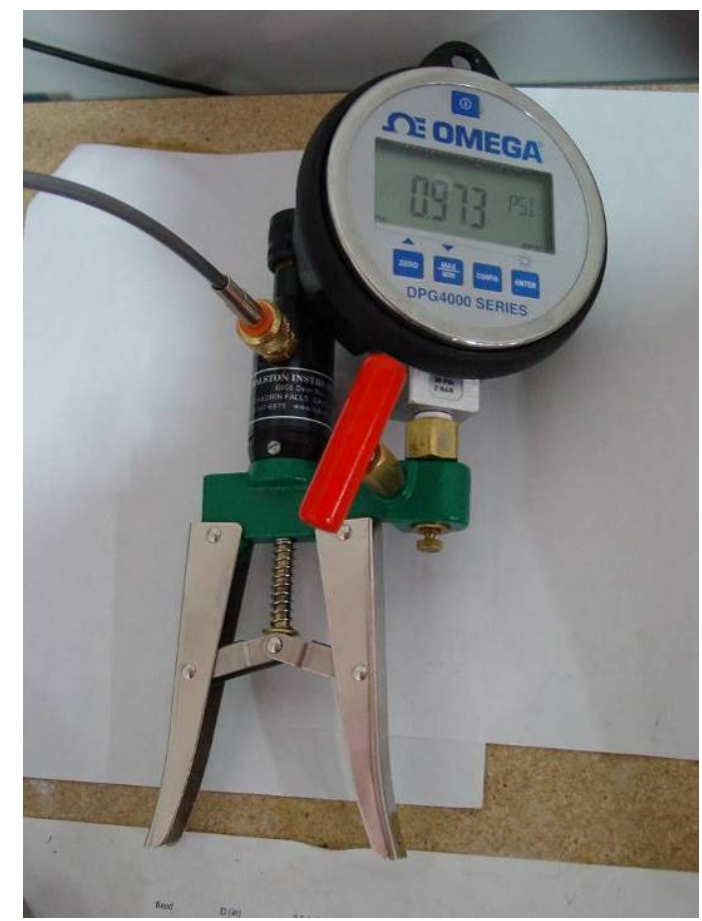

Figure 2.7. Air Pressure Pump and Pressure Gauge 


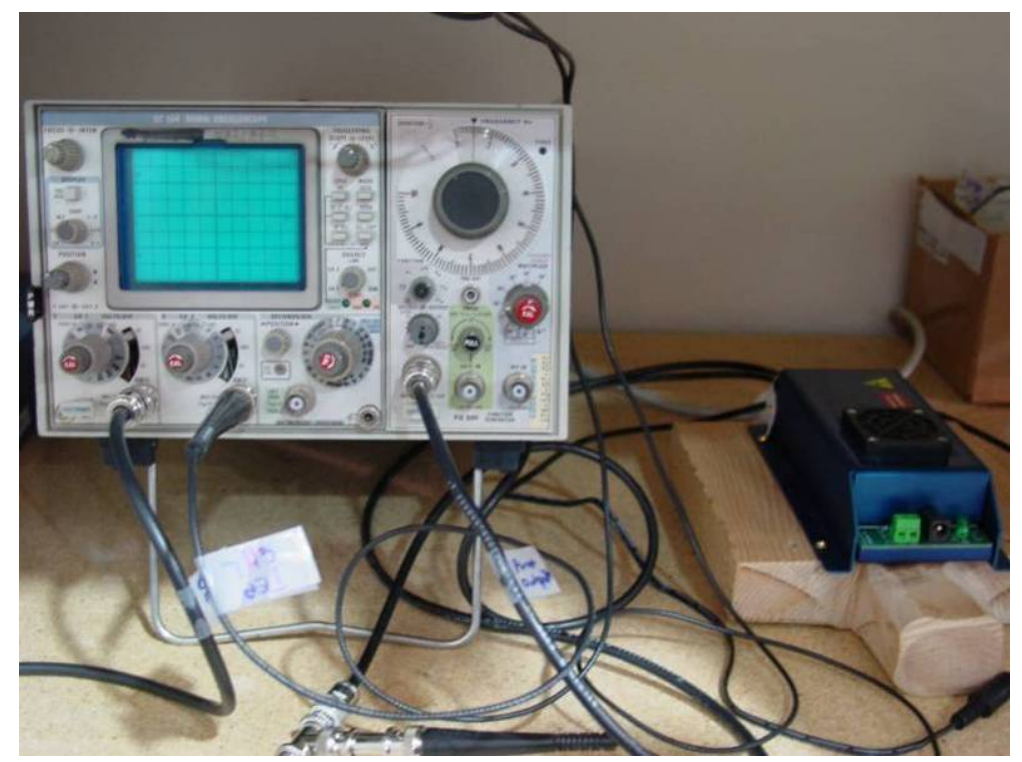

(a)

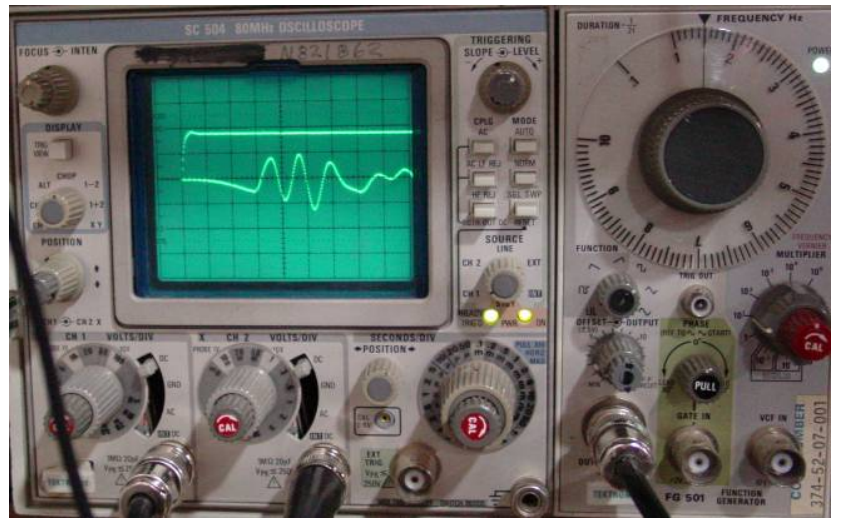

(b)

Figure 2.8. Bender Element System (a) with Signal Readout (b) 
Table 2.2. Test Equipment Primary Components

\begin{tabular}{ccc}
\hline Equipment & Supplier & Part Number \\
\hline Weight & & \\
Metric Weight Set, 32KG & Durham Geo Slope indicator & S-449 \\
Fixed Ring & Durham Geo Slope indicator & S-44902 \\
Digital Dial Gauge & Durham Geo Slope indicator & S-445 \\
USB data cable & Chicago Dial Indicator & BG2110 \\
Strain Gauge Readouts & Chicago Dial Indicator & G13-0048 \\
Bridge Completer Modules & Precision Digital & PD691 \\
Strain Gauges & Omega & BCM1 \\
Bender Elements & Vishay Micro Measurements & CEA-13-250UW-350/P2 \\
Oscilloscope & Piezo.com & T-220-A4-303Y \\
Signal Generator & Tektronics & SC 504 \\
Power Amplifier 90V & Tektronics & FG 501 \\
Electronic pressure gauge & Piezo.com & EPA-007-012 \\
Hand pressure pump & Omega & DPG4000-30 \\
\hline
\end{tabular}

\subsubsection{Parameter Calculation and Uncertainty}

The measured parameters required for the lateral earth pressure at rest, $\mathrm{k}_{0}$, are, per Equation (2.1), the horizontal and vertical effective stresses, $\sigma_{\mathrm{h}}^{\prime}$ and $\sigma_{\mathrm{v}}^{\prime}$, respectively. The horizontal effective stress is the outer air chamber pressure, and the vertical effective stress is given by

$$
\sigma_{\mathrm{v}}^{\prime}=\frac{\mathrm{mAg}}{\frac{\pi}{4} \mathrm{D}^{2}}
$$

where $m$ is the mass on lever arm of consolidation frame, $A$ is the lever arm advantage (10:1), and $g$ is the gravitational acceleration.

The uncertainty in the measured lateral earth at rest, $\mathrm{u}_{\mathrm{k}_{0}}$, is determined via a standard propagation of the independent measurement error (e.g., see Figliola and Beasley 1995), or

$$
\mathrm{u}_{\mathrm{k}_{0}}=\left(\sum_{\mathrm{i}=1}^{\mathrm{n}}\left(\frac{\delta \mathrm{k}_{0}}{\delta \mathrm{x}_{\mathrm{i}}} \mathrm{u}_{\mathrm{x}_{\mathrm{i}}}\right)^{2}\right)^{\frac{1}{2}}
$$

where $\mathrm{n}$ is the number of parameters, $\mathrm{x}_{\mathrm{i}}$ is the $\mathrm{i}^{\text {th }}$ parameter, and $\mathrm{u}_{\mathrm{xi}}$ is the uncertainty in the $\mathrm{i}^{\text {th }}$ parameter.

The partial derivatives are evaluated at the average results. The uncertainty in the vertical effective stress is determined by applying Equation (2.7) to Equation (2.6).

The shear modulus, Gmax, Equation (2.5), includes the shear wave velocity 


$$
\mathrm{V}_{\mathrm{S}}=\frac{\mathrm{L}}{\mathrm{t}}
$$

where $\mathrm{L}$ is the distance between the tips of the bender elements given by

$$
\mathrm{L}=\mathrm{h}-\mathrm{h}_{\mathrm{S}}-\mathrm{h}_{\mathrm{B}}-\mathrm{h}_{\mathrm{T}}-\Delta \mathrm{h}
$$

where $\Delta \mathrm{h}$ is the displacement resulting from the consolidation. Time $\mathrm{t}$ is taken from the oscilloscope reading of $\mathrm{msec} /$ division multiplied by the number of divisions, $\mathrm{d}$. The sample density is determined from a mass and volume determination on a sub-sample of the consolidated material. The uncertainties of the measured parameters are listed in Table 2.3 together with the instrumentation information.

\begin{tabular}{|c|c|c|c|}
\hline Parameter & \multicolumn{2}{|c|}{ Uncertainty (units) } & Measurement Device \\
\hline$\sigma_{\mathrm{h}}$ & 0.0005 & (psi) & $\begin{array}{l}\text { Omega DPG4000 pressure gauge, } \\
\text { Calibration No. } 26965\end{array}$ \\
\hline $\mathrm{m}$ & 0.05 & (g) & $\begin{array}{l}\text { Sartorius CP 34001S, Calibration No. } \\
22650374\end{array}$ \\
\hline $\mathrm{D}$ & 0.0005 & (in.) & Electronic Digital Caliper $^{(\mathrm{a})}$ \\
\hline $\mathrm{h}$ & 0.0005 & (in.) & Electronic Digital Caliper \\
\hline $\mathrm{h}_{\mathrm{S}}$ & 0.0005 & (in.) & Electronic Digital Caliper \\
\hline $\mathrm{h}_{\mathrm{B}}$ & 0.0005 & (in.) & Electronic Digital Caliper \\
\hline $\mathrm{h}_{\mathrm{T}}$ & 0.0005 & (in.) & Electronic Digital Caliper \\
\hline$\rho^{(b)}$ & $\begin{array}{l}0.005 \\
1.25\end{array}$ & $\begin{array}{l}(\mathrm{g}) \\
(\mathrm{mL})\end{array}$ & $\begin{array}{l}\text { Mettler PM6100, Calibration No. } \\
\text { N54034 } \\
\text { BD Falcon } 50 \mathrm{~mL} \text { centrifuge cone }\end{array}$ \\
\hline d & 0.1 & division & HP oscilloscope \\
\hline$\Delta \mathrm{h}$ & 0.00005 & (in.) & Digital Dial Gauge \\
\hline
\end{tabular}

Table 2.3. Uncertainty of Measured Parameters

(a) See Table 2.1.

(b) Measured per Daniel. ${ }^{(a)}$

\subsubsection{Test Methodology}

The test methodology followed established techniques. Specific techniques were developed in the current work via the kaolin clay testing as will be described. All testing was performed at ambient laboratory conditions. Kaolin clay test results are provided in Section 4. The test procedure is provided in Appendix B.

(a) Daniel RC. 2007. PNNL Technical Procedure, "Measurement of Physical and Rheological Properties of Solutions, Slurries and Sludges.” RPL-COLLOID-02, Rev. 1, Pacific Northwest National Laboratory, Richland, Washington. 


\subsubsection{Consolidation and Horizontal Pressure}

ASTM Standard D 2435-04 (2004) was followed for consolidation. Per the standard, the porous plates were kept saturated in liquid, and filter paper was used between the sample and the porous plates. The samples were immersed under water (kaolin clay) or the specific liquid (Simulants 1 and 2).

Two specific methods for determining the end of primary consolidation are provided by ASTM Standard D 2435-04 (2004). It is also stated that "...the requesting agency may specify a method of its choice and still be in conformance with this test method..." The two methodologies are summarized as:

1. 12.3.1. Deformation is plotted as a function of the log of time. A line tangent to the linear portion of the end of the consolidation curve and a line tangent to the steepest part of the consolidation curve are drawn. The intersection of these two lines is the end of primary consolidation.

2. 12.3.2. Deformation is plotted as a function of the square root of time. Draw a line tangent to the initial deformation that exhibits a straight line trend and extrapolate back to zero time. Draw a second line with the same intercept and a slope equal to $85 \%$ of the first line. The intersection of this second line and the deflection data is $90 \%$ of primary consolidation (displacement is equal to $\mathrm{d} 90$ ). The end of primary consolidation is determined by multiplying d90 minus the intercept by $1 \frac{1}{9}$.

Drawbacks to the first method include the rather arbitrary definition of the end of the consolidation curve and the necessity to test beyond primary consolidation to subsequently determine that it actually has been reached. Kaolin testing at both PNNL and UW demonstrated that, typically, the predicted end of displacement was greater than the steady state displacement (i.e., displacement no longer changing with time) that was actually achieved.

For method 12.3.1, a zero-slope line for the linear portion of the end of the consolidation curve is truly that. The required information is the expected final extent of the deformation. Kaolin testing demonstrated that steady-state displacement was typically reached at less than 0.01 inch beyond d90. Thus, the method of determining the end of consolidation for the current work is to determine $\mathrm{d} 90$ via 12.3.2 and determine the time of the end of primary consolidation via 12.3.1 as the intersection of the constant line given by $\mathrm{d} 90$ plus 0.01 inch and the line tangent to the steepest part of the consolidation curve.

An example of the employed methodology to determine the end of primary consolidation is provided in Figure 2.9 and Figure 2.10. In Figure 2.9, d90 is shown to be approximately 0.12 inches. The time of the end of primary consolidation is approximately 500 minutes (Figure 2.10). In the description of method 12.3.1 provided in ASTM Standard D 2435-04 (2004), the slope of the line tangent to the linear portion of the end of the consolidation curve is greater than zero. Thus, the approach depicted in Figure 2.10 using a zero slope at a displacement representing steady state is not expected to under-predict the end of primary consolidation. This assumes a level of confidence that the horizontal and vertical pressures are effective stresses (see Section 2.2.1). In the current work, constant horizontal pressure, i.e. constant $\mathrm{k}_{0}$, is achieved at this time. 


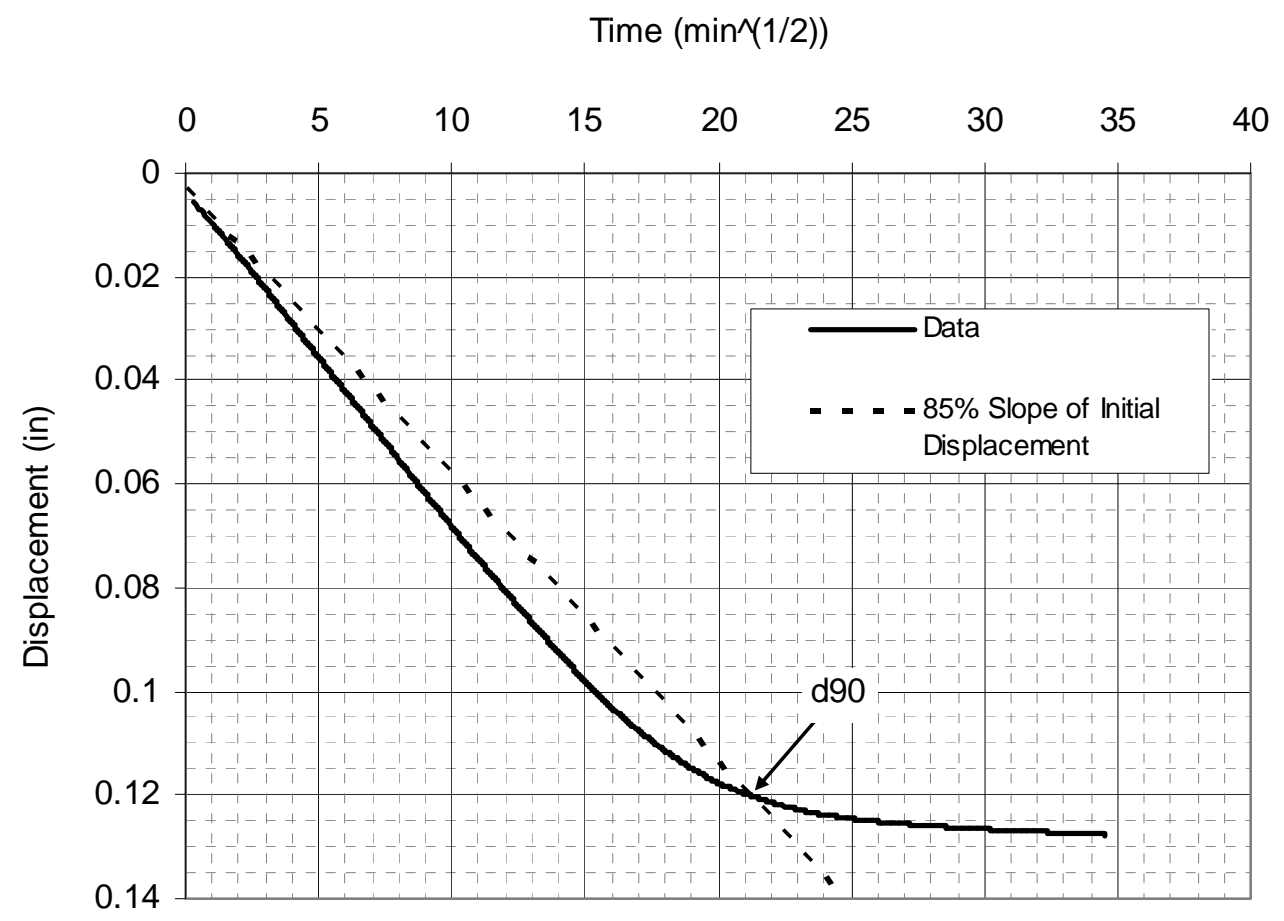

Figure 2.9. Example of Displacement as a Function of the Square Root of Displacement Time. d90 per ASTM Standard D 2435-04 (2004), method 12.3.2.

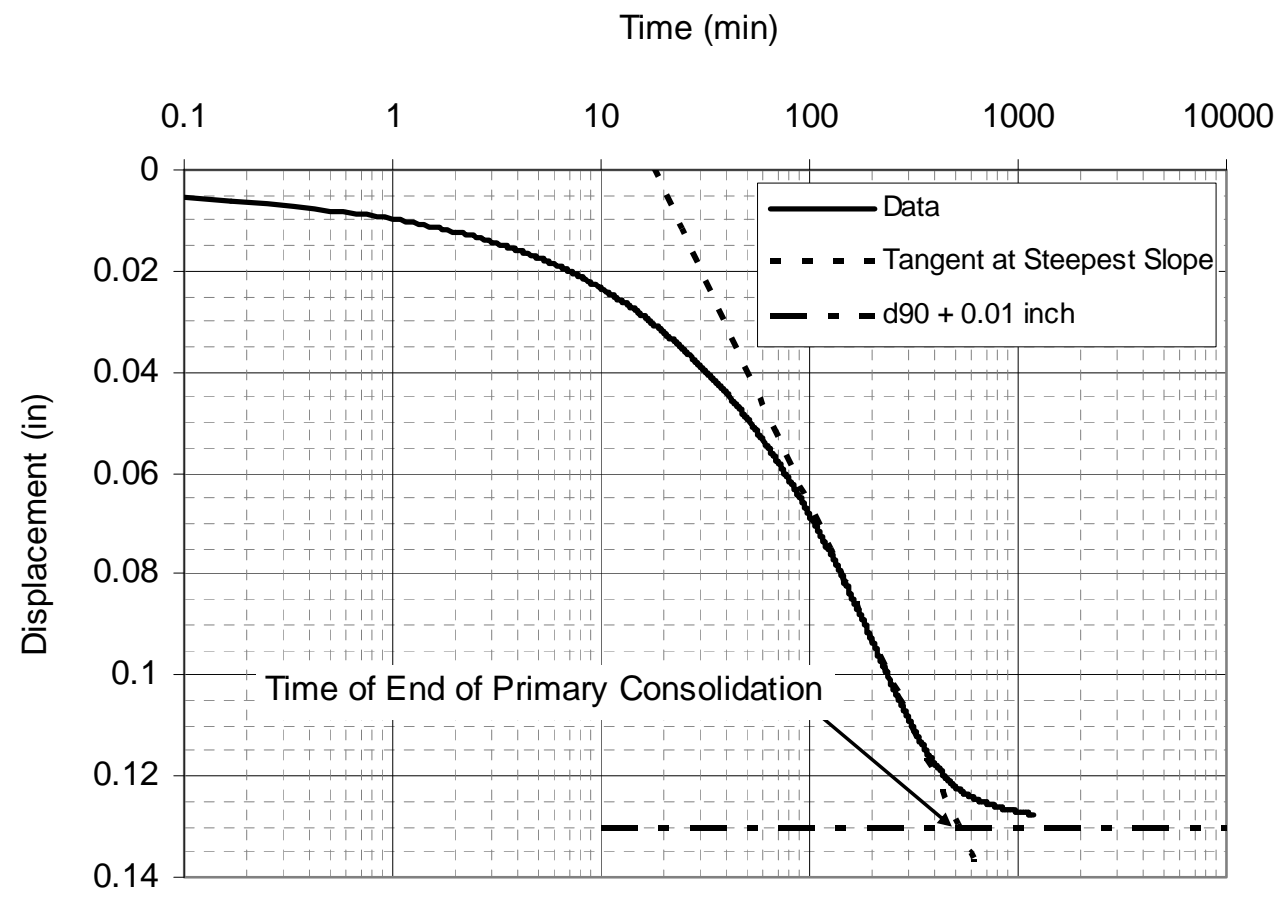

Figure 2.10. Example of Displacement as a Function of the Displacement Time. Time of end of primary consolidation adopted from ASTM Standard D 2435-04 (2004), method 12.3.1. 
During consolidation, the horizontal pressure is adjusted such that the average of the strain gauges mounted on the sample chamber sleeve is maintained at zero counts (zero counts is 0.0000 on strain gauge readouts), maintaining the sample in an at-rest condition (Section 2.2.1). The response of the sleeve strain gauges to horizontal pressure is shown in Figure 2.11. The $\mathrm{k}_{0}$ consolidometer was in an unloaded configuration (no sample) when these measurements were taken. As such, the applied horizontal pressure was limited to avoid over-stressing the 0.005 -in. sleeve wall. The change in strain gauge reading per horizontal pressure is approximately 20 counts/psi (20 counts is 0.0020 on strain gauge readouts).

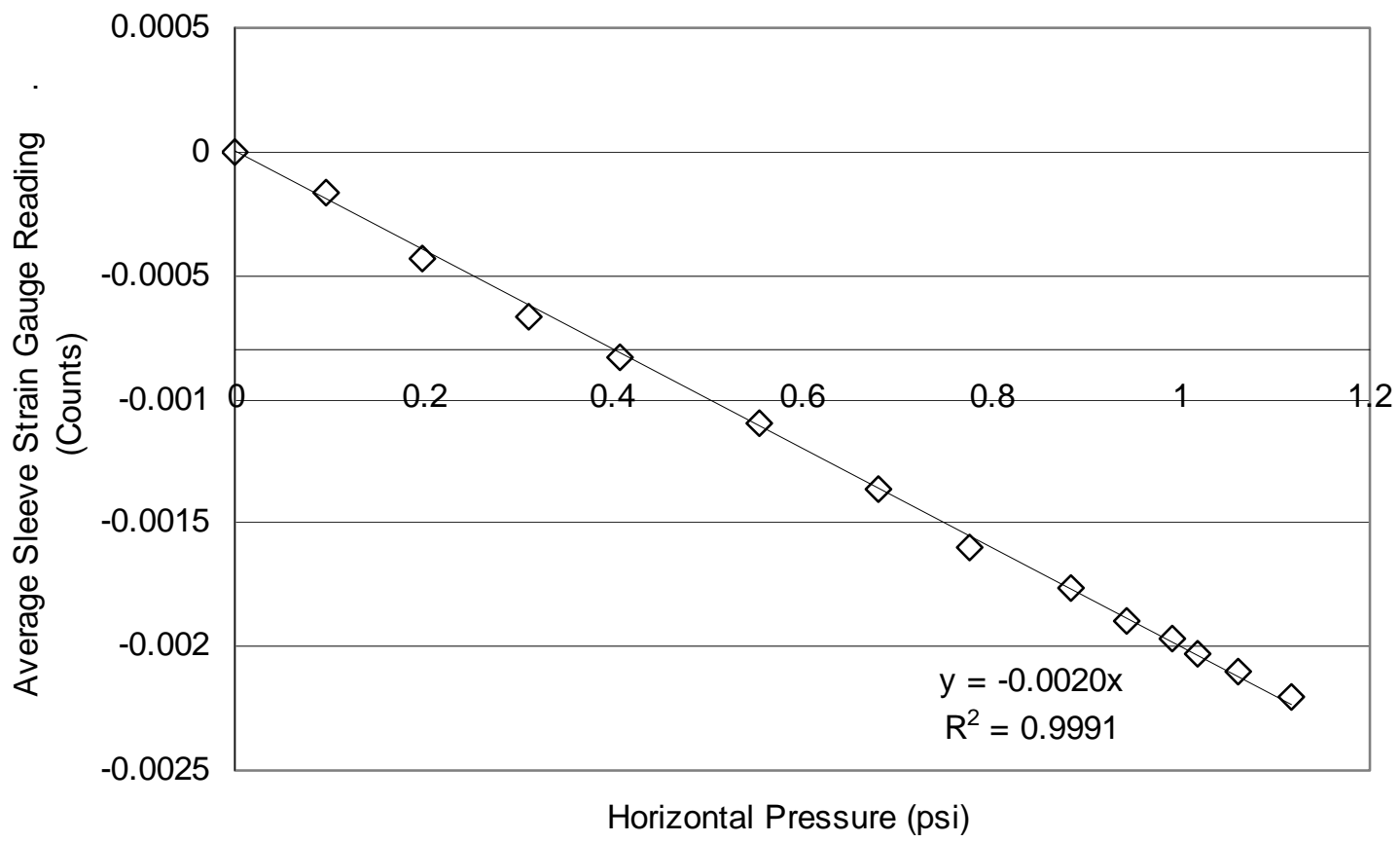

Figure 2.11. Average Sleeve Strain Gauge Reading (readout value shown, 1.0 counts is 0.0001 on readout) as a Function of Outer Chamber Air Pressure

\subsubsection{Bender Element Operation}

The bender element measurements are taken at the end of primary consolidation. The input signal and interpretation of the response for the bender elements was developed based on the literature and actual system performance in kaolin clay. A sine wave is typically used for the transmitting signal to ensure that the output wave is of the same form (Black 2009, Lee and Santamarina 2005). The ability to detect the arrival time can change dramatically, depending on the frequency of the input signal as the bender element system response is enhanced. This occurs when the frequency of the input signal approaches the resonant frequency of the bender element-sample system. However, as this frequency is unknown for the chemical simulants of the current work, a step input signal, which includes all input frequencies, is used as recommended by Lee and Santamarina (2005).

The amplitude of the input step function, 40 volts peak-to-peak, was selected based on the ability in kaolin testing to achieve response (limiting the lower extent of the amplitude) and limit over-stimulation. The frequency of the input was also selected via kaolin testing. Minimal difference in the response was 
observed until the frequency was high enough to cause "cross-talk" in the response between different input pulses; the selected frequency of $15 \mathrm{~Hz}$ did not exhibit these effects.

The response time was interpreted with the methodologies described in Lee and Santamarina (2005) and the kaolin data of Black (2009) and Oh et al. (2008). Lee and Santamarina (2005) note that determining the arrival time is somewhat controversial. Options for selecting the arrival time of the signal include 1) first deflection, 2) first deflection peak, 3) zero after first deflection, and 4) first major peak, with options 3 ) and 4) being the most universally accepted interpretation.

Examples of bender element input signal and response observed for the current work are provided in Figure 2.12 and Figure 2.13 (figures are from test procedure, Appendix B). When single or multiple response peaks of similar amplitude are observed, the arrival time is selected, when possible, as the zero after the first deflection ( $\mathrm{tC}$, option 3 ) and the first peak (tP, option 4) otherwise. To be consistent within tests, all results presented in Section 3 are at $\mathrm{tP}$, option 4. When the response consists of multiple peaks with a major peak, the arrival time is selected, when possible, as the zero before the major peak or the major peak otherwise.

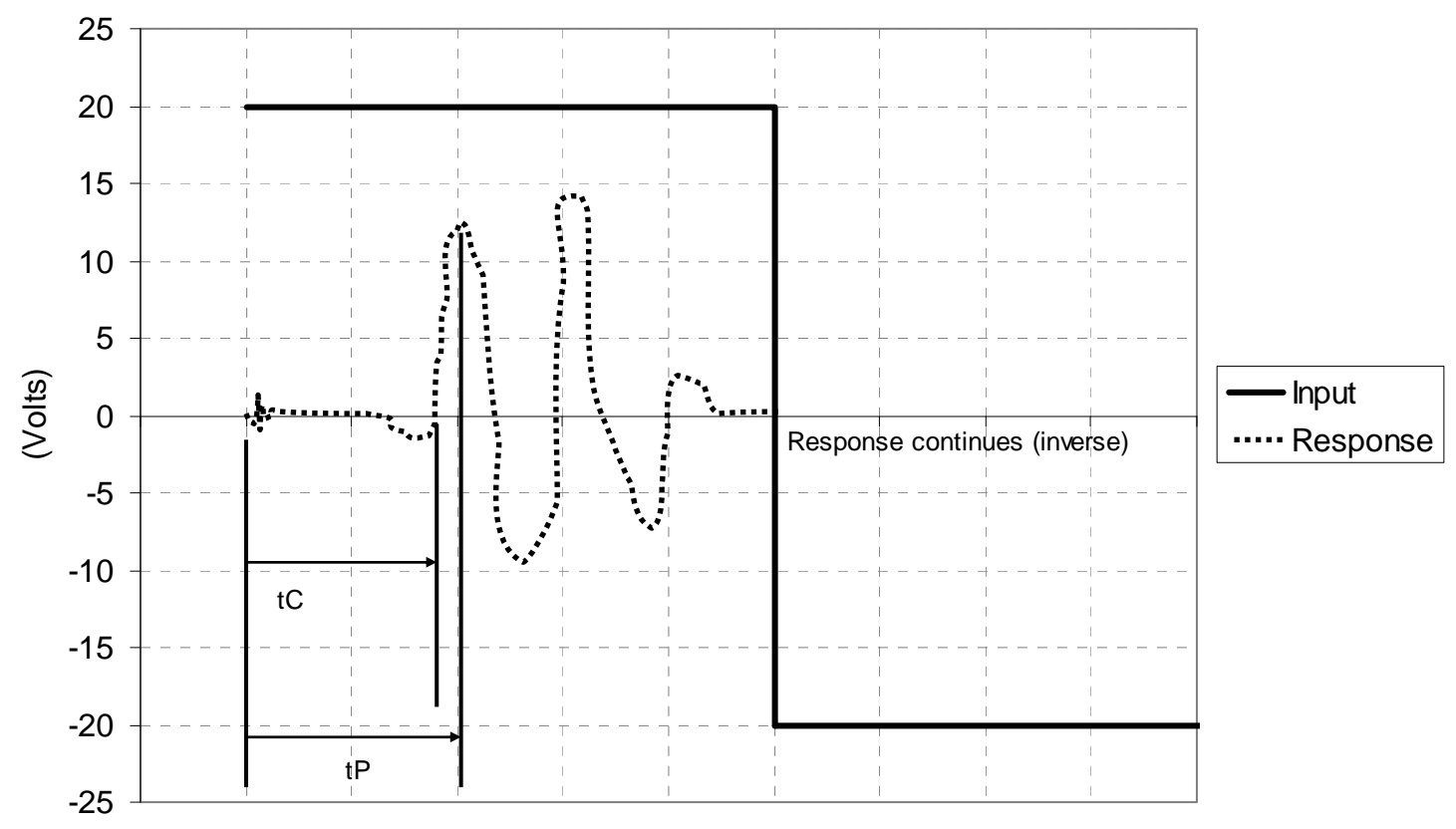

Figure 2.12. Bender Element Response Example, Single or Equal Peaks 


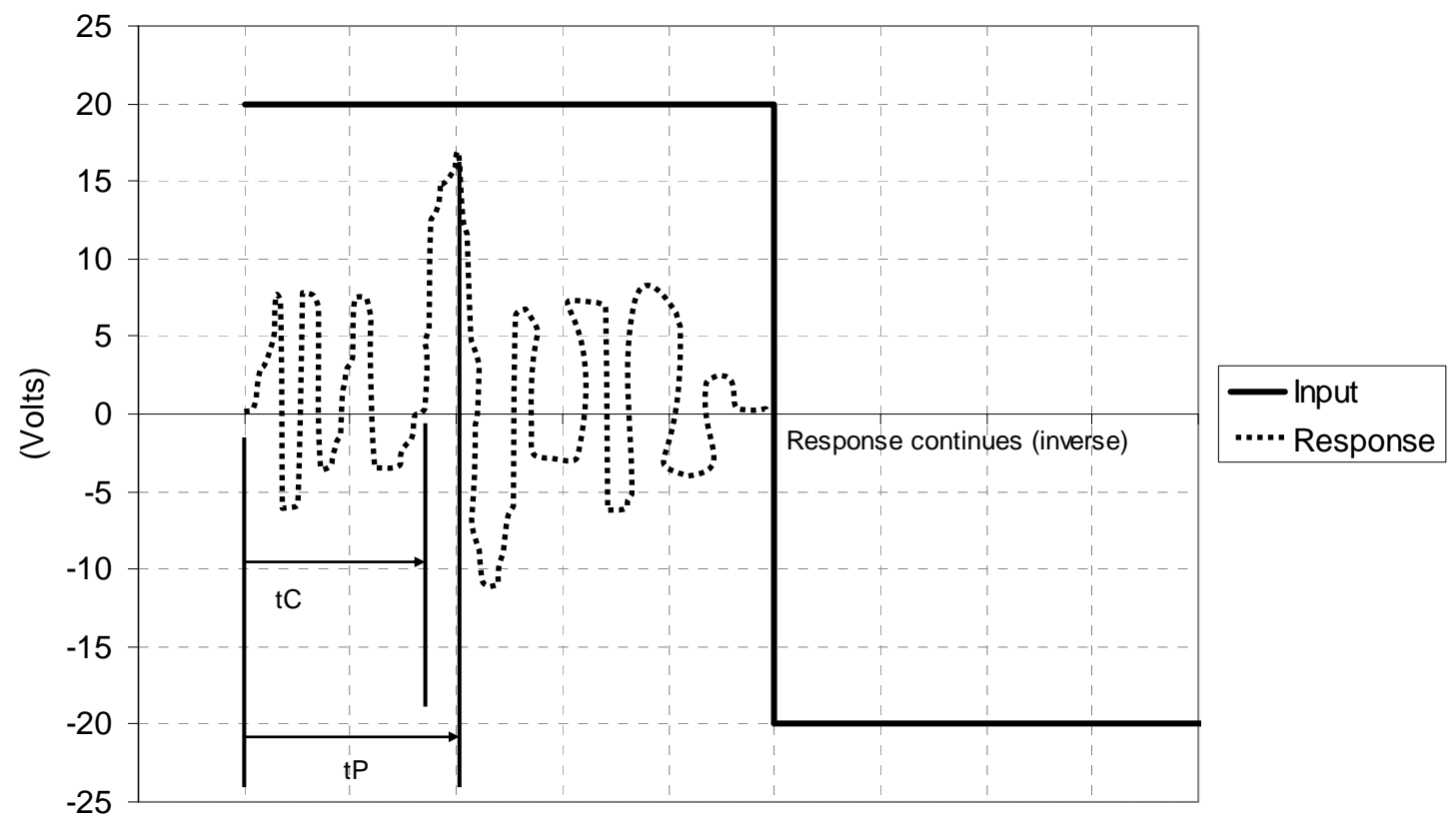

Figure 2.13. Bender Element Response Example, Unequal Peaks 



\subsection{Results}

Lateral earth pressure at rest and shear modulus measurements were performed on kaolin clay and two chemical Hanford sludge simulants. The kaolin clay results are discussed in Section 3.1, and the chemical simulant results are provided in Section 3.2.

\subsection{Kaolin Results}

The PNNL and UW kaolin results for lateral earth pressure at rest, Section 3.1.1, and shear modulus, Section 3.1.2, are considered with respect to the literature. The kaolin clay used by both PNNL and UW was from the same supplier and lot. Additional kaolin test details are provided in Appendix C.

\subsubsection{Kaolin $\mathbf{k}_{0}$}

PNNL and UW conducted independent tests with kaolin clay at an initial clay concentration of $57 \mathrm{wt} \%$. Kaolin tests at other concentrations were also performed by UW. The $\mathrm{k}_{0}$ results of these tests are provided in Table 3.1 .

Initial concentrations, or shear strengths, were selected such that the end-of-test shear strength would address a shear strength range similar to Hanford sludge (from less than 1,000 $\mathrm{Pa}$ up to $10,000 \mathrm{~Pa}$ at the $95 \%$ empirical limit, Wells et al. 2010) for a given deflection. A deflection fraction of nominally 0.10 was targeted because initial testing indicated that the vertical loads used for low (less than approximately $5 \%$ deflection) were insufficient to cause deflection in the sleeve wall, thereby preventing the measurement of $\mathrm{k}_{0}$. Large deflections were not desirable as the initial sample required would then have a very low shear strength.

A fixed-ring consolidometer was employed to determine the required vertical load for a given initial shear strength to achieve nominal 10\% deflection. Although consolidation behavior between the fixedring and $\mathrm{k}_{0}$ consolidometer was not consistent, the target deflection fraction was nearly achieved as shown in Table 3.1. The tested shear strength range for the kaolin was thus approximately 1,000 Pa to 4,500 Pa. Although attempts were made to measure $\mathrm{k}_{0}$ at lower concentrations, no meaningful (i.e., no horizontal pressure was applied) $\mathrm{k}_{0}$ results were achieved with kaolin samples at an initial shear strength of approximately $120 \mathrm{~Pa}$. Increasing the vertical load to potentially achieve a $\mathrm{k}_{0}$ result was expected to result in increased consolidations such that previously measured shear strengths would be approached.

The kaolin k0 results are shown in Figure 3.1 as a function of the mass fraction of kaolin clay in the initial sample. The independent variable, the initial kaolin concentration, was selected to maximize the amount of identified literature data available for comparison, and the literature data are included in Figure 3.1. Insufficient data are provided in the literature to investigate the functionality of $\mathrm{k}_{0}$ with the associated shear strength.

Variability in the results is observable. The data of Abdelhamid and Krizek (1976) at an approximately constant 29\% initial kaolin concentration and Vardhanabhuti (2007) at an approximately constant $45 \%$ initial kaolin concentration show $\mathrm{k}_{0}$ variation of 0.06 and 0.12 , respectively. Both the PNNL and UW $\mathrm{k}_{0}$ results match reasonably well with the literature data. The physical trend of increasing 
$\mathrm{k}_{0}$ with decreasing kaolin concentration (water $\mathrm{k}_{0}=1.0$ ) is observable, and a linear relation provides the best correlation for the literature data.

The uncertainties on the PNNL $\mathrm{k}_{0}$ results are determined from the change in strain gauge reading per horizontal pressure, 0.0020 counts/psi, Section 2.2.5.1, and allowing for a \pm 0.0001 count uncertainty in the maintenance of the sleeve strain gauges at 0.0000 counts. These uncertainties are two orders of magnitude greater than the uncertainties determined via the error propagation approach described in Section 2.2.4 and are on the order of the variation seen in the literature data as described previously.

Table 3.1. Kaolin $\mathrm{k}_{0}$ Results

\begin{tabular}{|c|c|c|c|c|c|c|}
\hline \multirow[b]{2}{*}{ Test ID } & \multirow[b]{2}{*}{$\begin{array}{c}\text { Initial } \\
\text { kaolin Mass } \\
\text { Fraction }^{1} \\
\end{array}$} & \multirow[b]{2}{*}{$\begin{array}{c}\text { Initial Shear } \\
\text { Strength } \\
(\mathrm{Pa})^{2}\end{array}$} & \multirow[b]{2}{*}{$\mathrm{k}_{0}{ }^{3}$} & \multicolumn{3}{|c|}{ End-of-Test } \\
\hline & & & & $\begin{array}{c}\text { End-of-Test } \\
\text { kaolin Mass } \\
\text { Fraction }^{1}\end{array}$ & $\begin{array}{c}\text { Shear } \\
\text { Strength } \\
(\mathrm{Pa})^{2}\end{array}$ & $\begin{array}{c}\text { End-of-Test } \\
\text { Deflection } \\
\text { Fraction } \\
\end{array}$ \\
\hline KA57PNNL1 & 0.57 & 960 & 0.51 & 0.62 & 2882 & 0.08 \\
\hline KA57PNNL2 & 0.57 & 960 & 0.70 & 0.61 & 2890 & 0.08 \\
\hline KA57PNNL3 & 0.57 & 960 & 0.54 & 0.62 & 2976 & 0.06 \\
\hline UW29 & 0.53 & 460 & 0.62 & 0.57 & 1018 & 0.09 \\
\hline UW30 & 0.54 & 558 & 0.67 & 0.57 & 1018 & 0.09 \\
\hline UW21 & 0.56 & 818 & 0.68 & 0.60 & 1719 & 0.10 \\
\hline UW22 & 0.56 & 818 & 0.476 & 0.60 & 1719 & 0.09 \\
\hline UW23 & 0.57 & 990 & 0.61 & 0.62 & 2636 & 0.09 \\
\hline UW28 & 0.59 & 1453 & 0.407 & 0.62 & 2636 & 0.08 \\
\hline UW26 & 0.61 & 2131 & 0.46 & 0.64 & 3569 & 0.11 \\
\hline UW31 & 0.61 & 2131 & 0.49 & 0.65 & 4177 & 0.10 \\
\hline UW27 & 0.61 & 2131 & 0.52 & 0.65 & 4526 & 0.11 \\
\hline \multicolumn{7}{|c|}{ 1. PNNL results measured per Daniel. ${ }^{(a)}$} \\
\hline \multicolumn{7}{|c|}{$\begin{array}{l}\text { 2. PNNL results measured using shear vane per Daniel. }{ }^{(a)} \text { Average of three measurements. UW results } \\
\text { calculated from kaolin shear strength-weight } \% \text { solids correlation (Gauglitz et al. 2010). Differences of } \\
\text { approximately } 10 \% \text { to } 26 \% \text { can be determined between the Gauglitz et al. (2010) correlation and the measured } \\
\text { shear strength of the PNNL consolidated samples. } \\
\text { 3. PNNL } \mathrm{k}_{0} \text { results at time of end of primary deflection determined via the adopted ASTM Standard D 2435-04 } \\
\text { (2004) methodology described in Section 2.2.5.1. UW k } \mathrm{k}_{0} \text { results at constant } \mathrm{k}_{0} \text { after d90 per ASTM Standard } \\
\text { D 2435-04 (2004) methodology } 12.3 .2 \text { (see Appendix C). }\end{array}$} \\
\hline
\end{tabular}

(a) RC Daniel. 2007. PNNL Technical Procedure, "Measurement of Physical and Rheological Properties of Solutions, Slurries and Sludges.” RPL-COLLOID-02, Rev. 1, Pacific Northwest National Laboratory, Richland, Washington. 


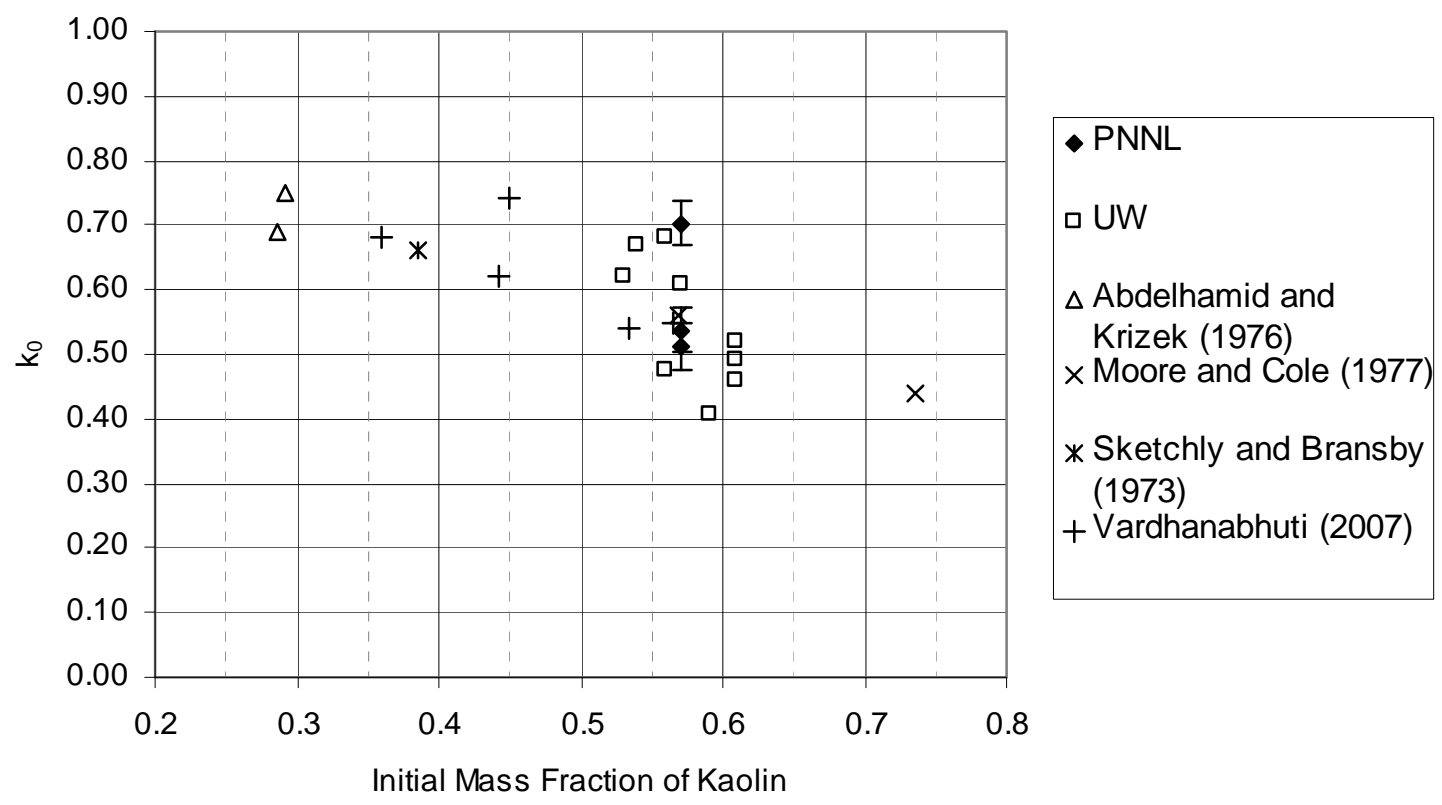

Figure 3.1. $\mathrm{k}_{0}$ as a Function of the Initial Mass Fraction of Kaolin

As discussed in Burns et al. (2010), the rheological properties of kaolin may vary depending on the kaolin source and lot. To consider this type of effect with respect to Figure $3.1, \mathrm{k}_{0}$ is plotted as a function of the plasticity index of the respective kaolin clays in Figure 3.2. Data from Figure 3.1 wherein the plasticity index is not reported are necessarily excluded, and additional data wherein the kaolin concentration was not available for Figure 3.1 is included in Figure 3.2.

The Prashant (2005) results are determined using the angle of internal fraction, $\phi^{\prime}$, reported therein, and the relation

$$
\mathrm{k}_{0}=0.95-\sin \phi^{\prime}
$$

reported in Edil and Dhowian (1981) to be more appropriate than the Jaky (1948) relation for normally consolidated clays. The calculated results for the sample configuration most closely resembling the current configuration, a solid cylindrical sample, are included in Figure 3.2.

There is no meaningful indication in Figure 3.2 that variability of the kaolin itself, as represented by the plasticity index, influences the results of Figure 3.1. The range of $\mathrm{k}_{0}$ results in the literature at similar plasticity indices is similar to that of the PNNL/UW results. The comparison of the $\mathrm{k}_{0}$ results for kaolin clay from PNNL and UW to the literature supports the use of the $\mathrm{k}_{0}$ consolidation device to provide meaningful results for the chemical simulants. 


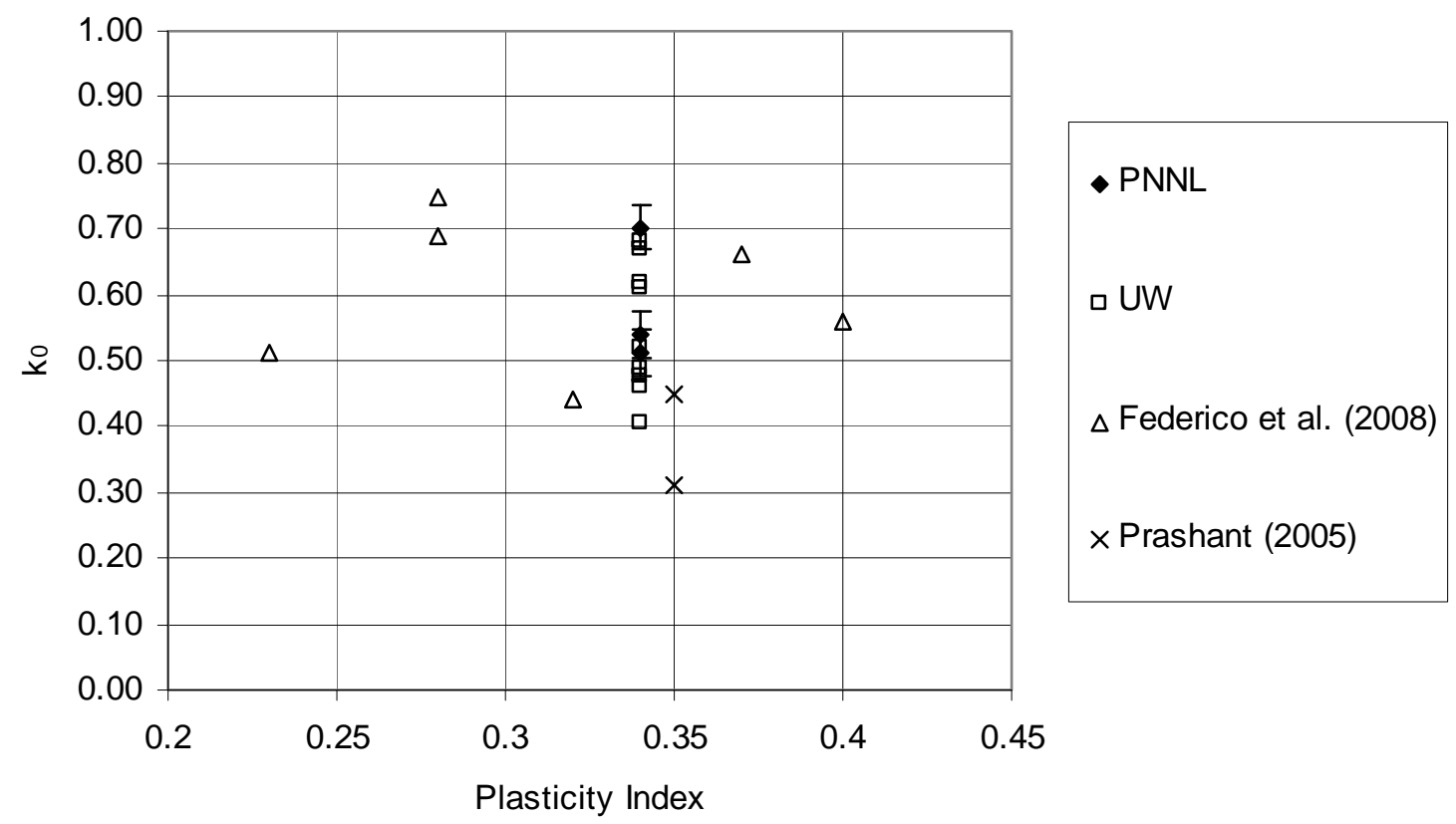

Figure 3.2. $\mathrm{k}_{0}$ as a Function of the Kaolin Plasticity Index

\subsubsection{Kaolin $\mathbf{G}_{\max }$}

Shear modulus measurements for PNNL and UW tests are provided in Table 3.2. The shear wave velocity as a function of the mass fraction of kaolin clay in the sample is shown in Figure 3.3. Good agreement is shown between the PNNL and UW results. The uncertainties on the PNNL data are determined as specified in Section 2.2.4.

Limited data for low shear strength kaolin slurries are available in the literature. Oh et al. (2008) provide the shear wave velocity as a function of shear strength approaching that of interest for the current work as presented with the PNNL and UW results in Figure 3.4. Again, good agreement is shown. The trend of increasing shear wave velocity with increasing shear strength (i.e., increasing concentration) was expected as described by Wells et al. (2010).

Comparison of the approximated shear strength-shear modulus relation estimated from $\mathrm{Oh}$ et al. (2008) and the PNNL/UW results appears quite favorable (Figure 3.5). A linear relation is indicated. Alderman et al. (1991) provided power-law functionality for the shear strength and shear modulus of bentonite clay. Thus, the linear indication in Figure 3.5 is reasonable. Similar functionality may be expected between the UDS concentration and shear strength-shear modulus of the chemical simulants. ${ }^{\text {(a) }}$

The comparison of the shear modulus results for kaolin clay from PNNL and UW to the literature provides support that the current approach will provide meaningful results for the chemical simulants.

(a) Exponential functionality is used to describe the relation of UDS concentration and shear strength for kaolin clay and certain Hanford wastes (e.g., Gauglitz et al. 2009, 2010). 
As described in Wells et al. (2010), Alderman et al. (1991) provide an extension of the shear vane technique to determine the shear modulus, $\mathrm{G}$, as

$$
\mathrm{G}=\frac{1}{4 \pi \omega \mathrm{H}}\left(\frac{\mathrm{dT}}{\mathrm{dt}}\right)\left(\frac{1}{\mathrm{R}^{2}}-\frac{1}{\mathrm{R}_{\mathrm{C}}^{2}}\right)
$$

where

$$
\begin{aligned}
& \omega= \text { angular velocity of the vane } \\
& \mathrm{H}= \text { vane height } \\
& \mathrm{dT} / \mathrm{dt}= \text { slope of the linear portion of the torque-time curve resulting from the Hookean } \\
& \text { elastic response of the sample } \\
& \mathrm{R}= \text { vane radius } \\
& \mathrm{R}_{\mathrm{C}} \quad \text { radius of the sample container. }
\end{aligned}
$$

This technique is applied to the shear vane measurements of the PNNL kaolin tests. The kaolin shear modulus determined with Equation (3.2) under-predicts the Table 3.2 results by a median factor of 114, ranging from factors of 79 to 133 . These results are compared to the chemical simulant results discussed in Section 3.2. 
Table 3.2. Kaolin $\mathrm{G}_{\max }$ Results

Sample Density at

Shear Wave Time of Measurement

\begin{tabular}{|c|c|c|c|c|}
\hline Test ID & Velocity $(\mathrm{m} / \mathrm{s})$ & $\begin{array}{l}(\mathrm{g} / \mathrm{mL})^{1} \\
\end{array}$ & $\begin{array}{l}\text { Shear Miodulus } \\
\qquad(\mathrm{kPa})^{2}\end{array}$ & Measurement $(\mathrm{Pa})^{3}$ \\
\hline KA57PNNL1 & 22.5 & 1.638 & 826 & 2882 \\
\hline KA57PNNL2 & 25.2 & 1.622 & 1032 & 2890 \\
\hline KA57PNNL3 & 27.3 & 1.645 & 1227 & 2976 \\
\hline UW29 & 18.2 & 1.552 & 514 & 1018 \\
\hline UW30 & 16.9 & 1.552 & 443 & 1018 \\
\hline UW23 & 26.8 & 1.631 & 1171 & 2636 \\
\hline UW28 & 24.4 & 1.631 & 971 & 2636 \\
\hline UW26 & 37.3 & 1.657 & 2306 & 3569 \\
\hline UW31 & 58.9 & 1.671 & 5798 & 4177 \\
\hline UW27 & 42.8 & 1.679 & 3075 & 4526 \\
\hline UW30A & 8.6 & 1.506 & 111 & 550 \\
\hline UW30B & 11.9 & 1.527 & 218 & 731 \\
\hline UW30C & 15.6 & 1.534 & 375 & 806 \\
\hline UW30D & 13.0 & 1.545 & 263 & 928 \\
\hline UW30E & 14.3 & 1.549 & 316 & 978 \\
\hline UW30F & 15.7 & 1.552 & 381 & 1017 \\
\hline UW30G & 16.6 & 1.554 & 426 & 1044 \\
\hline UW30H & 16.7 & 1.556 & 434 & 1062 \\
\hline UW30I & 16.9 & 1.556 & 445 & 1063 \\
\hline UW31A & 25.9 & 1.610 & 1077 & 2078 \\
\hline UW31B & 34.0 & 1.645 & 1899 & 3102 \\
\hline UW31C & 41.4 & 1.653 & 2833 & 3409 \\
\hline UW31D & 49.3 & 1.664 & 4039 & 3862 \\
\hline UW31E & 52.4 & 1.671 & 4580 & 4151 \\
\hline UW31F & 56.5 & 1.674 & 5350 & 4295 \\
\hline UW31G & 59.0 & 1.675 & 5823 & 4357 \\
\hline UW31H & 58.9 & 1.676 & 5805 & 4387 \\
\hline
\end{tabular}

1. PNNL densities measured per Daniel. ${ }^{(\mathrm{a})}$ UW densities calculated from reported kaolin concentration and conservation of mass with the kaolin density at $2.65 \mathrm{~g} / \mathrm{mL}$ (kaolin density, Bontha et al. 2010), water density $1 \mathrm{~g} / \mathrm{mL}$.

2. Computed per Equation (2.5).

3. PNNL results measured using shear vane per Daniel. ${ }^{(a)}$ Average of three measurements. UW results calculated from kaolin shear strength-weight \% solids correlation, Gauglitz et al. (2010).

(a) RC Daniel. 2007. PNNL Technical Procedure, "Measurement of Physical and Rheological Properties of Solutions, Slurries and Sludges.” RPL-COLLOID-02, Rev. 1, Pacific Northwest National Laboratory, Richland, Washington. 


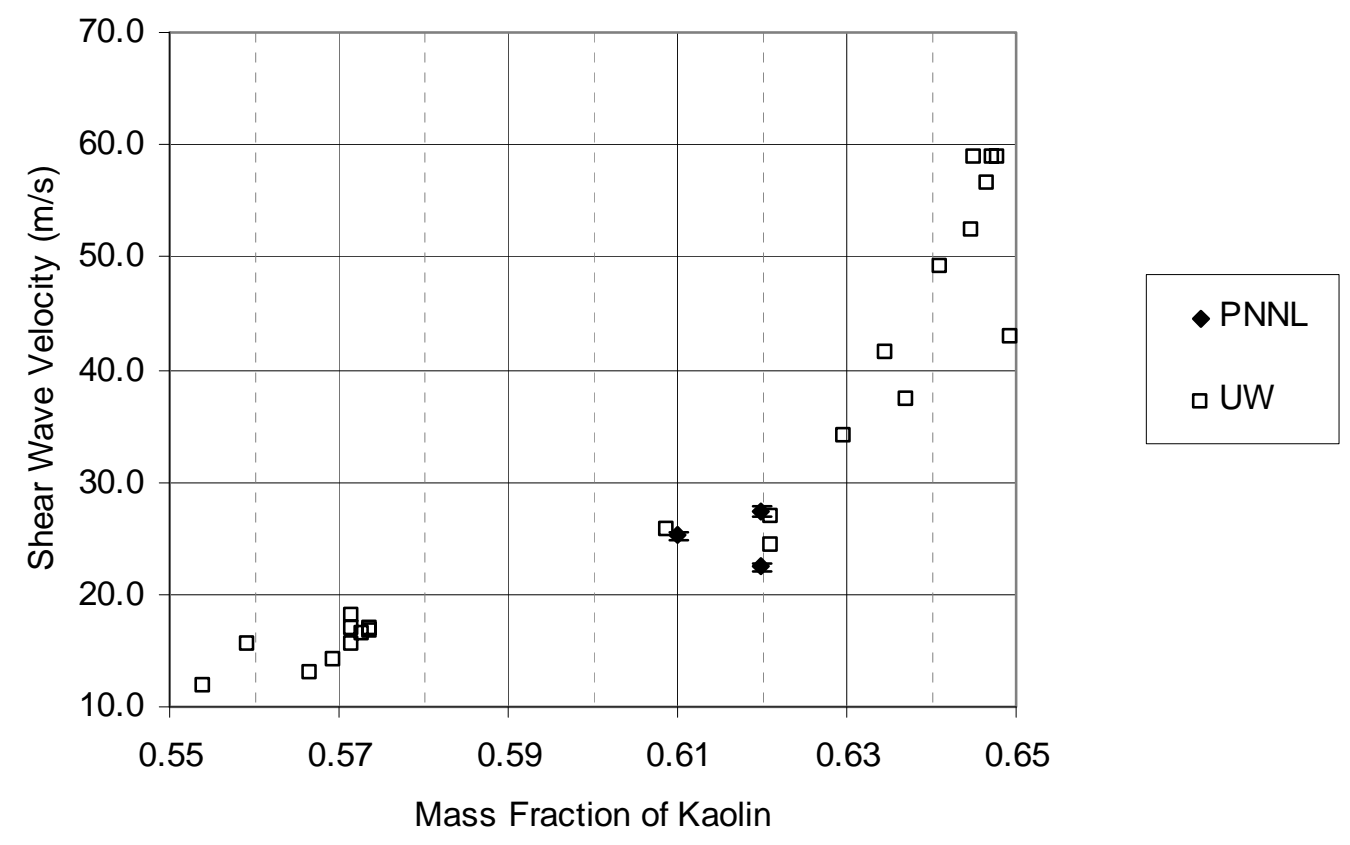

Figure 3.3. Shear Wave Velocity as a Function of the Time-of-Measurement Mass Fraction of Kaolin

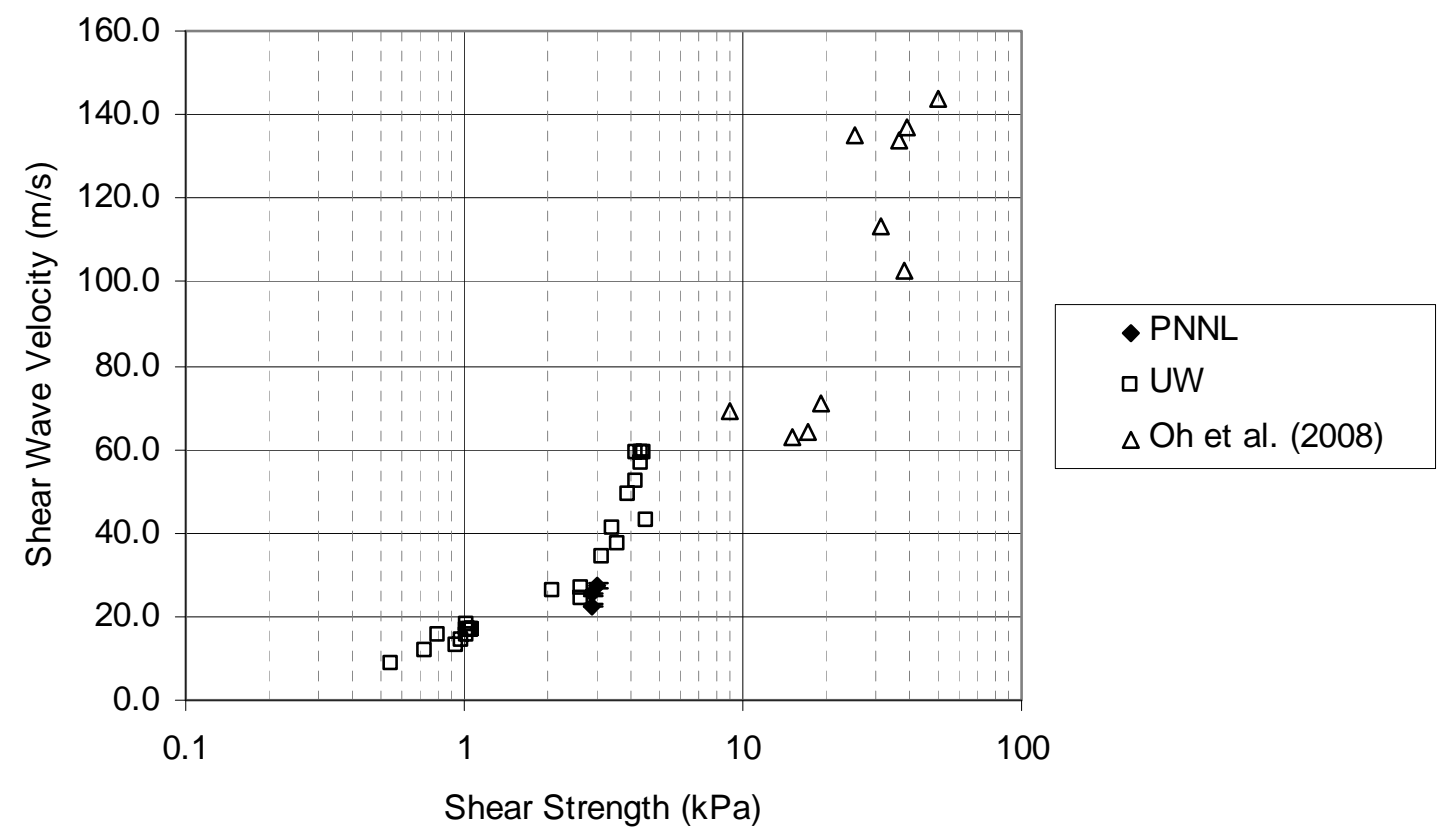

Figure 3.4. Kaolin Shear Wave Velocity as a Function of Sample Shear Strength 


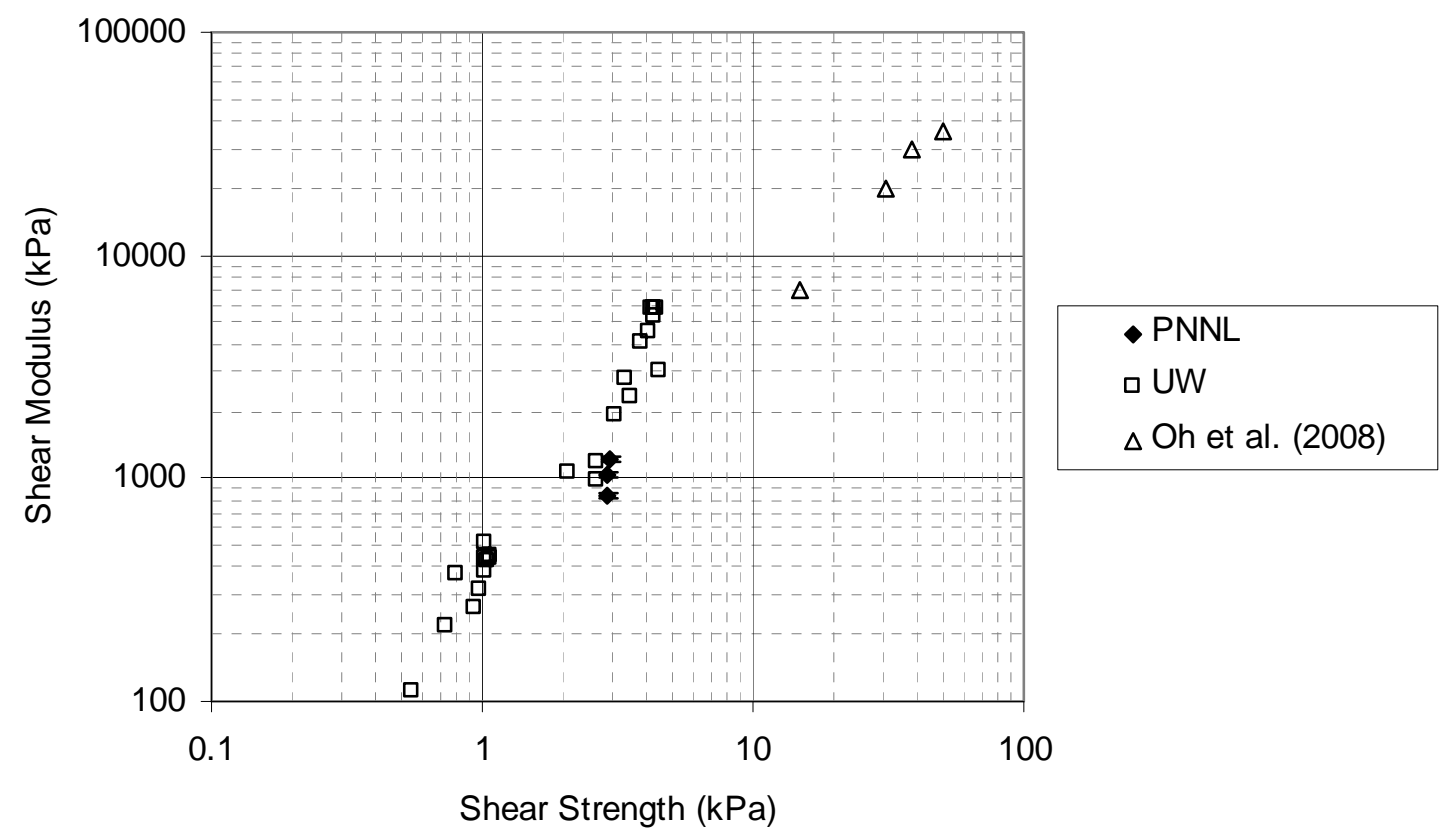

Figure 3.5. Kaolin Shear Modulus as a Function of Sample Shear Strength. Oh et al. (2008) results are approximated from the supporting data.

\subsection{Chemical Simulant Results}

Eleven lateral earth pressure at rest and shear modulus measurements were taken on the two chemical simulants of Wells et al. (2010), and the results are provided in Table 3.3. Additional test details are provided in Appendix D.

The initial sample shear strengths were selected such that the resultant end-of-primary consolidation shear strength, for a given deflection, would approximate the shear strength range of Hanford sludge (from less than 1,000 $\mathrm{Pa}$ up to $10,000 \mathrm{~Pa}$ at the $95 \%$ empirical limit, approximately $20,000 \mathrm{~Pa}$ maximum, Wells et al. 2010). The uniqueness of the chemical simulants with respect to the shear strength-solid concentration is apparent. The initial shear strength for tests S1A and S1B and S2A through S2C are similar, but the lower deflection fraction in Simulant 1 results in a much higher shear strength with respect to Simulant 2 .

The consolidation behavior of the two chemical simulants is very different as shown in the consolidation times of Table 3.3. The end-of-primary consolidation time is substantially lower for Simulant 1. This result is counter-intuitive with respect to the increased solid concentration (see Appendix D), which is equivalent to lower porosity, as well as the lower particle size and distribution breadth (Wells et al. 2010) of Simulant 1 with respect to Simulant 2, and may therefore be attributable to the chemistry differences.

The larger deflection fractions for the $220 \mathrm{~Pa}$ and $389 \mathrm{~Pa}$ shear strength tests (S1E and S2F, respectively) result from keeping the vertical load constant, the same as that of the $596 \mathrm{~Pa}$ and $1091 \mathrm{~Pa}$ shear strength tests (S1C and S1D, S2D and S2E, respectively). This was done because, as described in 
Section 3.1, tests with the kaolin simulant demonstrated that for relatively low vertical loads, no meaningful $\mathrm{k}_{0}$ results were achieved. Further, given the change in strain gauge reading per applied horizontal pressure (Section 2.2.5.1), uncertainty in $\mathrm{k}_{0}$ exceeding the variation indicated by the literature (see Section 3.1) would result in lower vertical loads.

The chemical simulant $\mathrm{k}_{0}$ results are shown in Figure 3.6 as a function of the shear strength measured at the end of primary consolidation. The measurement uncertainties are determined as described for the kaolin results in Section 3.1. As with the kaolin, a linear relation is indicated. However, both the dependent $\left(\mathrm{k}_{0}\right)$ and independent (shear strength) parameters are dependent on the same independent parameter, the UDS concentration. As described in Meyer et al. (2009), including the same independent parameter on both sides of a relation can artificially inflate the apparent relationship and measures thereof, resulting in a spurious correlation. This possibility is acknowledged, but, in order to facilitate the future comparison of the chemical simulant measurements to in situ Hanford sludge conditions, functional relationships are considered further with shear strength as the independent variable.

Table 3.3. Chemical Simulant Results

\begin{tabular}{|c|c|c|c|c|c|c|}
\hline Test ID ${ }^{1}$ & $\begin{array}{c}\text { Initial } \\
\text { Shear } \\
\text { Strength } \\
(\mathrm{Pa})^{2} \\
\end{array}$ & $\mathrm{k}_{0}$ & $\begin{array}{l}\text { Shear } \\
\text { Modulus } \\
(\mathrm{kPa})\end{array}$ & $\begin{array}{c}\text { End of } \\
\text { Primary } \\
\text { Consolidation } \\
\text { Shear Strength } \\
(\mathrm{Pa})^{2} \\
\end{array}$ & $\begin{array}{c}\text { End of } \\
\text { Primary } \\
\text { Consolidation } \\
\text { Deflection } \\
\text { Fraction } \\
\end{array}$ & $\begin{array}{c}\text { Time of End } \\
\text { of Primary } \\
\text { Consolidation } \\
\text { (min) }\end{array}$ \\
\hline S1A & 2727 & 0.35 & 23041 & 18777 & 0.06 & 28 \\
\hline S1B & 2727 & 0.39 & 23657 & $18180^{3}$ & 0.05 & 27 \\
\hline $\mathrm{S} 1 \mathrm{C}$ & 596 & 0.44 & 3736 & 4655 & 0.06 & 65 \\
\hline S1D & 596 & 0.52 & 3072 & 4578 & 0.06 & 78 \\
\hline S1E & 220 & 0.47 & 2589 & 1851 & 0.07 & 70 \\
\hline S2A & 2478 & 0.25 & 2396 & 9874 & 0.10 & 620 \\
\hline S2B & 2478 & 0.47 & 2828 & 10853 & 0.10 & 700 \\
\hline $\mathrm{S} 2 \mathrm{C}$ & 2478 & 0.37 & 2520 & 8456 & 0.10 & 570 \\
\hline S2D & 1091 & 0.47 & 926 & 3457 & 0.07 & 1000 \\
\hline S2E & 1091 & 0.42 & 947 & 3874 & 0.07 & 1010 \\
\hline $\mathrm{S} 2 \mathrm{~F}$ & 389 & 0.44 & 769 & 2040 & 0.12 & 850 \\
\hline \multicolumn{7}{|c|}{$\begin{array}{l}\text { 1. S1 denotes Simulant } 1 ; \mathrm{S} 2 \text { denotes Simulant } 2 . \\
\text { 2. Measured per Daniel. (a) Average of three measurements. } \\
\text { 3. Average of two measurements. Sample fractured and subsequent shear strength measurements were biased low. }\end{array}$} \\
\hline
\end{tabular}

(a) RC Daniel. 2007. PNNL Technical Procedure, "Measurement of Physical and Rheological Properties of Solutions, Slurries and Sludges.” RPL-COLLOID-02, Rev. 1, Pacific Northwest National Laboratory, Richland, Washington. 


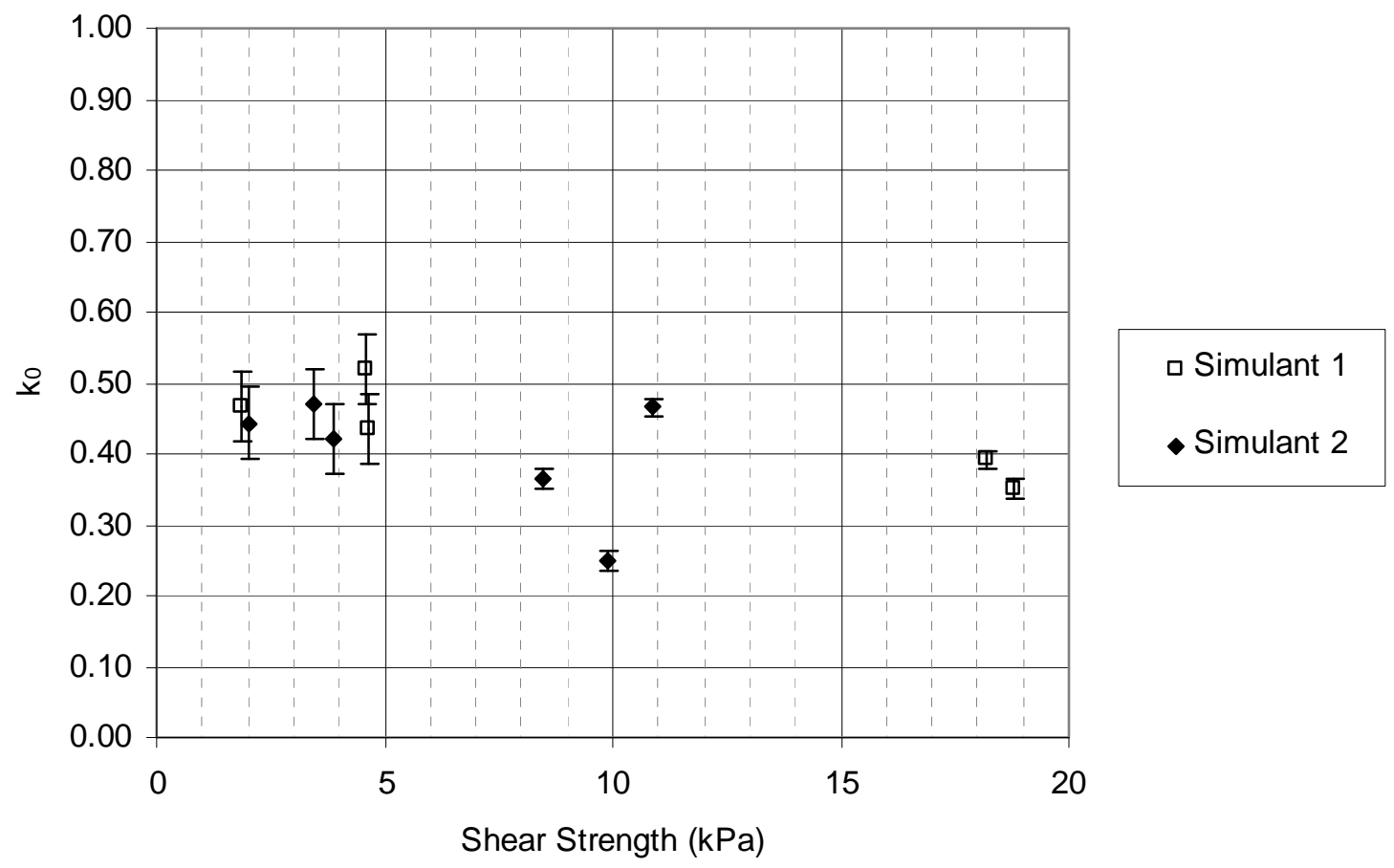

Figure 3.6. Chemical Simulant $\mathrm{k}_{0}$ as a Function of Sample Shear Strength

The $\mathrm{k}_{0}$ result for test $\mathrm{S} 2 \mathrm{~A}$ does not trend similarly to the other test results, and the variation for tests S2A through S2C (tests at same initial conditions) exceeds that shown in the kaolin literature. The linear data fits shown in Figure 3.7, therefore, do not include the S2A result. For the range of shear strength tested, minimal difference is shown for the fits of the individual and entire chemical simulant data set. The S1 and S2 linear relation between $\mathrm{k}_{0}$ and shear strength $\tau$ in $\mathrm{kPa}$ for the range of shear strength tested is

$$
\mathrm{k}_{0}=-0.0054 \tau+0.4742
$$

with an $\mathrm{R}^{2}$ of 0.43 . The linear relation of Equation (3.3) does not trend to a $\mathrm{k}_{0}$ of unity at low shear strength, i.e., the low UDS concentration as physically meaningful. As discussed in Section 3.1, the functionality of $\mathrm{k}_{0}$ with UDS concentration is indicated to be linear, while the functionality of shear strength with UDS concentration is typically exponential or power law. Power law applies to the chemical simulants (see Figure D.2, Appendix D), and provides the required functionality with $\mathrm{k}_{0}$ as shown in Figure 3.7. The power-law fit of Figure 3.7,

$$
\mathrm{k}_{0}=0.5052 \tau^{-0.0927}
$$

has an $\mathrm{R}^{2}$ of 0.40 , is essentially equivalent to the linear fit on Equation (3.3) over the range of shear strength tested, and necessarily has the expected physical behavior. The difficulty of measuring $\mathrm{k}_{0}$ in relatively low-strength simulants was discussed in Section 3.1.1. Thus, there are currently no data to demonstrate the accuracy of Equation (3.4) below approximately $2000 \mathrm{~Pa}$. 
The variation of $\mathrm{k}_{0}=0.08$ in Equation (3.4) is shown in Figure 3.7 to encompass the data spread. This variation is not the uncertainty of the fit. This variation in $\mathrm{k}_{0}$ of the fit across the shear strength range evaluated is similar to the kaolin $\mathrm{k}_{0}$ variation shown in the literature.

The chemical simulant $\mathrm{G}_{\max }$ results are shown in Figure 3.8 as a function of the shear strength measured at the end of primary consolidation. The measurement uncertainties are determined as described for the kaolin results in Section 3.1. The spurious correlation discussion for the $\mathrm{k}_{0}$ results from above again applies.

The linear fits for $\mathrm{G}_{\max }$ in Figure 3.8 are

$$
\mathrm{G}_{\max }=1232.2 \tau
$$

for Simulant 1 and

$$
\mathrm{G}_{\max }=264.6 \tau
$$

for Simulant 2 with the physical intercept of zero for both equations. The $\mathrm{R}^{2}$ of the fits are 0.98 and 0.96 , respectively.

The $\mathrm{G}_{\max }$ results for the chemical simulants are unique with respect to each other. As described in Wells et al. (2010), the simulants do not represent the possible range of actual Hanford sludge. Thus, it is reasonable to expect variations in the shear modulus for different waste types and simulants thereof.

The Alderman et al. (1991) shear modulus technique, Equation (3.2), is applied to the chemical simulant shear vane data. A comparison of the shear modulus determination is made in Figure 3.9. The Simulant 2 results are similar to the kaolin in that the shear modulus determined with Equation (3.2) under-predicts the Table 3.3 results by a median factor of 89 , ranging from factors of 77 to 119 . For Simulant 1, Equation (3.2) under-predicts the Table 3.3 results by a median factor of 339, ranging from factors of 278 to 400 . Comparison of the Alderman et al. (1991) shear modulus technique to the Table 3.3 results is thus dependent on the simulant considered. The trend of increasing shear modulus with increasing shear strength (UDS concentration) is reproduced as evident in the relatively constant ratios. 


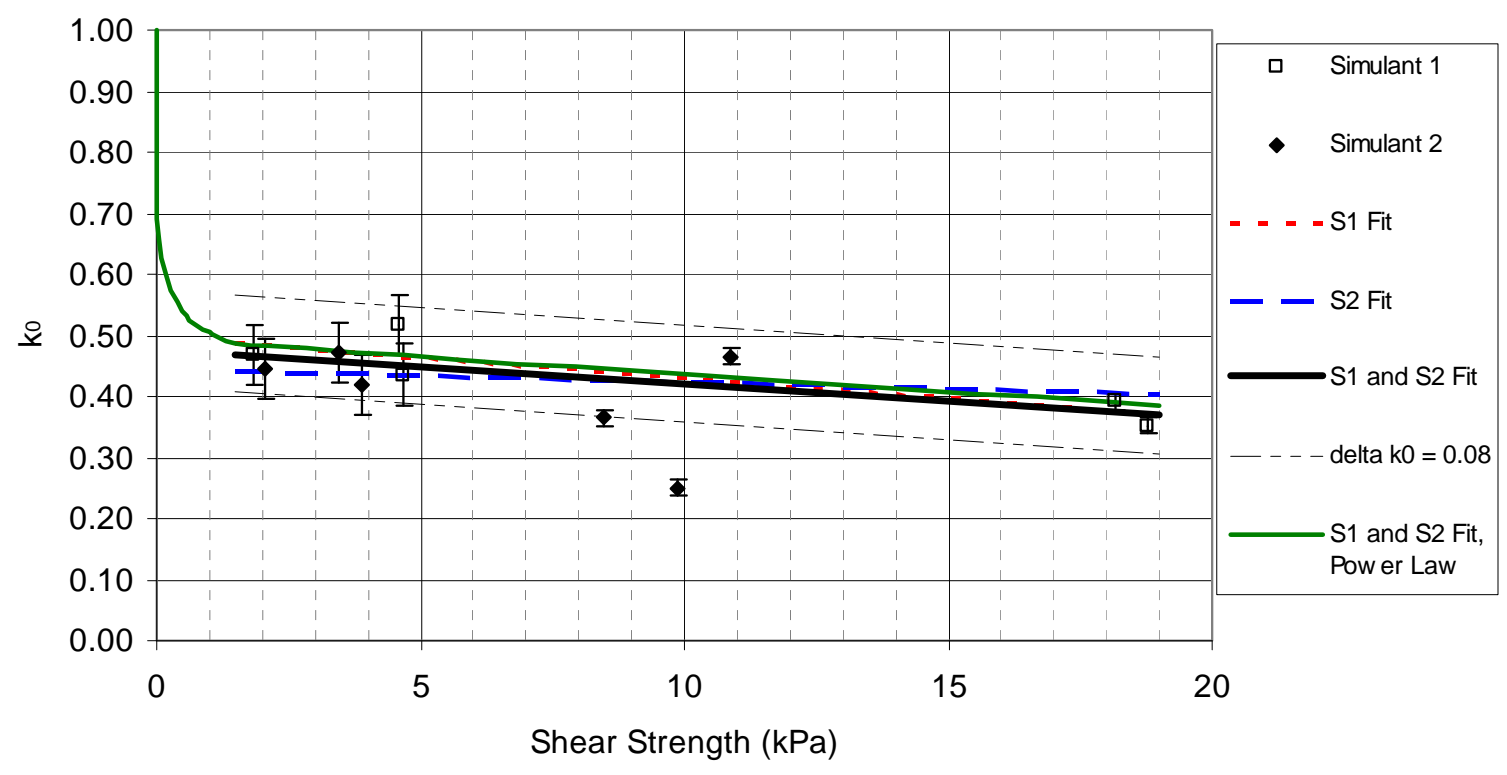

Figure 3.7. Chemical Simulant $\mathrm{k}_{0}$ as a Function of Sample Shear Strength, Linear Functionality. S2A result is not included in data fits.

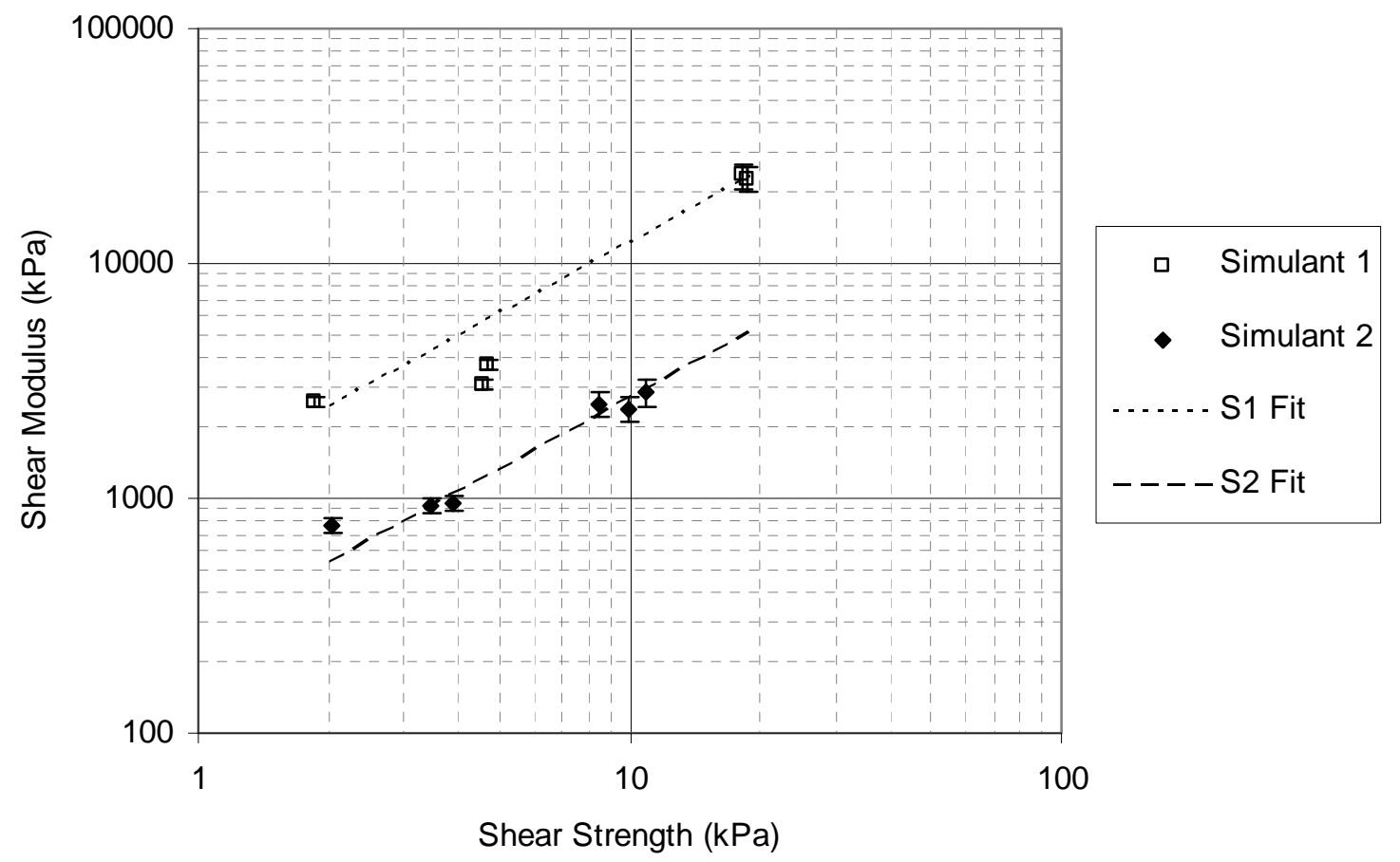

Figure 3.8. Chemical Simulant $\mathrm{G}_{\max }$ as a Function of Sample Shear Strength 


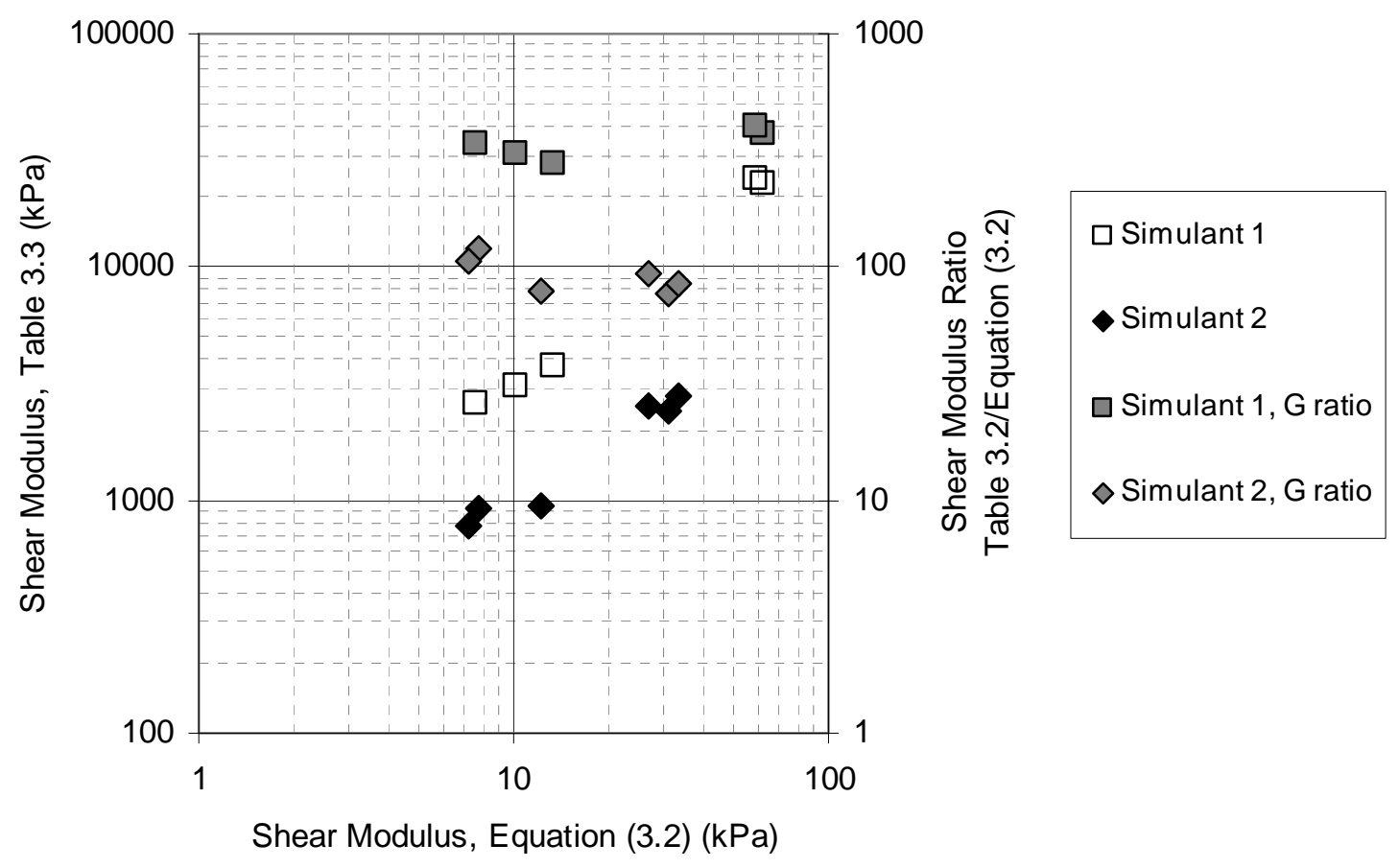

Figure 3.9. Chemical Simulant; Comparison of Shear Modulus Methods 



\subsection{Summary}

A device to concurrently measure the lateral earth pressure at rest $\left(\mathrm{k}_{0}\right)$ and shear modulus $\left(\mathrm{G}_{\max }\right)$, the " $\mathrm{k}_{0}$ consolidometer," was designed and produced. Independent measurements taken with reproductions of this device using kaolin clay slurries over a shear strength range similar to that of Hanford sludge are shown to be in agreement with the literature.

The $\mathrm{k}_{0}$ consolidometer was used to measure the $\mathrm{k}_{0}$ and $\mathrm{G}_{\max }$ of chemical Simulants 1 and 2 of Wells et al. (2010), which have chemical and physical properties that match well with all of the Hanford sludge parameters considered. Simulant 1, chosen from Hanford sludge simulants that have previously been produced and characterized, was selected to represent the Hanford sludge as a whole. Simulant 2 was developed in Wells et al. (2010) to represent the resultant sludge of a specific SST into a DST retrieval scenario (C-104, C-111, and C-112 retrieval into AN-101). The simulants are unique with respect to each other for some of the parameters considered and fall within the broad variation of Hanford wastes.

The lateral earth pressure at rest of the chemical simulants have nominally similar functionality with respect to their shear strength. Decreasing $\mathrm{k}_{0}$, described from the data by

$$
\mathrm{k}_{0}=0.5052 \tau^{-0.0927}
$$

with a variation of $\mathrm{k}_{0}=0.08$ (variation to encompass data spread, not uncertainty of Equation (4.1)) approximates both chemical simulants over the range of shear strength tested. Unique relations are described for $\mathrm{G}_{\max }$ as

$$
\mathrm{G}_{\max }=1232.2 \tau
$$

for Simulant 1 and

$$
\mathrm{G}_{\max }=264.6 \tau
$$

for Simulant 2.

No measurements of the lateral earth pressure at rest and shear modulus are currently available for actual Hanford sludge. Thus, it is not possible to establish that the lateral earth pressure at rest and shear modulus measured on Simulants 1 and 2 and the relationship to shear strength described by these measurements represent these parameters for actual Hanford sludge. Further, although the simulants are unique with respect to each other, they do not represent the possible range of actual Hanford sludge (e.g., see Wells et al. 2010). The reported variation in the consolidation behavior as well as the $\mathrm{G}_{\max }$ results of the simulants suggests differences in the in situ behavior of the Hanford sludge to the simulants as well as within the waste itself.

Follow-on recommendations include:

- Additional experiments on the two chemical simulants within the range of shear strengths presented would improve confidence in the correlations provided for these simulants. 
- Additional testing on other well-characterized simulants may be used to provide additional confidence in the test apparatus and methodology.

- Given the variation in the experimental results for the chemical simulants and their relation to the possible range of Hanford sludge, the development of and testing on additional chemical simulants representing other Hanford sludge would provide further insight into the variability of the measured parameters.

- The bender elements can be deployed into samples that are not consolidated. Thus, the shear modulus data set can relatively expediently (as compared to the test time required for $\mathrm{k}_{0}$ consolidation tests) be expanded for the current as well as additional simulants, thereby increasing the understanding of the functionality and potential variability of actual Hanford sludge.

- An analysis of shear vane data from actual Hanford sludge via Alderman et al. (1991) can be used to

o Determine the potential range of shear modulus based on the described variability of the bender-element test.

o Describe the relative change in shear modulus for a given change in shear strength for a particular waste.

- The low sample volume required for testing using the $\mathrm{k}_{0}$ consolidometer device, and the relative simplicity of operation, combined with its caustic tolerance, can lend itself to hot-cell testing of actual Hanford sludge samples. 


\subsection{References}

Abdelhamid MS and RJ Krizek. 1976. "At rest lateral earth pressure of a consolidating clay." Journal of Geotechnical Engineering Division, ASCE 102(7):721-728.

Alderman NJ, GH Meeten, and JD Sherwood. 1991. "Vane Rheometry of Bentonite Gels." Journal of Non-Newtonian Fluid Mechanics 39:291-310.

ASTM Standard D 2435-04. 2004. Standard Test Methods for One-Dimensional Consolidation Properties of Soils Using Incremental Loading. ASTM International, West Conshohocken, Pennsylvania.

Barnes HA and QD Nguyen. 2001. "Rotating Vane Rheometry - A Review.” Journal of Non-Newtonian Fluid Mechanics 989:1-14.

Bishop AW and DJ Henkel. 1962. The Measurement of Soil Properties in the Triaxial Test. 2nd ed., Edward Arnold Ltd., London, 228 pp.

Black JA. 2009. Shear Wave Velocity Measurement of Kaolin During Undrained Unconsolidated Triaxial Compression. GeoHalifax, Halifax, Nova Scotia.

Bontha JR, CW Stewart, DE Kurath, PA Meyer, ST Arm, CE Guzman-Leong, MS Fountain, M Friedrich, SA Hartley, LK Jagoda, CD Johnson, KS Koschik, DL Lessor, F Nigl, RL Russell, GL Smith, W Yantasee, and ST Yokuda. 2005. Technical Basis for Predicting Mixing and Flammable Gas Behavior in the Ultrafiltration Feed Process and High-Level Waste Lag Storage Vessels with Non-Newtonian Slurries. PNWD-3676 (WTP-RPT-132, Rev. 0), Pacific Northwest National Laboratory, Richland, Washington.

Bontha JR, HE Adkins, KM Denslow, JJ Jenks, CA Burns, PP Schonewill, GP Morgan, MS Greenwood, J Blanchard, TJ Peters, PJ MacFarlan, EB Baer, and WA Wilcox. 2010. Test Loop Demonstration and Evaluation of Slurry Transfer Line Critical Velocity Measurement Instruments. PNNL-19441, Rev. 0, Pacific Northwest National Laboratory, Richland, Washington.

Burland JB. 1967. "Deformation of Soft Clay." Thesis presented to Cambridge University, England, in partial fulfillment of the requirements for the degree of Doctor of Philosophy.

Burns CA, PA Gauglitz, and RL Russell. 2010. Shear Strength Correlations for Kaolin/Water Slurries: A Comparison of Recent Measurements with Historical Data. PNNL-19094, Pacific Northwest National Laboratory, Richland, Washington.

Certa PJ and MN Wells. 2009. River Protection Project System Plan. ORP-11242 Rev. 4, Office of River Protection, Richland, Washington.

Craig RF. 2004. “Craig's Soil Mechanics.” ISBN 0-415-32702-4. Spon Press, New York, New York.

Duval JI. 1994. “A Laboratory Investigation of Lateral Stresses During Consolidation of San Francisco Bay Mud.” Master Thesis, University of Washington, 1994, pp 106. 
Edil TB and AW Dhowian. 1981. "At-rest lateral pressure of peat soils.” Journal of Geotechnical Engineering Division, ASCE 107(2):201-220.

Enderlin CW, G Terrones, CJ Bates, BK Hatchell, and B Adkins. 2003. Recommendations for Advanced Design Mixer Pump Operation in Savannah River Site Tank 18F. PNNL-14443, Pacific Northwest National Laboratory, Richland, Washington.

Federico A, G Elia, and V Germano. 2008. "A Short Note on the Earth Pressure and Mobilized Angle of Internal Friction in One-Dimensional Compression of Soils." Journal of GeoEngineering 3(1):41-46.

Figliola RS, and DE Beasly. 1995. Theory and Design for Mechanical Measurements. ISBN 0-47100089-2. John Wiley \& Sons, New York.

Gauglitz PA, and JT Aikin. 1997. Waste Behavior During Horizontal Extrusion: Effect of Waste Strength for Bentonite and Kaolin/Ludox Simulants and Strength Estimates for Wastes from Hanford Tanks 241-SY-103, AW-101, AN-103, and S-102. PNNL-11706, Pacific Northwest National Laboratory, Richland, Washington.

Gauglitz PA, LA Mahoney, DP Mendoza, and MC Miller. 1994. Mechanisms of Gas Bubble Retention. PNL-10120, Pacific Northwest Laboratory, Richland, Washington.

Gauglitz PA, SD Rassat, MR Powell, RR Shah, and LA Mahoney. 1995. Gas Bubble Retention and its Effect on Waste Properties: Retention Mechanisms, Viscosity, and Tensile and Shear Strength. PNL-10740, Pacific Northwest Laboratory, Richland, Washington.

Gauglitz PA, SD Rassat, PR Bredt, JH Konynenbelt, SM Tingey, and DP Mendoza. 1996. Mechanisms of Gas Bubble Retention and Release: Results for Hanford Waste Tanks 241-S-102 and 241-SY-103 and Single-Shell Tank Simulants. PNNL-11298, Pacific Northwest National Laboratory, Richland, Washington.

Gauglitz PA, BE Wells, JA Fort, and PA Meyer. 2009. An Approach to Understanding Cohesive Slurry Settling, Mobilization, and Hydrogen Gas Retention in Pulsed Jet Mixed Vessels. PNNL-17707, WTPRPT-177, Rev. 0, Pacific Northwest National Laboratory, Richland, Washington.

Gauglitz PA, B Buchmiller, JJ Jenks, J Chun, RL Russell, AJ Schmidt, and MM Mastor. 2010. The Disruption of Vessel-Spanning Bubbles with Sloped Fins in Flat-Bottom and 2:1 Elliptical-Bottom Vessels. PNNL-19345, Pacific Northwest National Laboratory, Richland, Washington.

Houlsby GT and CP Wroth. 1991. "The Variation of Shear Modulus of a Clay With Pressure and Overconsolidation Ratio.” Soils and Foundations 31(3):138-143.

Jaky J. 1948. "Pressure in Soils." In: The Second International Conference on Soil Mechanics and Foundation Engineering, London, Vol. 1, 103-107.

Kjellman W. 1936. "Report on an Apparatus for Consummate Investigation of the Mechanical Properties of Soils." In: Proceedings of the First International Conference on Soil Mechanics and Foundation Engineering, Cambridge, Vol. 1, p. 16. 
Kurath DE, PA Meyer, JR Bontha, AP Poloski, JA Fort, WH Combs, WC Buchmiller, ID Welch, and MD Bleich. 2007. Assessment of Pulse Tube Mixing for Vessels Containing Non-Newtonian Slurries. PNWD-3827 (WTP-RPT-155, Rev. 0), Pacific Northwest National Laboratory, Richland, Washington.

Lee JS and JC Santamarina. 2005. "Bender Elements: Performance and Signal Interpretation." Journal of Geotechnical and Geoenvironmental Engineering, ASCE 313(9):1063-1070.

Meyer PA, JA Bamberger, CW Enderlin, JA Fort, BE Wells, SK Sundaram, PA Scott, MJ Minette, GL Smith, CA Burns, MS Greenwood, GP Morgen, EBK Baer, SF Snyder, M White, GF Piepel, BG Amidan, A Heredia-Langner. 2009. Pulse Jet Mixing tests with Noncohesive Solids. PNNL-18098, WTP-RPT182, Rev. 0. Pacific Northwest National Laboratory, Richland, Washington.

Michalowski RL. 2005. "Coefficient of Lateral Earth Pressure at Rest." Journal of Geotechnical and Geoenvironmental Engineering, ASCE 131(11):1429-1433.

Moore PJ and BR Cole. 1977. "Discussion of at-rest lateral earth pressure of a consolidating clay." Journal of Geotechnical Engineering Division, ASCE 103(7):820-821.

Oh SH, DS Park, BJ Kim, EJ Kim, and YJ Mok. 2008. Laboratory Measurements of Stiffness of Soft Clay Using Bender Elements. In: The $14^{\text {th }}$ World Conference on Earthquake Engineering, October 12-17, 2008, Bejing, China.

Parry RHG and CP Wroth. 1976. Pore Pressures in Soft Ground. Rept. No. S-76-3, U.S. Army Engineer Waterways Experiment Station.

Poulos HG. 1978. "Normalised deformation parameters for Kaolin.” ASTM Geotechnical Testing Journal 1(2):102-106.

Powell MR, CM Gates, CR Hymas, MA Sprecher, and NJ Morter. 1995. Fiscal Year 1994 1/25th-Scale Sludge Mobilization Testing. PNL-10582, Pacific Northwest National Laboratory, Richland, Washington.

Poloski AP, HE Adkins, ML Bonebrake, J Chun, AM Casella, KM Denslow, MD Johnson, ML Luna, PJ MacFarlan, JM Tingey, and JJ Toth. 2009. Deposition Velocities of Non-Newtonian Slurries in Pipelines: Complex Simulant Testing. PNNL-18316 (WTP-RPT-189, Rev. 0), Pacific Northwest National Laboratory, Richland, Washington.

Prashant A and D Penumadu. 2005. "A Laboratory Study of Normally Consolidated Kaolin Clay." Canadian Geotechnical Journal 42:27-37.

Singh H. 1971. "The Behaviour of Normally Consolidated and Heavily Overconsolidated Clays at Low Effective Stresses." Thesis presented to Cornell University, at Ithaca, N.Y., in partial fulfillment of the requirements for the degree of Doctor of Philosophy.

Sketchley CJ and PL Bransby. 1973. "The behaviour of an overconsolidated clay in plane strain." In: Proc. 8th International Conference on Soil Mechanics and Foundation Engineering, Moscow, 1, $377-384$. 
Stewart CW, PA Meyer, ME Brewster, KP Recknagle, PA Gauglitz, HC Reid, and LA Mahoney. 1996. Gas Retention and Release Behavior in Hanford Single-Shell Waste Tanks. PNNL-11391, Pacific Northwest National Laboratory, Richland, Washington.

van Kessel T and WGM van Kesteren. 2002. "Gas Production and Transport in Artificial Sludge Depots.” Waste Management 22:19-28.

Vardhanabhuti B. 2007. "Determination of Coefficient of Earth Pressure at Rest of Natural Soft Clay Deposit Using COWK Triaxial Apparatus." Available at:

http://www.cv.titech.ac.jp/ jsps/activity report/2007/Barames..pdf. Accessed 09-26-2010.

Weber RA. 2008. Methodology and Calculations for the Assignment of Waste Groups for the Large Underground Waste Storage Tanks at the Hanford Site. RPP-10006, Rev. 8, CH2M HILL Hanford Group, Inc., Richland, Washington.

Wells BE, RL Russell, LA Mahoney, GN Brown, DE Rinehart, WC Buchmiller, EC Golovich, and JV Crum. 2010. Hanford Sludge Simulant Selection for Soil Mechanics Property Measurement.

PNNL-19250, Pacific Northwest National Laboratory, Richland, Washington. 
Appendix A

\section{$\mathrm{k}_{0}$ Consolidometer}





\section{Appendix A: $k_{0}$ Consolidometer}

The $\mathrm{k}_{0}$ consolidometer design drawings are provided in this appendix. Changes made during production of the devices include:

- The upper outer platen diameter was reduced by 0.05 inch to facilitate motion through sample chamber.

- Three vertical 0.25 -in. holes at $120^{\circ}$ orientation through top platen were added to provide additional pathways for liquid drainage.

- The bender element lead hole in the upper platen was changed to a 0.25 -in. slot.

- The top stone outer diameter was reduced by 0.01 inch to facilitate motion through sample chamber.

- The central hole in the main body was enlarged by 0.045 inch.

- The sleeve was machined to $0.050 \mathrm{inch}$, and then back cut from outer diameter to 0.005 inch for the 1.5-in. chamber.

- The sleeve ( 0.25 inch at 0.050 inch thick, top and bottom) is bonded to the consolidometer body using silver conductive epoxy.

- The bender element cups were made out of nylon.

- One of the stainless steel bender element cups was inserted into the top of the upper platen to serve as the contact point to the applied load. 


\section{KO CONSOLIDOMETER FOR MEASURING LATERAL EARTH PRESSURE AT REST AND SHEAR WAVE VELOCITY FOR THE DETERMINATION OF MAXIMUM SHEAR MODULUS}

SHEET 1 - TITLE PAGE

\section{DRAWING LIST}

SHEET 2 - MAIN BODY DETAIL

SHEET 3 - INNER WALL AND ACCESS DOOR SHEET 4- ASSEMBLY OF MAIN BODY

SHEET 5- POROUS STONES/BENDER ELEM. SHEET 6- PLATENS

SHEET 7- BENDER ELEMENT DETAIL

SHEET 8- ASSEMBLED CONSOLIDOMETER

STANDARD DRAWING NOTES:

UNITS ARE IN INCHES UNLESS OTHERWISE NOTED

TOLERANCES ARE $+/-.01$ UNLESS OTHERWISE NOTED

\begin{tabular}{|c|c|c|c|c|}
\hline 1 & \multicolumn{2}{|c|}{ MAIN BODY } & 1 & $316 \mathrm{SS}$ \\
\hline 2 & \multicolumn{2}{|c|}{ INNER WALL } & 1 & 316 SS \\
\hline 3 & \multicolumn{2}{|c|}{ ACCESS DOOR } & 3 & $316 \mathrm{SS}$ \\
\hline 4 & \multicolumn{2}{|c|}{ BENDER ELEMENT } & 2 & N/A \\
\hline 5 & \multicolumn{2}{|c|}{ BENDER ELEMENT CUP } & 2 & $316 \mathrm{SS}$ \\
\hline 6 & \multicolumn{2}{|c|}{ BASE POROUS STONE (S1628A) } & 2 & 8NTERED 88 \\
\hline 7 & \multicolumn{2}{|c|}{ TOP POROUS STONE (S1625A) } & 1 & 8NTERED 88 \\
\hline 8 & \multicolumn{2}{|c|}{ UPPER PLATEN } & 1 & ACRYLIC \\
\hline 9 & \multicolumn{2}{|c|}{ LOWER PLATEN } & 1 & ACRYLIC \\
\hline 10 & \multicolumn{2}{|c|}{ LOCATING PINS } & 3 & $316 \mathrm{SS}$ \\
\hline No & \multicolumn{2}{|c|}{ PART NaMe } & REOD & LATERILL \\
\hline HUS & \multicolumn{4}{|c|}{$\begin{array}{l}\text { UNIVERSITY OF WASHINGTON } \\
\text { GEOTECHNICAL ENGINEERING } \\
\text { CIVIL ENGINEERING DEPT. } \\
\text { SEATTLE, WASHINGTON }\end{array}$} \\
\hline \multicolumn{5}{|c|}{ KO CONSOLIDOMETER } \\
\hline \multicolumn{3}{|c|}{ DR BY: PETER KELLER } & & \multirow{2}{*}{$\begin{array}{c}\text { SHEET" } \\
1 / 8\end{array}$} \\
\hline & $5 / 11 / 2010$ & SCALE: $1 "=5 / 8 "$ & & \\
\hline
\end{tabular}



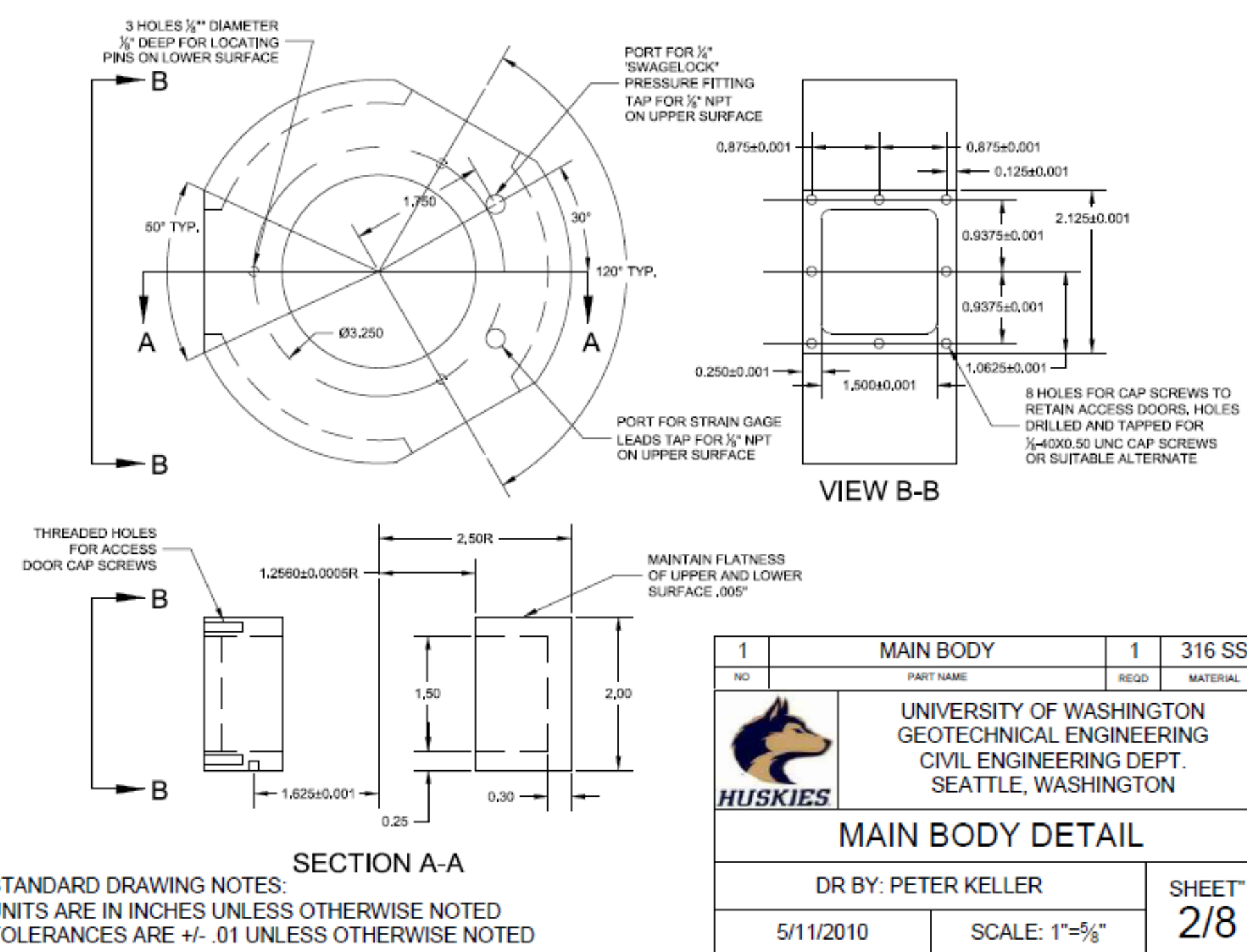

MANNTAN FLATNESS OF UPPER AND LOWER
SURFACE .005"

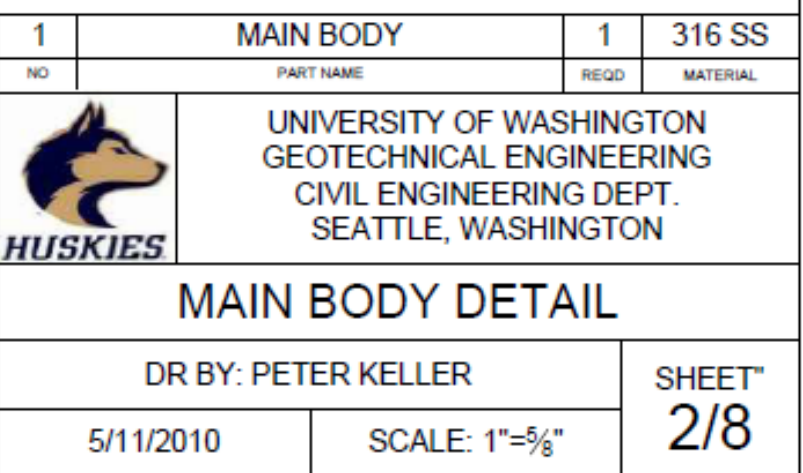




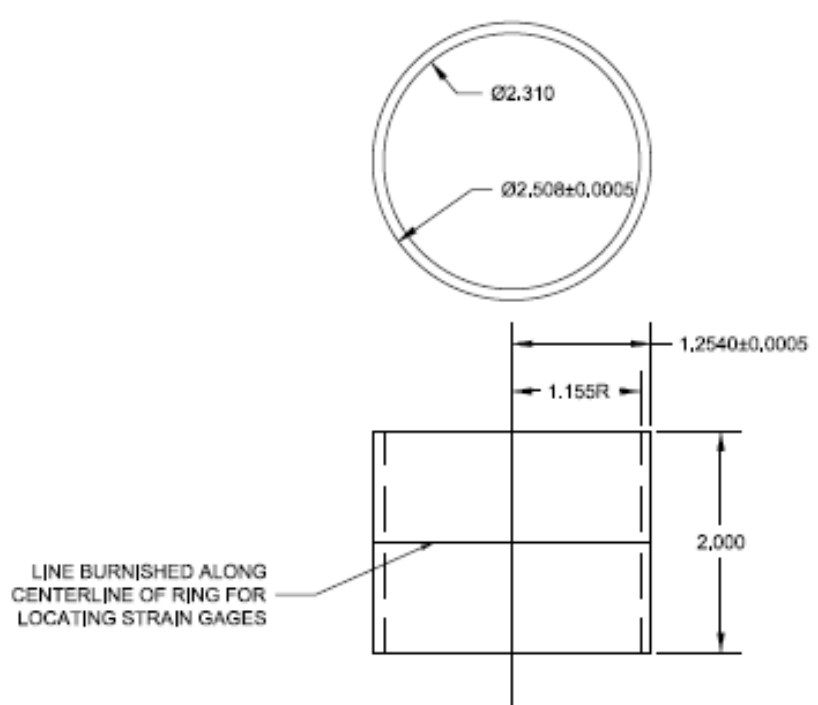

INNER WALL

\begin{tabular}{|c|c|c|c|}
\hline 2 & INNER WALL & 1 & $316 \mathrm{SS}$ \\
\hline 3 & ACCESS DOOR & 3 & $316 \mathrm{SS}$ \\
\hline No & \multirow{2}{*}{\multicolumn{3}{|c|}{$\begin{array}{l}\text { PART N MANE } \\
\text { UNIVERSITY OF WASHINGTON } \\
\text { GEOTECHNICAL ENGINEERING } \\
\text { CIVIL ENGINEERING DEPT. } \\
\text { SEATTLE, WASHINGTON }\end{array}$}} \\
\hline HUS & & & \\
\hline \multicolumn{4}{|c|}{ INNER WALL AND ACCESS DOOR } \\
\hline \multicolumn{3}{|c|}{ DR BY: PETER KELLER } & SHEET" \\
\hline & SCAL & & \\
\hline
\end{tabular}




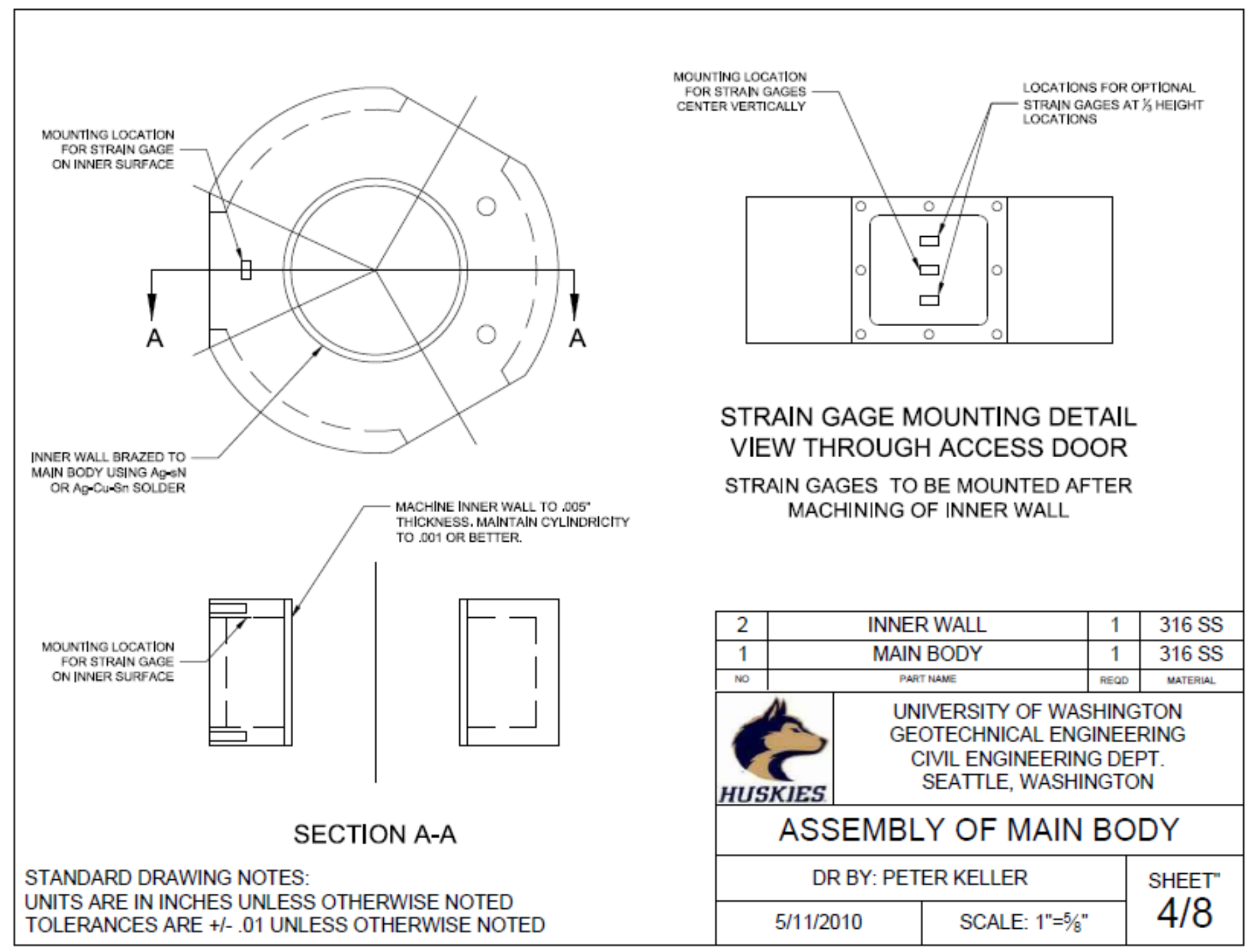




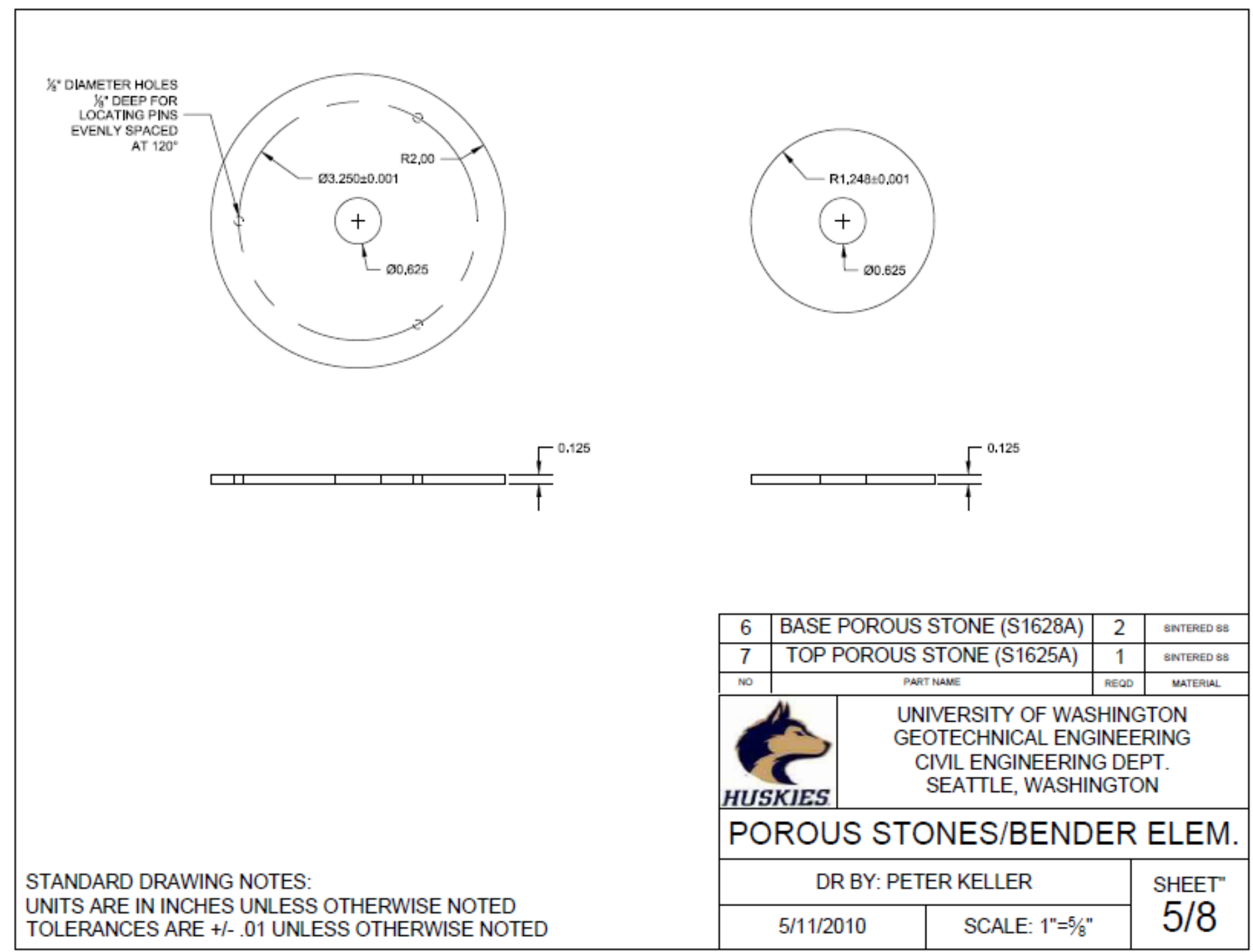




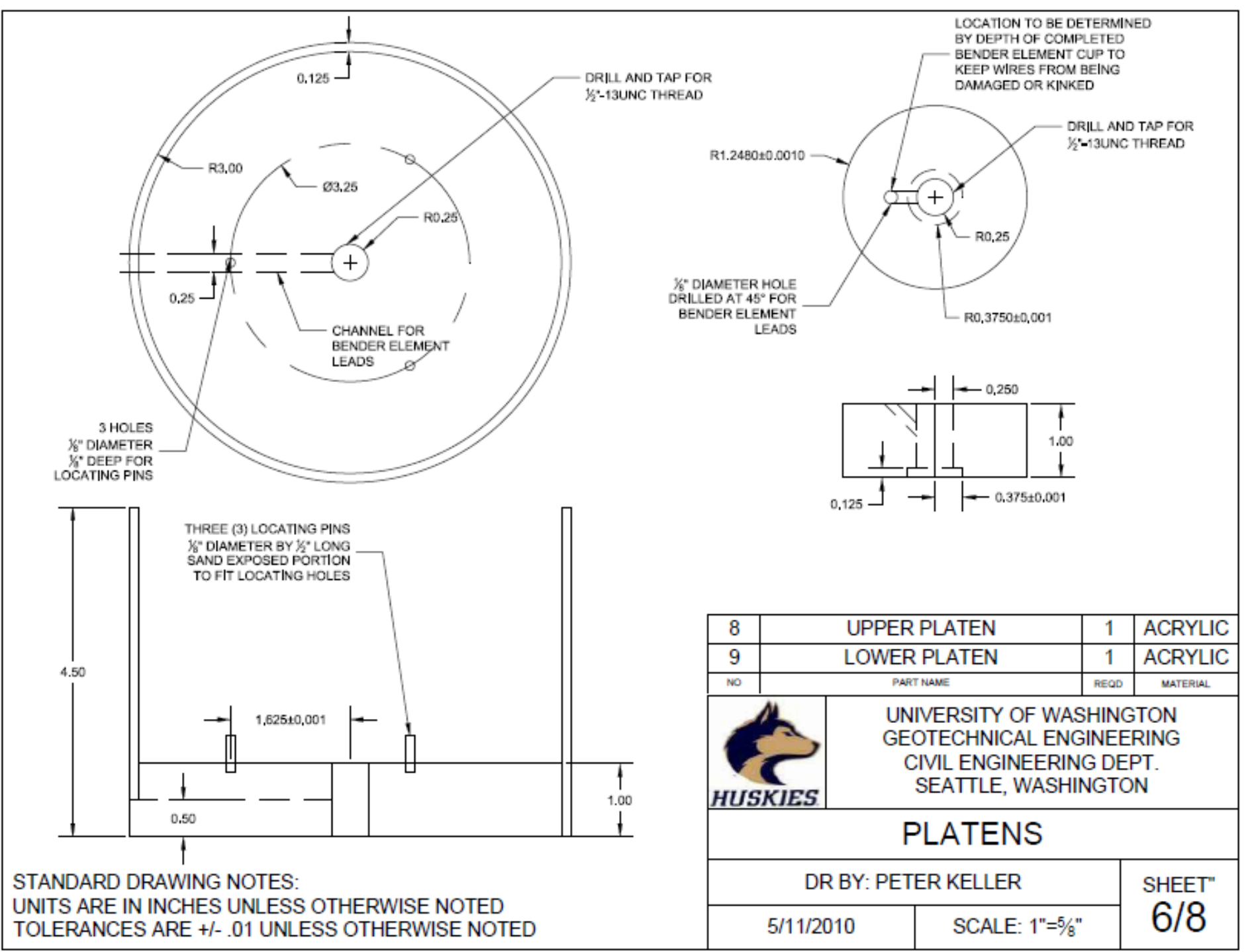




\section{BENDER ELEMENT CUP DETAIL}

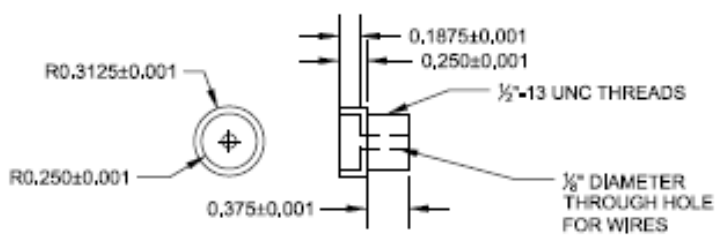

\section{BENDER ELEMENT MOUNTING DETAIL}

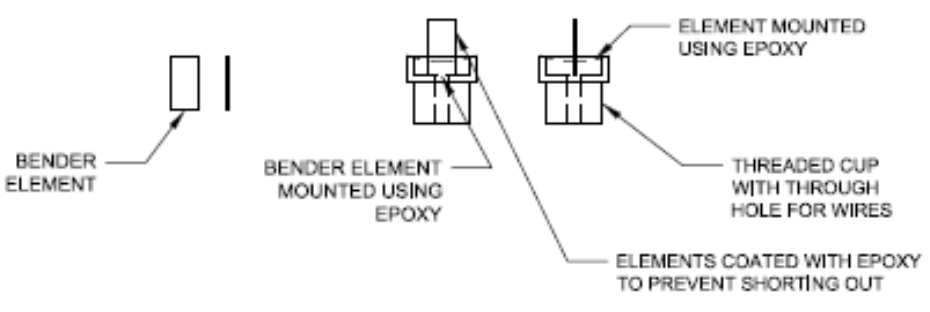

\begin{tabular}{|c|c|c|c|c|}
\hline 4 & \multicolumn{2}{|c|}{ BENDER ELEMENT } & & N/A \\
\hline 5 & \multicolumn{2}{|c|}{ BENDER ELEMENT CUP } & & $316 \mathrm{SS}$ \\
\hline No & \multicolumn{2}{|c|}{ PART NANE } & & $\begin{array}{l}\text { MATEPLLL } \\
\end{array}$ \\
\hline 10 & \multicolumn{4}{|c|}{$\begin{array}{l}\text { UNIVERSITY OF WASHINGTON } \\
\text { GEOTECHNICAL ENGINEERING } \\
\text { CIVIL ENGINEERING DEPT. } \\
\text { SEATTLE, WASHINGTON }\end{array}$} \\
\hline \multicolumn{5}{|c|}{ PLATENS } \\
\hline \multicolumn{4}{|c|}{ DR BY: PETER KELLER } & \multirow{2}{*}{$\begin{array}{c}\text { SHEET" } \\
7 / 8\end{array}$} \\
\hline & $1 / 2010$ & SCALE: $1 "$ & & \\
\hline
\end{tabular}

UNITS ARE IN INCHES UNLESS OTHERWISE NOTED

TOLERANCES ARE +/-.01 UNLESS OTHERWISE NOTED 


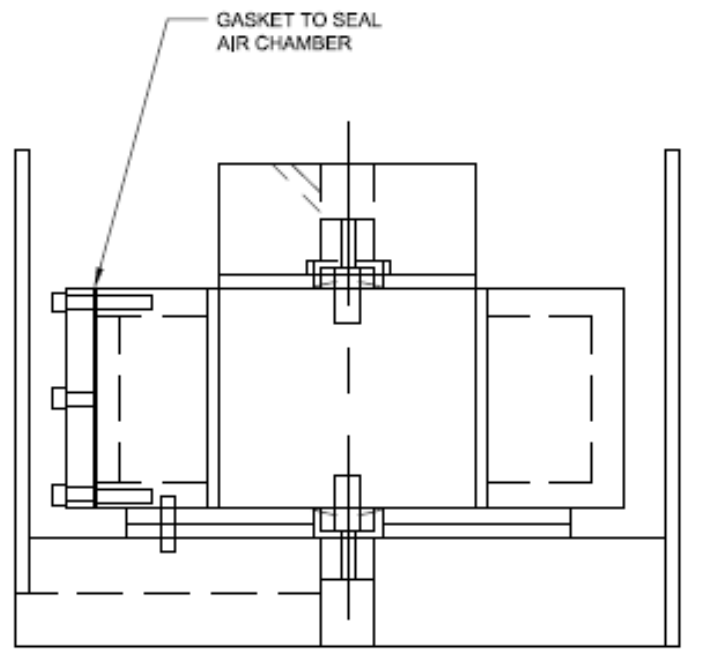

CROSS SECTIONAL VIEW OF ASSEMBLED CONSOLIDOMETER

STANDARD DRAWING NOTES:

UNITS ARE IN INCHES UNLESS OTHERWISE NOTED

TOLERANCES ARE $+/-.01$ UNLESS OTHERWISE NOTED

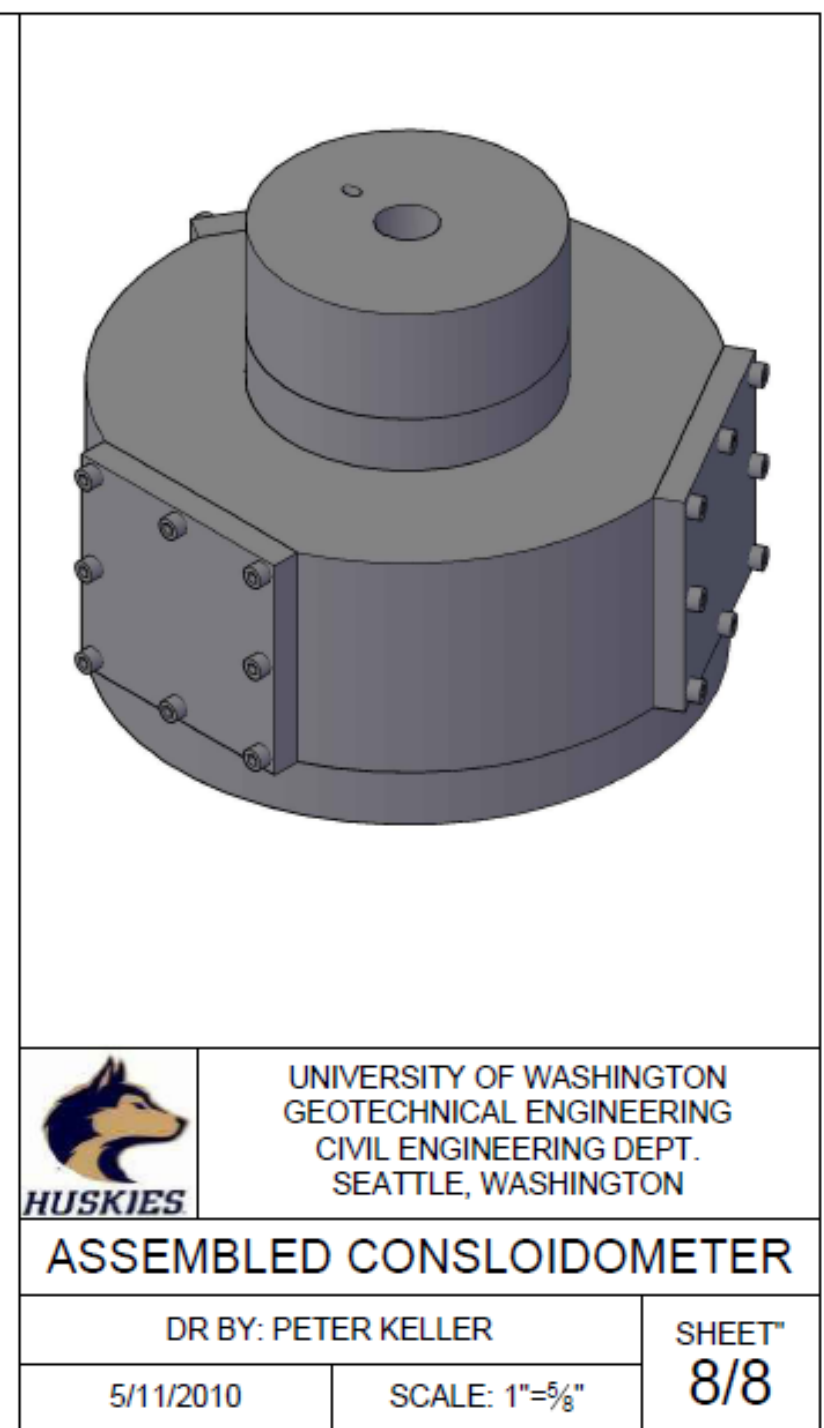



Appendix B

Test Procedure 



\section{Appendix B: Test Procedure}

Record appropriate information in laboratory record book. The test is denoted by YYMMDD-SSCC-LLLLL-rX where SS is the simulant (KA for kaolin, S1 for Simulant 1...), CC is the mass fraction of UDS in the simulant, LLLLL is the vertical load in $\mathrm{Pa}$, and $\mathrm{rX}$ is the test count for those conditions ( $\mathrm{r} 0$, $\mathrm{r} 1, \mathrm{r} 2 \ldots .$.$) .$

1. Strain gauge readout must be plugged in for at least 3 hours before starting the test.

2. Activate Wedgelink and Excel files to record displacement data.

a. Ensure that appropriate active cells are selected in the Excel file before recording the data. [DO NOT SELECT ANY CELL/PLOT/ETC. IN Excel DURING TEST.]

b. Turn on dial gauge.

3. Prepare consolidation frame.

a. Set cross-member height and level and tighten in place.

b. Balance and level the consolidation frame at 10:1 (middle hole) and set stop.

4. Select appropriate mass " $\mathrm{M}$ " to apply desired vertical pressure $(\mathrm{Pv}) . \quad \mathrm{Pv}=\left(10^{*} \mathrm{M} * 9.81\right) / 0.0032 \mathrm{~Pa}$ (consolidometer area $=0.0032 \mathrm{~m}^{2}$ ). If a clay mass is used, place in plastic bag to preclude evaporation. The mass of the bag and the clip must be included in the added mass.

5. Place mass on consolidation frame location and clip on.

6. Sample Preparation

a. Porous plates have been in liquid storage for a minimum of 24 hours.

b. Sample prepared to desired concentration. Mix by hand just before test.

c. Select two filter papers and cut as needed, adding $1 / 2$-in. slits for bender elements. The bottom filter paper slit must be aligned with a pin hole on top of the bender element wire access port in the lower platen.

d. Tape "Sample Prep. Plastic" on top of consolidometer (over inner sleeve)

e. Place $100 \times 50$ PYREX dish face down inside box-top on bench edge.

f. Place conolidometer upside down on top of Pyrex dish. (Exercise care that strain gauge cable is hanging off table through box-top hole — do not pinch!)

g. Place top (small) porous stone in sleeve.

h. Place top filter paper on porous stone in sleeve, aligning bender element slit with access port 1.

i. Tape set holes to preclude filling with sample.

j. Fill ring with sample, taking care to minimize void. Sample must be even with top (i.e., bottom) of ring. [DO NOT TOUCH SLEAVE WALLS-VERY FRAGILE.] Wipe residual sample from periphery of sample ring.

k. Remove set hole tape.

1. Put pins in consolidometer body (set holes). Place large filter paper through set pins, aligning bender element slit with access port 1 .

m. Place both large porous stones atop filter paper and through set-pins. 
n. Place acrylic container over consolidometer, aligning bender element wire access with port 1. [BENDER ELEMENTS ARE VERY FRAGILE. USE CAUTION WHEN HANDLING AND IMPINGING INTO SAMPLE.]

o. Support bottom of PYREX dish flush on top of consolidometer and flip over entire assembly. [SAMPLE MUST NOT BE DISTURBED.]

p. Remove "Sample Prep Plastic."

7. Air supply preparation

a. Attach air supply to consolidometer, holding body firmly in container while tightening w/ 9/16-in. wrench. [DO NOT OVER-TIGHTEN; finger tight then 1 face (i.e., $1 / 6$ of a turn) tighter with wrench.]

8. Place upper platen carefully atop (small) porous plate with bender element in filter paper slit. Bender element wire access is aligned with port 1. [BENDER ELEMENTS ARE VERY FRAGILE. USE CAUTION WHEN HANDLING AND IMPINGING INTO SAMPLE.]

9. Place consolidometer on consolidation frame. Set pins on load frame are placed inside of consolidation body. Ensure that consolidometer is level on frame surface.

10. Ensure that all wiring will not interfere with the travel of the consolidation frame. Bender element wires are not connected to oscilloscope or amplifier; hang on South frame.

11. Use EXTREME care to align upper platen with inner sleeve of consolidometer.

12. Level cross-member front-to-back in consolidation frame using level.

13. Adjust load pin to be in contact with upper platen and tighten lock nut, keeping cross-member level (see step 12).

14. Re-check alignment of upper platen.

15. Fill lower platen with appropriate supernatant liquid. Fill level is approximate vertical middle of air supply port fitting.

16. Adjust dial gauge from 0.0 in. "free" to $\sim 0.9$ in. on top of load pin and tighten in place.

17. Zero dial gauge.

18. Ensure orange handle relief valve is closed on hand pump. [DO NOT OVERTIGHTEN, TWO FINGER TIGHT IS SUFFICIENT.]

19. Turn on and zero pressure gauge.

20. After strain gauges are steady following potential temperature change due to liquid addition, tare all strain gauges.

21. Activate Wedgelink software and immediately lower stop on the load frame arm.

22. Test.

a. Monitor sleeve strain gauges continuously throughout test and apply/reduce pressure with hand pump to keep sleeve in neutral position (keep average of sleeve strain gauges equal to zero). Approach zero deflection with air pressure slowly (i.e., do not overshoot).

Record pressure, strain gauge readings, temperatures, deflection, and test time in LRB before and after each pressure adjustment.

b. Follow displacement in Excel file and determine completion of primary consolidation following ASTM Standard D 2435 - 04. The test is continued until the displacement time reaches the time of the intersection of tangent to steepest slope of displacement-log time plot (see ASTM Standard D 2435 - 04, 12.3.1) and zero-slope line at d90 (ASTM Standard D $2435-04,12.3 .2$ ) plus 0.01 inch.

c. Record pressure, strain gauge readings, temperatures, deflection, and test time in LRB. 
23. Stop Wedgelink.

24. Immediately raise stop on the load frame arm to just support arm at final displacement) without disturbing sample.

25. Take Gmax measurements.

a. Connect bender element wires as labeled. Power on oscilloscope followed by powering on amplifier. Do not change any settings except as specified below (frequency $15 \mathrm{~Hz}$, peak-to-peak $40 \mathrm{~V}$, step function). Bender element in lower platen is transmitter connected to amplifier/CH1. Bender element in upper platen is receiver connected to $\mathrm{CH} 2$. All "Cal" dials must be completely to right.

b. Adjust sec/div until able to see complete input pulse and response (complete step function).

c. Reduce sec/div until resolution is sufficiently high enough to determine time differences tC and tP; see Figures B.1 and B.2.

d. Record time and oscilloscope settings in LRB.

e. Take image of oscilloscope screen.

f. Power off amplifier followed by oscilloscope.

g. Disconnect bender element wires.

26. Save Excel file as YYMMDD-SS-CC-LLLLL-rX.xls.

27. Remove liquid from lower platen.

28. Depressurize system and disconnect air supply.

29. Remove sample from consolidometer with as little disturbance as possible and place in doublesealed containment.

30. Label sample using YYMMDD-SS-CC-LLLLL-rX and time sample was placed in container.

31. Remove mass from load frame and record weight in LRB using calibrated scale in APEL 102.

32. Turn off dial gauge.

33. Clean ring as appropriate. [USE CAUTION WHEN CLEANING BENDER ELEMENTS. Bender elements should be completely cleaned very gently (i.e., use wetted soft brush or similar.)]

34. Place porous plates in DI water storage.

35. Post-test sample analysis per RPL-COLLOID-02, record in LRB with YYMMDD-SS-CCLLLLL-rX sample name.

a. Shear strength.

b. Mass fraction of solids.

c. Bulk density. 


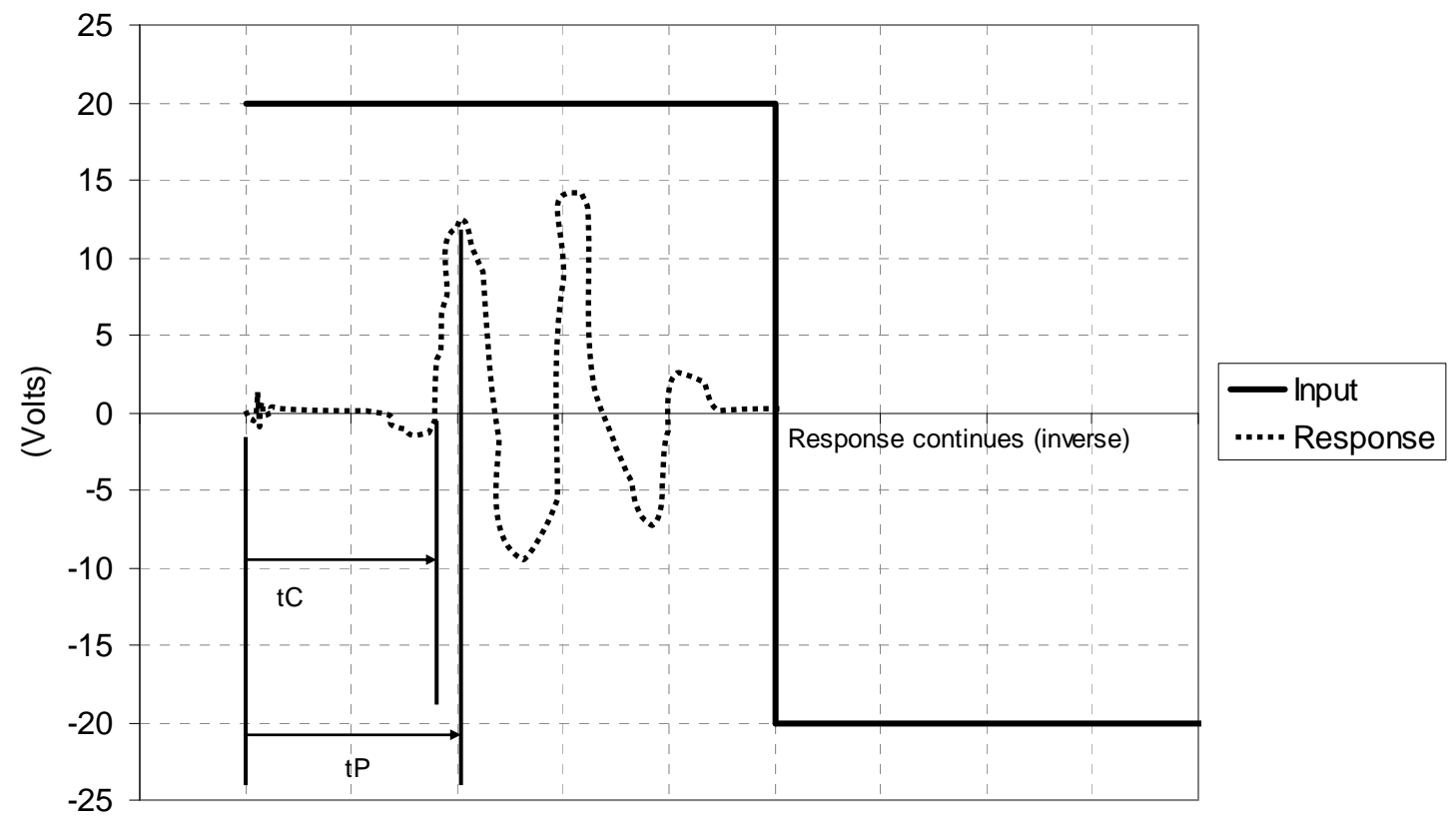

Figure B.1. Bender Element Response Example, Single or Equal Peaks

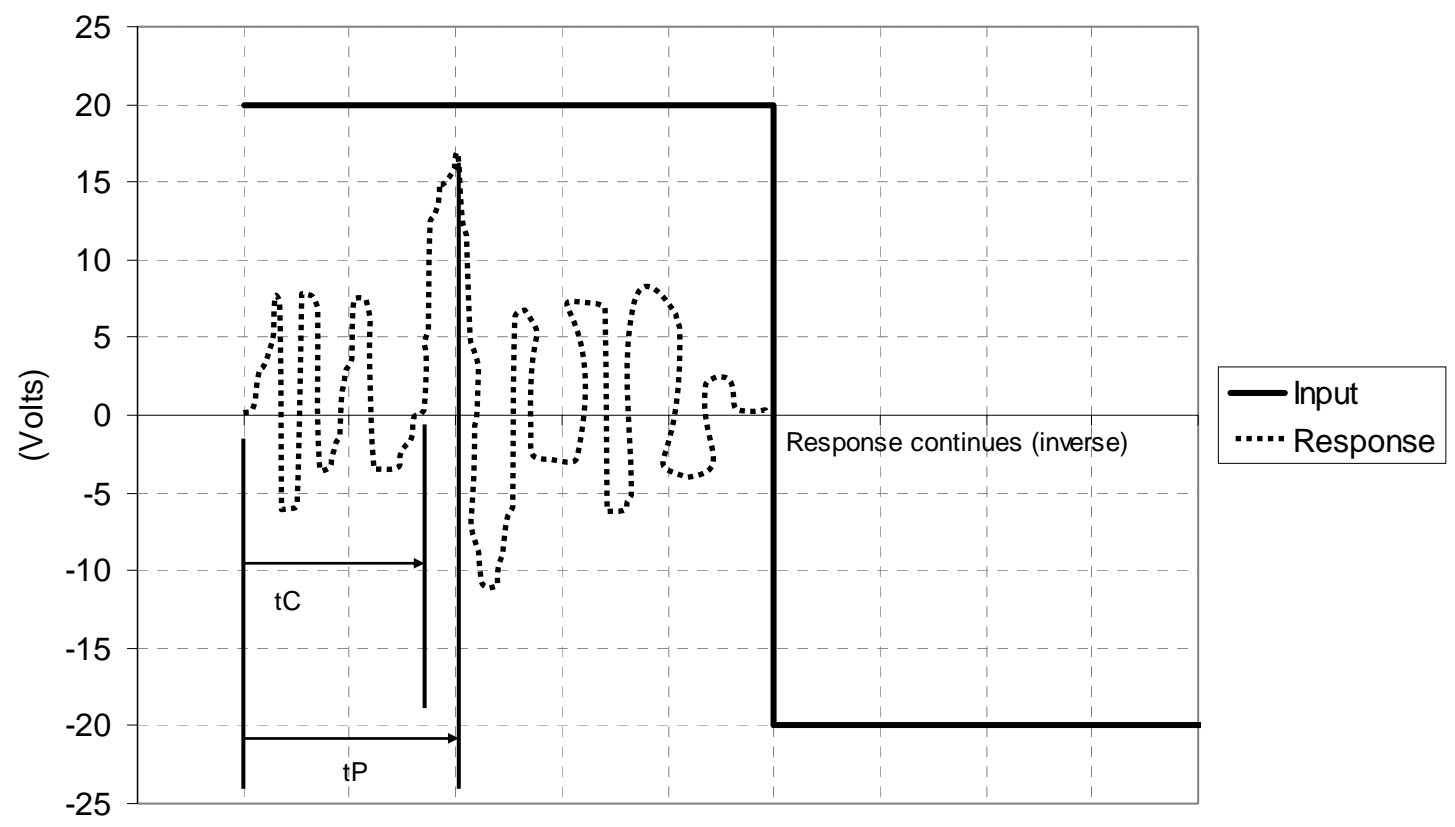

Figure B.2. Bender Element Response Example, Unequal Peaks 
Appendix C

\section{Kaolin Test Data}





\section{Appendix C: Kaolin Test Data}

PNNL and UW kaolin test details are provided in Sections C.1 and C.2, respectively.

\section{C.1 PNNL Kaolin Test Data}

Table C.1 provides PNNL kaolin test details. The displacement data and shear vane results are provided in the respective figures. 
Table C.1. PNNL Kaolin Test Data

\begin{tabular}{|c|c|c|c|c|c|c|c|c|c|c|c|}
\hline \multirow[b]{2}{*}{ Test ID } & \multicolumn{2}{|c|}{ Initial Sample } & \multicolumn{2}{|l|}{ Vertical Load } & \multicolumn{2}{|l|}{ Consolidation } & \multicolumn{5}{|l|}{ Final Sample } \\
\hline & $\begin{array}{l}\text { Solid Mass } \\
\text { Fraction }\end{array}$ & $\begin{array}{l}\text { Shear Strength } \\
(\mathrm{Pa})\end{array}$ & $\begin{array}{l}\text { Vertical Load } \\
\text { mass (g) }\end{array}$ & $\begin{array}{l}\text { Vertical Pressure, Pv } \\
\text { (psi) }\end{array}$ & End Time (min) & $\begin{array}{l}\text { End } \\
\text { Displacement } \\
\text { (in) }\end{array}$ & \begin{tabular}{|l} 
Solid Mass \\
Fraction
\end{tabular} & $\begin{array}{l}\text { Shear Strength } \\
(\mathrm{Pa})\end{array}$ & \begin{tabular}{|l} 
Mass for Density \\
(g)
\end{tabular} & $\begin{array}{l}\text { Volume for } \\
\text { Density }(\mathrm{mL})\end{array}$ & $\begin{array}{l}\text { Sample Density, } \\
\text { RhoB }(\mathrm{g} / \mathrm{mL})\end{array}$ \\
\hline \begin{tabular}{|l|} 
KA57PNNL1 \\
\end{tabular} & 0.57 & 960 & 314.6 & 1.415 & 520 & 0.1506 & 0.62 & 2882 & 60.6 & 37.00 & 1.638 \\
\hline \begin{tabular}{|l} 
KA57PNNL2 \\
\end{tabular} & 0.57 & 960 & 314.6 & 1.415 & 540 & 0.1462 & 0.61 & 2890 & 60 & 36.99 & 1.622 \\
\hline KA57PNNL3 & 0.57 & 960 & 314.6 & 1.415 & 505 & 0.1222 & 0.62 & 2976 & 59.24 & 36.01 & 1.645 \\
\hline
\end{tabular}

\begin{tabular}{|c|c|c|c|c|c|c|c|c|c|c|c|}
\hline Test ID & \begin{tabular}{|l} 
Horizontal \\
Pressure (psi)
\end{tabular} & k0 & $\begin{array}{l}\text { Time of Flight, ToF } \\
(\mathrm{msec})\end{array}$ & msec/div & $\mathrm{L}(\mathrm{mm})$ & $\begin{array}{l}\text { Shear } \\
\text { Wave } \\
\text { Velocity, } \\
\text { Vs (m/s) }\end{array}$ & Gmax $(\mathrm{kPa})$ & $\begin{array}{l}\text { Gmax } \\
\text { Alderman } \\
\text { et al. }(\mathrm{kPa})\end{array}$ & Plasticity Index & $\begin{array}{l}\text { Shear } \\
\text { Strength }(\mathrm{kPa})\end{array}$ & $\begin{array}{l}\text { Displ. } \\
\text { Fraction }\end{array}$ \\
\hline \begin{tabular}{|l|} 
KA57PNNL1 \\
\end{tabular} & 0.724 & 0.51 & 1.5 & 0.2 & 33.69 & 22.5 & 826 & 10 & 0.34 & 2.882 & 0.08 \\
\hline KA57PNNL2 & 0.994 & 0.70 & 1.34 & 0.2 & 33.80 & 25.2 & 1032 & 9 & 0.34 & 2.89 & 0.08 \\
\hline KA57PNNL3 & 0.761 & 0.54 & 1.26 & 0.2 & 34.41 & 27.3 & 1227 & 9 & 0.34 & 2.976 & 0.06 \\
\hline
\end{tabular}

$\Omega$

\begin{tabular}{|c|c|c|c|c|c|c|c|c|c|}
\hline \multirow[b]{2}{*}{ Test ID } & \multicolumn{5}{|c|}{ Uncertainty (u) in Gmax } & \multicolumn{2}{|c|}{ Uncertainty $(\mathrm{u})$ in $\mathrm{k} 0$} & \multirow[b]{2}{*}{ uK0, delta SG } & \multirow[b]{2}{*}{$\begin{array}{l}\text { Gmax } \\
\text { (Measured)/G } \\
\text { max } \\
\text { (Alderman) } \\
\end{array}$} \\
\hline & $\mathrm{uL}(\mathrm{m})$ & UToF (msec) & uVs (m/s) & u RhoB $(\mathrm{g} / \mathrm{mL})$ & uGmax (kPa) & uPv (psi) & uk0 & & \\
\hline KA57PNNL & $5.60817 \mathrm{E}-05$ & 0.02 & 0.30 & 0.06 & 22 & 0.000088 & 0.000354892 & 0.035 & 79 \\
\hline KA57PNNL & 5.60817E-05 & 0.02 & 0.38 & 0.05 & 31 & 0.000088 & 0.000356146 & 0.035 & 114 \\
\hline KA57PNNL & 5.60817E-05 & 0.02 & 0.44 & 0.06 & 39 & 0.000088 & 0.00035504 & 0.035 & 133 \\
\hline
\end{tabular}




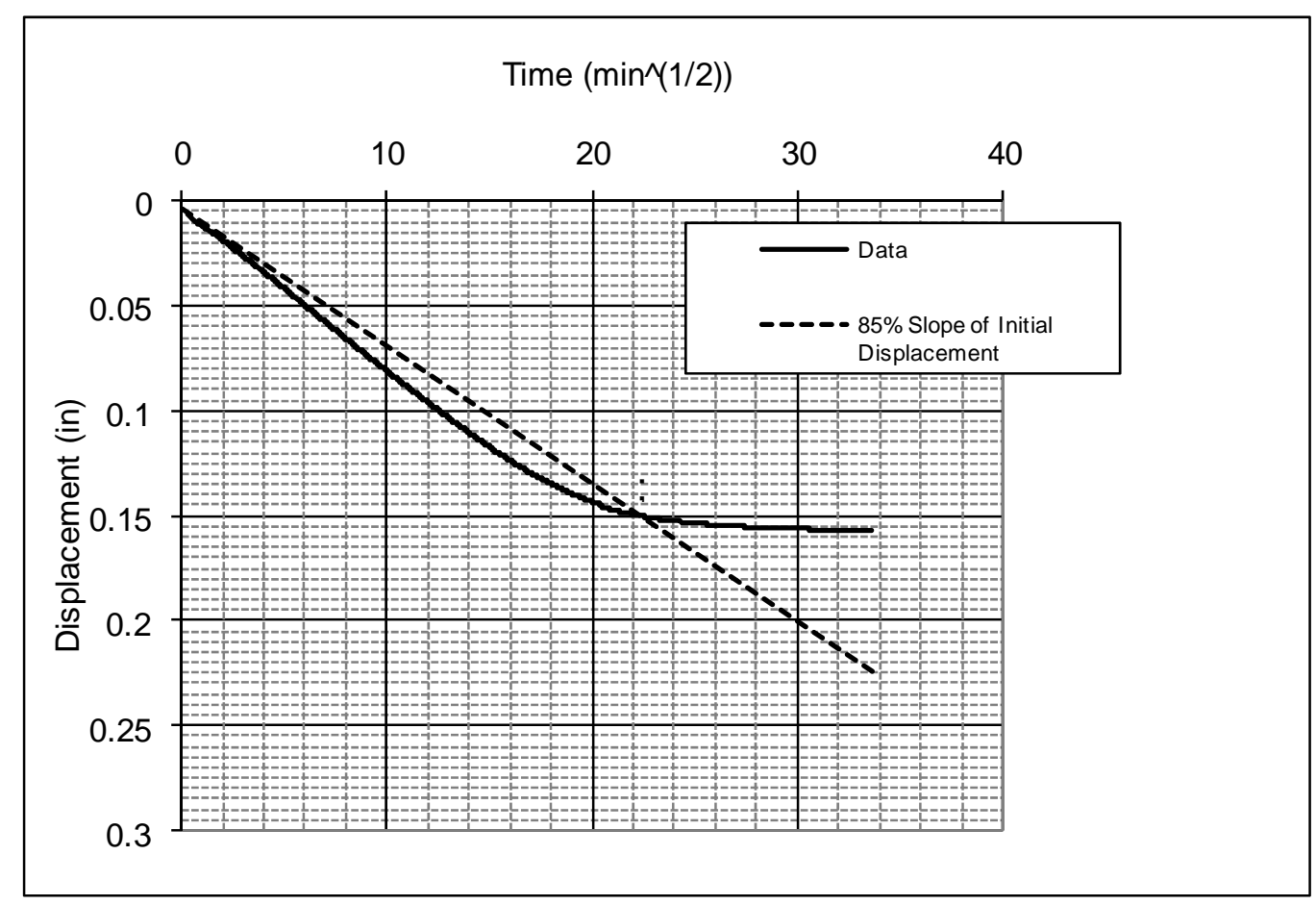

Figure C.1. Kaolin (57 wt\%) 100902 Displacement Versus Time ${ }^{1 / 2}$ (ASTM Standard D $2435-04,12.3 .2$ )

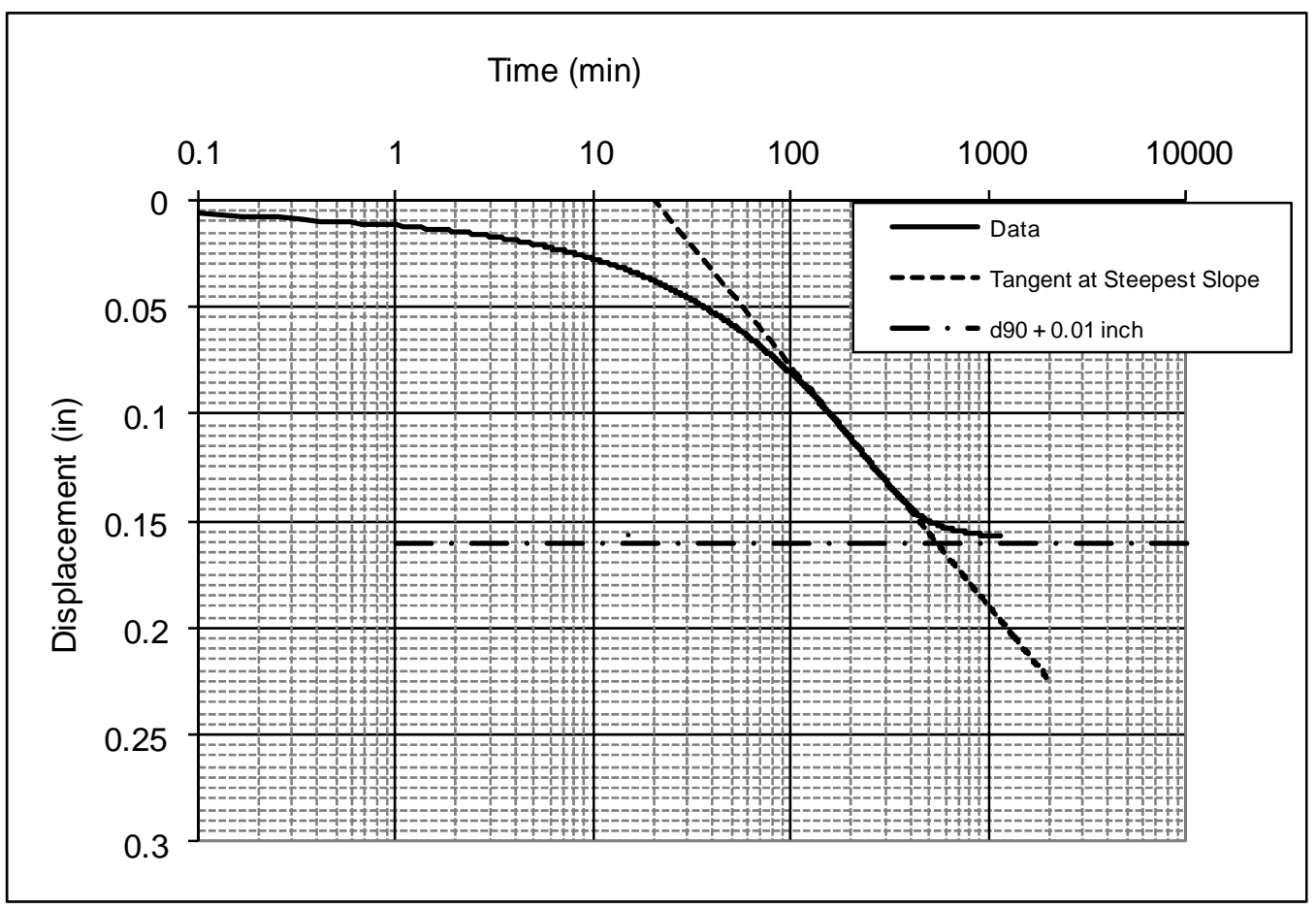

Figure C.2. Kaolin (57 wt\%) 100902 Displacement Versus Time Ti/2 $^{1 / 2}$ (ASTM Standard D 2435 - 04, 12.3.1) 


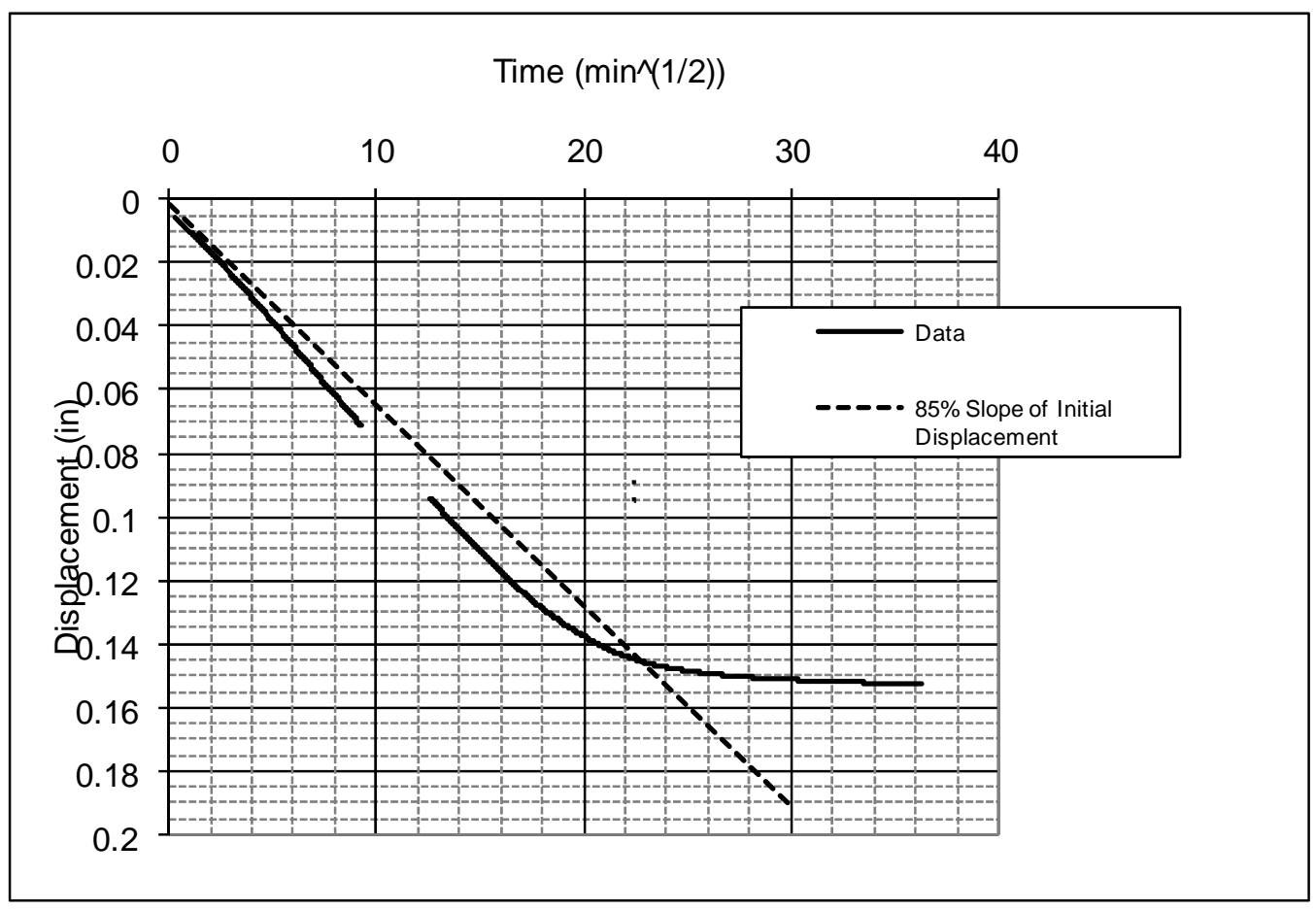

Figure C.3. Kaolin (57 wt\%) 100906 Displacement Versus Time ${ }^{1 / 2}$ (ASTM Standard D $2435-04,12.3 .2$ )

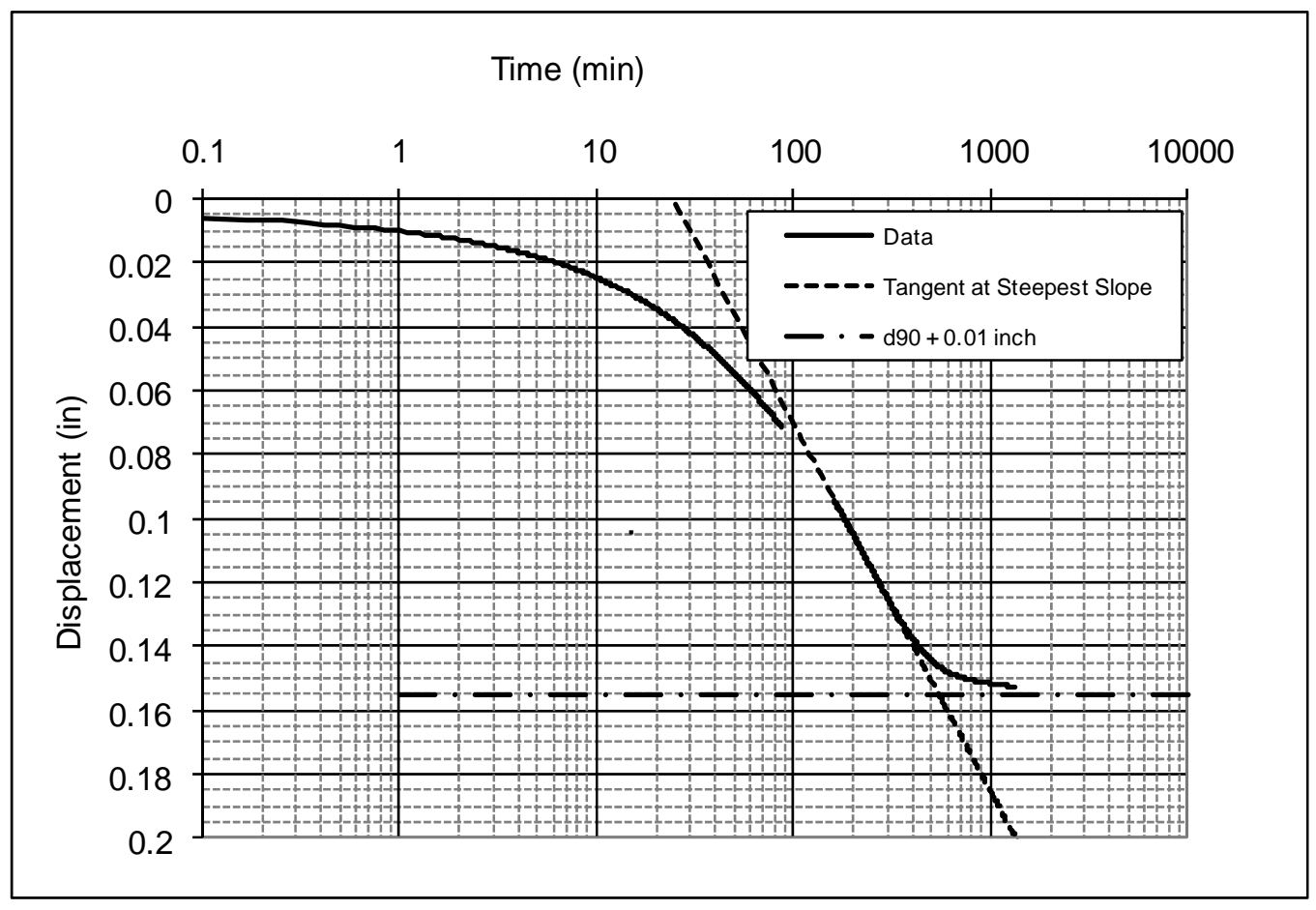

Figure C.4. Kaolin (57 wt\%) 100906 Displacement Versus Time ${ }^{1 / 2}$ (ASTM Standard D 2435 - 04, 12.3.1) 


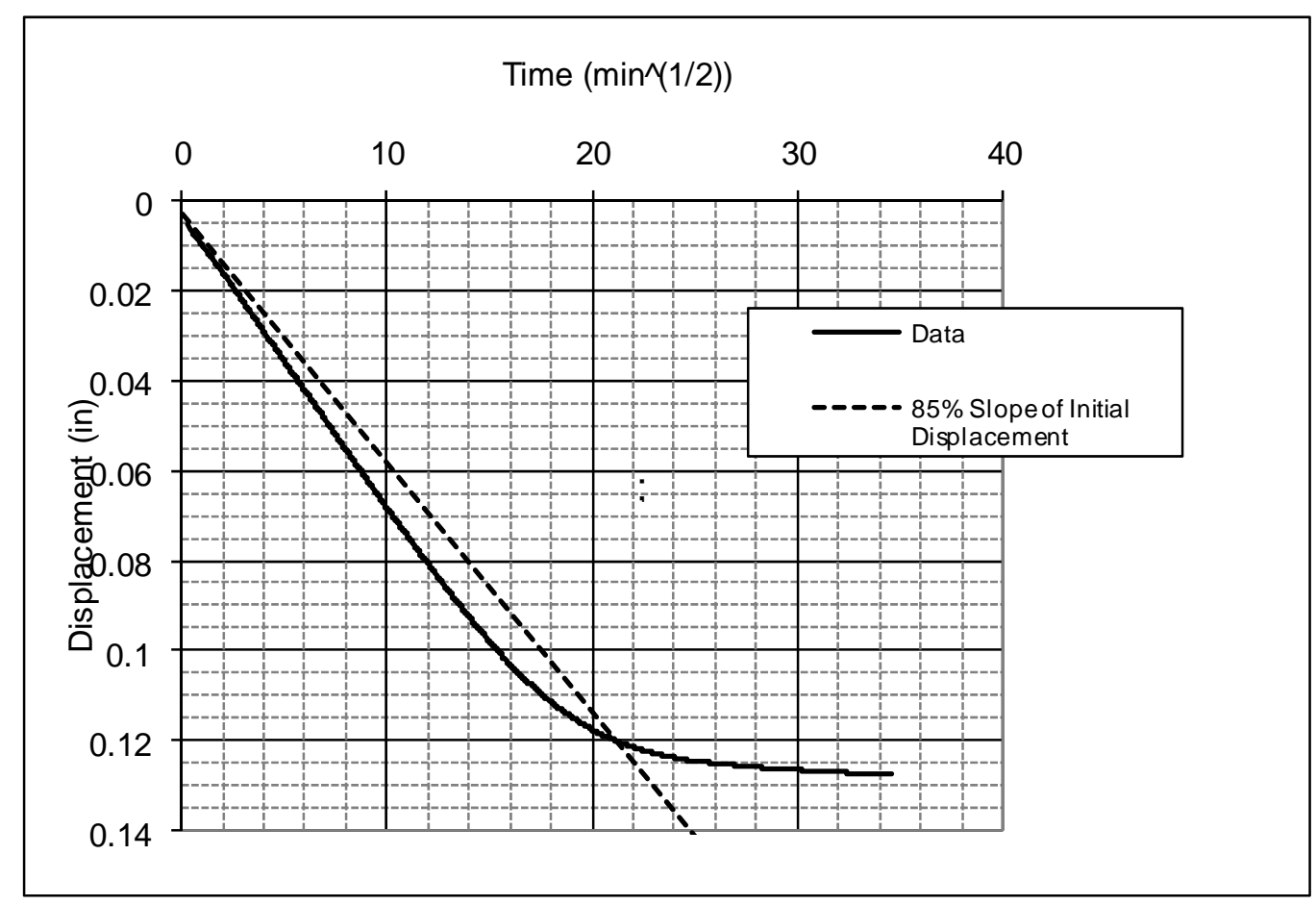

Figure C.5. Kaolin (57 wt\%) 100907 Displacement Versus Time ${ }^{1 / 2}$ (ASTM Standard D 2435 - 04, 12.3.2)

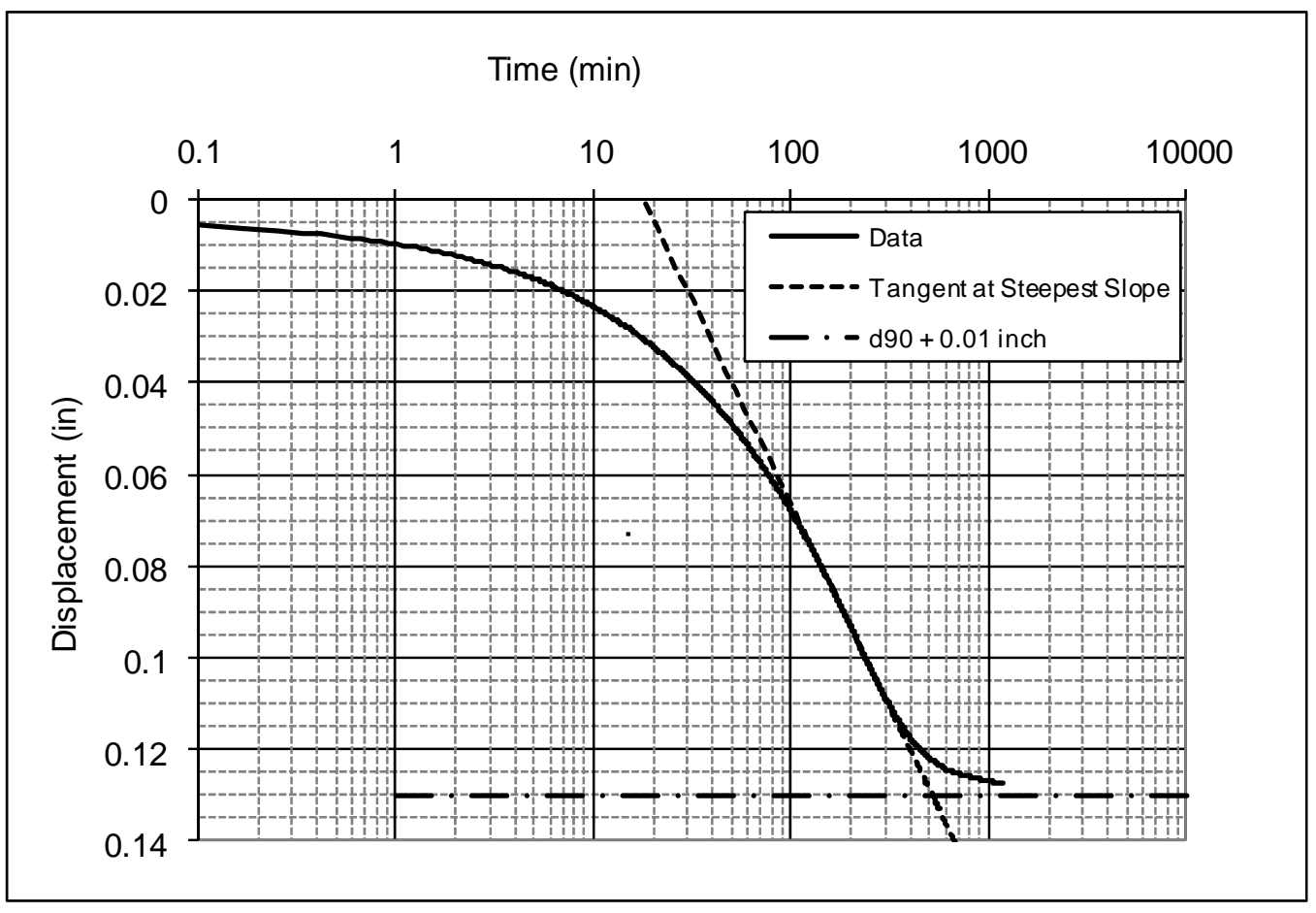

Figure C.6. Kaolin (57 wt\%) 100907 Displacement Versus Time Tit2 $^{1 / 2}$ (ASTM Standard D 2435 - 04, 12.3.1) 
ThermoHaake RheoWin 9/24/2010/9:50 AM

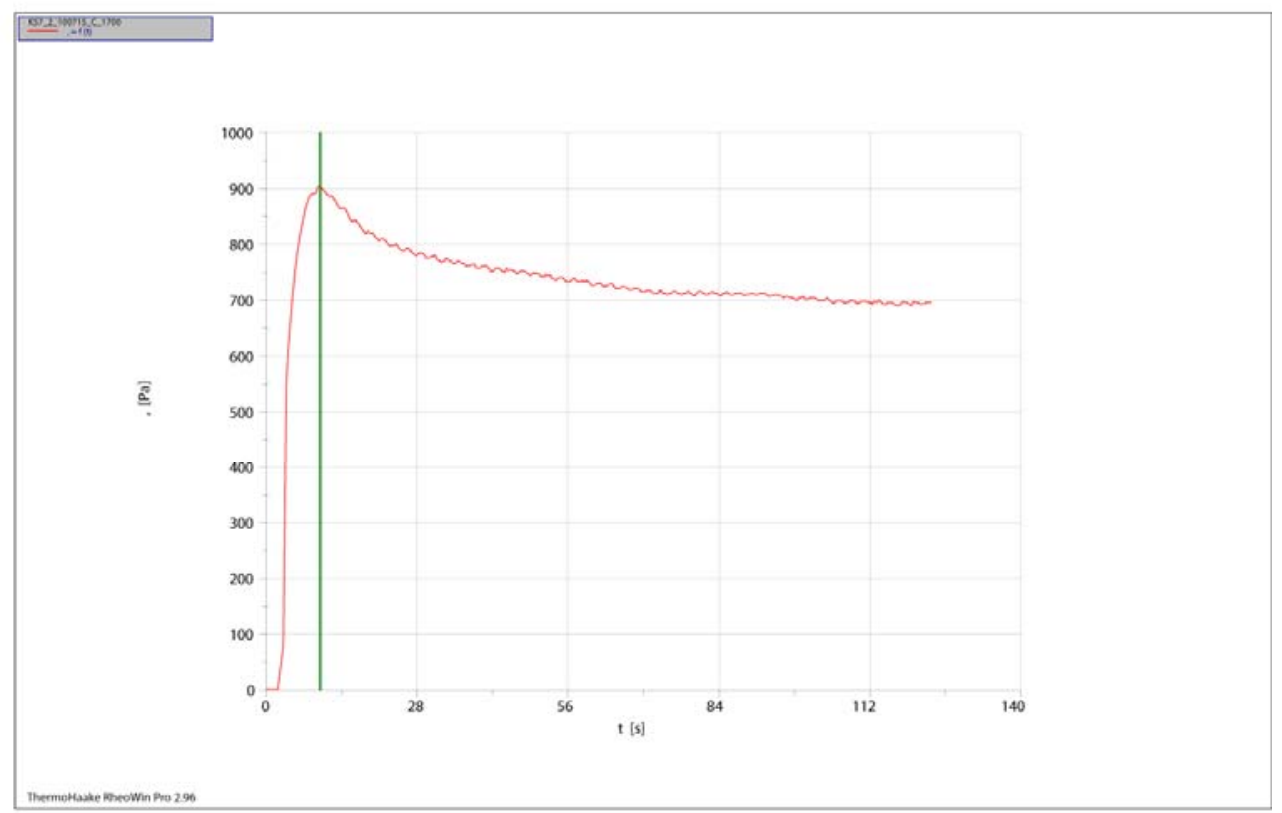

1: C:IRheoloqy Results\JWWRPS\Kaolin\Pre-Supernate in Ko tests\K57_2_100715_C_1700.rwd

Company / Operator: PNNL / Jeromy Jenks

Date / Time / Version: 15.07.2010/16.57.05 PM / RheoWin Pro 296

Substance / Sample no: K57_2 / K57___100715_C_1700

Curve discussion: Greatest value $\mathrm{t}[\mathrm{s}] 10.05$, [Pa] 903.0

Figure C.7. Initial Kaolin(57 wt\% ) shear strength (PA) as a function of time Measured at Center

ThermoHaake RheoWin 9/24/2010/9:51 AM

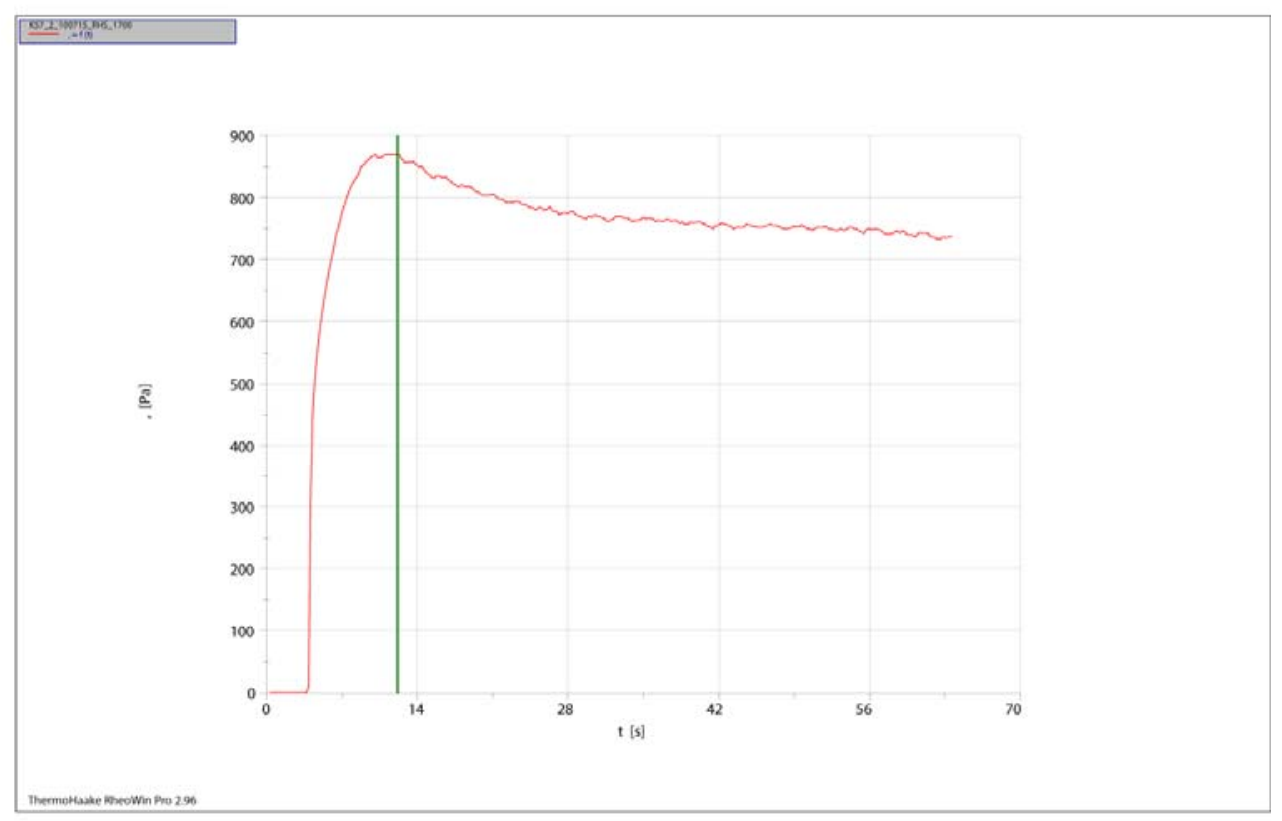

1: C:IRheoloqy Results\JWWRPSKaolin\Pre-Supernate in Ko tests\K57_2_100715_RHS_1700.rwd

Company / Operator: PNNL / Jeromy Jenks

Date / Time / Version: 15.07.2010 / 17:01:30 PM / RheoWin Pro 296

Substance / Sample no: K57_2 / K57_ 2_100715_RHS_1700

Curve discussion: Greatest value $\mathrm{t}[\mathrm{s}] 12.15$, [Pa] 870.8

Figure C.8. Initial Kaolin(57 wt\% ) Shear Strength (PA) as a Function of Time Measured at RHS 


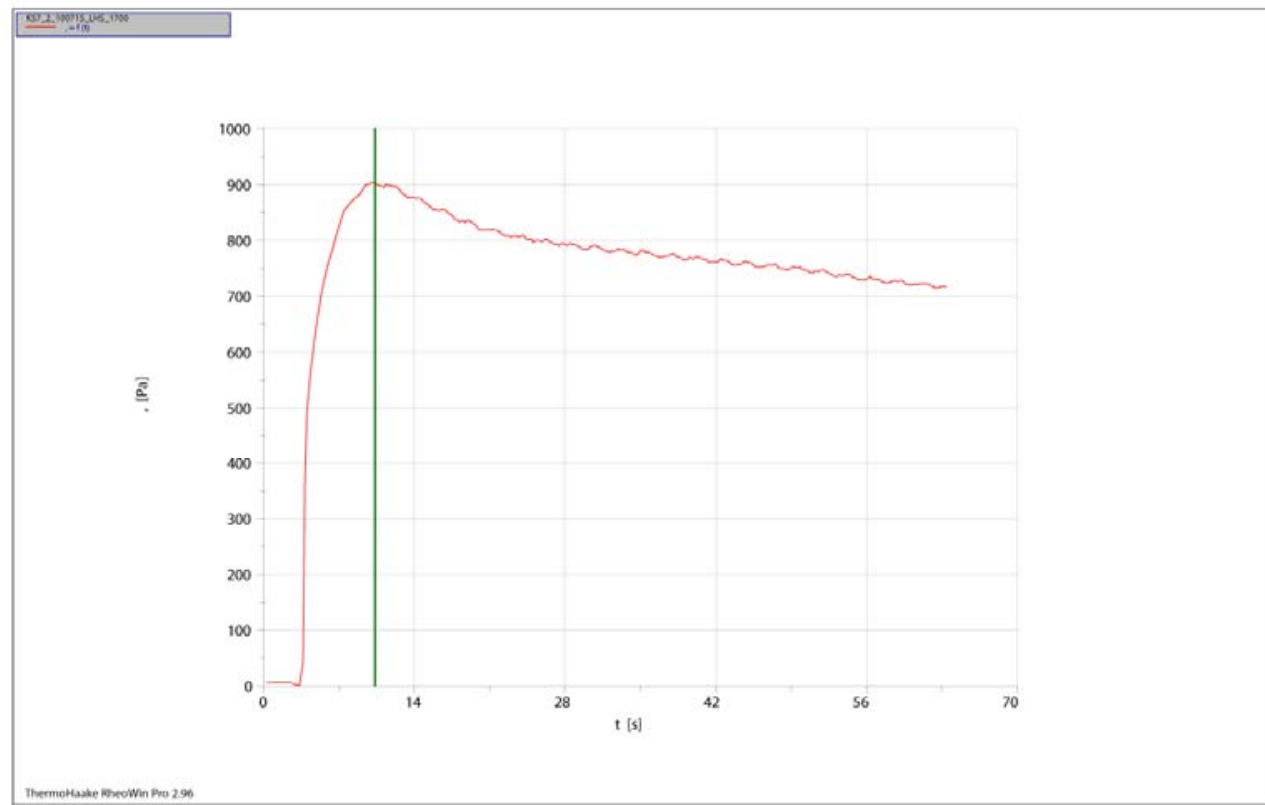

1: C:IRheoloqy Results\JWWRPS\Kaolin\Pre-Supernate in Ko tests\K57_2_100715_LHS_1700.rwd

Company / Operator: PNNL / Jeromy Jenks

Date / Time / Version: 15.07.2010 / 17.04:06 PM / RheoWin Pro 296

Substance / Sample no: K57_2/K57_2_100715_LHS_1700

Curve discussion: Greatest value $\mathrm{t}[\mathrm{s}] 10.36$, [Pa] 903.0

Figure C.9. Initial Kaolin(57 wt \%) Shear Strength (PA) as a Function of Time Measured at LHS

ThermoHaake RheoWin 9/24/2010/9:37 AM

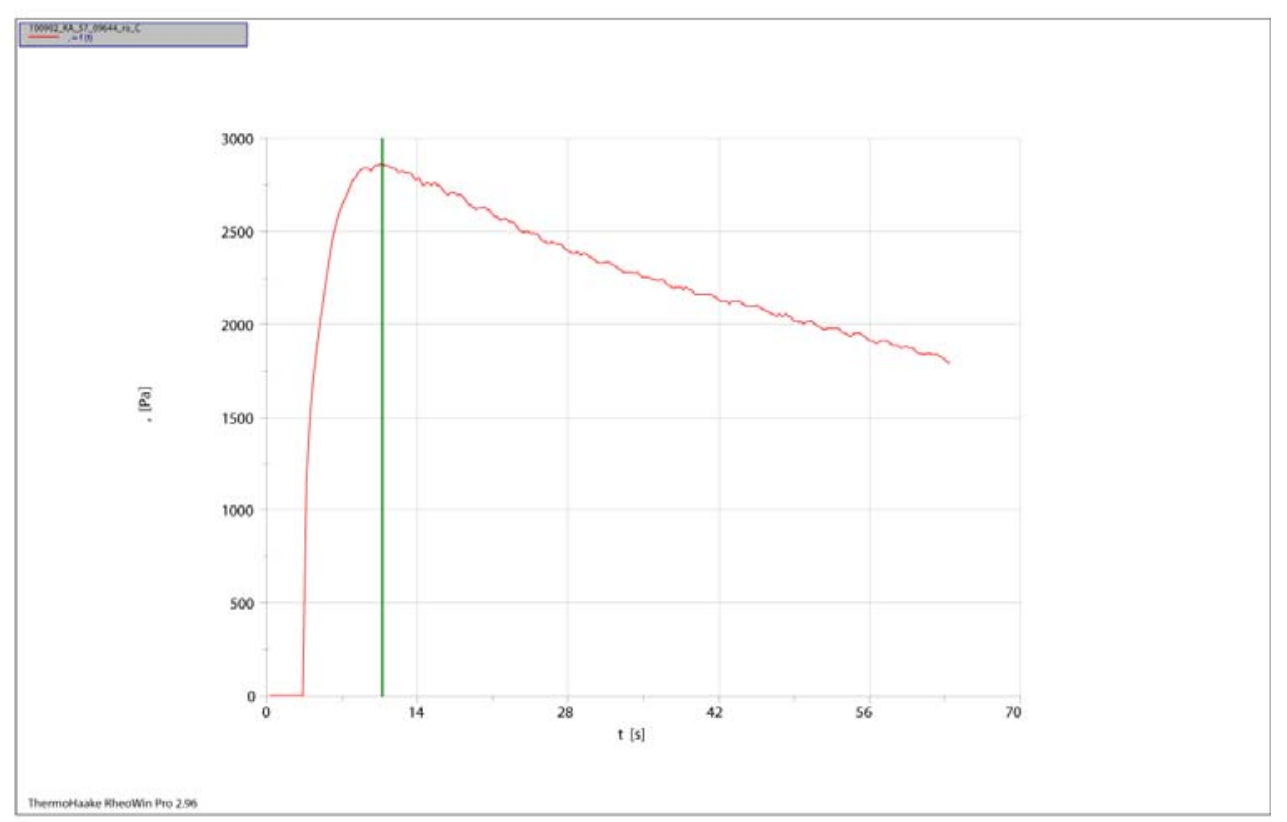

1: C:IRheoloqy Results \J\WRPS\Kaolin\Consolidated Samples\100902_KA_57_09644_ro_C.rwd

Company / Operator: PNNL / Jeromy Jenks

Date / Time / Version: 09.09.2010 / 14:17:08 PM / RheoWin Pro 296

Substance / Sample no: KA-57 / 100902 KA_57_09644_ro_C

Curve discussion: Greatest value $\mathrm{t}[\mathrm{s}] 10.75,[\mathrm{~Pa}] 2869$.

Figure C.10. Consolidated Kaolin(57 wt\% ) 100902 Shear Strength (PA) as a Function of Time Measured at Center 
ThermoHaake RheoWin 9/24/2010/9:39 AM

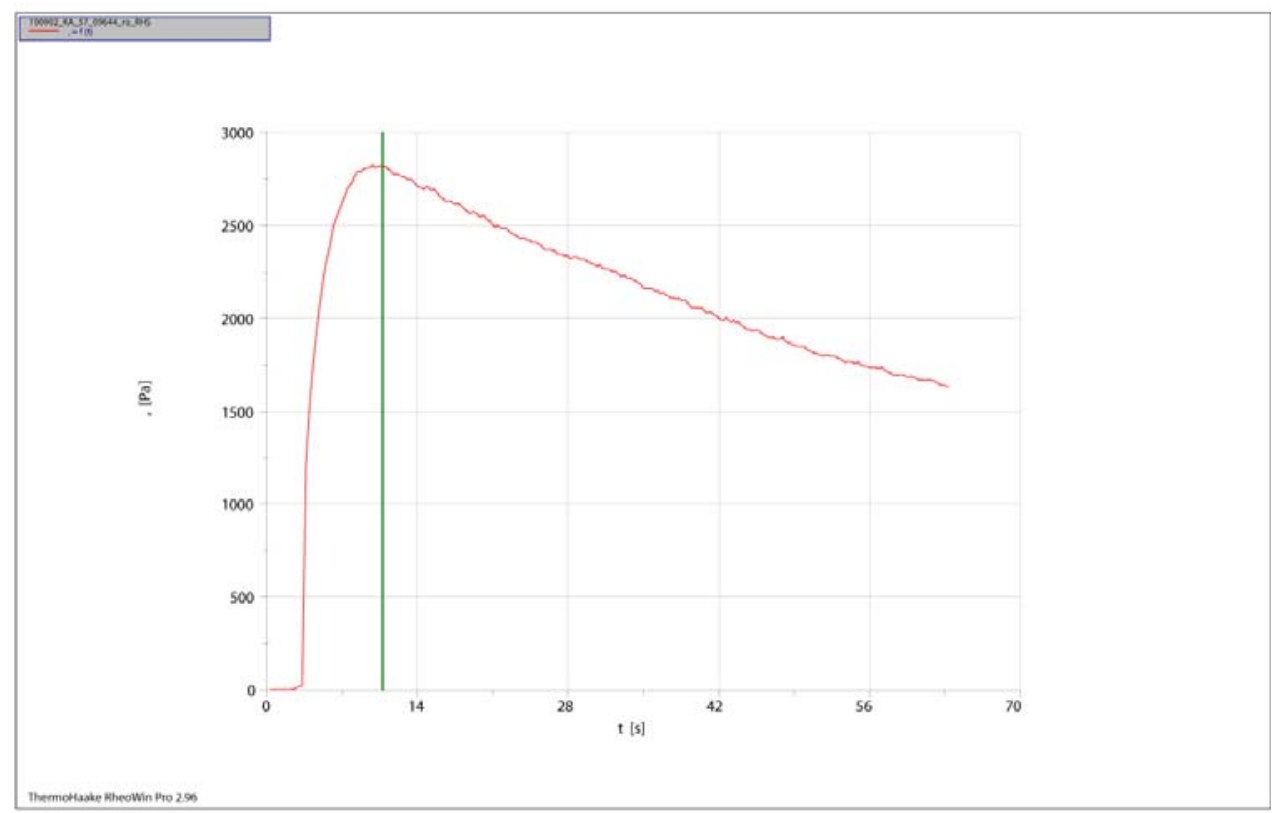

1: C:IRheoloqy Results UJ\WRPS\Kaolin \Consolidated Samples\100902_KA_57_09644_ro_RHS.rwd Company / Operator: PNNL / Jeromy Jenks

Date / Time / Version: 09.09.2010 / 14:11:00 PM / RheoWin Pro 296

Substance / Sample no: KA-57 / 100902_KA_57_09644_ro_RHS

Curve discussion: Greatest value $\mathrm{t}[\mathrm{s}] 10.78$, [Pa] 2826.

Figure C.11. Consolidated Kaolin(57 wt\%) 100902 Shear Strength (PA) as a Function of Time

Measured at RHS

ThermoHaake RheoWin 9/24/2010/9:47 AM

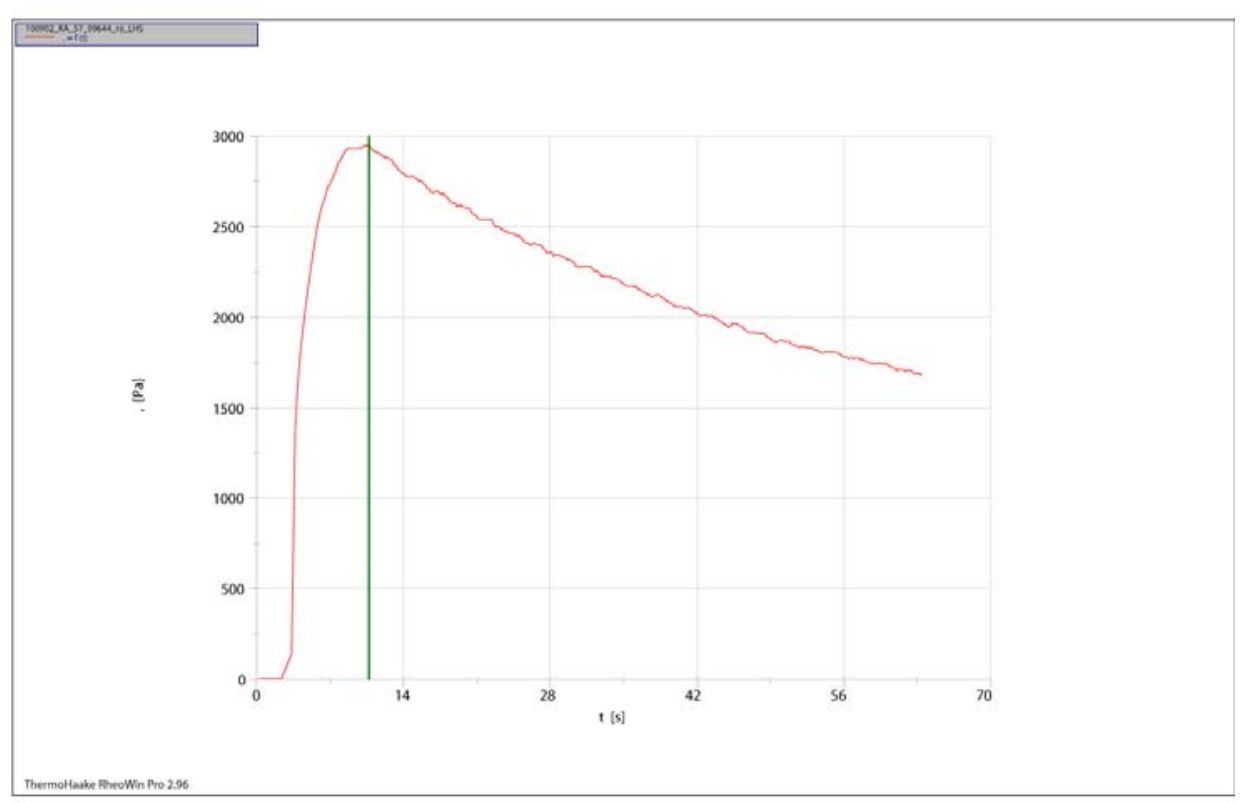

1: C:IRheology Results UJIWRPS\Kaolin\Consolidated Samples\100902_KA_57_09644_ro_LHS.rwd Company / Operator: PNNL / Jeromy Jenks

Date / Time / Version: 09.09.2010 / 14:14:11 PM / RheoWin Pro 296

Substance / Sample no: KA-57 / 100902 KA_57_09644_ro_LHS

Curve discussion: Greatest value $\mathrm{t}[\mathrm{s}] 10.71,[\mathrm{~Pa}] 2952$.

Figure C.12. Consolidated Kaolin(57 wt\% ) 100902 Shear Strength (PA) as a Function of Time Measured at LHS 
ThermoHaake RheoWin 9/24/2010/9:40 AM

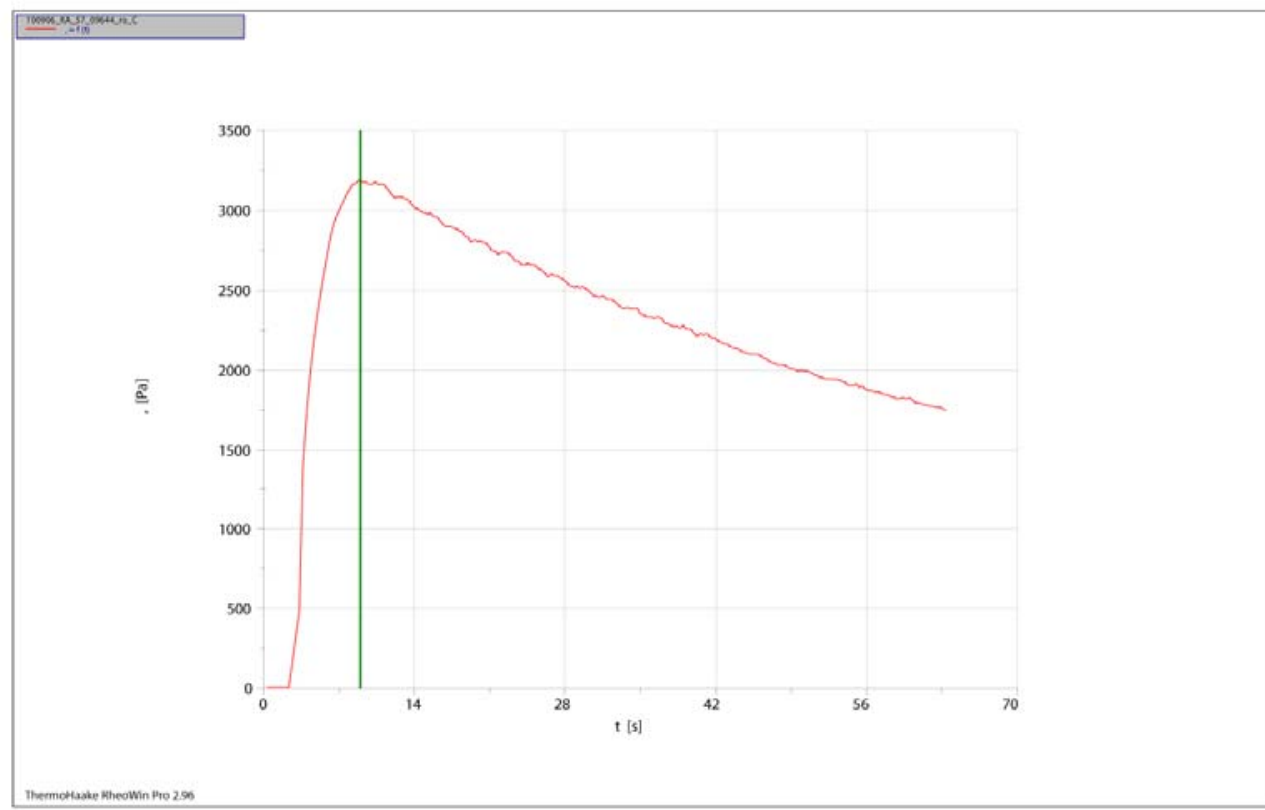

1: C:IRheoloqy Results\J\WRPS\Kaolin\Consolidated Samples\100906_KA_57_09644_ro_C.rwd

Company / Operator: PNNL / Jeromy Jenks

Date / Time / Version: 09.09.2010 / 14:21:24 PM / RheoWin Pro 296

Substance / Sample no: KA-57 / 100906_KA_57_09644_ro_C

Curve discussion: Greatest value $\mathrm{t}[\mathrm{s}] 8.990$, [Pa] 3191.

Figure C.13. Consolidated Kaolin(57 wt\% ) 100906 Shear Strength (PA) as a Function of Time Measured at Center

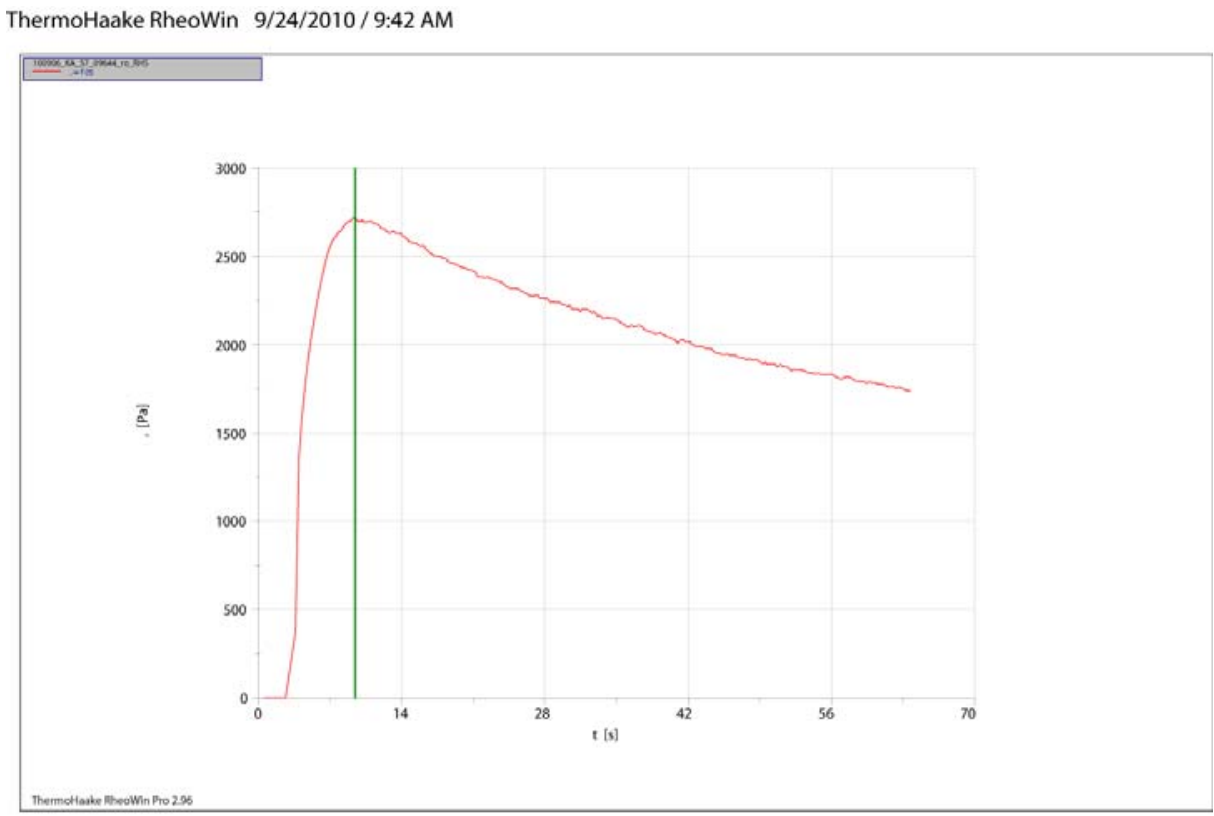

1: C:IRheology Results UJ\WRPS\Kaolin\Consolidated Samples\100906_KA_57_09644_ro_RHS.rwd Company / Operator: PNNL / Jeromy Jenks

Date / Time / Version: 09.09.2010 / 14:24:26 PM / RheoWin Pro 296

Substance / Sample no: KA-57/100906 KA 5709644 ro RHS

Curve discussion: Greatest value $\mathrm{t}[\mathrm{s}] 9.451$, [Pa] 2717.

Figure C.14. Consolidated Kaolin(57 wt\% ) 100906 Shear Strength (PA) as a Function of Time Measured at RHS 
ThermoHaake RheoWin 9/24/2010/9:41 AM

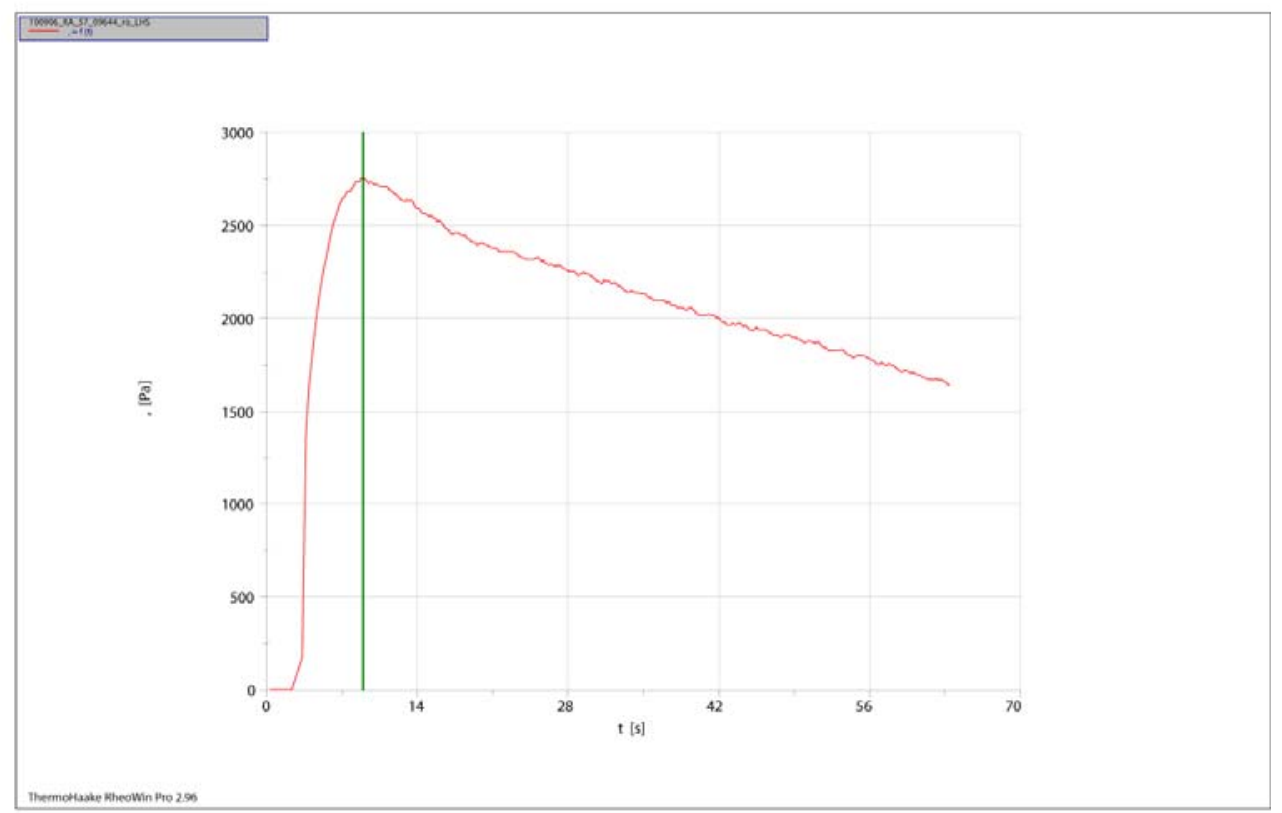

1: C:IRheoloqy Results UJ\WRPS\Kaolin \Consolidated Samples\100906_KA_57_09644_ro_LHS.rwd

Company / Operator: PNNL / Jeromy Jenks

Date / Time / Version: 09.09.2010 / 14:27:26 PM / RheoWin Pro 296

Substance / Sample no: KA-57 / 100906_KA_57_09644_ro_LHS

Curve discussion: Greatest value $\mathrm{t}[\mathrm{s}] 8.960,[\mathrm{~Pa}] 2761$.

Figure C.15. Consolidated Kaolin(57 wt\%) 100906 Shear Strength (PA) as a Function of Time

Measured at LHS

ThermoHaake RheoWin 9/24/2010/9:43 AM

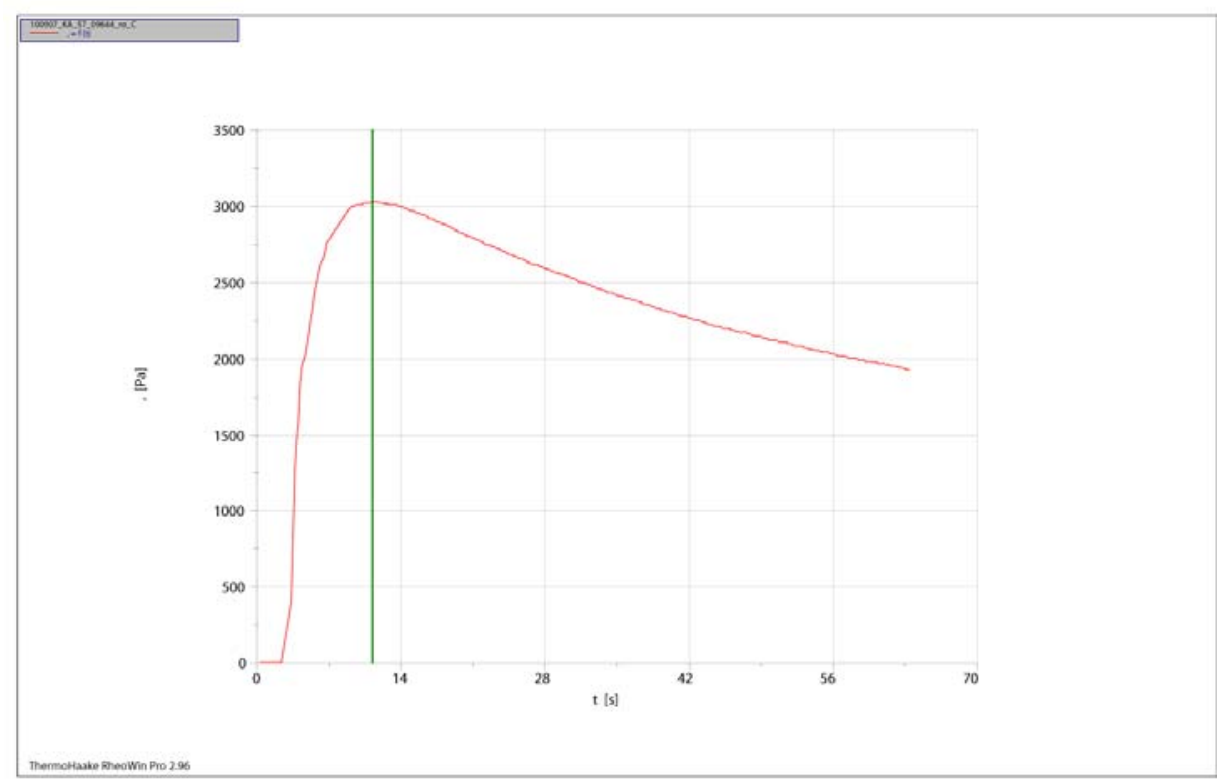

1: C:\Rheology Results UJWWRS\Kaolin\Consolidated Samples \100907_KA_57_09644_ro_C.rwd

Company / Operator: PNNL / Jeromy Jenks
Date / Time / Version: 09.09.2010 / 14:33:47 PM / RheoWin Pro 296

Substance / Sample no: KA-57 / 100907 KA 57 09644_ro C

Curve discussion: Greatest value $\mathrm{t}[\mathrm{s}] 11.24,[\mathrm{~Pa}] 3030$.

Figure C.16. Consolidated Kaolin(57 wt\%) 100907 Shear Strength (PA) as a Function of Time Measured at Center 
ThermoHaake RheoWin 9/24/2010/9:45 AM

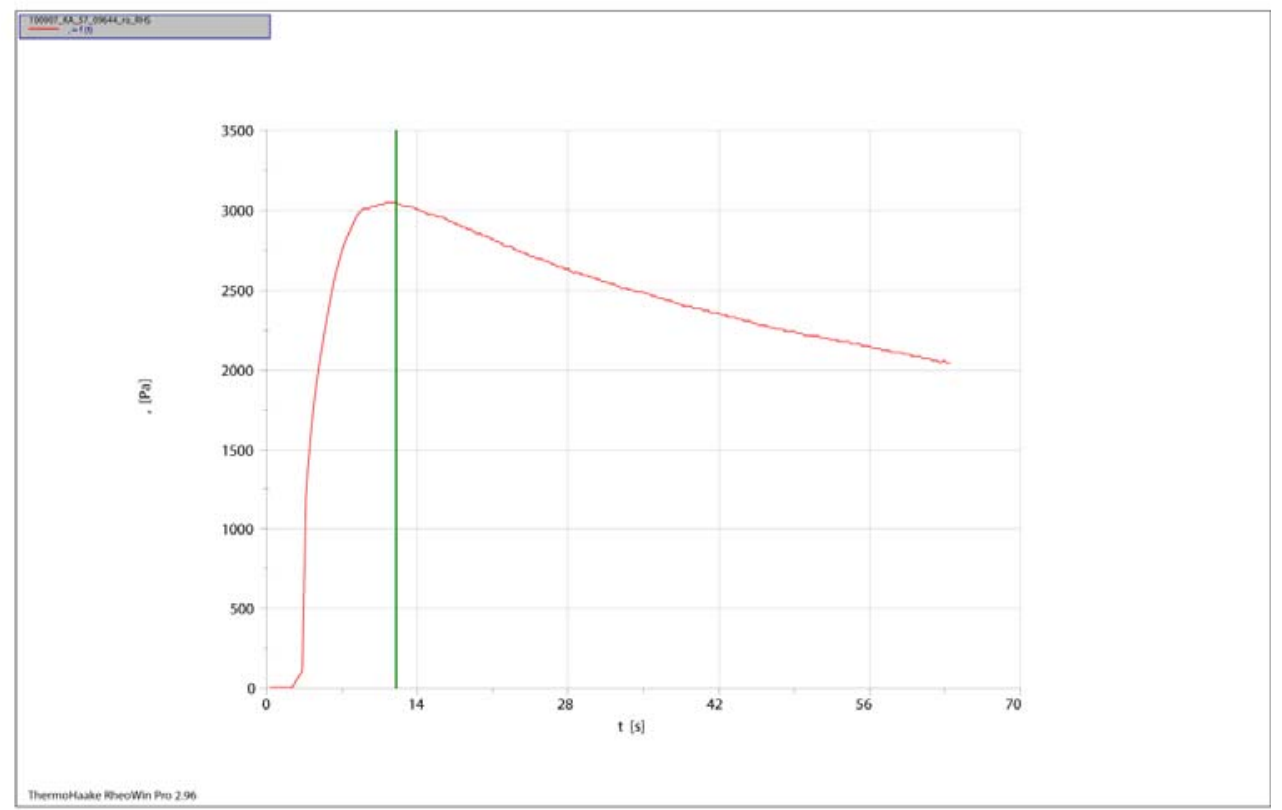

1: C:IRheoloqy Results\JWWRPS\Kaolin\Consolidated Samples\100907_KA_57_09644_ro_RHS.rwd Company / Operator: PNNL / Jeromy Jenks

Date / Time / Version: 09.09.2010 / 14:36:48 PM / RheoWin Pro 296

Substance / Sample no: KA-57 / 100907_KA_57_09644_ro_RHS

Curve discussion: Greatest value $\mathrm{t}$ [s] 12.04 , [Pa] 3047.

Figure C.17. Consolidated Kaolin(57 wt\% ) 100907 Shear Strength (PA) as a Function of Time

Measured at RHS

ThermoHaake RheoWin 9/24/2010/9:44 AM

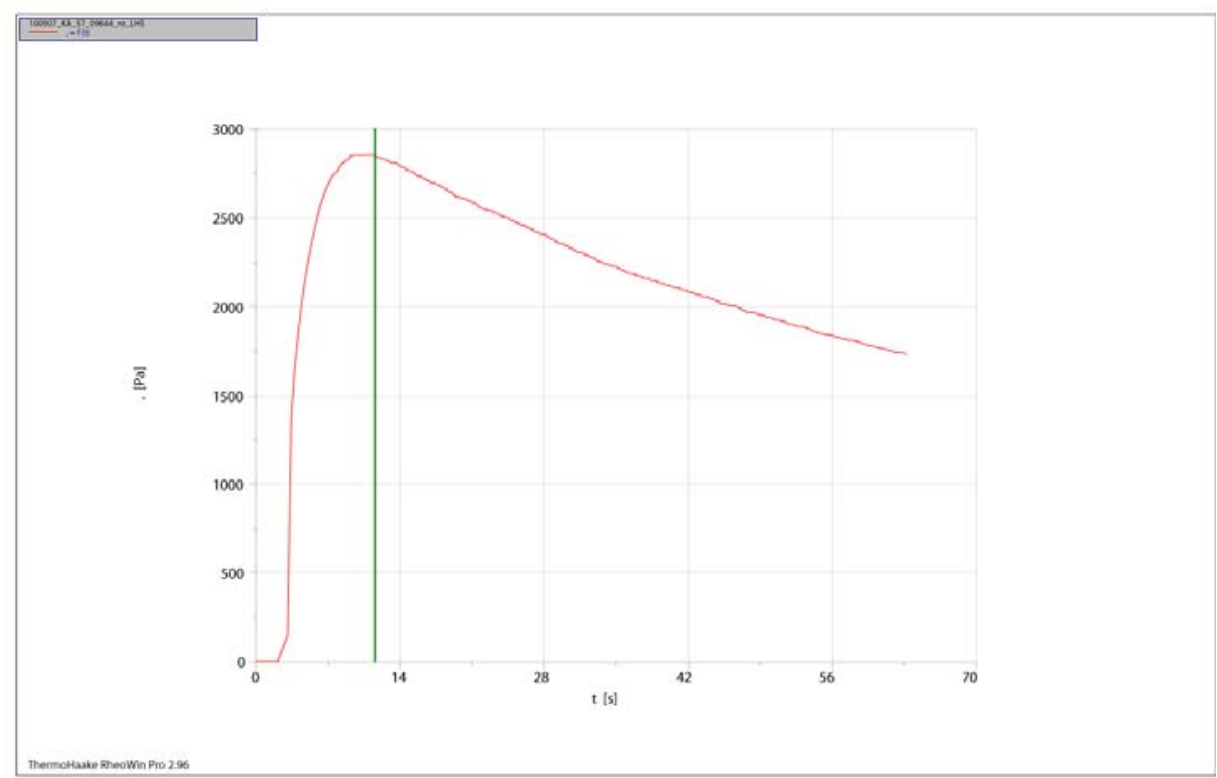

1: C:IRheology Results\JWRPS\Kaolin\Consolidated Samples\100907_KA_57_09644_ro_LHS.rwd Company / Operator: PNNL / Jeromy Jenks

Date / Time / Version: 09.09.2010 / 14:39:42 PM / RheoWin Pro 296

Substance / Sample no: KA-57 / 100907_KA 57_09644_ro LHS

Curve discussion: Greatest value $\mathrm{t}$ [s] 11.57, [Pa] 2852.

Figure C.18. Consolidated Kaolin(57 wt\%) 100907 Shear Strength (PA) as a Function of Time Measured at LHS 


\section{C.2 UW Kaolin Test Data}

The following write-up provided by UW described their testing and results. 


\section{Introduction}

\section{Introduction}

Radioactive wastes in Hanford tanks generate flammable gases by radiolysis of water, decomposition of organic compounds, and corrosion of the steel tank walls. In some tanks, specifically those with deep layers of supernatant liquid and sediment, the generated gas can accumulate until the waste becomes sufficiently buoyant to overcome its weight and the strength of the surrounding material restraining it. The sufficiently buoyant portion then rises through the supernate, and the resultant expansion of the retained gas yields the retaining material such that a fraction of the retained gas is released, and the remaining non-buoyant material sinks back into the sediment. This gas release process defines what is called a buoyant displacement gas release event (BDGRE).

The current System Plan (Rev. 4, Certa and Wells 2009) uses relaxed BDGRE controls for deep sludge (i.e. high level waste [HLW]) tanks, which allow the tank farms to use more storage space, i.e. increase the sediment depth, in some double shell tanks. The relaxed BDGRE controls are based on preliminary analysis of a gas release model from van Kessel and van Kesteren (2002). Application of the van Kessel and van Kesteren model requires parametric information for the sediment including the undrained shear strength, void ratio, undissolved solids and liquid density, lateral earth pressure coefficient at rest, shear modulus, average floc size, and the undisturbed channel radius. Some of these parameters are known for Hanford sludge sediment. However, no measurements are currently available for the shear modulus and lateral earth pressure coefficient for Hanford sludge sediments.

\section{Objective}

The main objectives of the proposed work were to develop an instrument to directly measure the lateral earth pressure coefficient, $k_{o}$, and shear modulus, $G_{\max }$, of Hanford sludge sediment stimulants and perform a validation study using kaolin clay slurries. This work was completed in cooperation with the Pacific Northwest National Laboratory (PNNL).

To accomplish these goals the following tasks were proposed:

1 Instrument Design and Production

a. An instrument was developed at UW that could demonstratably directly measure the lateral earth pressure coefficient at rest $k_{o}$, and shear modulus $G_{\max }$, for the Hanford sludge sediment simulants at the conditions represented in the van Kessel and van Kesteren (2002) model (i.e. the shear strength is unconsolidated, undrained).

b. Fabrication of the instrument(s). Done at PNNL. Four instruments were constructed; one instrument was transferred to UW ownership.

2 Instrumentation Operation

a. PNNL staff was trained by UW staff to operate the newly developed instrumentation.

3 Independent Measurements with Instrumentation

a. Instrumentation was used at PNNL and UW to perform independent measurements on PNNL provided kaolin clay slurries. 
b. Comparison of kaolin clay measurement results at PNNL and UW was made to verify operations.

\section{Instrument Design}

\section{Measurement of lateral stresses at rest}

The evaluation of the lateral earth pressure coefficient at rest, $k_{o}$ of soils has been an important topic of research for many years. Measurement of lateral stresses in the laboratory was attempted in Sweden as early as 1936 through the use of a complicated three-dimensional mechanical pressure device (Kjellman, 1936). As the years progressed, more emphasis was placed on simulating the condition of a natural clayey material. Since natural clays are consolidated under conditions of zero lateral strain, it became important to develop testing equipment that could both measure three-dimensional stress-strain-time relationships and maintain the constrained condition. A zero lateral strain condition is usually referred as a $k_{o}$, or at rest, condition; where:

$$
k_{0}=\frac{\sigma_{h}^{\prime}}{\sigma_{v}^{\prime}} \quad \begin{aligned}
& \sigma_{h}^{\prime} \text { is the horizontal effective stress and } \\
& \sigma_{v}^{\prime} \text { is the vertical effective stress. }
\end{aligned}
$$

Over the years several unique pressure cells were devised for the specific purpose of measuring lateral pressures under zero lateral strain, $k_{o}$, conditions. The development of the cylindrical triaxial cell in the 1930s offered a new method to measure lateral stresses during consolidation. With the added capability of a lateral strain detector (Bishop and Henkel, 1962), this device could be used for studying fundamental consolidation behavior. Difficulty in maintaining a zero lateral strain condition in the triaxial cell, especially for soft or sensitive clayey material, prompted the use of electromechanical servo systems that automated the adjustment of lateral or cell pressure. These difficulties prompted many researchers to turn to specially modified oedometer rings, where constrained conditions are less difficult and costly to maintain and conventional consolidation equipment (i.e. oedometers) can be used. Over the years three basic oedometer ring designs emerged (Duval, 1994):
a) the rigid cell;
b) the semi-rigid confining ring; and
c) the null indicator.

The rigid cell or confining ring is a thick walled cylinder that allows the measurement of strain or pressure at points around the diameter of the cell. The rigidness of the cell ensures the soil is in an at rest condition. However, the value of $k_{o}$ is determined from a single point, and extrapolated for the whole sample.

The semi-rigid confining ring uses a thin wall with strain gages or wires wrapped around the exterior. The device is calibrated to known lateral pressures and allows the correlation of strain to pressure. This calibration factor is then used to determine the pressure from the strain measurements. Unfortunately allowing lateral deformations to take place, raises questions about the validity of the at rest condition in the specimen.

The null indicator ring is similar to the semi-rigid ring, except the thin wall is part of a pressure chamber. The strain gages measure any deflection of the thin wall. This deflection can then be brought to zero by 
applying pressure to the thin wall chamber. This allows the direct measurement of the horizontal pressures at the at rest condition.

\section{Oedometer Ring Design}

Due to its simplicity, the null indicator was chosen for this project as a basis for the design of a new oedometer ring. The null indicator offers continuous measurement about the periphery of the sample while avoiding the complicated calibration equations and procedures of other methodologies.

The first step in the design process of a null indicator ring is to determine the mode of deformation associated with the imposed state of stress. Using elasticity, the stresses in a thin-walled pressure vessel subjected to a uniform pressure differential, $\Delta P$, can be easily calculated. Assuming the walls stretch as a membrane results in the following equations:

$$
\begin{gathered}
\sigma_{1}=\sigma_{\text {axial }}=\frac{r \Delta P}{2 t} \\
\sigma_{2}=\sigma_{\text {hoop }}=\frac{r \Delta P}{t}
\end{gathered}
$$

In these equations, $r$ is the radius of the oedometer ring, $t$ is the ring thickness, and $\Delta P$ is the differential pressure. The deformation, $\delta$, that results from this biaxial state of stress can be expressed in terms of elastic modulus, $E$, and Poisson's ratio $v$ as,

$$
\delta=\frac{r^{2} \Delta P(2-v)}{t E}
$$

In this project the radius of the ring was chosen as 1.25 in. to conform to standard practice and to allow the ring to be used with available consolidation testing equipment. To account for the effect of the sludge sediment weight pressure differentials, $\Delta P$, of the order of 0.5 psi to 10 psi were used. This pressure differential range represents the expected stresses generated by the weight of $20 \mathrm{ft}$ of sludge sediments. Poisson's ratio and Young's modulus are dependent on the ring's material being considered. For 316 stainless steel, $E=28,000,000 \mathrm{psi}$ and $v=0.3$. Using these parameters the calculated strain levels for $\Delta P=0.5 \mathrm{psi}$ and a wall thickness of $0.005 \mathrm{in}$. is $2.4 \mu \varepsilon$. For a wall thickness of 0.003 in. the calculated strain level is $4 \mu \varepsilon$. For $\Delta P=10$ psi the estimated strain levels are $24 \mu \varepsilon$ and $40 \mu \varepsilon$ respectively. Conventional strain gages are capable of measuring strain levels on this range. Stainless steel was chosen for its corrosion resistance to the simulants that were tested by PNNL. 


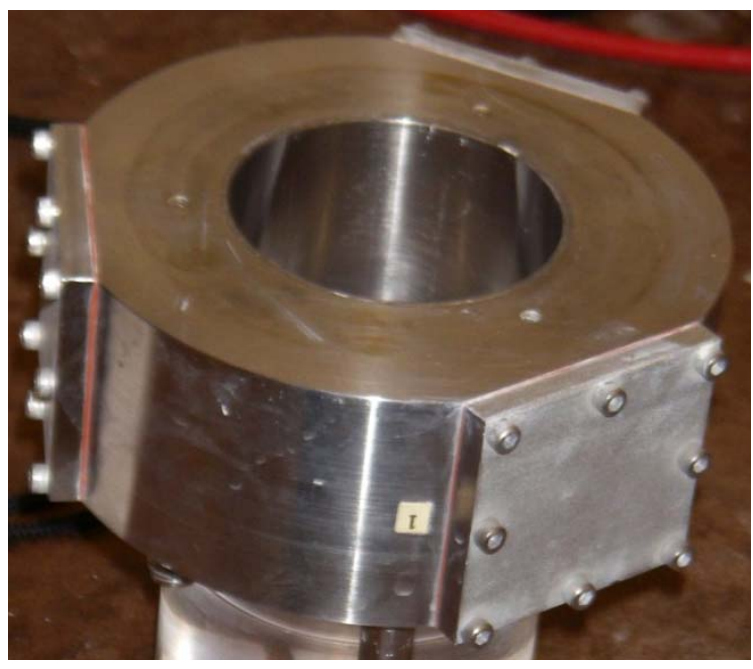

Figure 1 Ko Consolidometer Ring

Operation of the null indicator ring involves: a) the application of a vertical load and measurement of the corresponding lateral deflection and $b$ ) increase of the ring wall chamber pressure to bring to zero this deflection. In this project the vertical loads was generated using a dead weight oedometer device. This device applies a vertical load either by the application of weights on a lever arm that multiplies the force by a factor of 9,10 or 11 . In this case a factor of 10 is used for simplicity of calculations. In this project a commercially available dead weightn oedometer was used (www.durhamgeo.com). A typical dead weight oedometer produced by Durham Geo is shown in Figure 2.

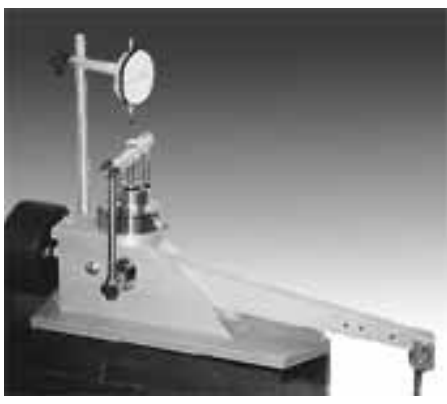

Figure 2. Durgham-Geo dead weight oedometer

Bender elements were used to determine the shear wave velocity of the material. A bender element was placed in the top of the sample and another at the bottom. Both bender elements were attached to the porous stones using specially designed fittings. The bottom bender element was set to act as a transmitter and the top one as a receiver. A wave pulse was sent through the soil and its arrival time was determined. The shear wave velocity, $V_{s}$, was calculated from the time and distance the wave travels. $G_{\max }$ was then be determined using the basic relationship:

$$
G_{\max }=\rho \cdot V_{s}^{2}
$$

where $\rho$ is the sludge simulant density. The distance the wave travels depends on the ring thickness. Conventional oedometer equipment uses $1.0 \mathrm{in}$. rings. In this project a ring thickness of $2.0 \mathrm{in}$. was used to facilitate the measurement of the shear modulus. 


\section{Simulant and Equipment}

\section{Simulant}

The simulant used in these tests was a EPK kaolin (Edgar Minerals Inc. Edgar, FL) provided by PNNL. The samples were generated by mixing the kaolin with de-ionized water. The samples were mixed thoroughly by hand and allowed to sit for 16 hours to allow the kaolin to adsorb the water. The samples were made in 200 gram lots with the appropriate amount of water added to reach the desired water content. Water content is the amount of water of in sample divided by the mass of the soilis. That is

$$
w=\frac{m_{w}}{m_{s}}=\frac{\text { mass of water }}{\text { mass of solids }}
$$

Mass fraction is the amount of undisolved solids in the sample. The water content is related to the mass fraction by

$$
\text { mass fraction of solids }=\frac{1}{w+1}
$$

These equations allowed for the use of water content as one of the independent variables. Water content is a standard geotechnical quantitythat is commonly used in geotechnical practice.

\section{Equipment}

The $\mathrm{K}_{0}$ consolidation ring (or null indicator ring) was designed in cooperation with PNNL. The plans for this device are available elsewhere within this document. The $\mathrm{K}_{0}$ ring and the dead weight load frame were provided by PNNL. A picture of the setup used and individual equipment is shown below. Unlike PNNL the UW device strain gages and pressure were controlled by a program built using the LabView software from National Instruments. This allowed them both to be monitored at the same time, and the pressure to be adjusted as necessary. The bender element data was also recorded using LabView. The strain gages and bender elements were connected to a National Instruments SCXI 1321 Offset-Null and Shunt Calibration Terminal Block which was plugged into an SCXI 1121 4-Channel Isolation Amplifier with Excitation. These were in turn plugged into a SCXI 1000 frame which provided the module with power and allowed the acquisition of the data into the computer using a PCI MIO 16XE-10 DAQ card. The 1121 module allowed the strain gages to be excited at 3.33v. The bender elements were connected using a similar set up, except without the excitation voltage. The pressure was controlled using a different DAQ card and a terminal board. This board adjusted the control voltage of a Fairchild T7800 electro pneumatic pressure transducer. This pressure transducer has a range of 0-30 psi, and was able to increase the pressure in $.01 \mathrm{psi}$ increments. The dial gage was also connected to the system as well via the USB cable. This allowed the deformation to be displayed in real time with the strain gages and pressure data. This setup also allowed for remote monitoring of the test when the tests ran more than 8 to 12 hours. 
Table 1 Equipment Used for the $K_{0}$ and Bender Element Tests

\begin{tabular}{|c|c|c|}
\hline Equipment & Supplier & Part Number \\
\hline Consolidation Frame, Dead Weight & Durham Geo Slope indicator & S-449 \\
\hline Pressure Transducer & Durham Geo Slope indicator & E-126 \\
\hline Digital Transducer Readout & Durham Geo Slope indicator & E-405 \\
\hline Digital Dial Gauge & Chicago Dial Indicator & BG2110 \\
\hline USB data cable & Chicago Dial Indicator & G13-0048 \\
\hline Strain Gauges & Vishay Micro Measurements & CEA-13-250UW-350/P2 \\
\hline Bender Elements & Piezo.com & T-220-A4-303Y \\
\hline Data Acquisition Frame & National Instruments & SCXI-1000 \\
\hline Data Acquisition Module & National Instruments & SCXI-1121 \\
\hline Terminal Block & National Instruments & SCXI-1321 \\
\hline Data Acquisition Card & National Instruments & PCI MIO 16XE-10 \\
\hline Data Acquisition Card & National Instruments & PCI-6221 (37 pin) \\
\hline Data Acquisition Board & National Instruments & CB-37F-LP \\
\hline Oscilloscope & Tektronics & TDS 320 \\
\hline Signal Generator & Systron-Donner Corporation & Datapulse 401 \\
\hline Power Amplifier 50V & Hewlett Packard & 6824A \\
\hline Power Supply & Elengo Precision & XP-580 \\
\hline Electro-Pneumatic Pressure Transducer & Fairchild & TT7800-004 \\
\hline Stopwatch & Magnum & Accusplit 705X \\
\hline
\end{tabular}

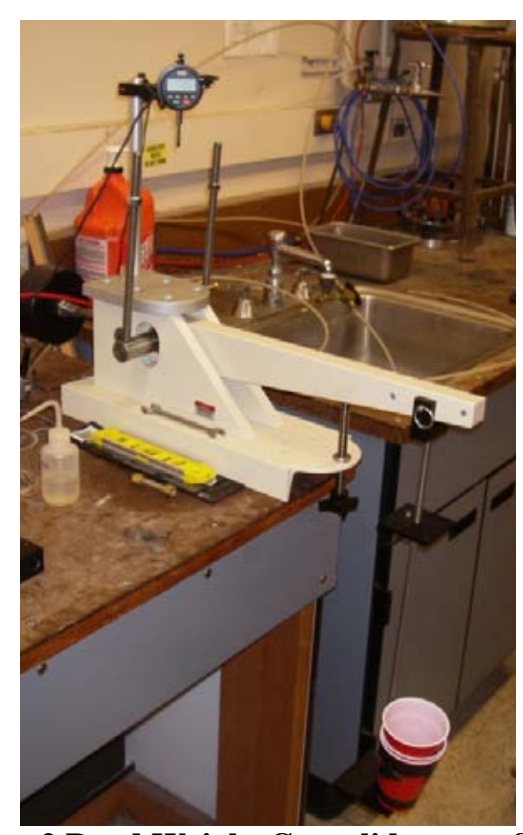

Figure 2 Dead Weight Consolidometer Setup

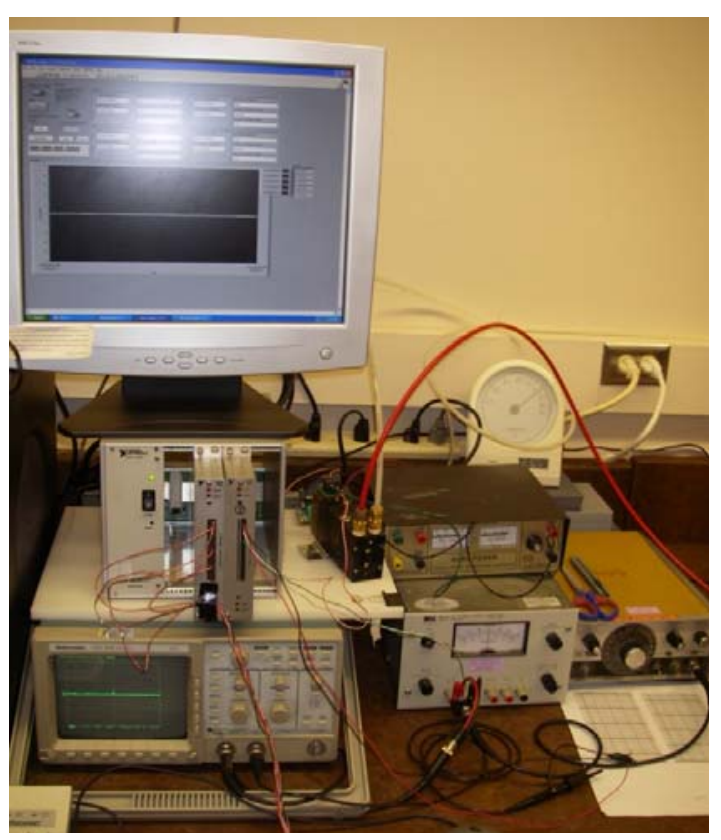

Figure 3 Computer and Electronic Equipment Setup 


\section{Tests Results and Data}

\section{Preliminary Tests}

Several preliminary tests were performed on the kaolin samples that were sent to the University of Washington by PNNL to determine the characteristics of the kaolin. These tests included Atterberg Limit tests performed per ASTM D 4318-00 and two hydrometer tests per ASTM D 422-63. The results of these tests are listed below.

Table 2 Atterberg Limits

\begin{tabular}{|c|c|}
\hline Plastic Limit & 33 \\
\hline Liquid Limit & 67 \\
\hline Plasticity Index & 34 \\
\hline
\end{tabular}

\section{Grain Size Distribution}

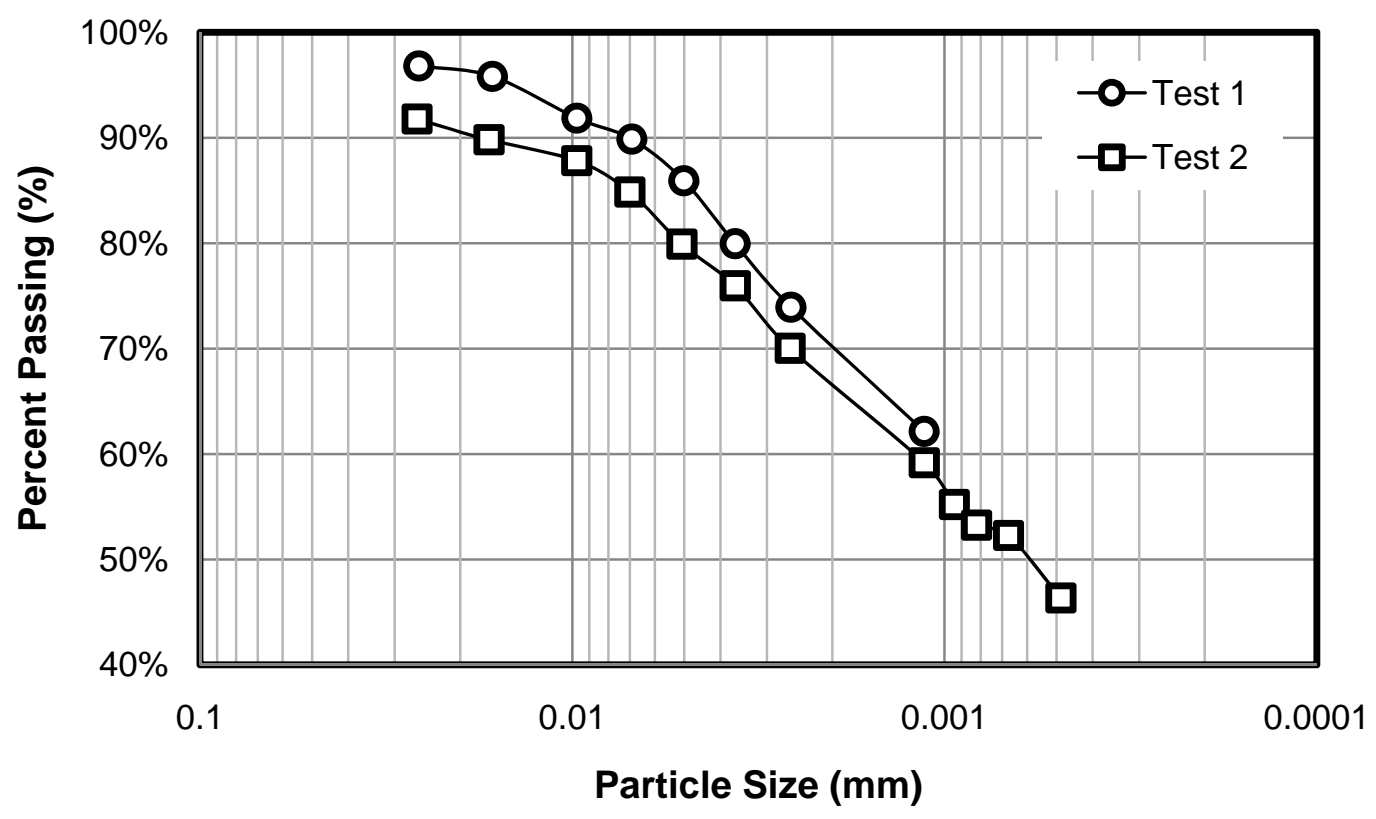

Figure 4 Hydrometer Test Results 


\section{Consolidation Test Results}

A conventional consolidation test was performed using ASTM D 2435-04. The results of the test are shown below. The loads used to perform the test are given in the table below. These loads are much higher than those used to perform the $k_{0}$ tests. Not only does this test give some insight on the characteristics of the kaolin that was used, but it also gives some estimate on the testing time involved for each loading cycle. The sample was a remolded sample of the kaolin, with an initial water content of around $70 \%$. The mixture was allowed to sit for 16 hours to allow the clay particles to adsorb the water in the mixture. This is a standard methodology used in almost all geotechnical laboratories, so the clay can reach a more uniform state. The value of the compression index $\mathrm{C}_{\mathrm{c}}=.166$, while the recompression index $\mathrm{C}_{\mathrm{r}=.017}$. These values are used in Geotechnical consolidation calculations to determine the amount of settlement that would occur in a soil profile.

Table 3 Load Increments for Consolidation Test

\begin{tabular}{|r|r|}
\hline $\begin{array}{c}\text { Load } \\
\text { Increment }\end{array}$ & $\begin{array}{c}\text { Load } \\
(\mathrm{Pa})\end{array}$ \\
\hline 0.8 & 7037 \\
\hline 1.6 & 30901 \\
\hline 3.2 & 77680 \\
\hline 6.4 & 171236 \\
\hline 12.8 & 358350 \\
\hline 6.4 & 171236 \\
\hline 3.2 & 77680 \\
\hline 1.6 & 30901 \\
\hline 3.2 & 77680 \\
\hline
\end{tabular}

\begin{tabular}{|c|r|}
\hline $\begin{array}{c}\text { Load } \\
\text { Increment }\end{array}$ & $\begin{array}{c}\text { Load } \\
(\mathrm{Pa})\end{array}$ \\
\hline 6.4 & 171236 \\
\hline 12.8 & 358350 \\
\hline 25.6 & 732578 \\
\hline 51.2 & 1481033 \\
\hline 25.6 & 732578 \\
\hline 12.8 & 358350 \\
\hline 6.4 & 171236 \\
\hline 3.2 & 77680 \\
\hline 1.6 & 30901 \\
\hline
\end{tabular}




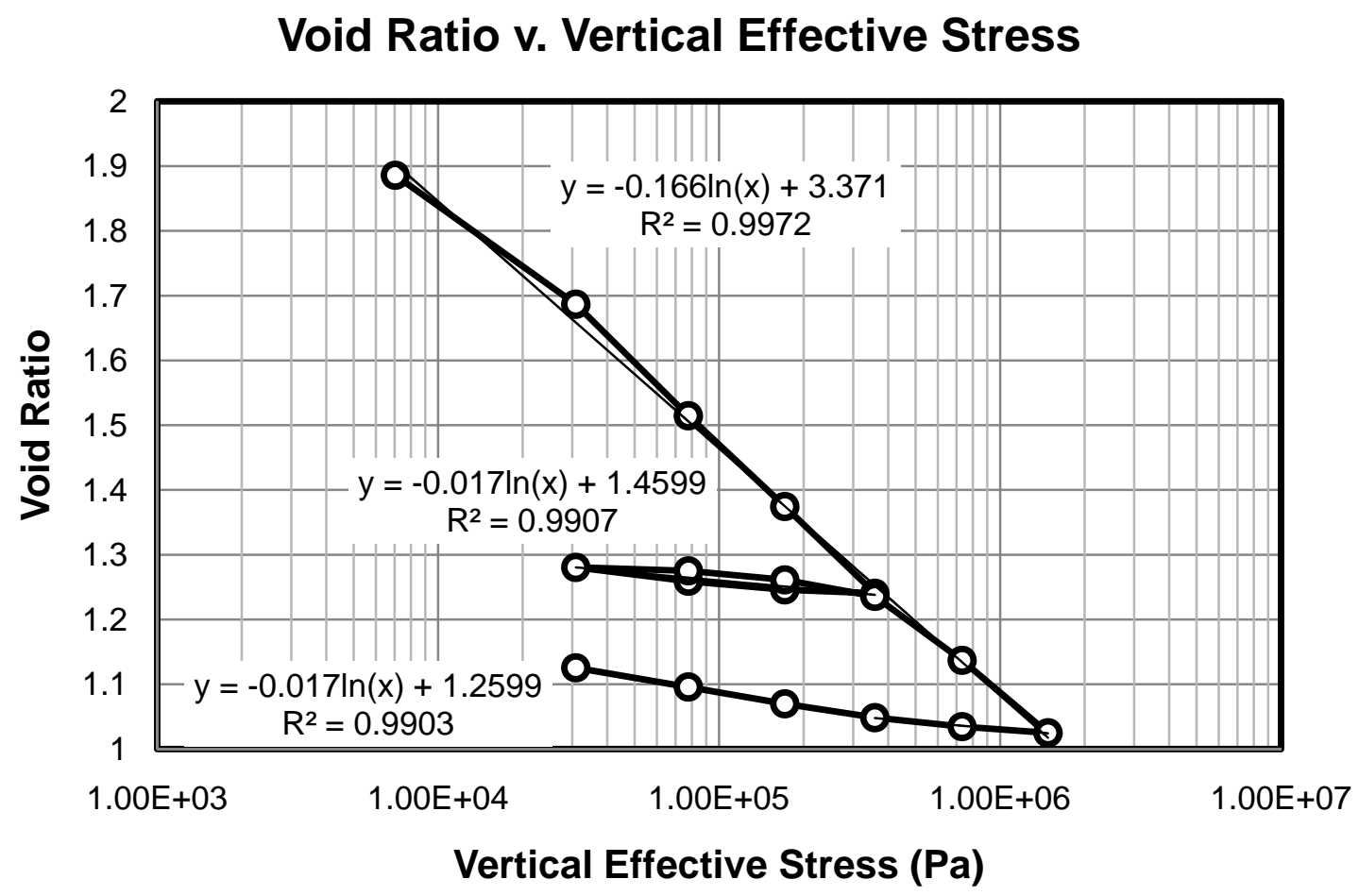

Figure 5 Void Ratio v. Vertical Effective Stress

Water Content v. Vertical Effective Stress

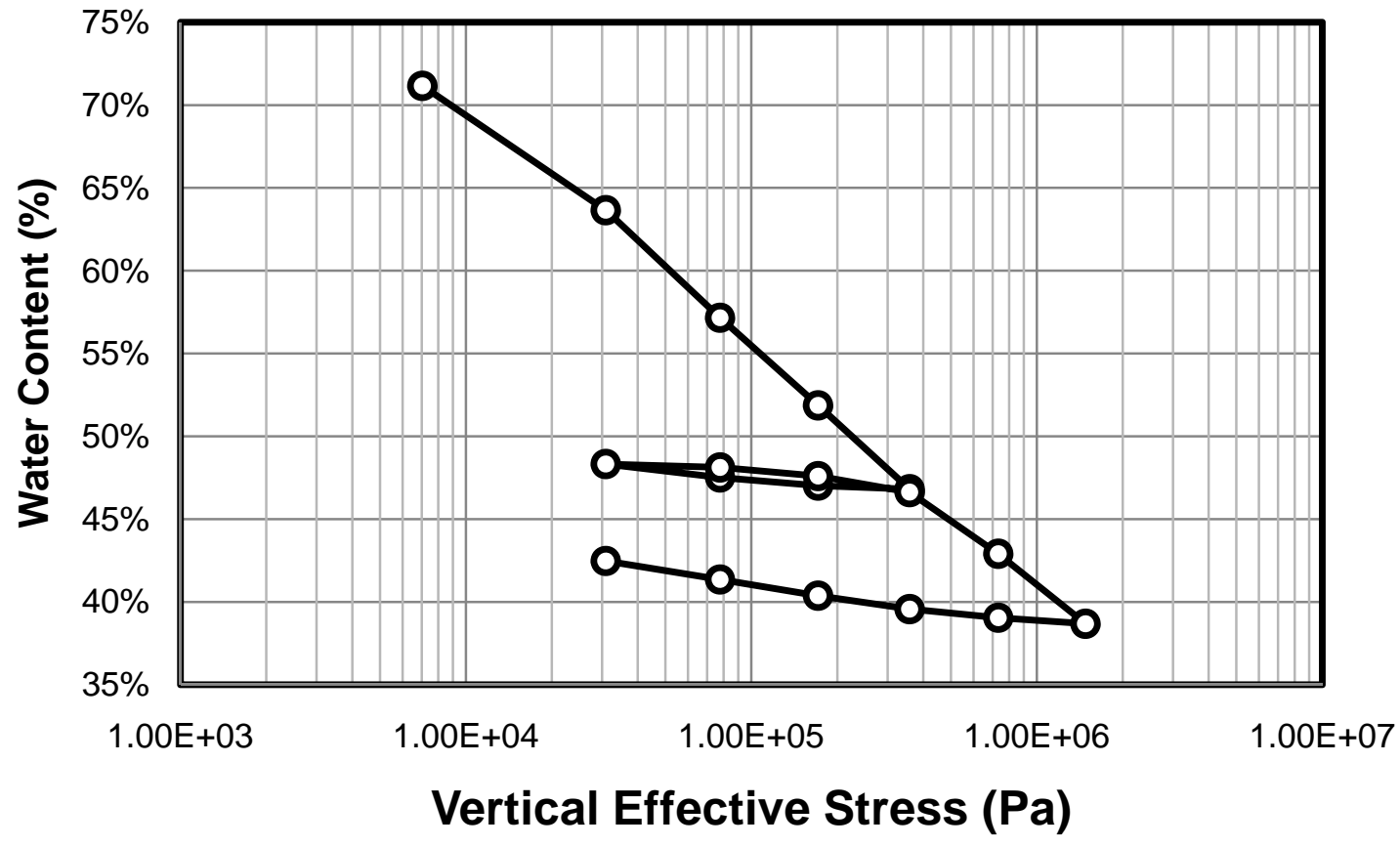

Figure 6 Water Content v. Vertical Effective Stress 


\section{Shear Strength Test}

The shear strengths presented below were generated in two ways. The PNNL data was generated using a laboratory vane shear test. The UW data was generated using the fall cone test. The shear strengths for the fall cone test come from a correlation of the depth of penetration of the cone. This depth has been correlated to shear strengths for soft Swedish clays similar to the kaolin clay used in this project. The two strengths given for the UW data are for undisturbed and remolded clays. Undisturbed clays still contain the original structure from when they were deposited. Remolded clays have been remixed, and the original structure of the clay is no longer intact. The PNNL data presented below was obtained from two PNNL report; PNNL-19094 and PNNL-19345. The UW Fall cone data was generated using the methodology proposed by Hansbo (1957).

The water contents for the PNNL data were determined using

$$
w=\frac{1-w t \% \text { Kaolin }}{w t \% \text { Kaolin }}
$$

This assumes that the wt \% Kaolin is the mass of solids and the rest of the mixture is water.

As can be seen below, there is a good correlation between the PNNL1 data and the UW data. The correlations used for the fall cone penetration are based on soft Swedish clays which is similar to the EPK Kaolin that was tested. However, as stated, these correlations are for Swedish clays and do not truly represent the EPK Kaolin.

\section{Fall Cone Test}

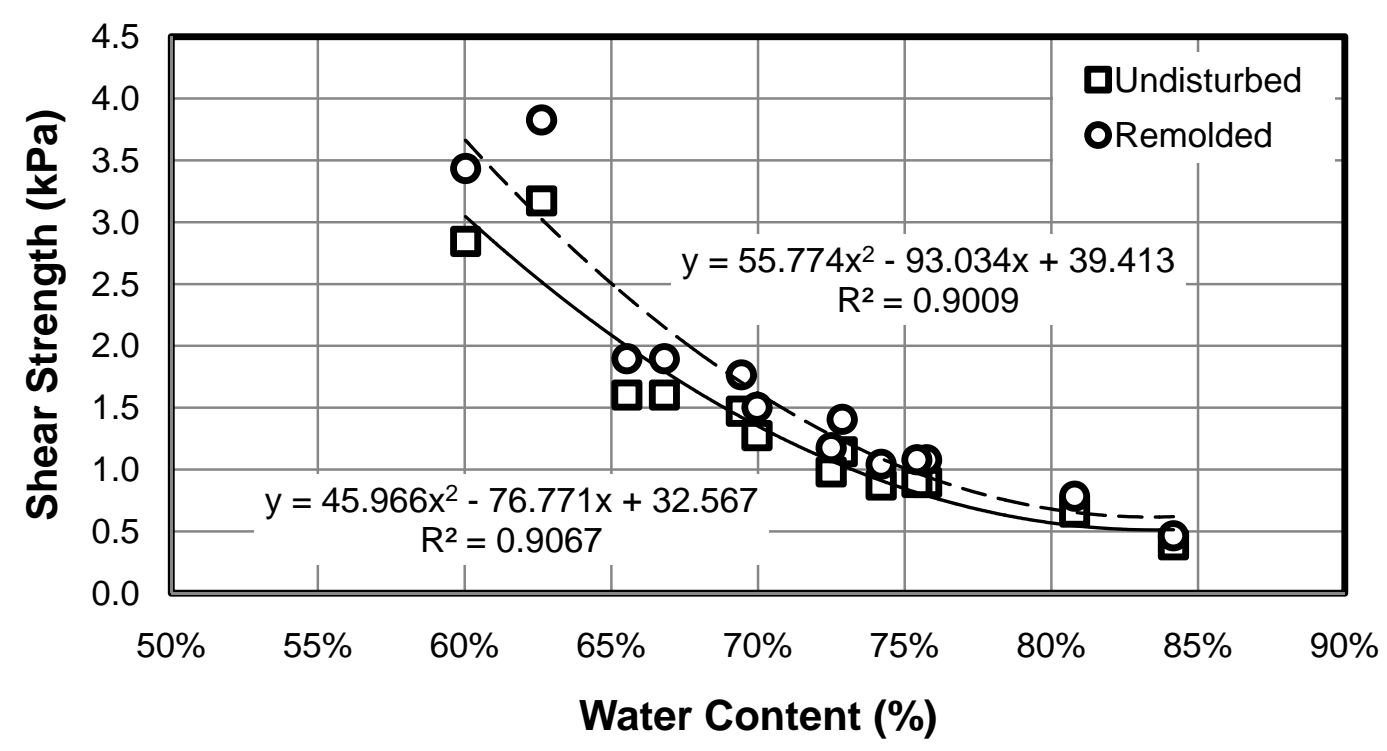

Figure 7 Shear Strength v. Water Content from Fall Cone Test 


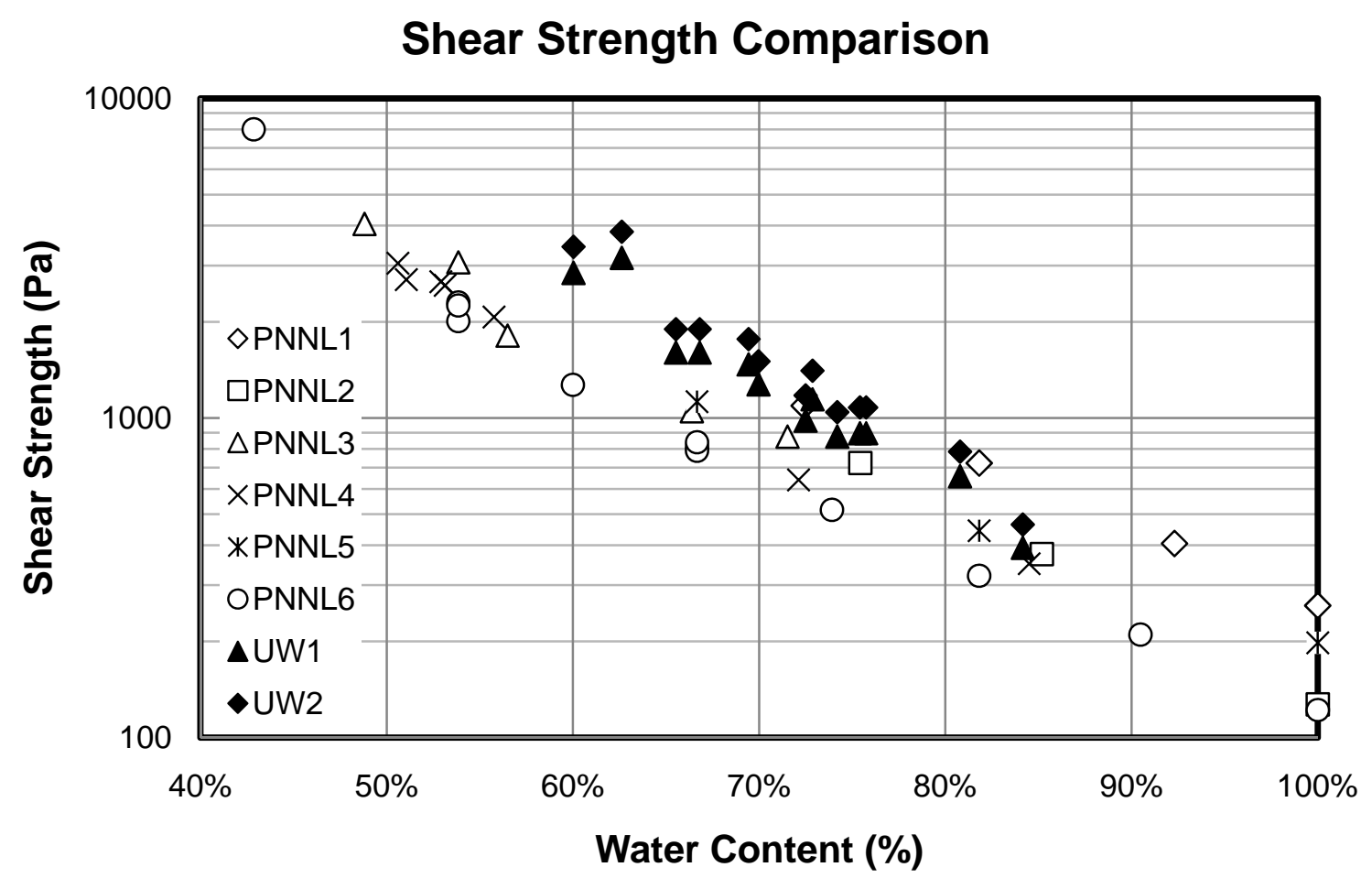

Figure 8 Shear Strength v. Water Content

Table 4 Sources of Shear Strength Data

\begin{tabular}{|c|l|}
\hline Name & \multicolumn{1}{|c|}{ Source } \\
\hline PNNL1 & PNNL-19345 53451-RPT08 from Section 3.1.1, Table 3.1 \\
\hline PNNL2 & PNNL-19094 Test Results from Section 5.1, Table 5.1 \\
\hline PNNL3 & PNNL-19094 Test Results from Section 5.2, Table 5.2 \\
\hline PNNL4 & PNNL-19094 Test Results from Section 5.2, Table 5.3 \\
\hline PNNL5 & PNNL-19094 Test Results from Section 5.2, Table 5.4 \\
\hline PNNL6 & PNNL-19094 Test Results from Section 5.2, Table 5.5 \\
\hline UW1 & $\begin{array}{l}\text { Fall Cone test data from UW Tests correlated to } \\
\text { Undisturbed Strength of Swedish Clays }\end{array}$ \\
\hline UW2 & $\begin{array}{l}\text { Fall Cone test data from UW Tests correlated to Remolded } \\
\text { Strength of Swedish Clays }\end{array}$ \\
\hline
\end{tabular}

\section{$\mathrm{K}_{0}$ and Shear Wave Velocity Tests}

Nine tests were performed on Kaolin samples using the new stainless steel consolidation ring. The tests are numbered 21 to 23 and 26 to 31 . The water contents were varied with three of the samples mixed at a water content of $61 \%$, four samples at $75 \%$ and two samples at $85 \%$. During placement, the $75 \%$ and $85 \%$ samples were vibrated into the ring to reduce the number of air bubbles in the samples. Loading depended 
on the water content. The $85 \%$ water content samples were loaded at $6 \mathrm{kPa}$, the $75 \%$ were loaded at 10 $\mathrm{kPa}$, and the $61 \%$ were loaded at $35 \mathrm{kPa}$. These loads were chosen to allow the consolidation to reach $\mathrm{t}_{90}$ within a reasonable amount of time. The results and data for the tests are listed below.

The time curves are all similar and are consistent with typical consolidation results for clay. Only a single test crossed the $\mathrm{D}_{100}$ line that was calculated per ASTM D 2435-04. This is probably due to friction and the light loads that were being used. However, all the curves follow the same general patterns for both time and $\mathrm{K}_{0}$. The $\mathrm{K}_{0}$ values were determined at several points along the curve. These include $\mathrm{t}_{50}$, $t_{90}$, and $t_{\text {PLATEAU. }} t_{90}$ and $d_{90}$ were determined per section 12.3.2 of ASTM D 2435-04. $t_{50}$ was determined by calculating $\mathrm{d}_{50}$ per section 12.3.2.3 of the same ASTM. $\mathrm{t}_{\text {PLATEAU }}$ was were the $k_{0}$ value leveled out toward the end of the test. 
Table $5 \mathbf{K}_{\mathbf{0}}$ and Shear Wave Velocity Data

\begin{tabular}{|c|ccccccccc|}
\hline Test Number & 21 & 22 & 23 & 26 & 27 & 28 & 29 & 30 & 31 \\
\hline $\begin{array}{c}\text { Initial Water } \\
\text { Content } \\
\text { Final Water } \\
\text { Content }\end{array}$ & $78 \%$ & $79 \%$ & $74 \%$ & $64 \%$ & $64 \%$ & $69 \%$ & $88 \%$ & $85 \%$ & $64 \%$ \\
$\begin{array}{c}\text { Initial Mass } \\
\text { Fraction } \\
\text { Final Mass } \\
\text { Fraction }\end{array}$ & $56 \%$ & $56 \%$ & $57 \%$ & $61 \%$ & $61 \%$ & $59 \%$ & $53 \%$ & $54 \%$ & $61 \%$ \\
\hline $\mathrm{T}_{50}(\min )$ & 86 & 82 & 95 & 51 & 50 & 97 & 83 & 104 & 47 \\
$\mathrm{~K}_{0}$ at $\mathrm{T}_{50}$ & 0.89 & 0.91 & 0.92 & 0.82 & 0.84 & 0.86 & 0.97 & 0.88 & 0.84 \\
$\begin{array}{c}\text { Deformation } \\
\text { at } \mathrm{T}_{50}\end{array}$ & 0.1164 & 0.0964 & 0.0942 & 0.1399 & 0.1358 & 0.0820 & 0.0993 & 0.0959 & 0.1215 \\
\hline $\begin{array}{c}\mathrm{T}_{90}(\min ) \\
\mathrm{K}_{0} \text { at } \mathrm{T}_{90}\end{array}$ & 368 & 350 & 408 & 217 & 217 & 413 & 355 & 398 & 204 \\
$\begin{array}{c}\text { Deformation } \\
\text { at } \mathrm{T}_{90}\end{array}$ & 0.185 & .79 & .79 & .51 & .61 & .75 & .81 & .75 & .57 \\
\hline $\begin{array}{c}\mathrm{T}_{\text {PLATEAU }}(\mathrm{min}) \\
\mathrm{K}_{0} \text { at } \mathrm{T}_{\text {PLATEAU }}\end{array}$ & 1500 & 0.1638 & 0.1598 & 0.2020 & 0.2030 & 0.1370 & 0.1714 & 0.1653 & 0.1850 \\
\hline $\begin{array}{c}\text { Deformation } \\
\text { at } \mathrm{T}_{\text {PLATEAU }}\end{array}$ & 0.1919 & .1732 & 0.1691 & 0.2057 & 0.2120 & .1455 & 0.1792 & .1686 & 0.1929 \\
\hline $\begin{array}{c}\text { Shear Wave } \\
\text { Velocity (m/s) }\end{array}$ & - & - & 26.8 & 37.3 & 42.8 & 24.4 & 18.2 & 16.9 & 58.9 \\
$\begin{array}{c}\text { Water Content } \\
\text { for Shear } \\
\text { Wave Velocity }\end{array}$ & - & - & $61 \%$ & $57 \%$ & $54 \%$ & $61 \%$ & $75 \%$ & $75 \%$ & $55 \%$ \\
\hline
\end{tabular}


$\mathrm{K}_{0}$ v. Initial Water Content

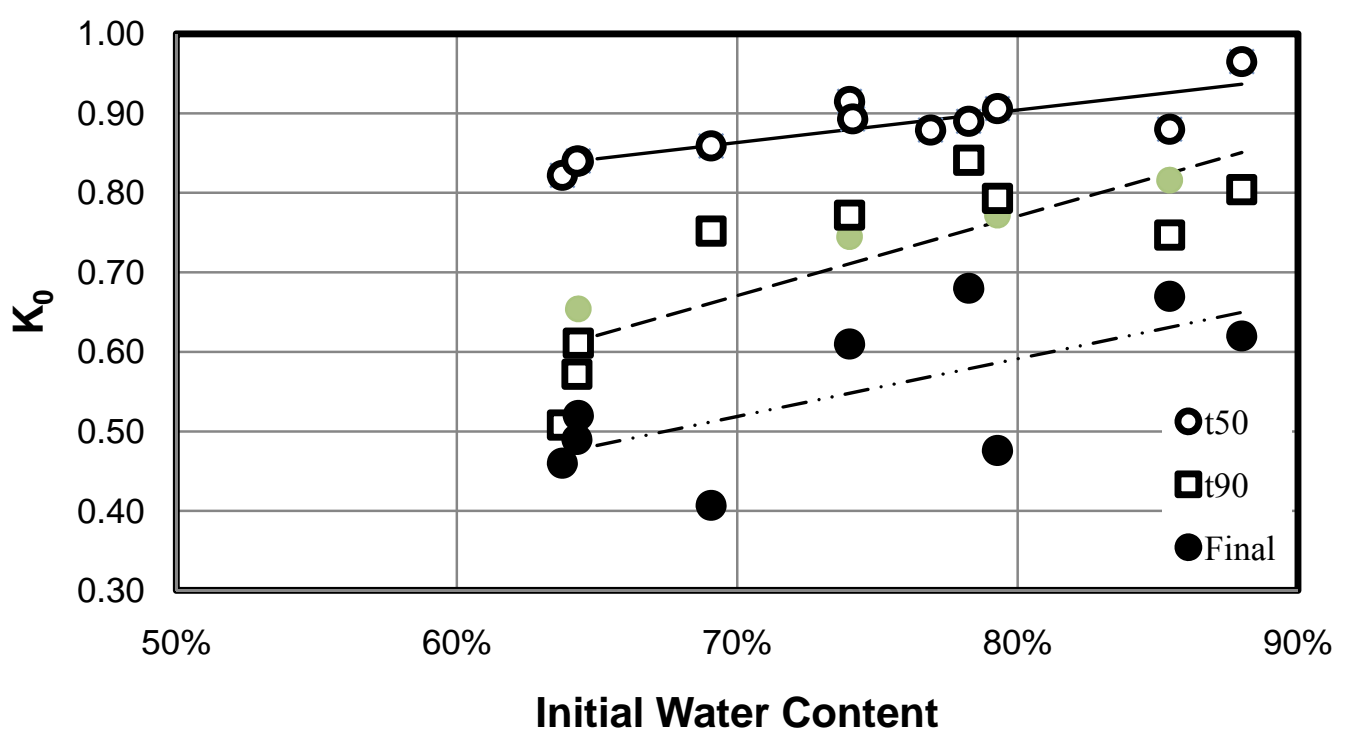

Figure $9 K_{0}$ v. Initial Water Content

$K_{0} v$. Final Water Content

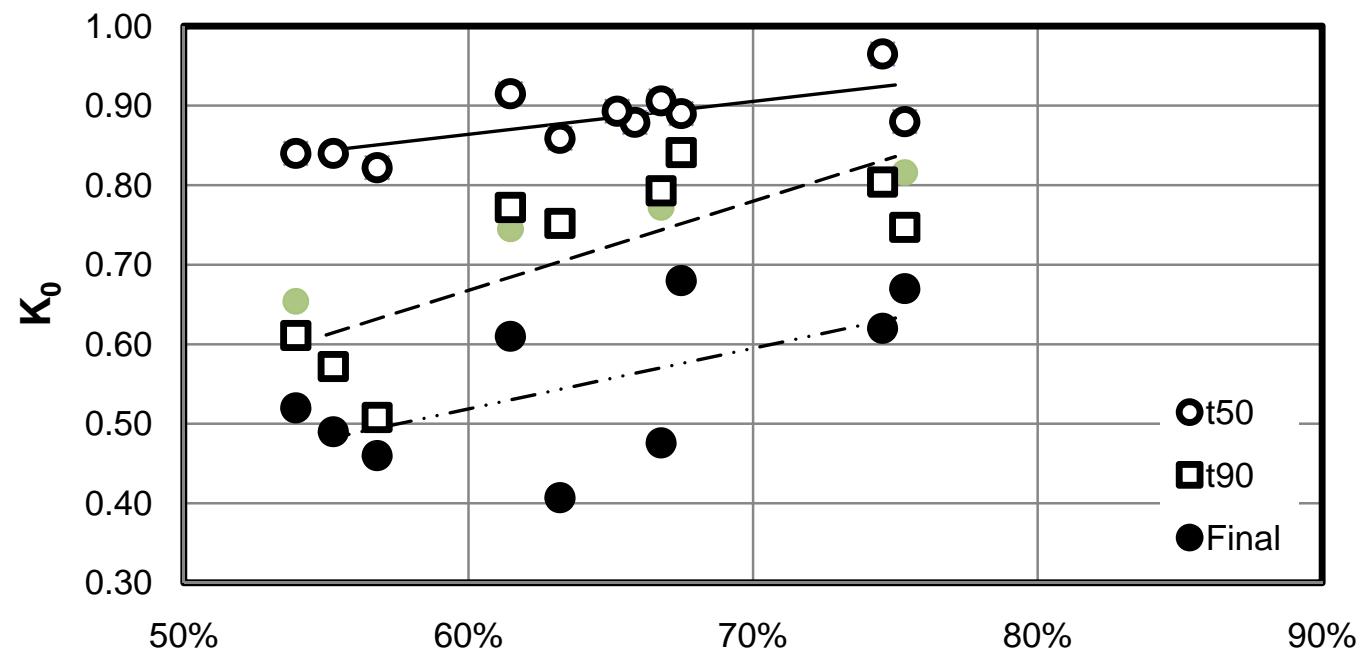

Final Water Content

Figure $10 K_{0}$ v. Final Water Content 


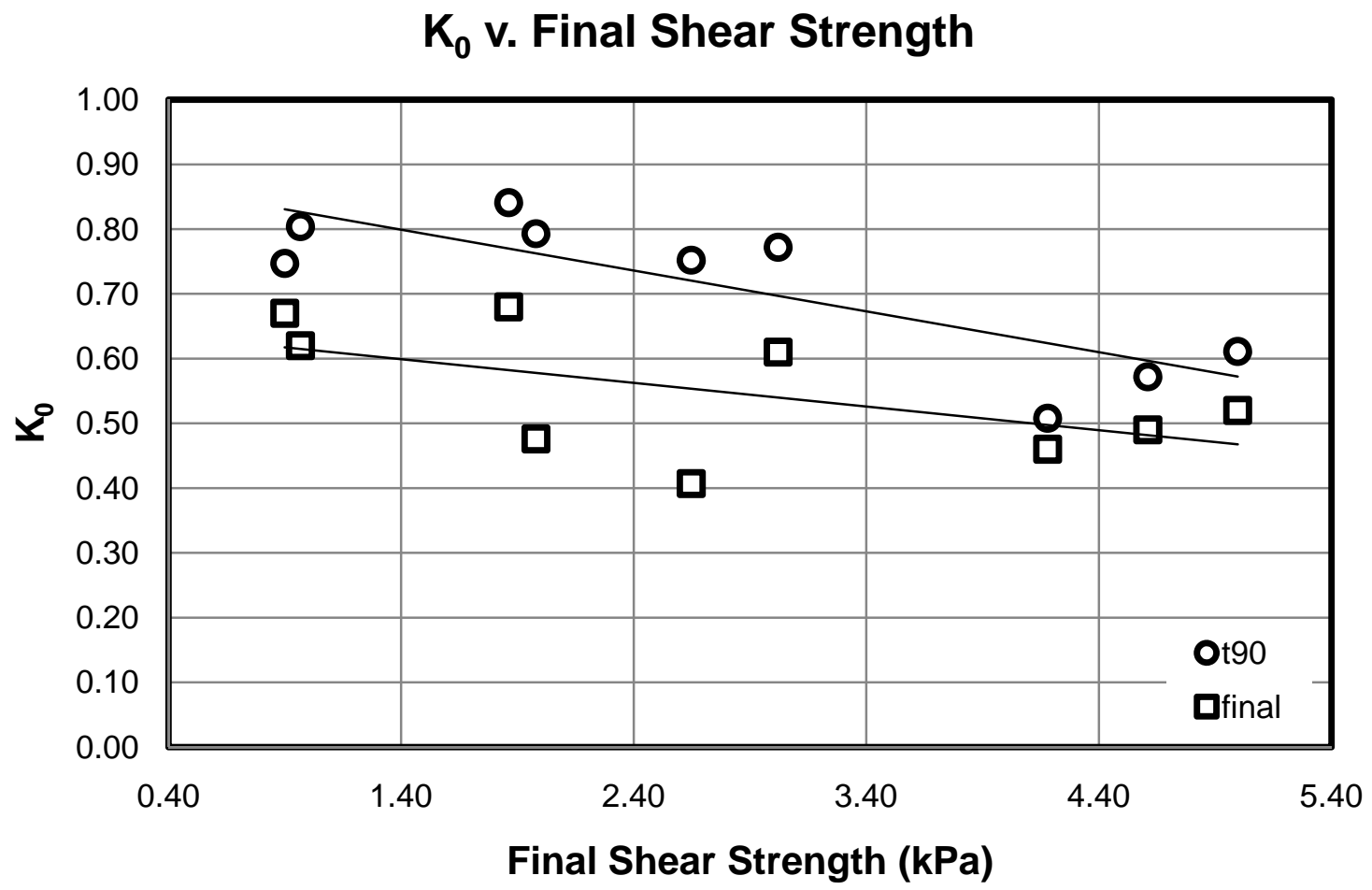

Figure $11 K_{0} v$. Final Shear Strength

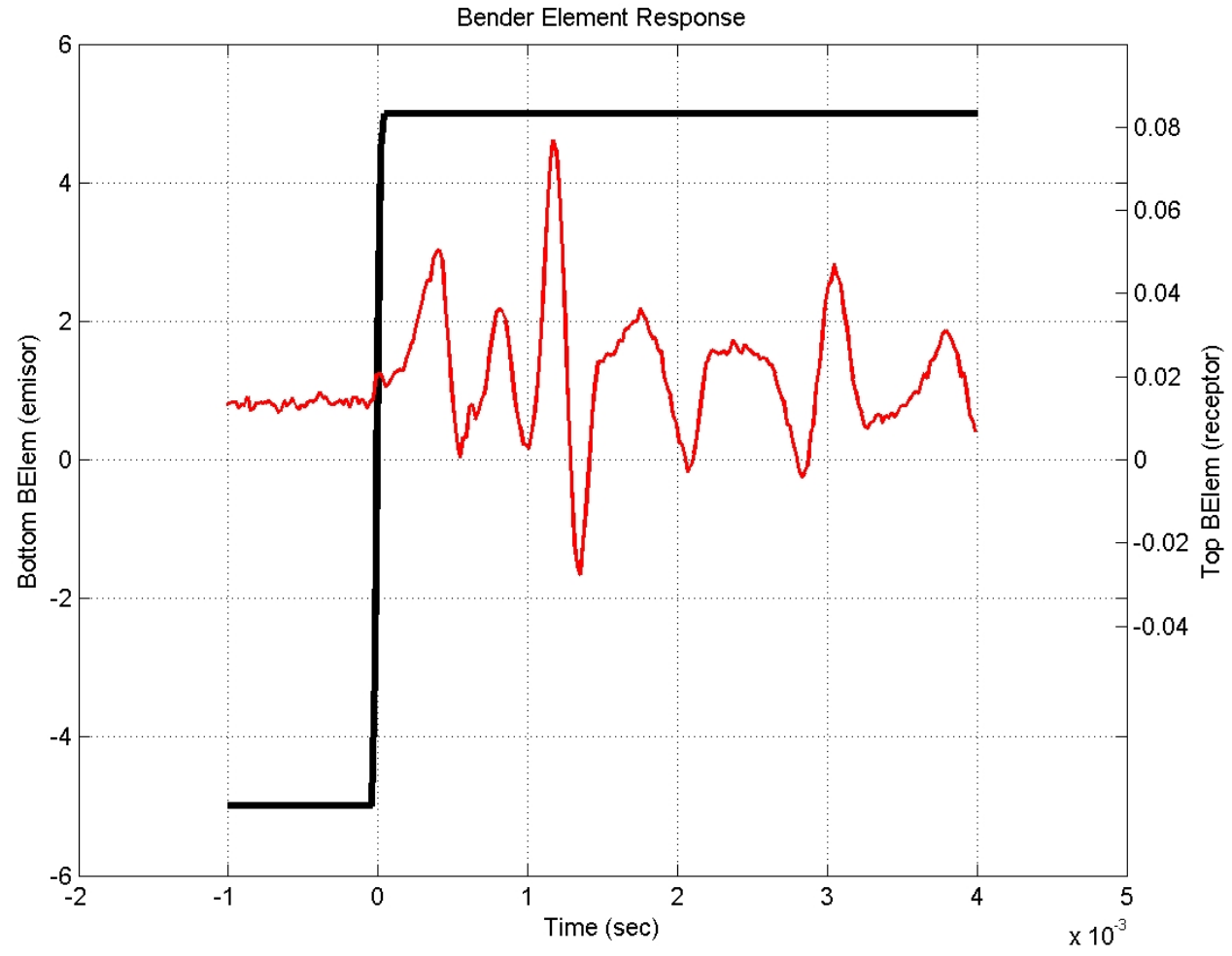

Figure 12 Bender Element plot for Test 23 


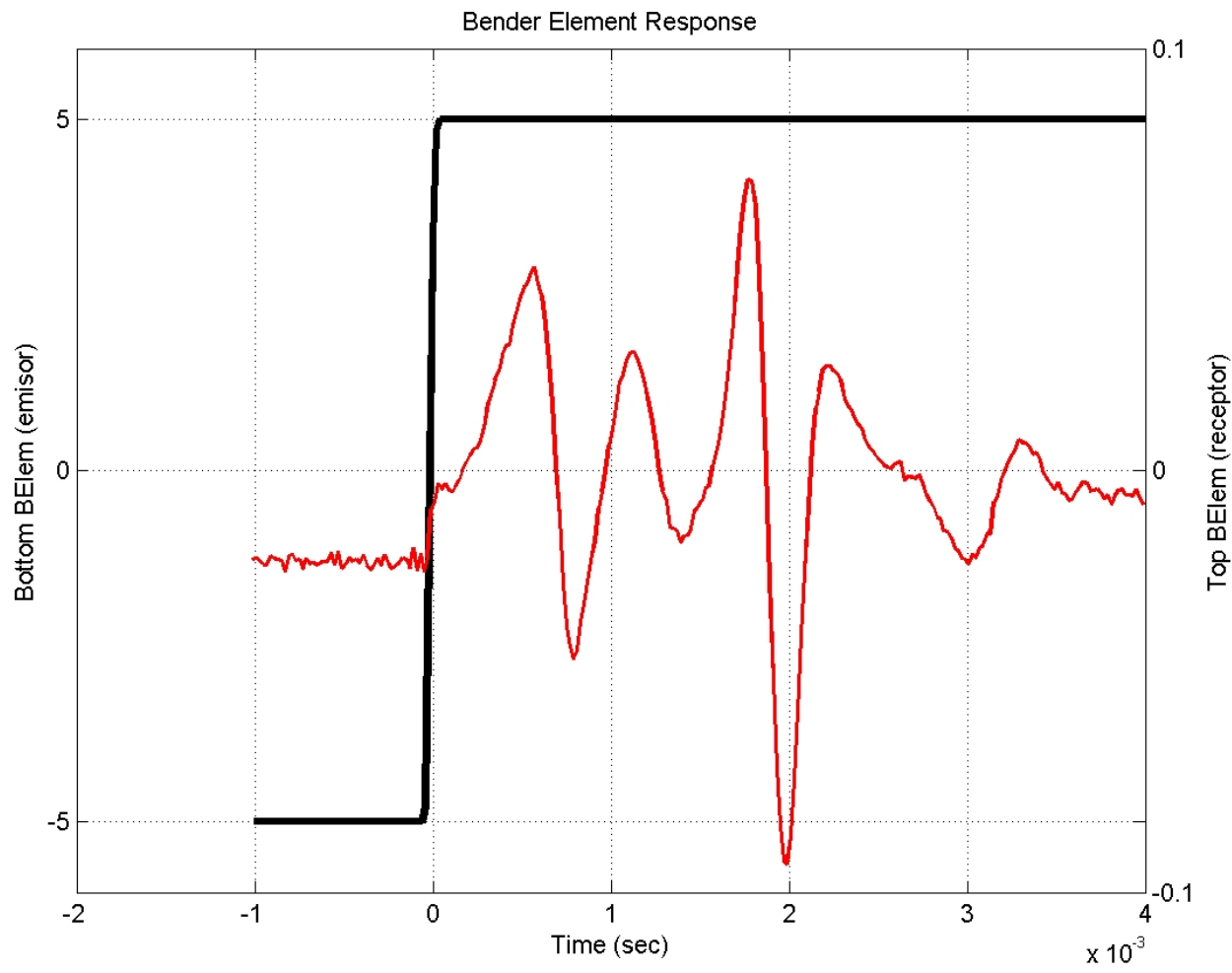

Figure 13 Bender Element plot for test 29 A

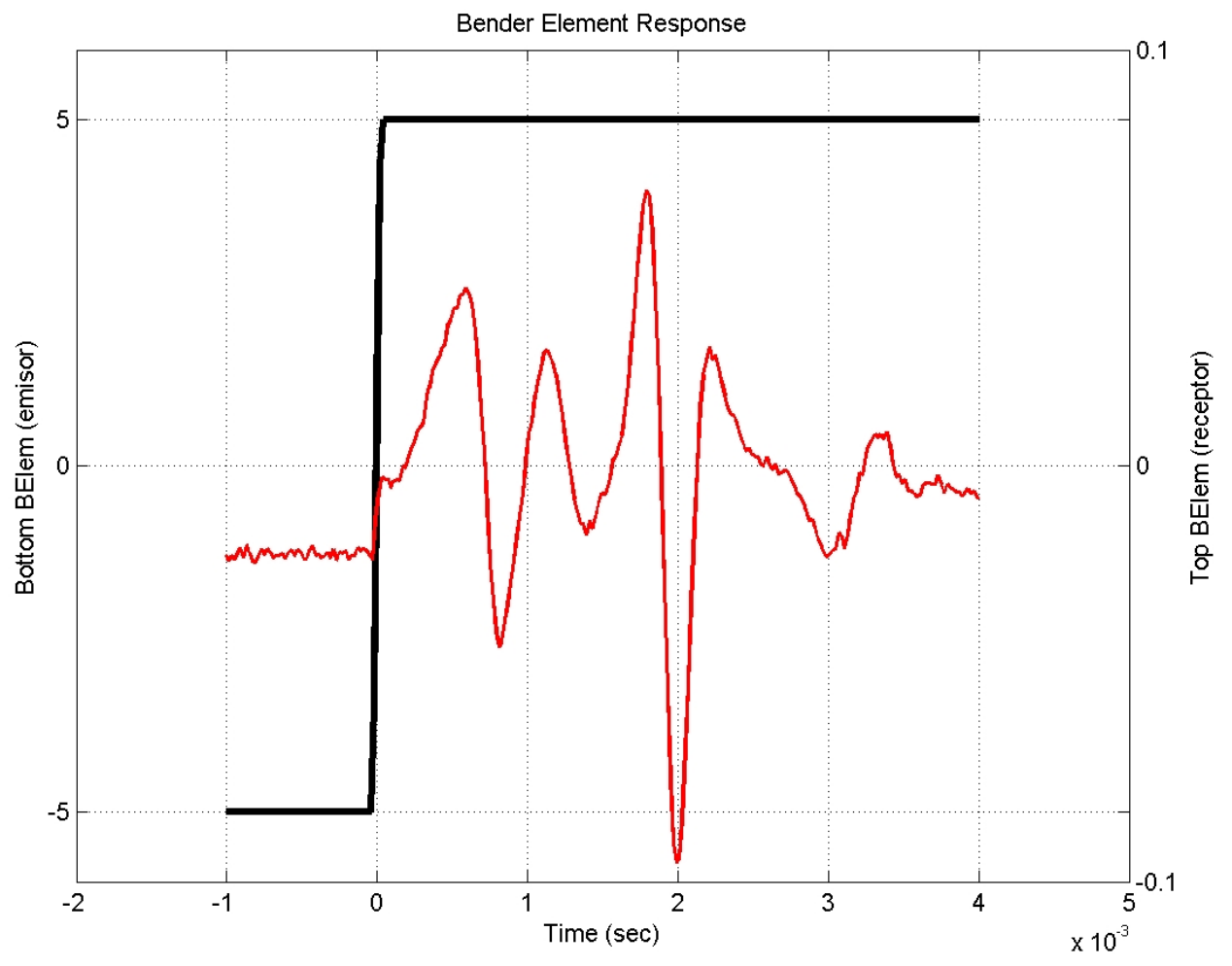

Figure 14 Bender Element plot for test 29 A 


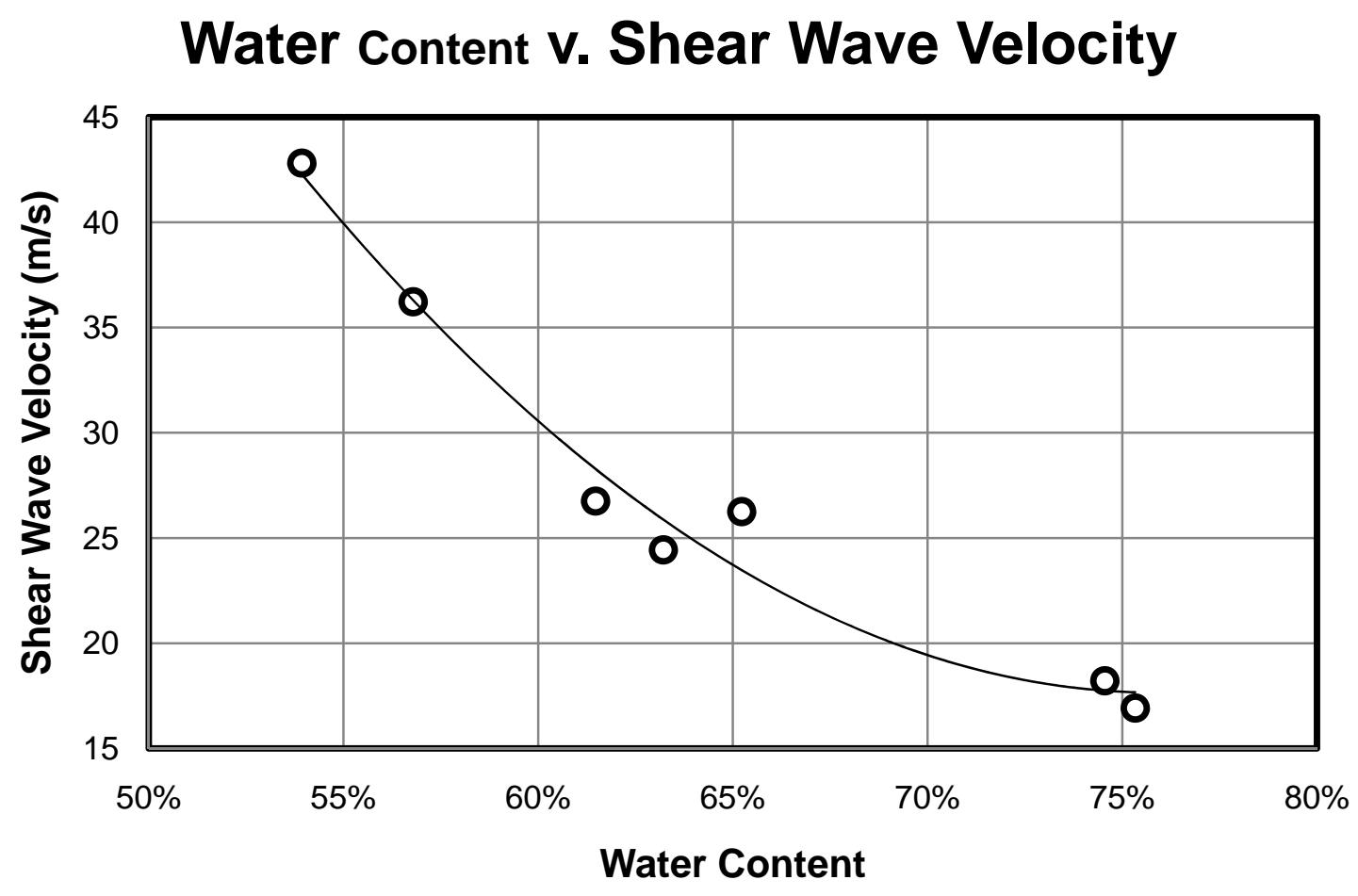

Figure 15 Water Content v. Shear Wave Velocity

Shear Strength v. Shear Wave Velocity

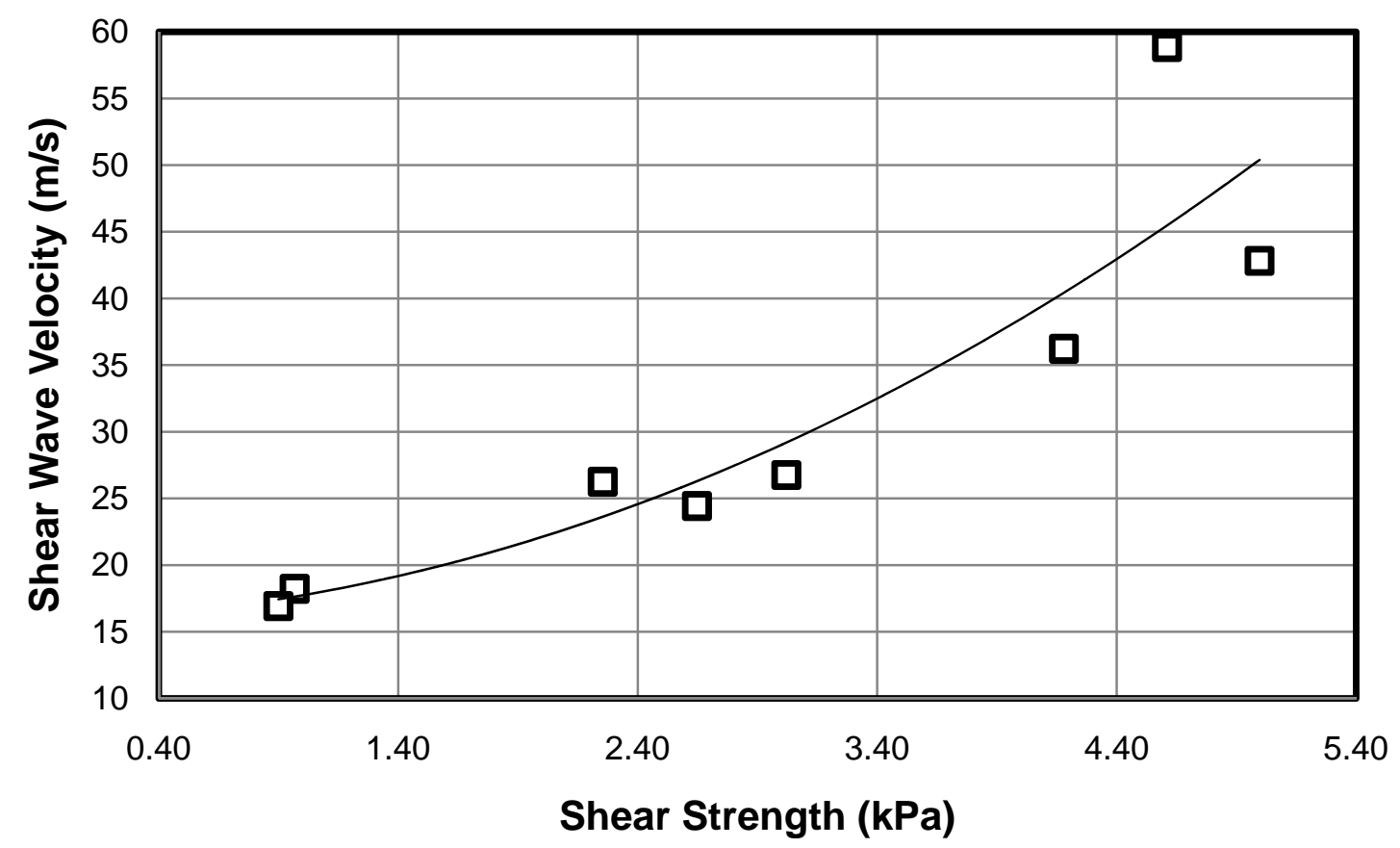

Figure 16 Shear Strength v. Shear Wave Velocity 
Test 30 \&31

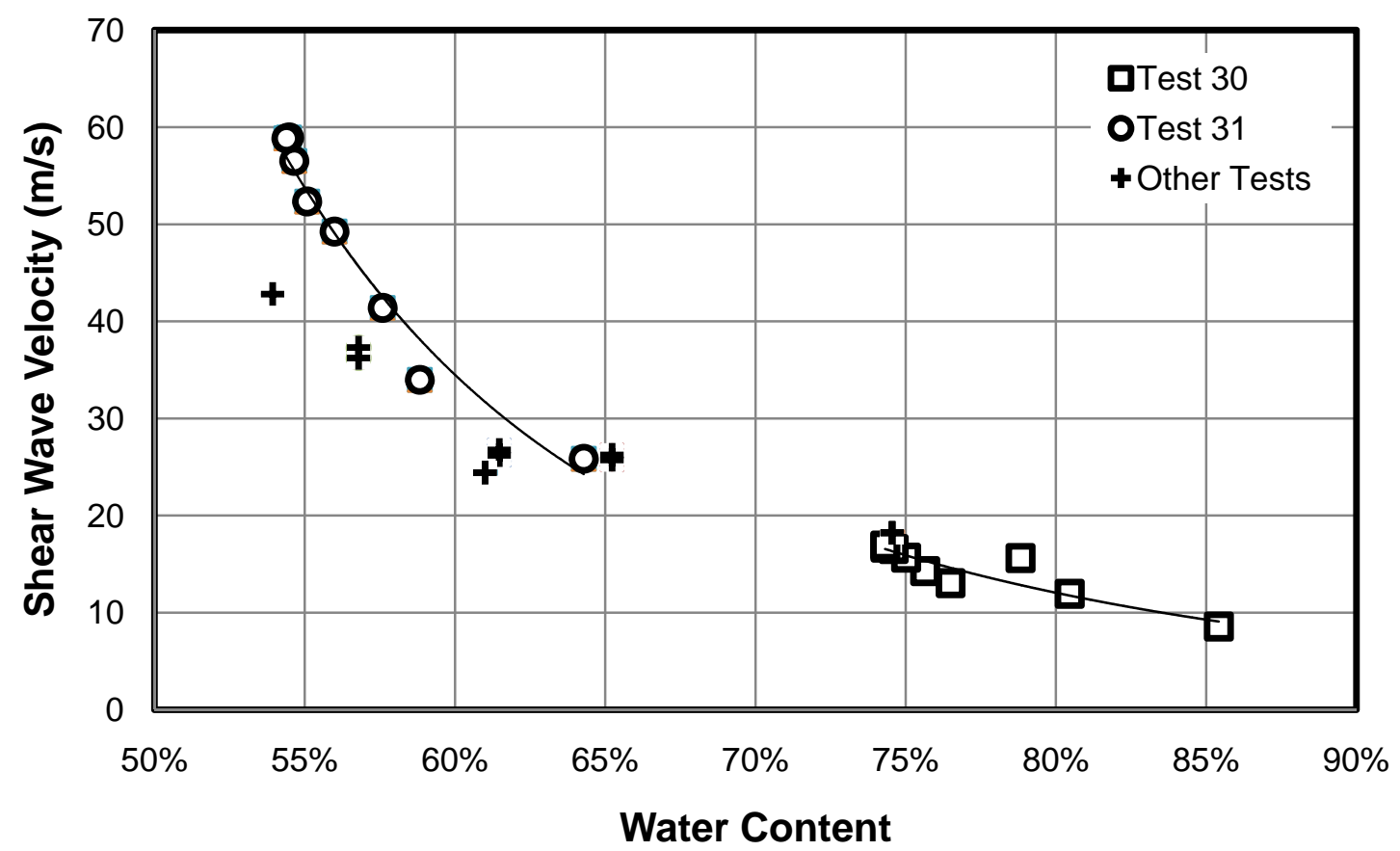

Figure 17 Water Content v. Shear Wave Velocity

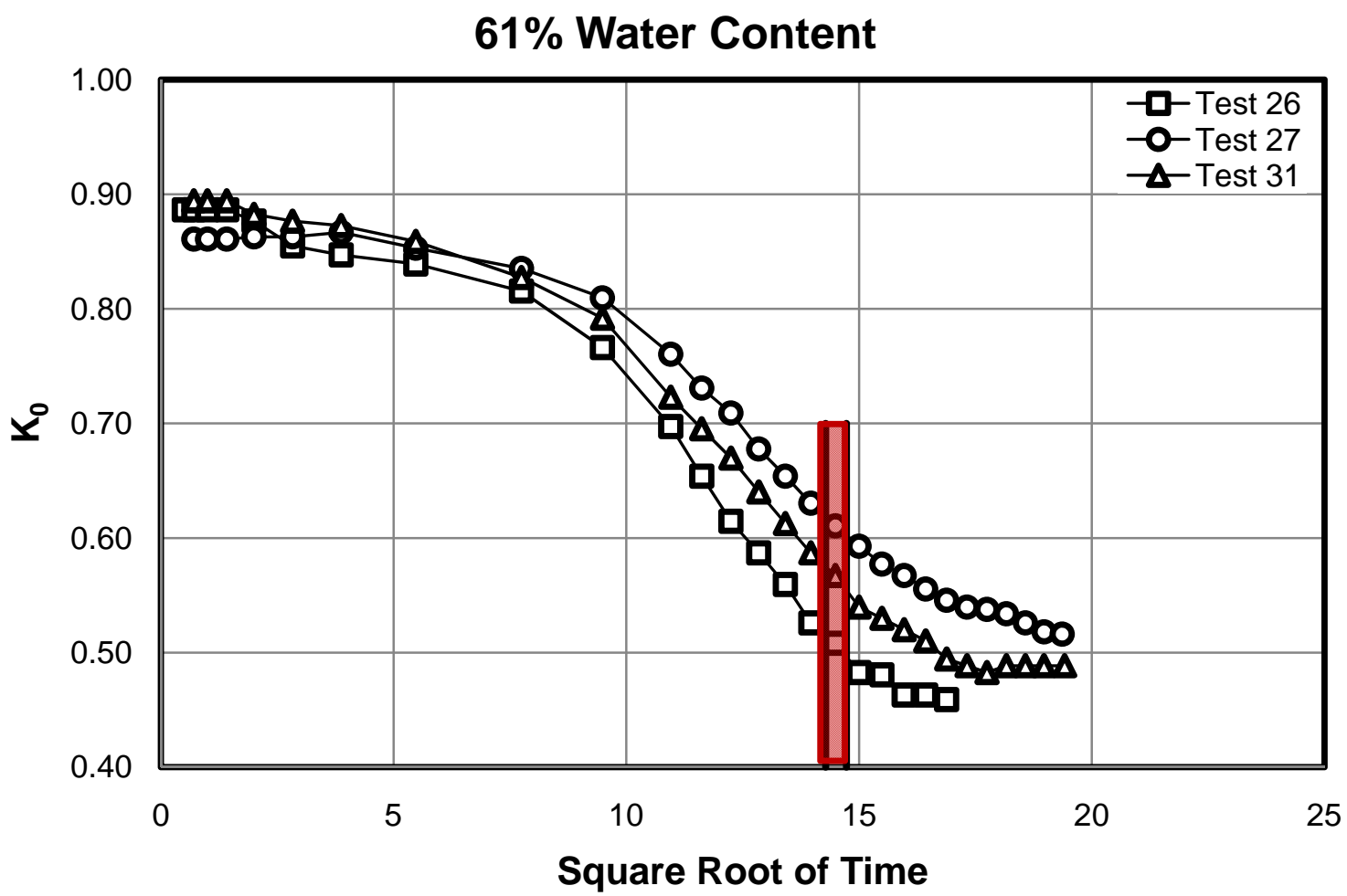

Figure 18 Square Root Time curves for $61 \%$ Water Content Samples 
Test 27

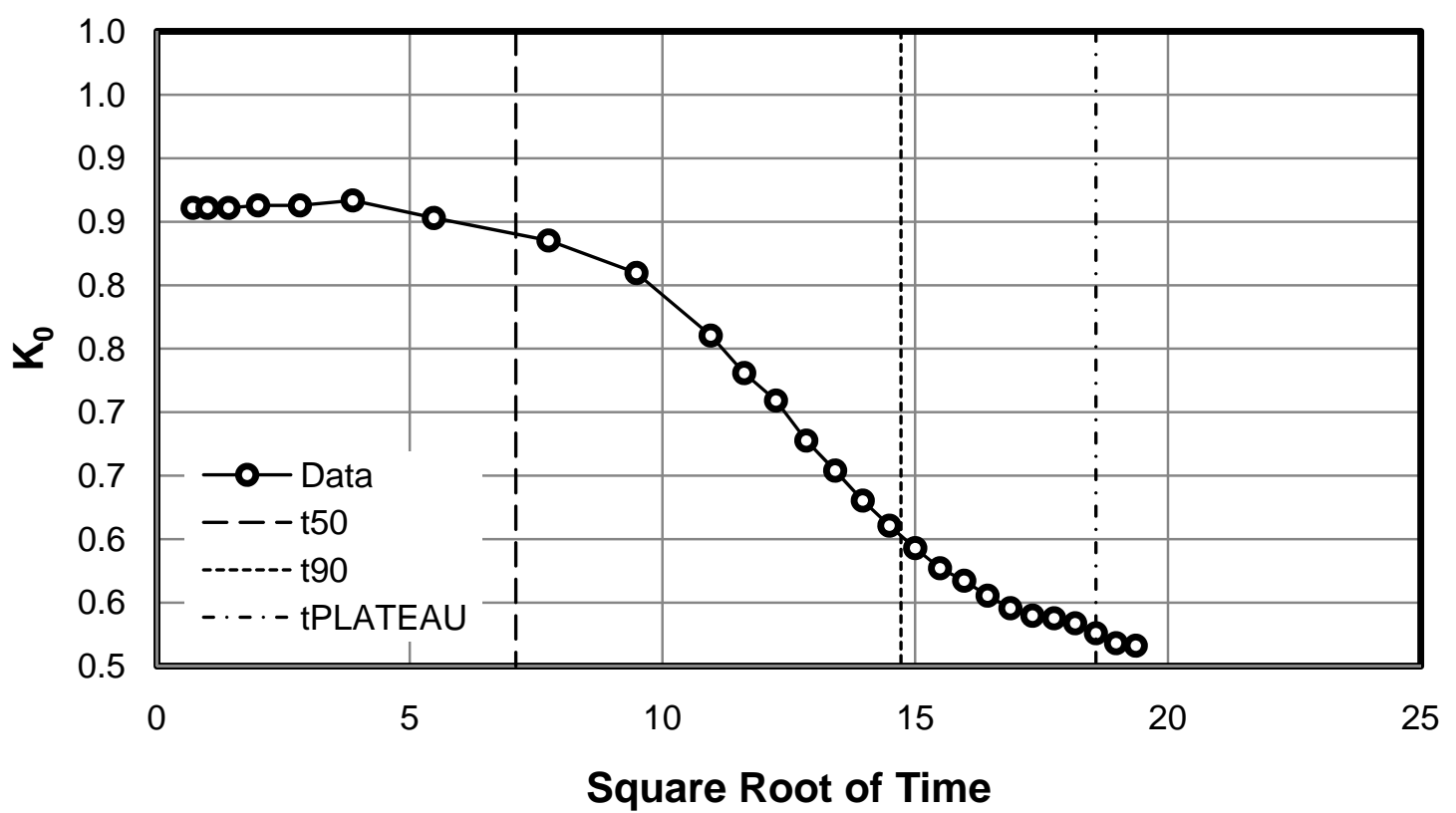

Figure 19 Example Ko v. Square Time curve for a test

Test 27

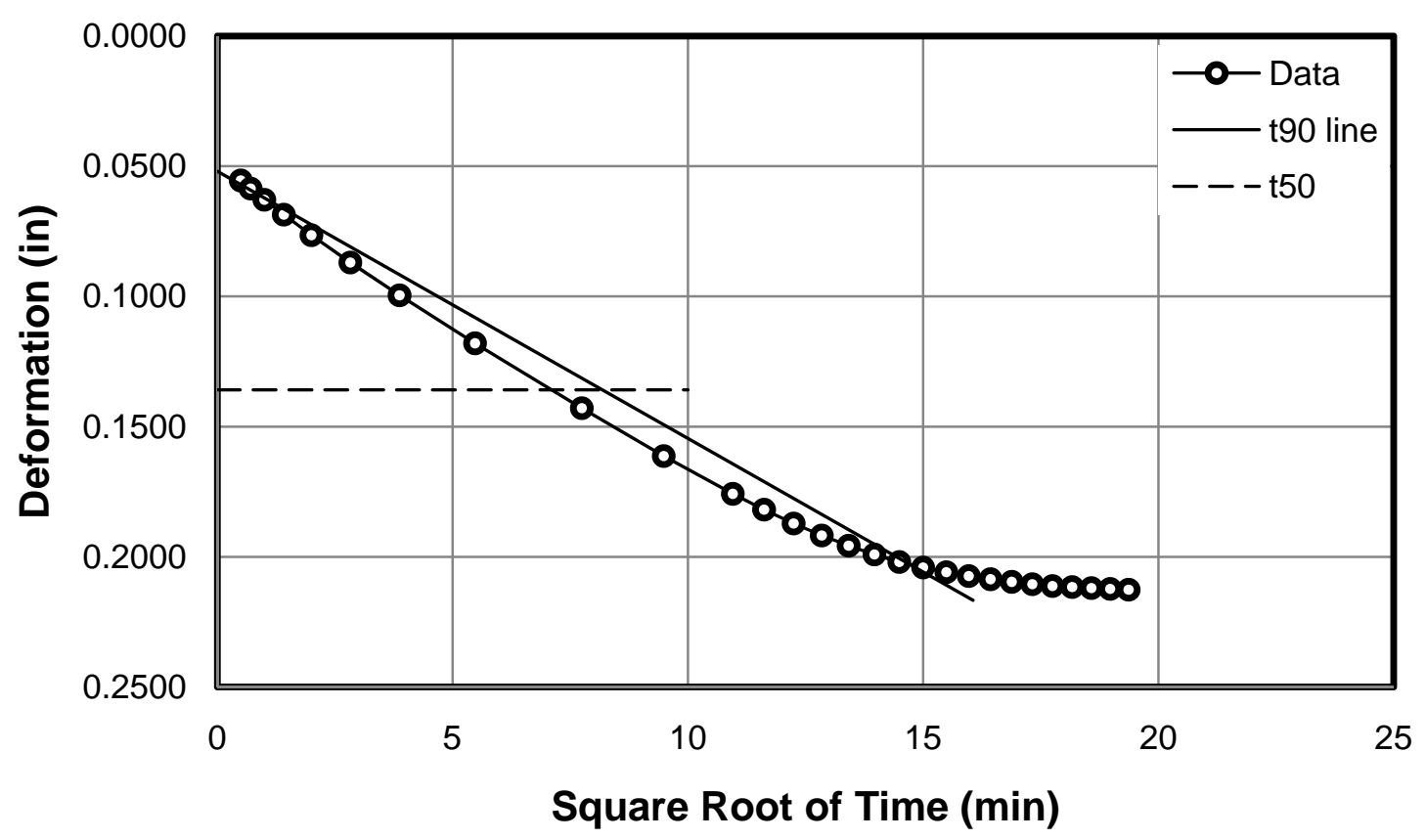

Figure 20 Square Root time curve for a test 
Test 27

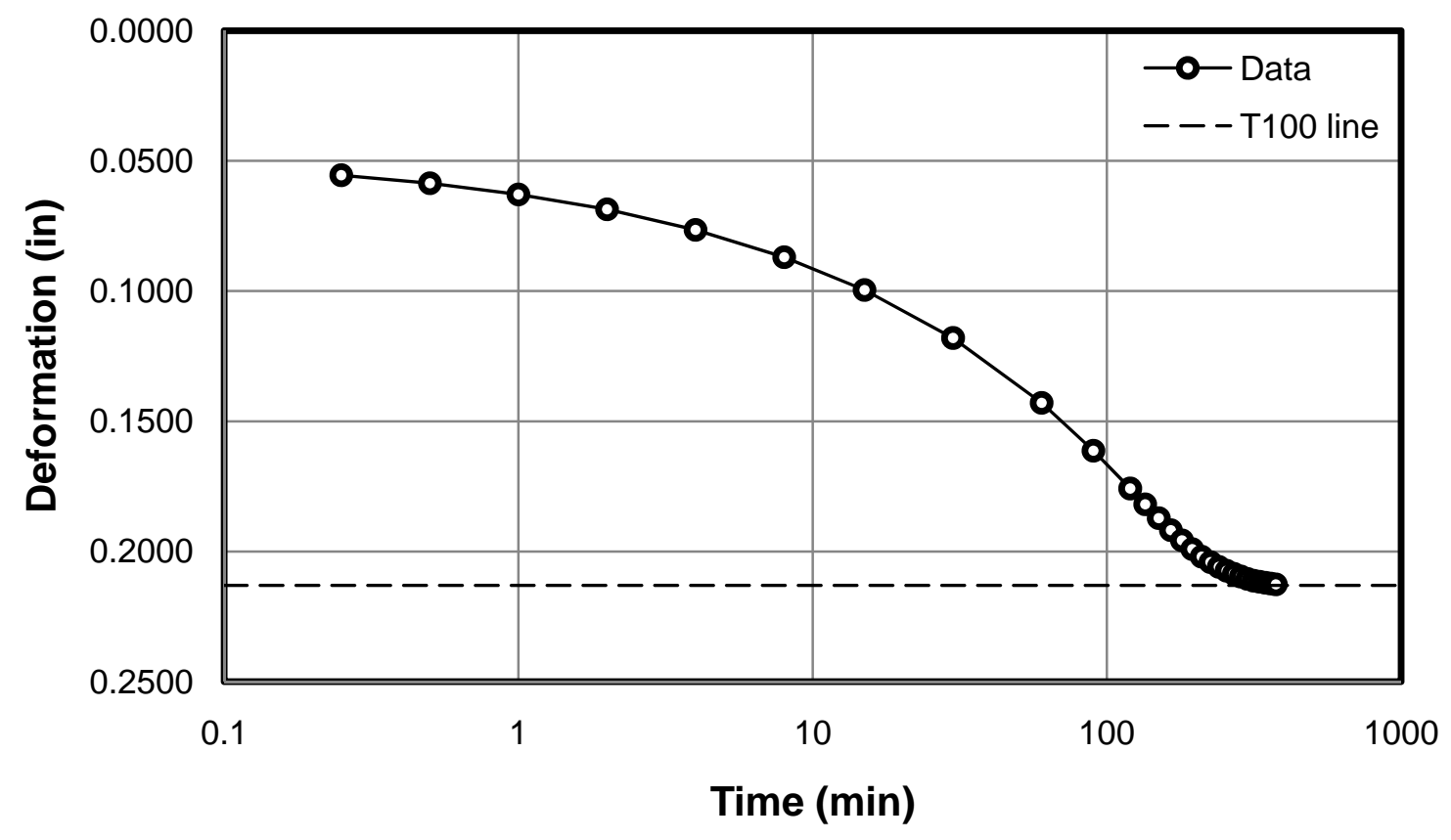

Figure 21 Time v. Deformation curve for a test 


\section{References}

Bishop, A. W. and Henkel, D. J. (1962), “The Measurement of Soil Properties in the Triaxial Test”, 2nd ed., Edward Arnold Ltd., London, 228 pp.

Burns CA, Gauglitz PA, Russell RL. (2010). Shear Strength Correlations for Kaolin/Water Slurries: A Comparison of Recent Measurements with Historical Data. PNNL-19094.

Certa PJ and MN Wells. (2009). River Protection Project System Plan. ORP-11242 Rev. 4. Office of River Protection, Richland, WA.

Duval, John I (1994), A Laboratory Investigation of Lateral Stresses During Consolidation of San Francisco Bay Mud", Master Thesis, University of Washington, 1994, pp 106.

Gauglitz PA, Buchmiller B, Jenks JJ, Chun J, Russell RLm Schmidt AJ. (2010) Preliminary Draft The disruption of vessel-spanning Bubbles with Sloped Fins in Flat=Bottom and 2:1 Ellipitcal-Bottom Vessels. PNNL-19345

Hansbo, Sven (1957), "A new approach to the determination of the shear strength of clay by the fall-cone test," Royal Swedish Geotechnical Institute Proceedings, No. 14.

Kjellman, W. (1936), "Report on an Apparatus for Consumate Investigation of the Mechanical Properties of Soils," Proceedings of the First International Conference on Soil Mechanics and Foundation Engineering, Cambridge, Vol. 1, p. 16.

Santamarina, J.C. and Lee, J. (2005). “Bender Elements: Performance and Signal Interpretation". Journal of Geotechnical and Geoenvironmental Engineering. September 2005. pp 1063-1070

van Kessel T and WGM van Kesteren. (2002). Gas Production and Transport in Artificial Sludge Depots. Waste Management 22 (2002) 19-28. 


\section{Appendix A-Test Procedure}

Due to the difference in equipment, there are some differences in the procedure that PNNL and the University of Washington used to perform these tests.

On a fresh page in the logbook, record the test number and date in the upper left hand corner. Below that write in spaces for the mass of the sample, the initial water content and the initial pressure. In the middle of the page set up columns for time, deformation and PSI readings. The time increments used depend on the water content of the sample being used.

1. Place the consolidometer ring upside down on the acrylic pillar.

2. Prepare the specimen at desired water content using de-ionized water. Place in marked plastic bag to maintain moisture level and allow to sit overnight. Also soak porous stones in de-ionized water.

3. Turn on the SCXI-1000 and allow the strain gages to warm up for at least 3 hours, preferably over night.

4. Check the balance of the strain gages.

a. Adjust voltages as necessary to move strain readings to zero.

b. Strain gages must maintain the zero level for 15 to 30 minutes to ensure they are balanced correctly.

5. Set up load frame;

a. Level loading arm and ensure it is balance under its own weight (this includes the weight of the cross bar.)

b. Remove the cross bar from the frame.

c. Place the $5 \mathrm{kPa}$ and $10 \mathrm{kPa}$ cups on the loading arm.

6. Take the specimen out of bag, remix and place back into bag.

7. Prepare filter paper by cutting 3 circles, 2 of 2.5 " diameter and 1 of 3 " diameter. Cut a slit in the center of the 3" and one of the 2.5 " diameter circles to allow them to fit over the bender elements.

8. Wet the 2.5" piece of filter paper and place inside ring on top of acrylic pillar.

9. Place pillar, ring and filter paper on scale and zero the scale.

10. Place pillar, ring and filter paper onto the vibrating table.

11. Depending on water content of the specimen start the vibrating table. If the specimen is to stiff, the vibrating table will be of little help in placing the specimen.

12. Spoon the specimen into the center of the ring. Be careful to avoid the sides as much as possible as they are delicate. Also make sure the specimen fills in all the edges of the ring, and does not leave air bubbles.

13. When the top is reached, make sure the specimen forms a small mound.

14. Using a palette knife, remove the excess specimen from the ring. Wipe the excess specimen from around the edges of the ring to ensure a clean mating between the ring and the bottom porous stone. Place remaining specimen back into bag to maintain water content.

15. Assemble the acrylic base, the locating pins and the two lower porous stones. Ensure all locating pins on both the top and bottom of the device are in place.

16. Wet the 3" diameter filter paper circle and place on top of the lower porous stones. Ensure there are no wrinkles in the paper, and that it is completely saturated.

17. Place the acrylic base over the ring and lower into place. Ensure pin alignment and wire alignment before pushing the bender element into the specimen. 
18. Holding both the acrylic base and acrylic pillar flip them over.

19. Place the acrylic base on the loading frame. Ensure the locating pins fit into their holes. Also ensure that the strain gages wires, air connection, and bender element wires all come off the front of the loading frame and that they are not pinched.

20. Carefully remove the acrylic pillar from the ring.

21. Using a utility knife blade, carefully remove the filter paper from the top of the specimen.

22. Carefully attach the upright air tube to the ring and tighten gently with a wrench.

23. Assemble the upper platen and the upper porous stone.

24. Place the 2.5" diameter disk of filter paper with the silt in it onto the porous stone and wet down with de-ionized water.

25. Align the marks on the upper platen and the consolidometer ring to ensure bender element alignment.

26. Place upper platen with stone into the alignment ring.

27. Then carefully place the upper platen and alignment ring onto the specimen. The upper platen should be able to fit within the ring and should only be slightly visible in and edge on view.

28. Carefully fill the acrylic base with de-ionized water. The level of water should not be higher than the threads on the strain gage wiring tube.

29. Carefully will the alignment ring and the holes in the upper platen with de-ionized water.

30. Place the crossbar onto the loading frame. Ensure that it is level and that the loading screw does not come close to the upper platen.

31. Lock down the cross bar using the threaded knobs provided.

32. Slowly lower the loading screw until it is just above the seating cup.

33. Adjust the left to right alignment of the loading screw by moving the loading arm. Align it as best as possible with the loading cup.

34. Lower the loading screw until it does not turn with light pressure, then lock it into place using the locking ring.

35. Loosen the threaded knob that hold the dial indicator, and move the dial indicator in position.

36. Carefully attach the air supply hose to the upright air tube. Tighten gently with a wrench.

37. Turn on and zero the pressure transducer.

38. Turn on and zero the dial indicator.

39. Let device stand for 30min to 1 hour to ensure the strain gages have reached a constant level.

40. At this time apply pressure to bring the average strain gage line so that it is at the same level as the zero line.

41. Weigh a pan and also weigh the pan plus an amount of specimen from that remaining to obtain the initial water content of the specimen. Place the pan in an oven at $110^{\circ}$ for 24 hours. Reseal the remaining specimen in the bag.

42. Adjust pressure as necessary over the next $30 \mathrm{~min}$ to 1 hour to maintain this level.

43. Make sure the file name is correct for the test that will be recorded, and press the record button on the LabView program.

44. With the stop watch in hand, start the stop watch at the same time the leveling screw is lowered away from the loading arm.

45. Record the deformations and psi at the indicated times, and adjust pressure to maintain level.

46. Plot the $t_{90}$ curve using the appropriate spreadsheet as time allows. This will also plot $\mathrm{K}_{0}$ as well from the applied pressure and load. 
47. Continue readings for 1 to 2 hours past $t_{90}$.

48. Stop the LabView program for the strain gages, and turn on the signal generator, oscilloscope and power supply. Ensure that the signal generator is set up to send a $1 \mathrm{~Hz}$ square wave.

49. Listen next to the acrylic base to hear the click of the bender element and make sure it is working.

50. Check the name of the file for the bender element to record to, and start the bender element program. Note the deformation at which this occurs.

51. After the bender element program has finished, turn the strain gage program back on, and set the pressure to zero, and allow it to be registered by the program.

52. Turn the strain gage program off.

53. Disassemble the device carefully; make sure to drain the water before removing the upper platen.

54. Place the ring onto a specimen bowl and slowly push the upper platen through the ring to place the specimen into the bowl.

55. Weigh a pan and also weigh the pan plus an amount of specimen from that remaining to obtain the final water content of the specimen. Place the pan in an oven at $110^{\circ}$ for 24 hours.

56. Seal remaining specimen in bowl into a plastic bag to maintain water content.

57. Finish disassembling the device, and clean all the part. Place the stone back into a bath of deionized water, and place the ring upside down on the acrylic pillar. 
Appendix D

\section{Chemical Simulant Test Data}





\section{Appendix D: Chemical Simulant Test Data}

Table D.1 provides chemical simulant test details. In Figure D.2, the simulant shear strength as a function of the mass fraction of UDS at both the initial and the end of primary consolidation samples (data from Table D.1) is presented. Power-law functionality is shown. There is no indication that the shear strength of the simulants is affected by the consolidation condition. That is, the shear strength is a function of the mass fraction of UDS independent of consolidation. The large difference in the shear strength-mass fraciton of UDS relation for Simulant 1 between Figure D.2 and the data of Wells et al. (2010) is not understood.

The displacement data and shear vane results are provided in the respective figures. 
Table D.1. Chemical Simulant Test Data

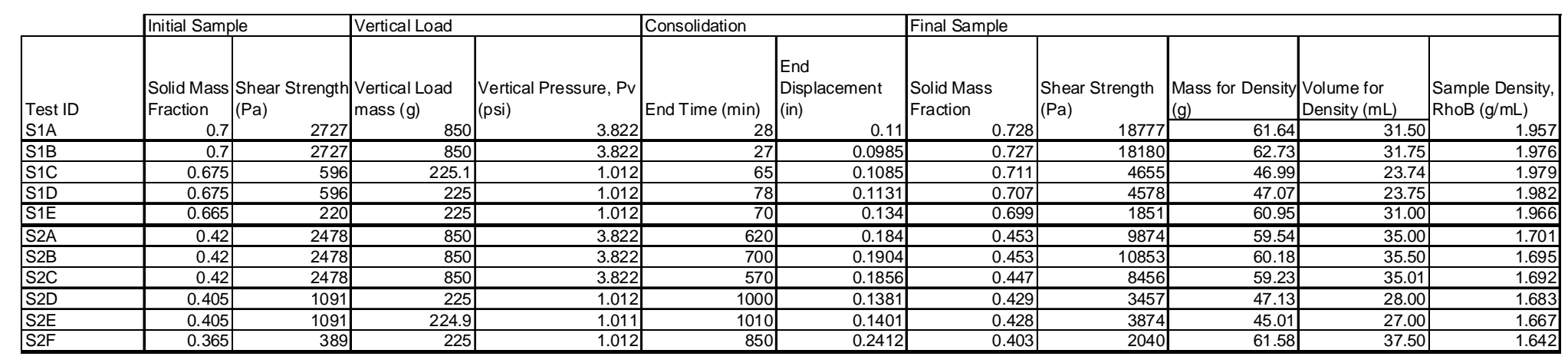

\begin{tabular}{|c|c|c|c|c|c|c|c|c|c|c|c|}
\hline Test ID & \begin{tabular}{|l} 
Horizontal \\
Pressure (psi)
\end{tabular} & k0 & $\begin{array}{l}\text { Time of Flight, ToF } \\
(\mathrm{msec})\end{array}$ & msec/div & $\mathrm{L}(\mathrm{mm})$ & \begin{tabular}{|l|} 
Shear \\
Wave \\
Velocity, \\
Vs (m/s)
\end{tabular} & Gmax (kPa) & \begin{tabular}{|l|} 
Gmax \\
Alderman \\
et al. $(\mathrm{kPa})$
\end{tabular} & Plasticity Index & $\begin{array}{l}\text { Shear } \\
\text { Strength (kPa) }\end{array}$ & $\begin{array}{l}\text { Displ. } \\
\text { Fraction } \\
\end{array}$ \\
\hline S1A & {$\left[\begin{array}{r}1.342 \\
\end{array}\right.$} & 0.35 & 0.32 & \begin{tabular}{|r|}
0.2 \\
\end{tabular} & 34.72 & 109 & 23041 & $\begin{array}{r}63 \\
\end{array}$ & & 18.777 & 0.06 \\
\hline S1B & 1.498 & 0.39 & 0.32 & 0.2 & 35.01 & 109 & 23657 & 59 & & 18.18 & 0.05 \\
\hline S1C & 0.441 & 0.44 & 0.8 & 0.2 & 34.76 & 43 & 3736 & 13 & & 4.655 & 0.06 \\
\hline S1D & 0.524 & 0.52 & 0.88 & 0.2 & 34.64 & 39 & 3072 & 10 & & 4.578 & 0.06 \\
\hline S1E & 0.473 & 0.47 & 0.94 & 0.2 & 34.11 & 36 & 2589 & 8 & & 1.851 & 0.07 \\
\hline $\mathrm{S} 2 \mathrm{~A}$ & 0.954 & 0.25 & 0.875 & 0.5 & 32.84 & 38 & 2396 & 31 & & 9.874 & 0.10 \\
\hline S2B & 1.778 & 0.47 & 0.8 & 0.5 & 32.68 & 41 & 2828 & 33 & & 10.853 & 0.10 \\
\hline $\mathrm{S} 2 \mathrm{C}$ & 1.396 & 0.37 & 0.85 & 0.5 & 32.80 & 39 & 2520 & 27 & & 8.456 & 0.10 \\
\hline S2D & 0.477 & 0.47 & 1.45 & 0.5 & 34.01 & 23 & 926 & 8 & & 3.457 & 0.07 \\
\hline S2E & 0.425 & 0.42 & 1.425 & 0.5 & 33.96 & 24 & 947 & 12 & & 3.874 & 0.07 \\
\hline S2F & 0.449 & 0.44 & 1.45 & 0.5 & 31.39 & 22 & 769 & 7 & & 2.04 & 0.12 \\
\hline
\end{tabular}

\begin{tabular}{|c|c|c|c|c|c|c|c|c|c|}
\hline & Uncertainty $(\mathrm{u})$ in $\mathrm{C}$ & Gmax & & & & Uncertainty $(\mathrm{u})$ in & & & \\
\hline Test ID & uL (m) & UToF (msec) & uVs (m/s) & u RhoB (g/mL) & uGmax (kPa) & uPv (psi) & luk0 & uKO, delta SG & $\begin{array}{l}\text { Gmax } \\
\text { (Measured)/G } \\
\text { max } \\
\text { (Alderman) }\end{array}$ \\
\hline $\mathrm{S} 1 \mathrm{~A}$ & $5.60817 \mathrm{E}-05$ & 0.02 & 6.78 & $\begin{array}{r}0.08 \\
\end{array}$ & $\begin{array}{r}2881 \\
\end{array}$ & $\begin{array}{r}0.000237 \\
\end{array}$ & \begin{tabular}{|l|}
0.000132626 \\
\end{tabular} & $\begin{array}{r}0.013 \\
\end{array}$ & 368 \\
\hline S1B & $5.60817 \mathrm{E}-05$ & 0.02 & 6.84 & 0.08 & 2958 & 0.000237 & 0.000133065 & 0.013 & 400 \\
\hline S1C & $5.60817 \mathrm{E}-05$ & 0.02 & 1.09 & 0.10 & 187 & 0.000063 & 0.000494747 & 0.049 & 278 \\
\hline S1D & 5.60817E-05 & 0.02 & 0.90 & 0.10 & 140 & 0.000063 & 0.000495271 & 0.049 & 304 \\
\hline S1E & $5.60817 \mathrm{E}-05$ & 0.02 & 0.77 & 0.08 & 111 & 0.000063 & 0.000495078 & 0.049 & 339 \\
\hline $\mathrm{S} 2 \mathrm{~A}$ & $5.60817 \mathrm{E}-05$ & 0.05 & 2.15 & 0.06 & 274 & 0.000237 & 0.000131738 & 0.013 & 77 \\
\hline S2B & 5.60817E-05 & 0.05 & 2.55 & 0.06 & 354 & 0.000237 & 0.00013397 & 0.013 & 85 \\
\hline $\mathrm{S} 2 \mathrm{C}$ & $5.60817 \mathrm{E}-05$ & 0.05 & 2.27 & 0.06 & 297 & 0.000237 & 0.000132772 & 0.013 & 93 \\
\hline S2D & 5.60817E-05 & 0.05 & 0.81 & 0.08 & 64 & 0.000063 & 0.000495092 & 0.049 & 119 \\
\hline S2E & $5.60817 \mathrm{E}-05$ & 0.05 & 0.84 & 0.08 & 67 & 0.000063 & 0.000495134 & 0.049 & 78 \\
\hline S2F & 5.60817E-05 & 0.05 & 0.75 & 0.05 & 53 & 0.000063 & 0.000494994 & 0.049 & 107 \\
\hline
\end{tabular}




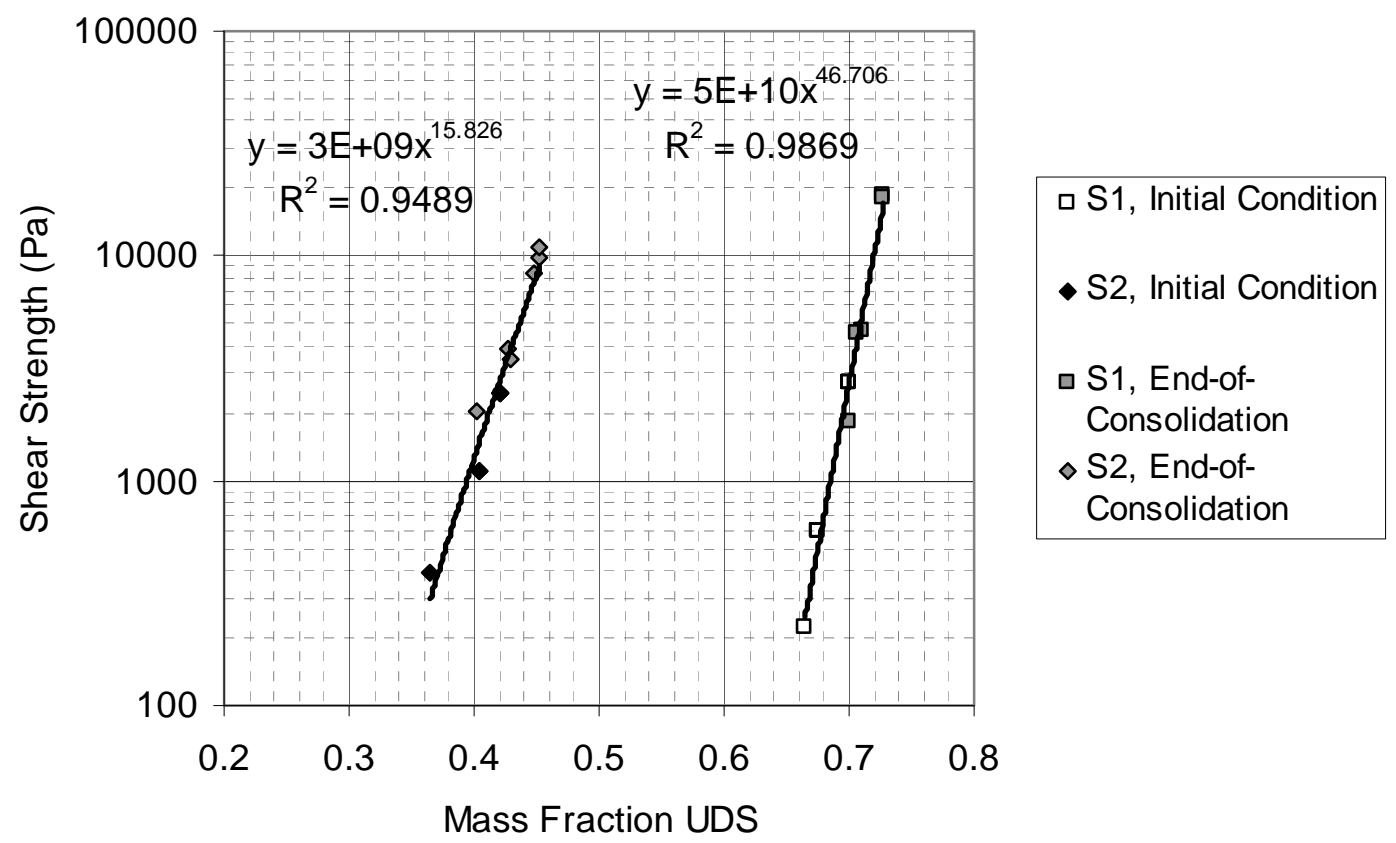

Figure D.1. Chemical Simulant Shear Strength as a Function of the Mass Fraction UDS

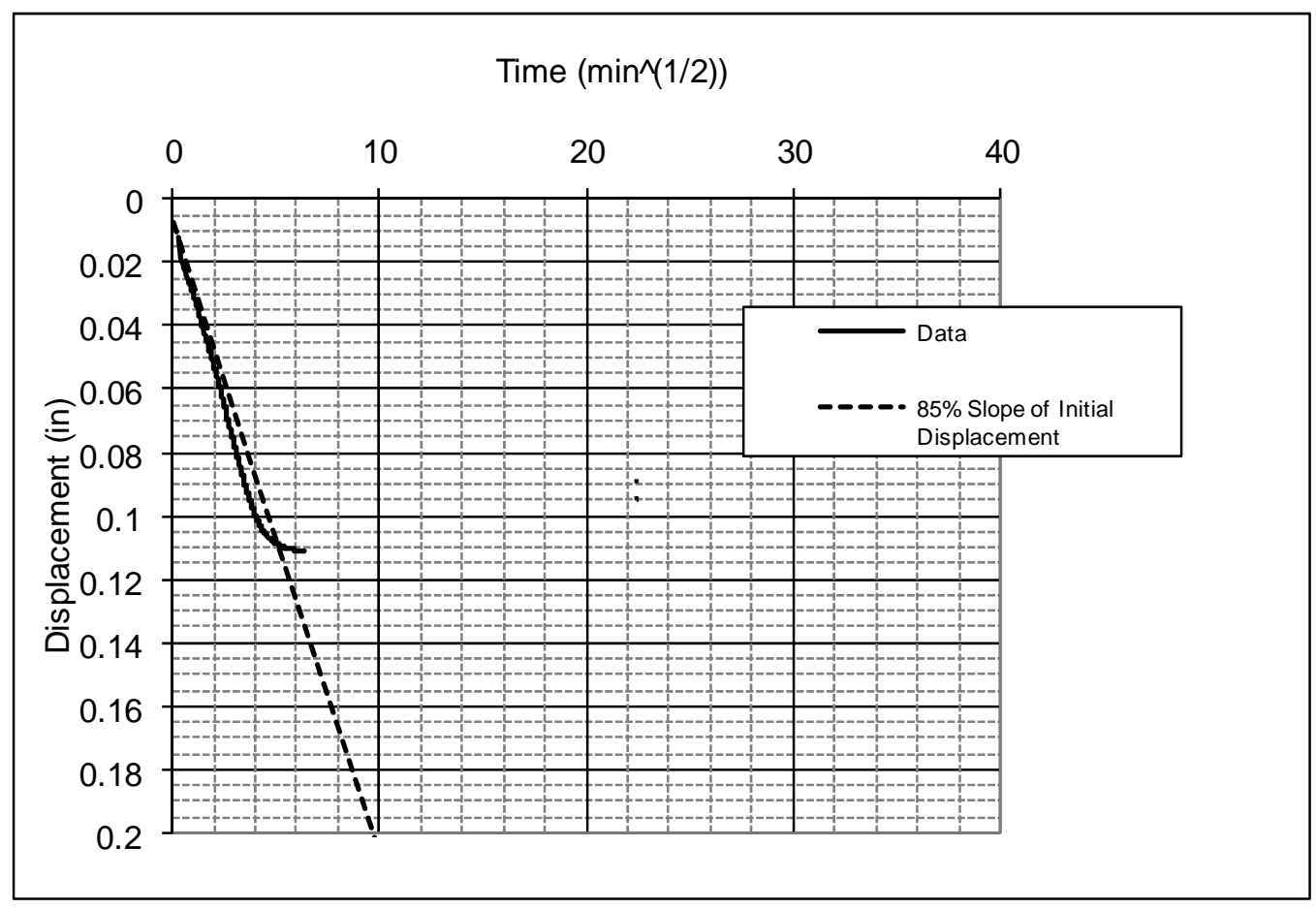

Figure D.2. Simulant 1 (70 wt \%) 100914-ro Displacement Versus Time ${ }^{1 / 2}$ (ASTM Standard D $2435-04,12.3 .2$ ) 


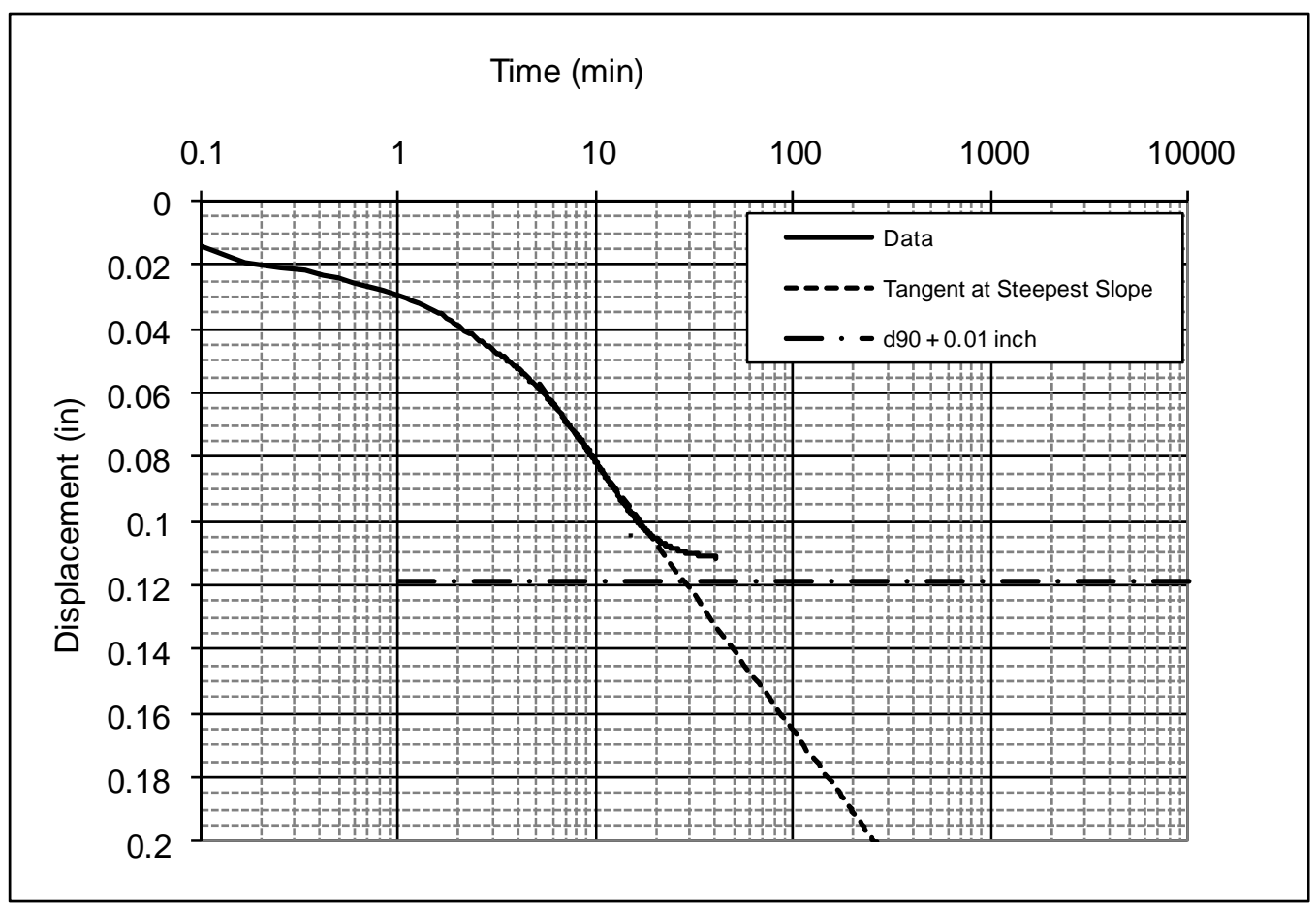

Figure D.3. Simulant 1 (70 wt\%) 100914-ro Displacement Versus Time ${ }^{1 / 2}$ (ASTM Standard D 2435 - 04, 12.3.1)

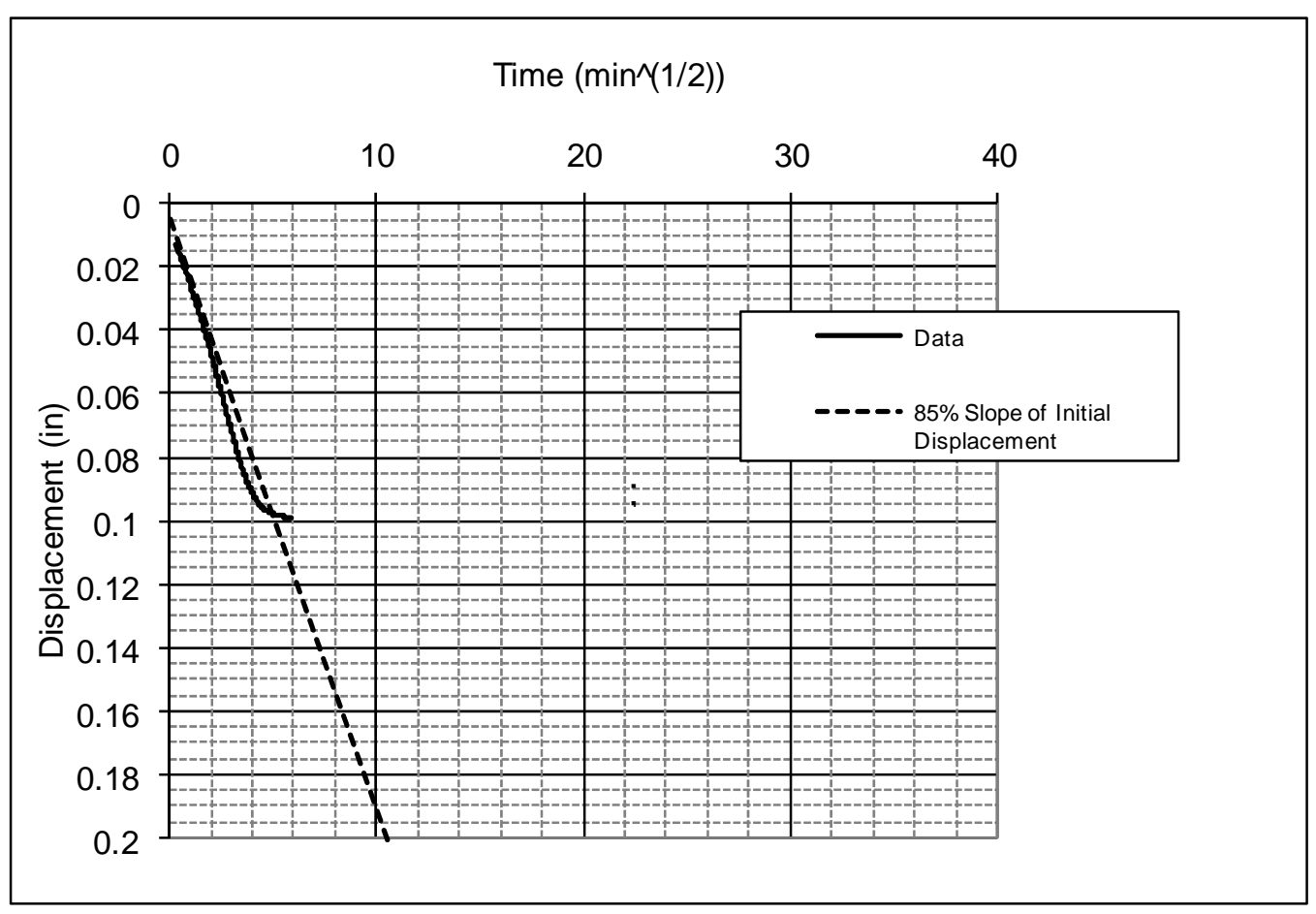

Figure D.4. Simulant 1 (70 wt\%) 100914-r1 Displacement Versus Time ${ }^{1 / 2}$ (ASTM Standard D 2435 - 04, 12.3.2) 


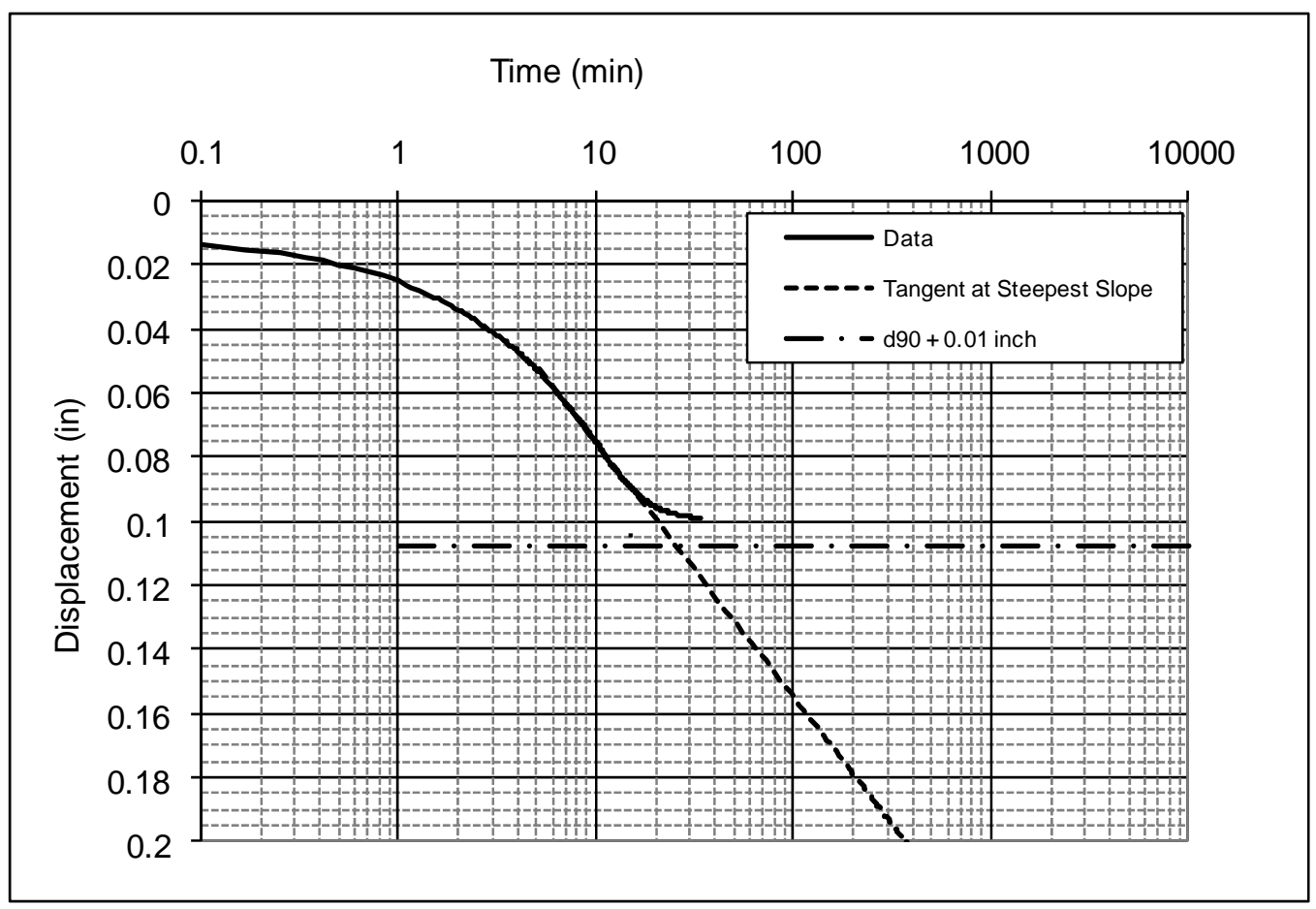

Figure D.5. Simulant 1 (70 wt\%) 100914-r1 Displacement Versus Time ${ }^{1 / 2}$ (ASTM Standard D 2435 - 04, 12.3.1)

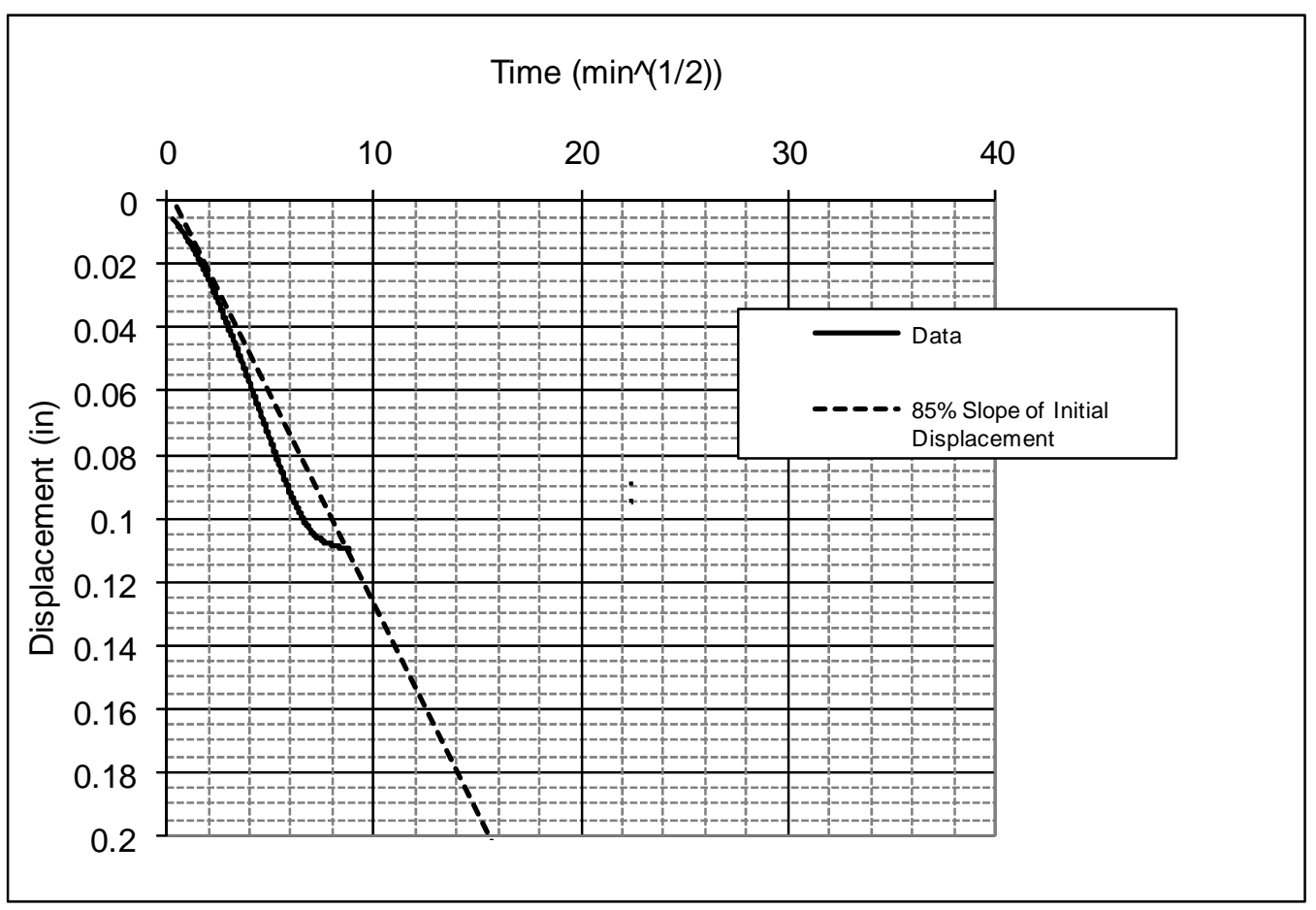

Figure D.6. Simulant 1 (67.5 wt\%) 100917 Displacement Versus Time ${ }^{1 / 2}$ (ASTM Standard D $2435-04,12.3 .2$ ) 


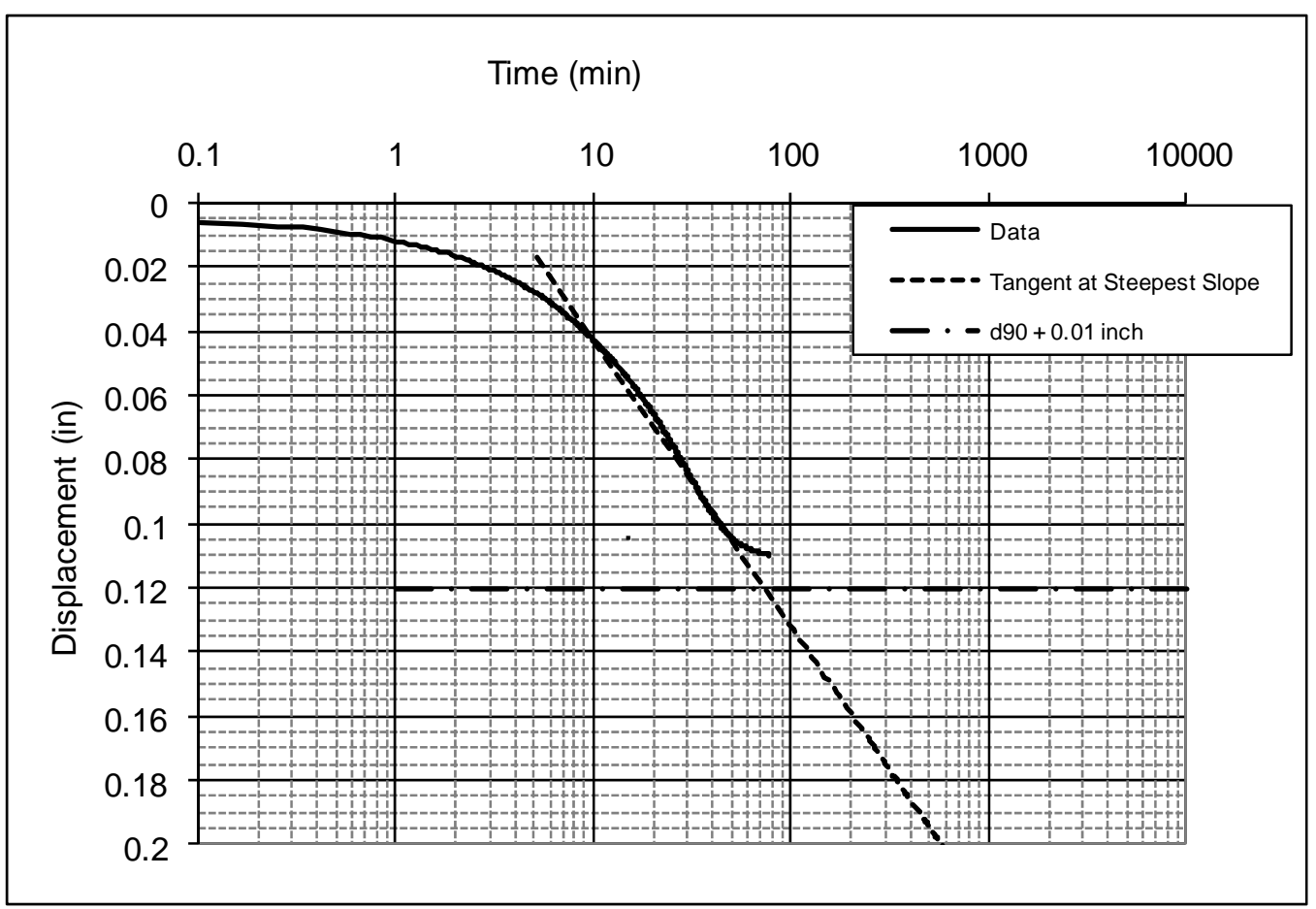

Figure D.7. Simulant 1 (67.5 wt\%) 100917 Displacement Versus Time ${ }^{1 / 2}$ (ASTM Standard D 2435 - 04, 12.3.1)

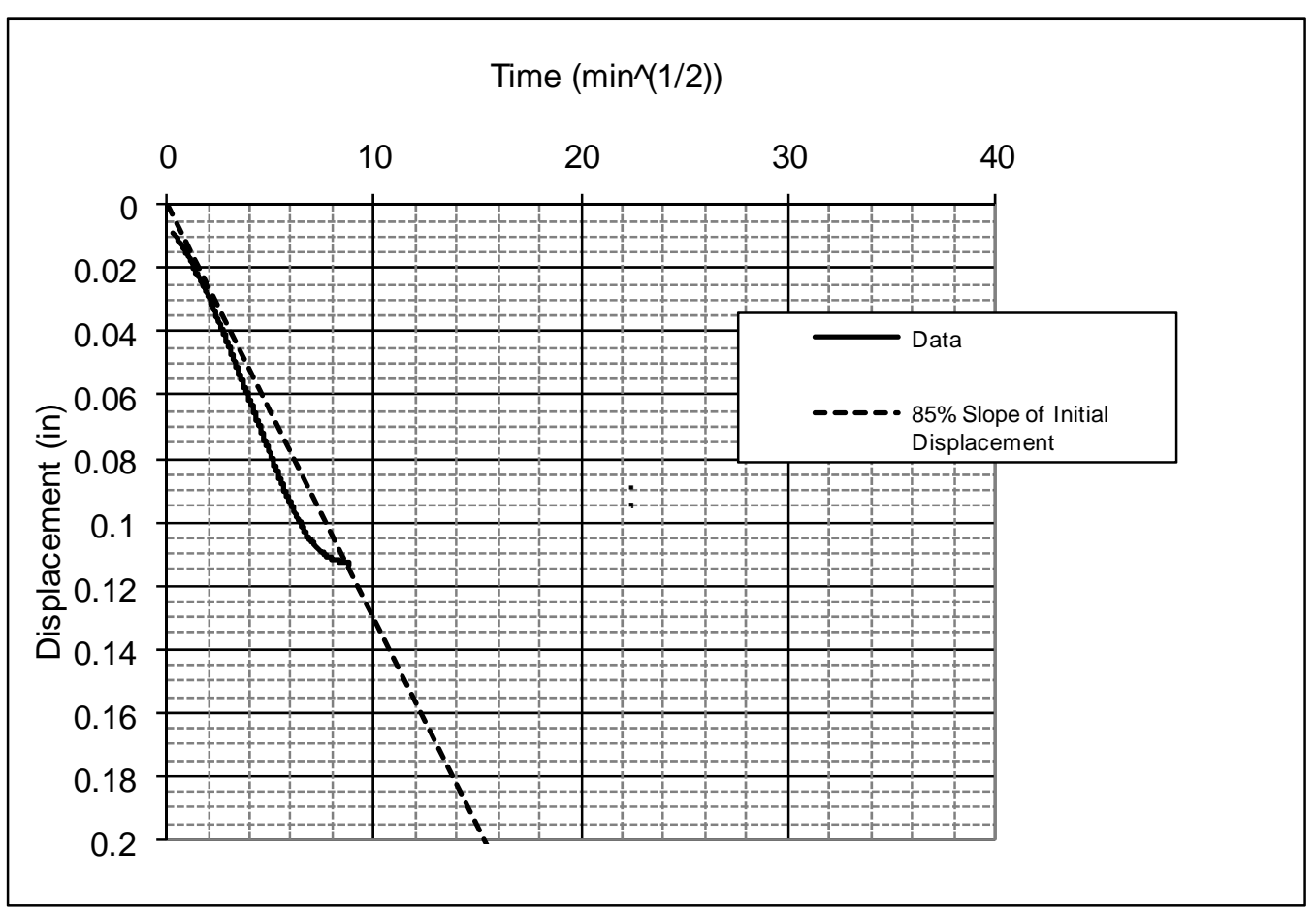

Figure D.8. Simulant 1 (67.5 wt\%) 100920 Displacement Versus Time ${ }^{1 / 2}$ (ASTM Standard D $2435-04,12.3 .2$ ) 


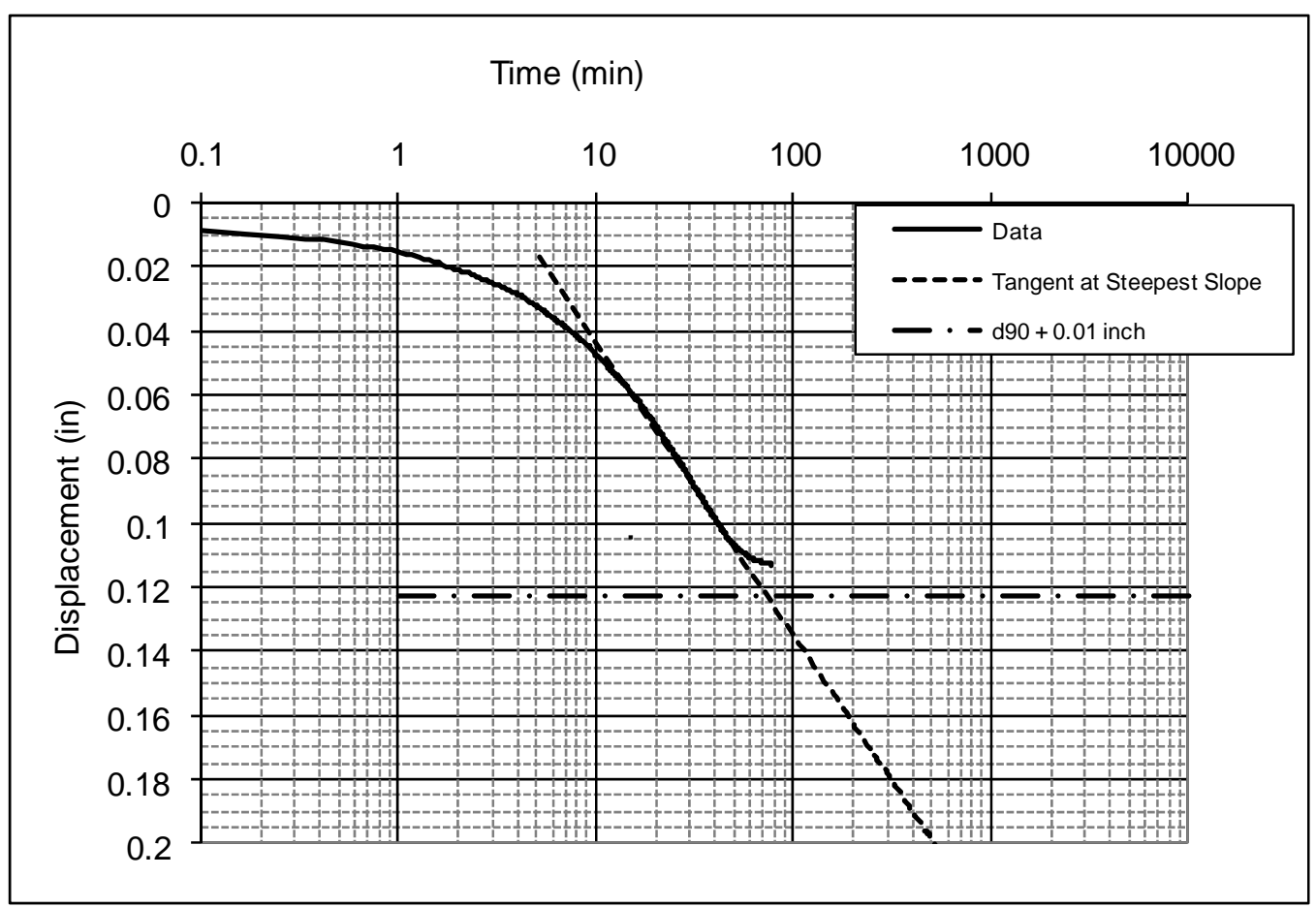

Figure D.9. Simulant $1(67.5 \mathrm{wt} \%) 100920$ Displacement Versus Time ${ }^{1 / 2}$ (ASTM Standard D 2435 - 04, 12.3.1)

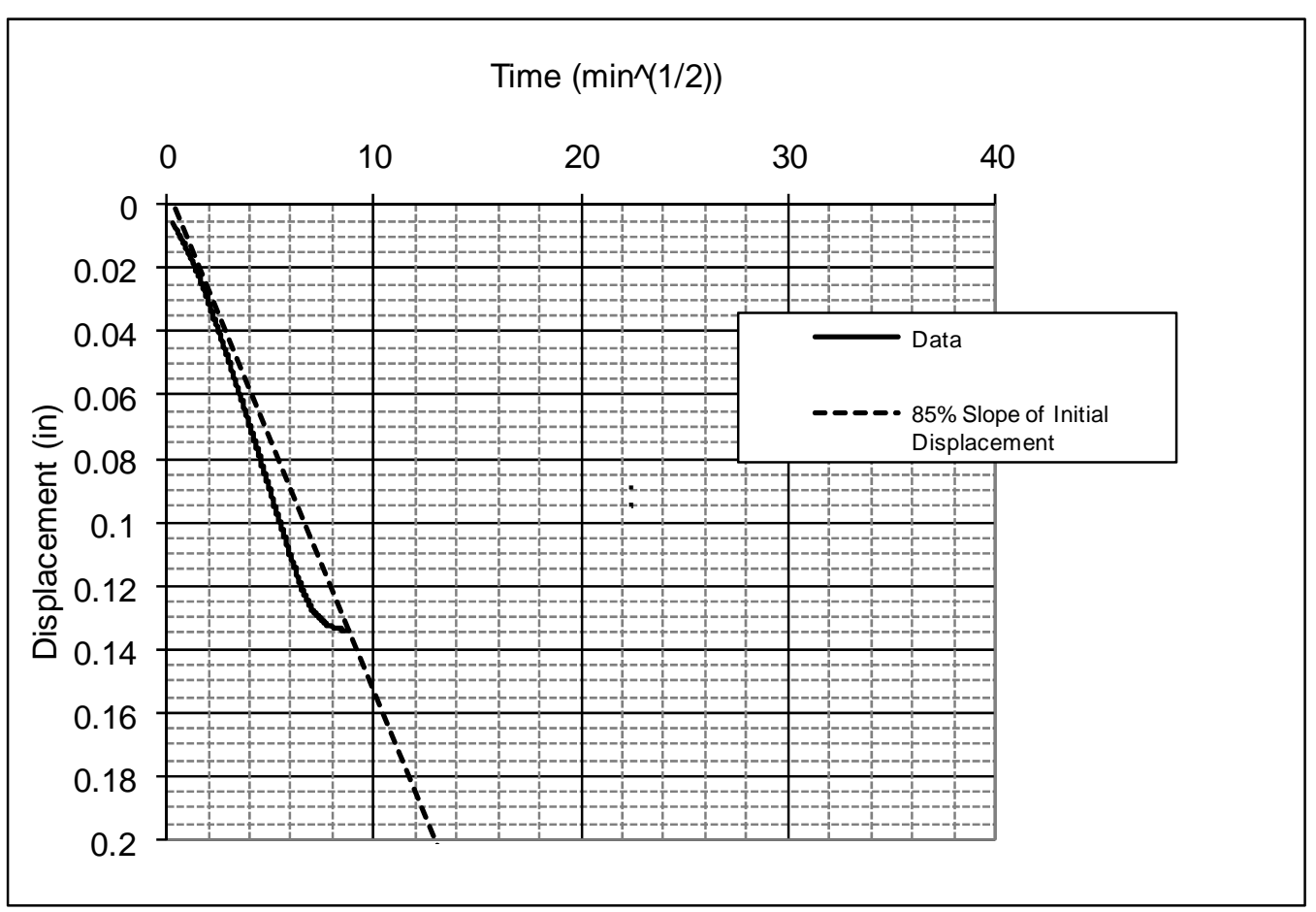

Figure D.10. Simulant 1 (66.5 wt\%) 100921 Displacement Versus Time ${ }^{1 / 2}$ (ASTM Standard D 2435 - 04, 12.3.2) 


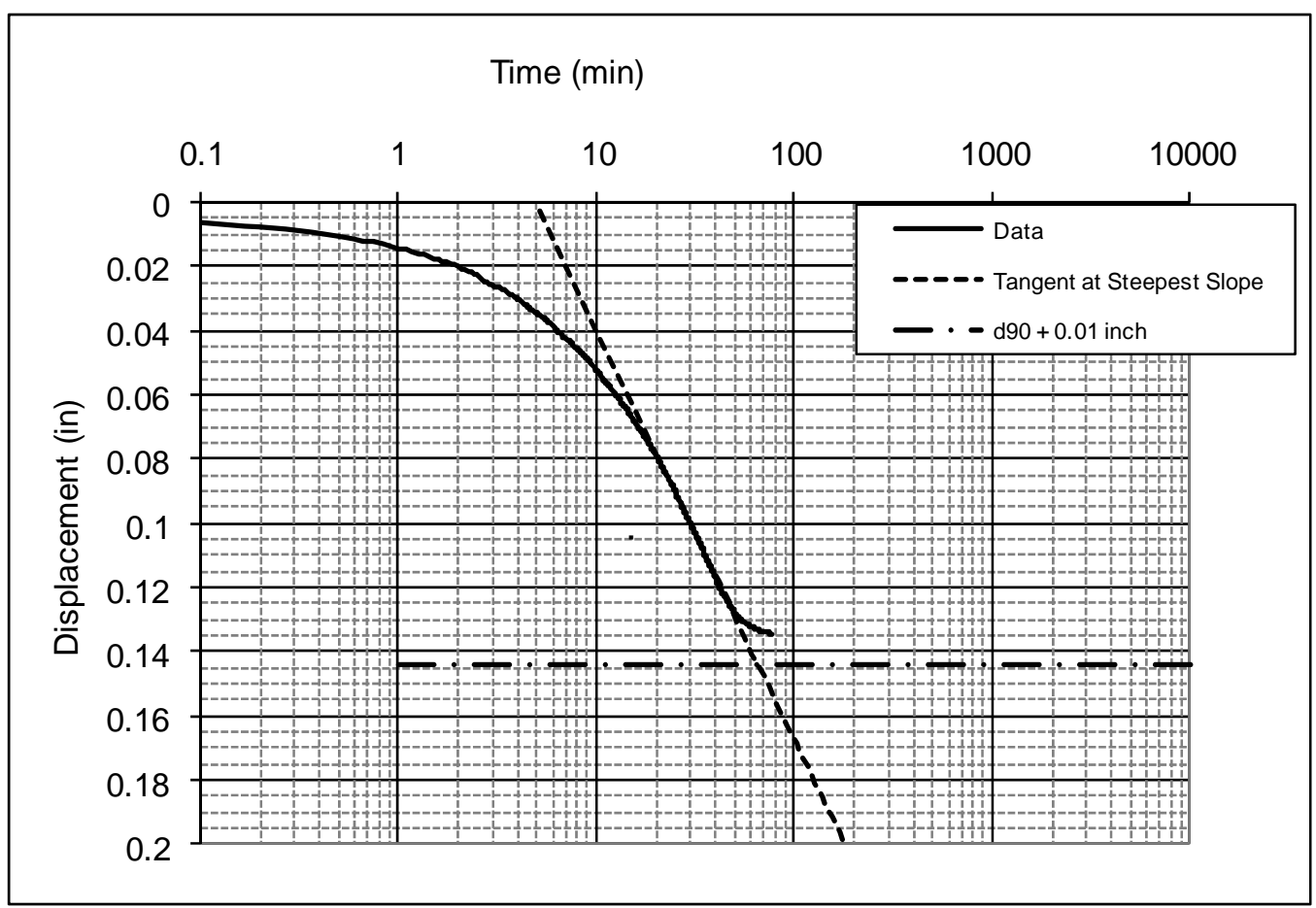

Figure D.11. Simulant 1 (66.5 wt\%) 100921 Displacement Versus Time ${ }^{1 / 2}$ (ASTM Standard D $2435-04,12.3 .1$ )

ThermoHaake RheoWin 9/24/2010/10:10 AM

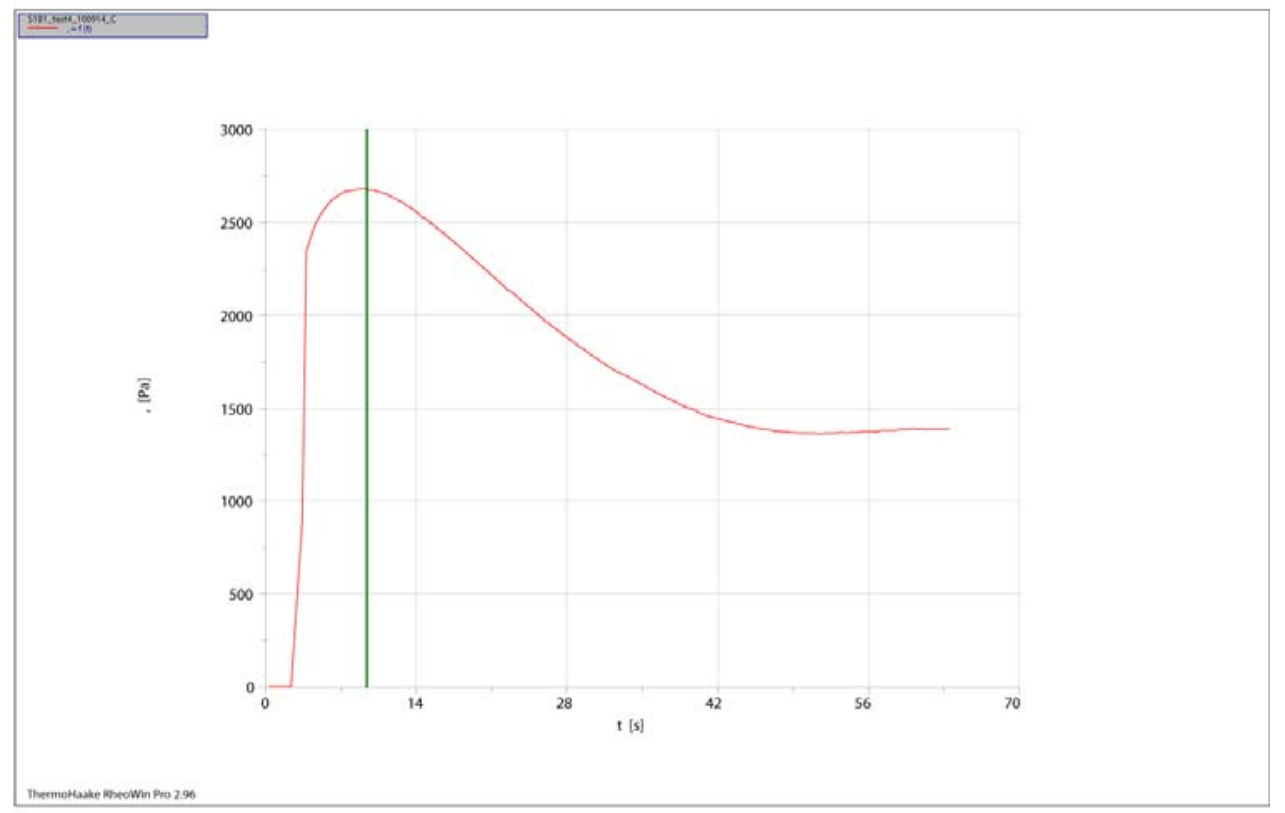

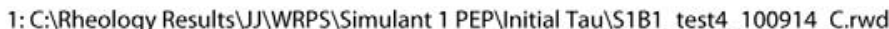

Company / Operator: PNNL / Jeromy Jenks

Date / Time / Version: 14.09.2010/11:21:33 AM / RheoWin Pro 296

Substance / Sample no: S1B1 / S1B1_test4_100914_C

Figure D.12. Initial Simulant $1(70 \mathrm{wt} \%$ ) shear strength $(\mathrm{PA})$ as a function of time Measured at Center 


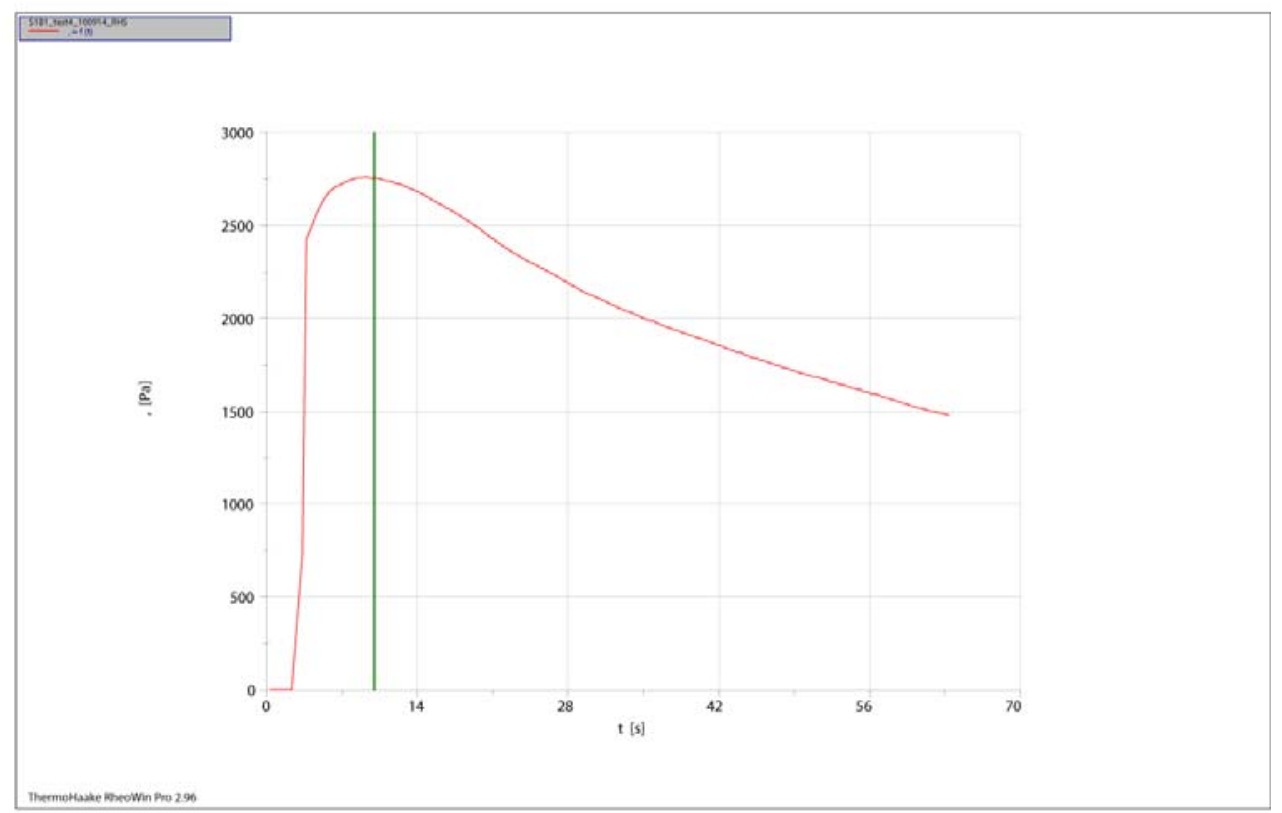

1: C:IRheoloqy Results UJ\WRPSISimulant 1 PEPVInitial Tau\S1B1_test4_100914_RHS.rwd

Company / Operator: PNNL / Jeromy Jenks

Date / Time / Version: 14.09.2010 / 11:24:10 AM / RheoWin Pro 296

Substance / Sample no: S1B1 / S1B1_test4_100914_RHS

Curve discussion: Greatest value $\mathrm{t}[\mathrm{s}] 10.01,[\mathrm{~Pa}] 2762$.

Figure D.13. Initial Simulant 1(70 wt\%) Shear Strength (PA) as a Function of Time Measured at RHS

ThermoHaake RheoWin 9/24/2010/10:11 AM

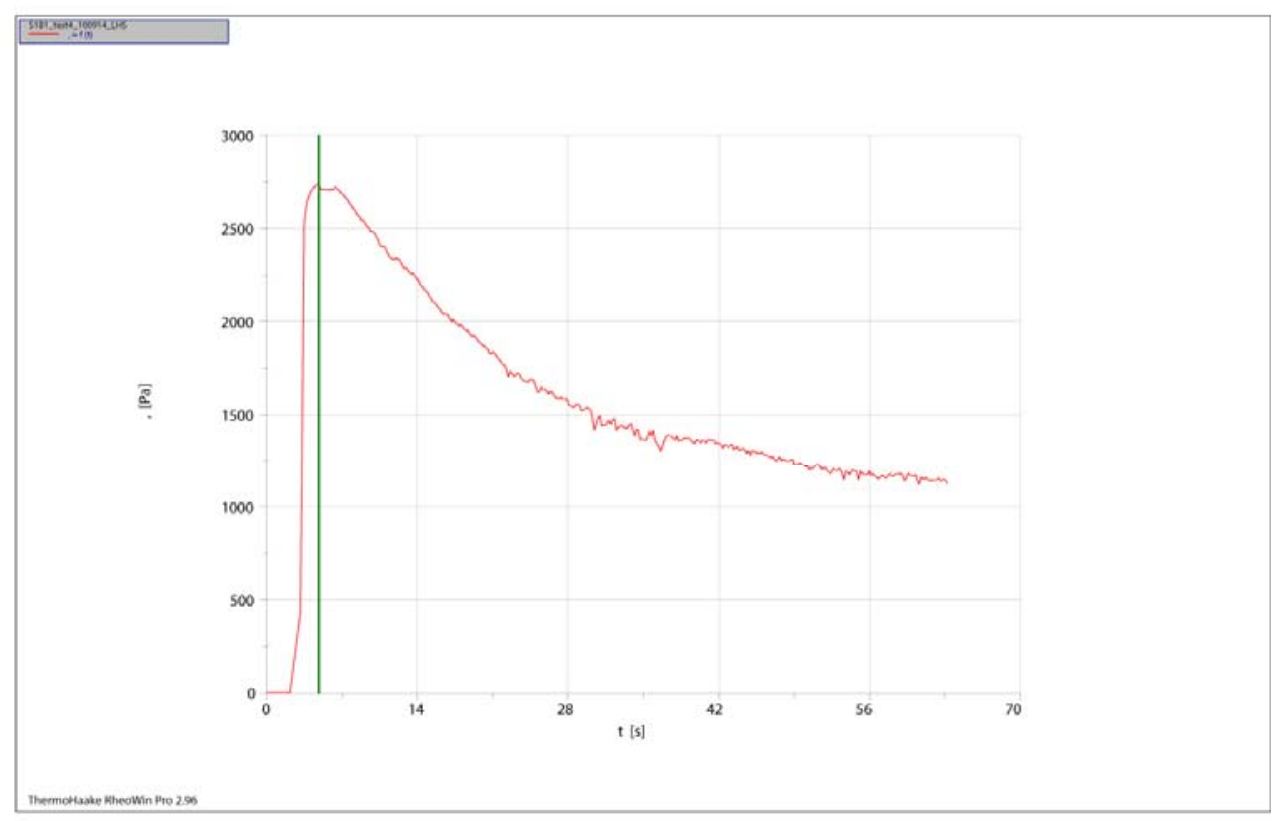

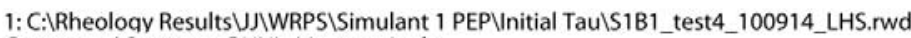

Company / Operator: PNNL / Jeromy Jenks

Date / Time / Version: 14.09.2010 / 11:27:09 AM / RheoWin Pro 296

Substance / Sample no: S1B1 / S1B1 test4_100914 LHS

Curve discussion: Greatest value $\mathrm{t}[\mathrm{s}] 4.87 \overline{4}$, [Pa] 2737.

Figure D.14. Initial Simulant 1(70 wt \%) Shear Strength (PA) as a Function of Time Measured at RHS 
ThermoHaake RheoWin 9/24/2010/9:55 AM

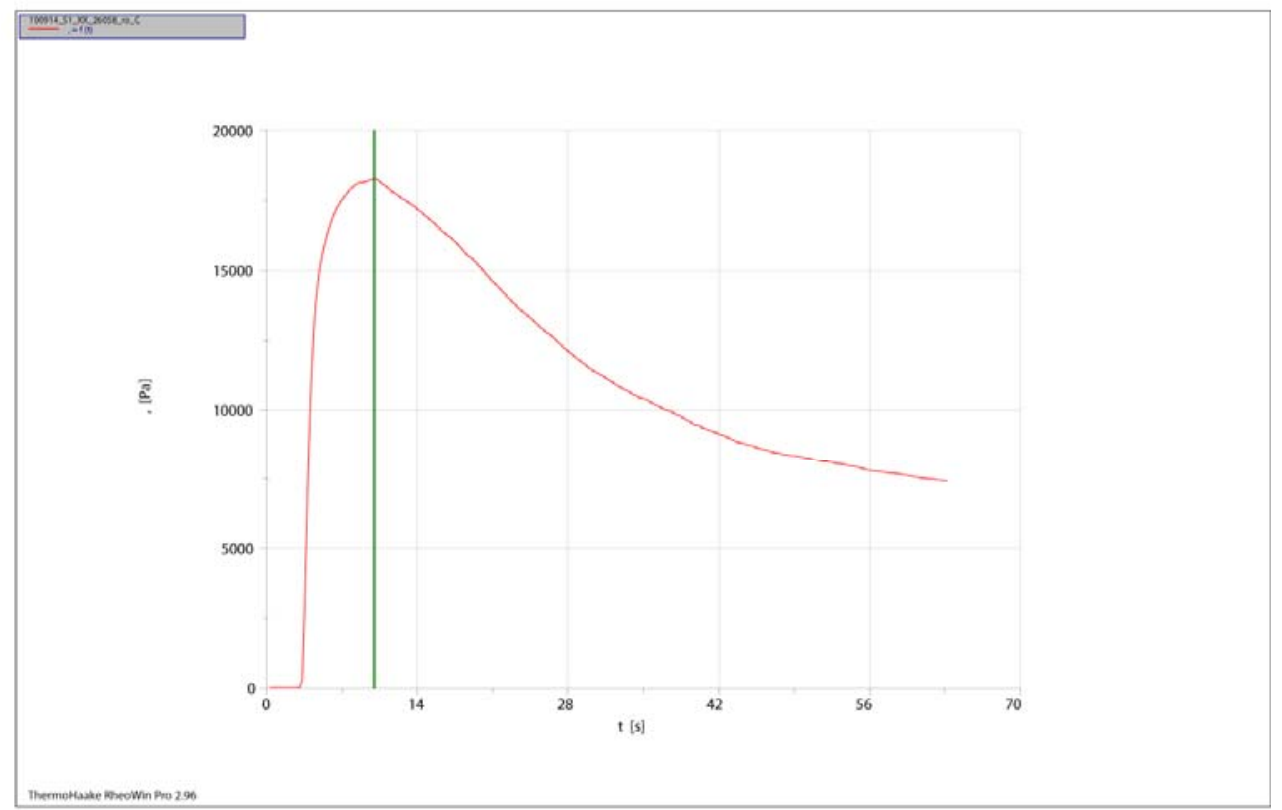

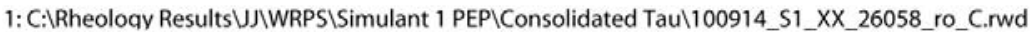

Company / Operator: PNNL / Jeromy Jenks

Date / Time / Version: 14.09.2010 / 16:36:29 PM / RheoWin Pro 296

Substance / Sample no: S1B1 / 100914_S1_XX_26058_ro_C

Curve discussion: Greatest value $\mathrm{t}[\mathrm{s}] 10.00,[\mathrm{~Pa}] 1.829 \mathrm{e}+04$

Figure D.15. Cosolidated Simulant 1 (72.9 wt\%) 100914 ro Shear Strength (PA) as a Function of Time Measured at Center

ThermoHaake RheoWin 9/24/2010/9:57 AM

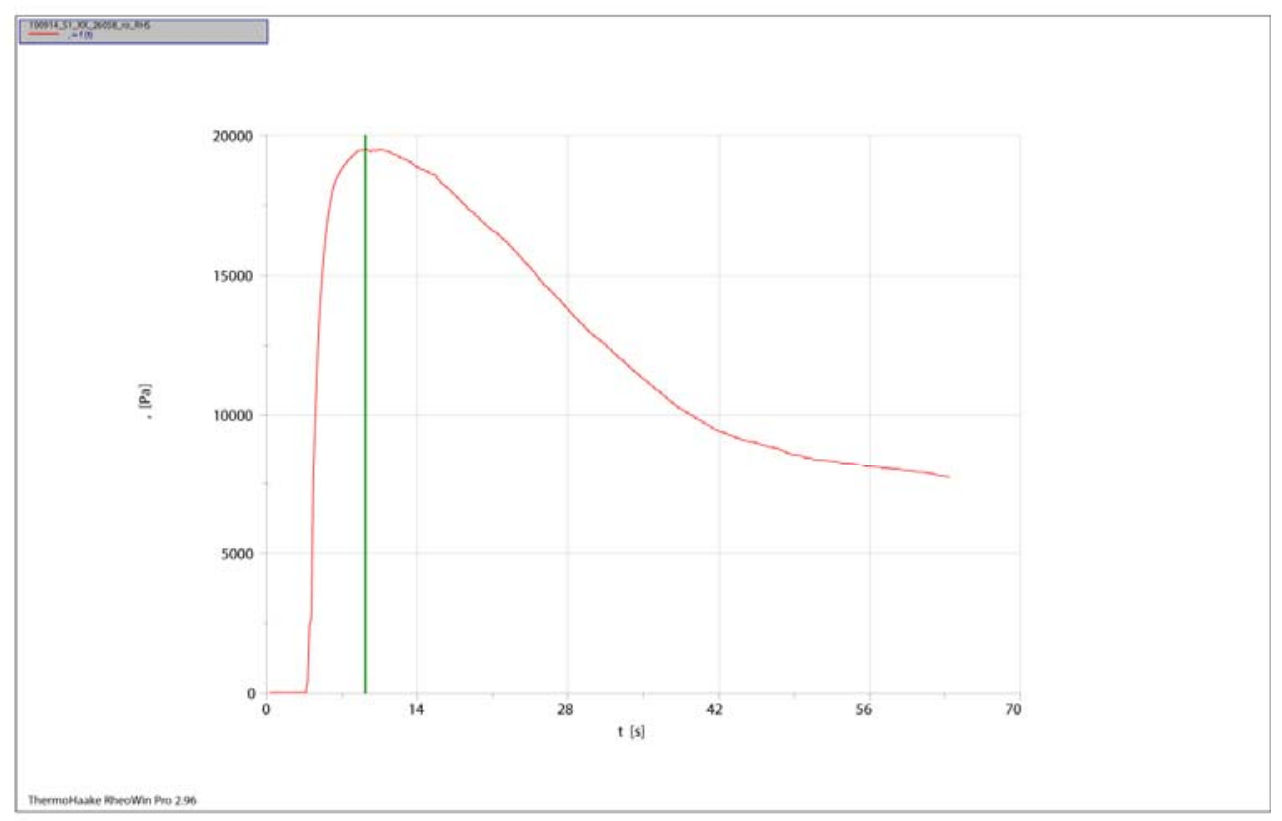

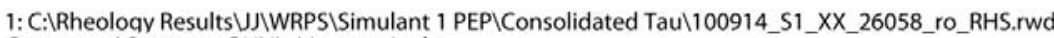
Company / Operator: PNNL / Jeromy Jenks

Date / Time / Version: 14.09.2010 / 16:40:40 PM / RheoWin Pro 296

Substance / Sample no: S1B1 / 100914 S1 XX 26058 ro RHS

Curve discussion: Greatest value $\mathrm{t}[\mathrm{s}] 9.16 \overline{3},[\overline{\mathrm{Pa}}] 1.949 \mathrm{e}+04$

Figure D.16. Cosolidated Simulant 1 (72.9 wt\%) 100914 ro Shear Strength (PA) as a Function of Time Measured at RHS 


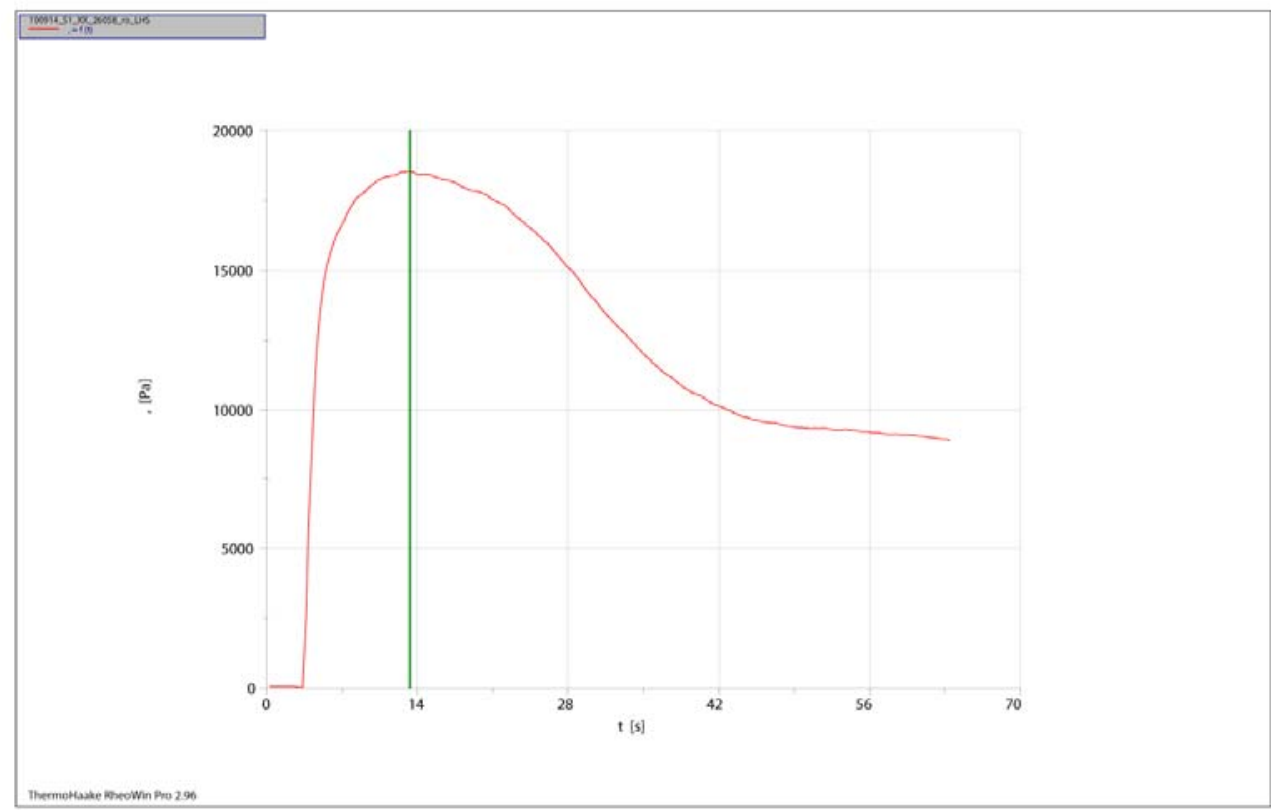

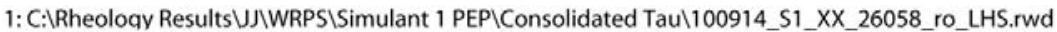

Company / Operator: PNNL / Jeromy Jenks

Date / Time / Version: 14.09.2010 / 16:44:40 PM / RheoWin Pro 296

Substance / Sample no: S1B1 / 100914_S1_XX_26058_ro_LHS

Curve discussion: Greatest value $\mathrm{t}[\mathrm{s}] 13.34,[\mathrm{~Pa}] 1.855 \mathrm{e}+04$

Figure D.17. Cosolidated Simulant $1(72.9 \mathrm{wt} \%) 100914$ ro Shear Strength (PA) as a Function of Time Measured at LHS

ThermoHaake RheoWin 9/24/2010/9:53 AM

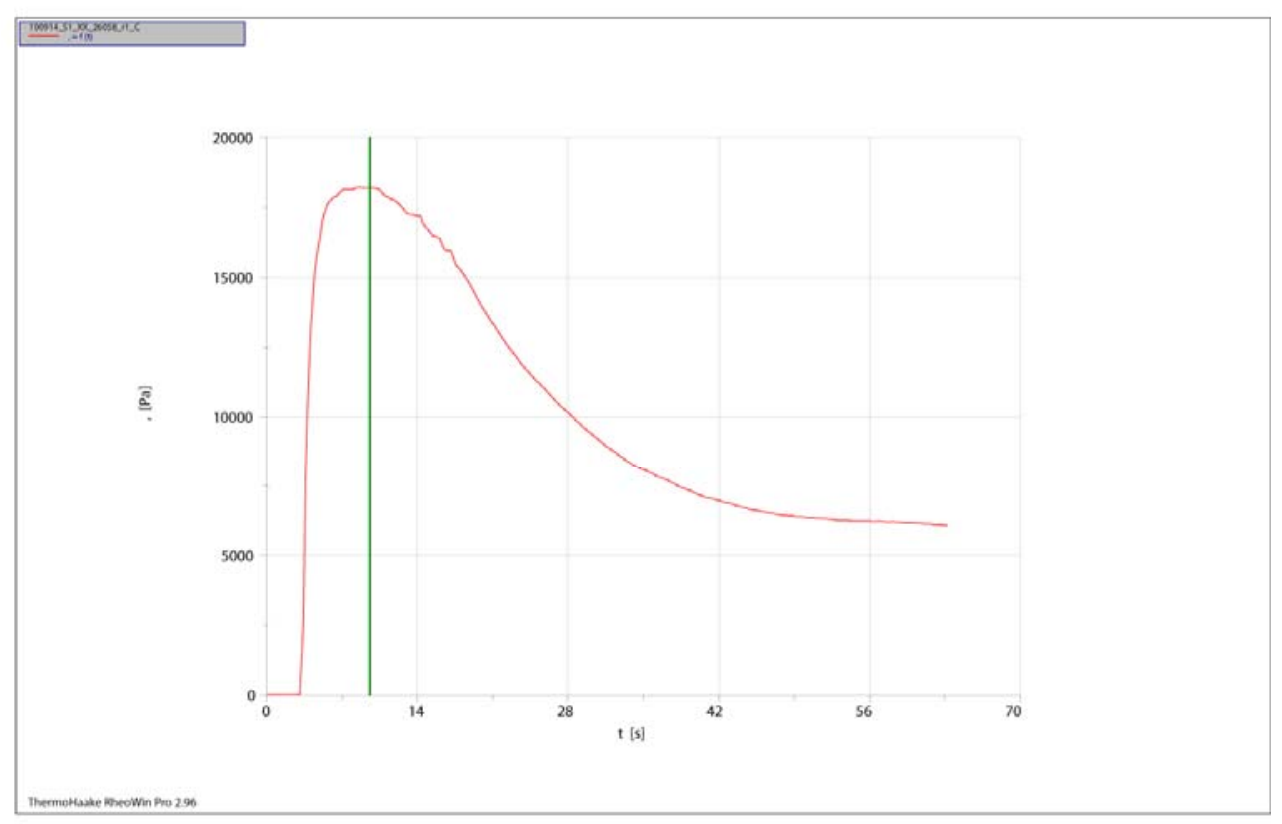

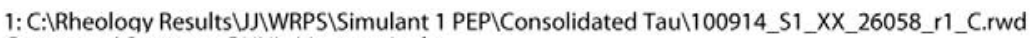
Company / Operator: PNNL / Jeromy Jenks

Date / Time / Version: 14.09.2010 / 16:49:39 PM / RheoWin Pro 296

Substance / Sample no: S1B1 / 100914 S1 XX 26058 r1 C

Curve discussion: Greatest value $\mathrm{t}[\mathrm{s}] 9.591,[\mathrm{~Pa}] 1.821 \mathrm{e}+04$

Figure D.18. Cosolidated Simulant 1 (72.8 wt\%) 100914 r1 Shear Strength (PA) as a Function of Time Measured at Center 
ThermoHaake RheoWin 9/24/2010/9:54 AM

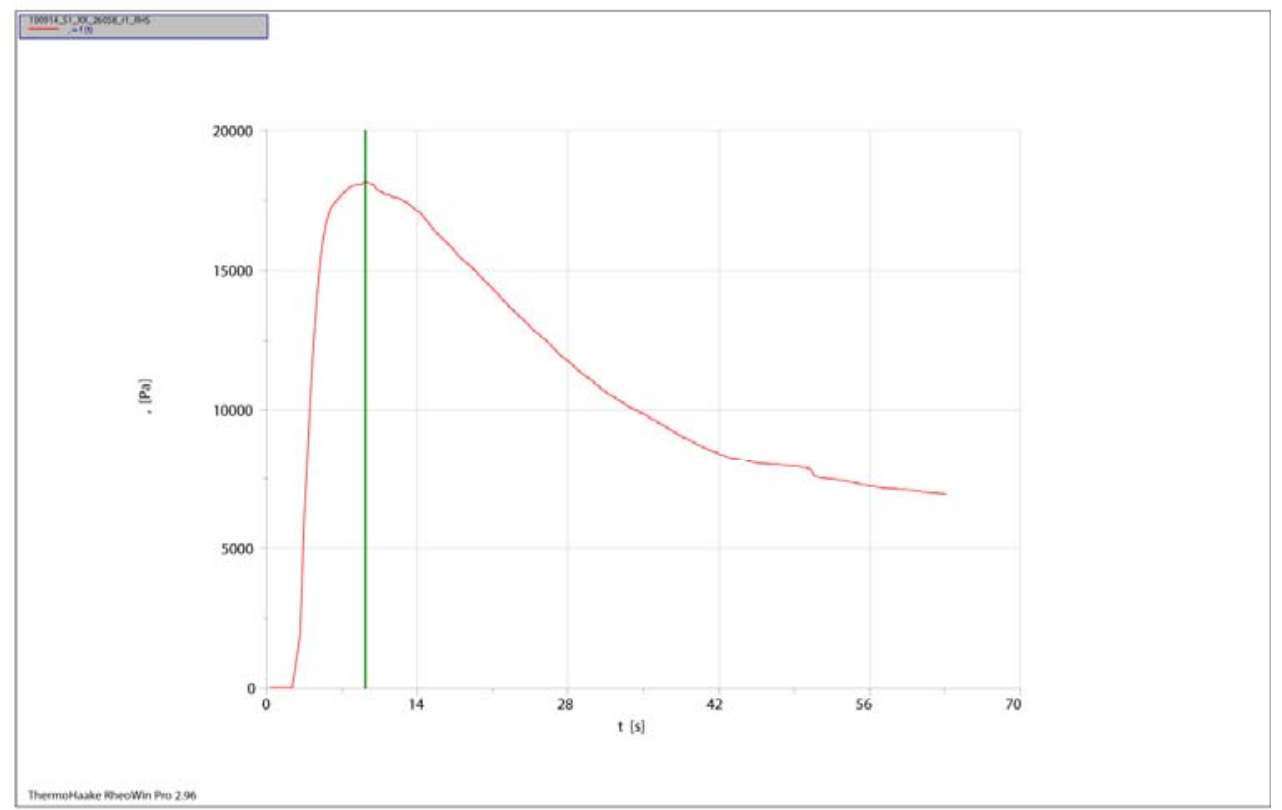

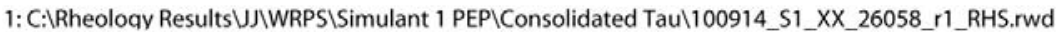

Company / Operator: PNNL / Jeromy Jenks

Date / Time / Version: 14.09.2010 / 16:53:24 PM / RheoWin Pro 296

Substance / Sample no: S1B1 / 100914_S1 XX_26058_r1_RHS

Curve discussion: Greatest value $\mathrm{t}[\mathrm{s}] 9.16 \overline{7},[\mathrm{~Pa}] 1.81 \overline{\mathrm{se}}+04$

Figure D.19. Cosolidated Simulant $1(72.8 \mathrm{wt} \%) 100914$ r1 Shear Strength (PA) as a Function of Time Measured at RHS

ThermoHaake RheoWin 9/24/2010/10:13 AM

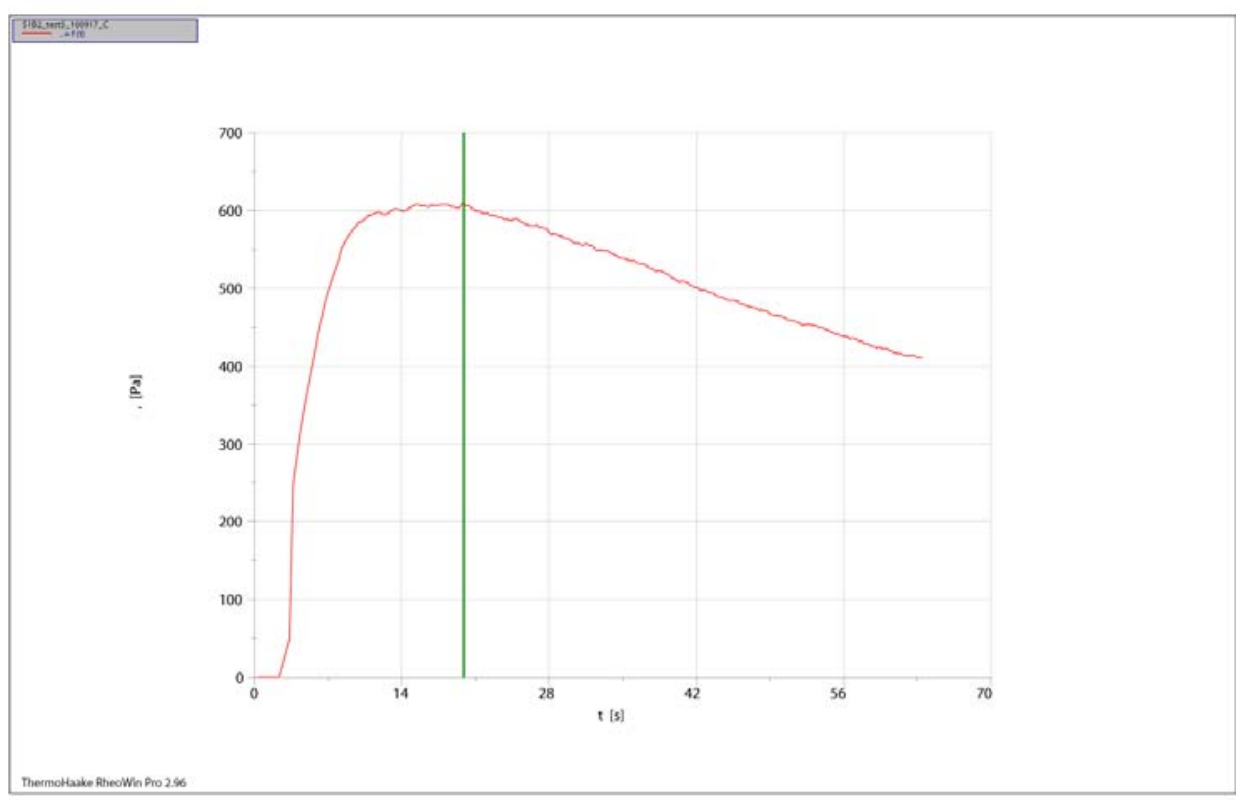

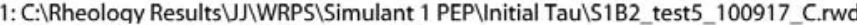

Company / Operator: PNNL / Jeromy Jenks

Date / Time / Version: 17.09.2010 / 9:20:53 AM / RheoWin Pro 296

Substance / Sample no: S1B2 / S1B2 test5 100917 C

Curve discussion: Greatest value $\mathrm{t}[\mathrm{s}] \mathrm{s}] 19.89$, [Pa] 608.8

Figure D.20. Initial Simulant 1 (67.5 wt\%) Shear Strength (PA) as a Function of Time Measured at Center 


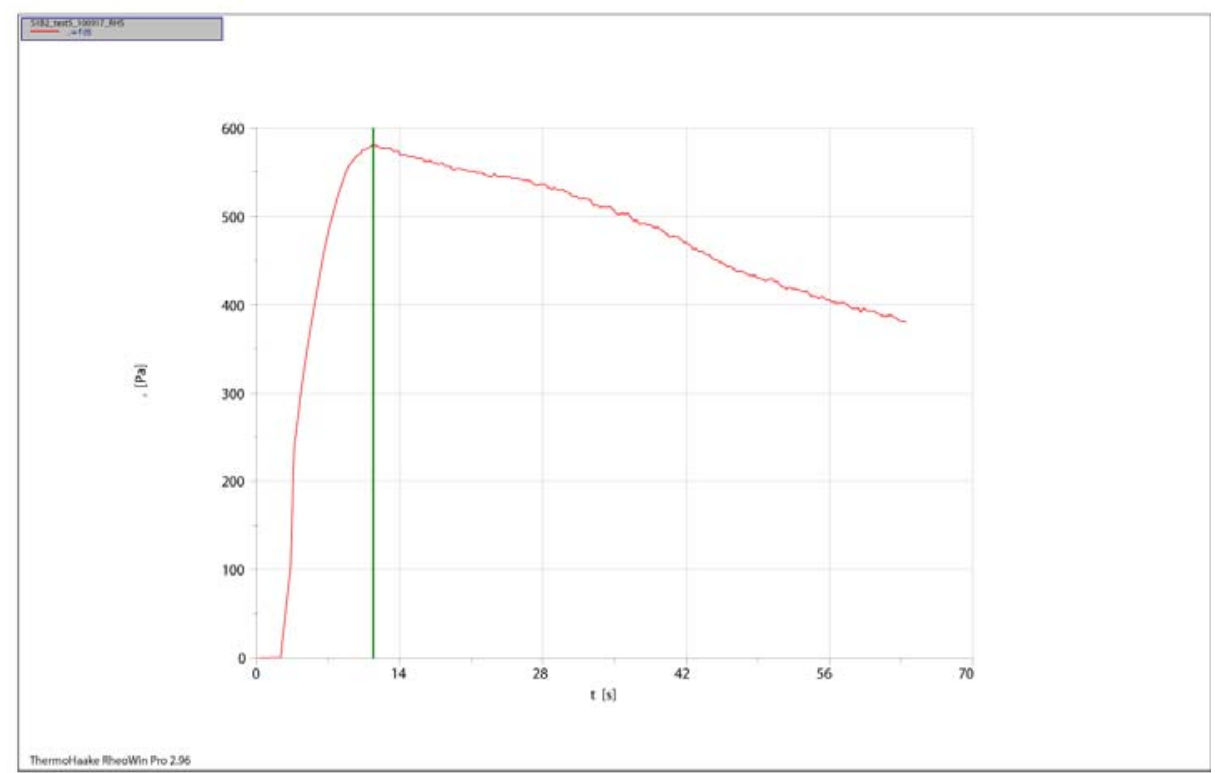

1: C:IRheology Results UJ IWRPSISimulant 1 PEPVInitial Tau IS1B2_test5_100917_RHS.rwd

Company / Operator: PNNL / Jeromy Jenks

Date / Time / Version: 17.09.2010 / 9:24:44 AM / RheoWin Pro 296

Substance / Sample no: S1B2 / S1B2 test5 100917 RHS

Curve discussion: Greatest value $\mathrm{t}[\mathrm{s}] \mathrm{11.42},[\mathrm{Pa}] 581.7$

Figure D.21. Initial Simulant $1(67.5 \mathrm{wt} \%)$ Shear Strength (PA) as a Function of Time Measured at RHS ThermoHaake RheoWin 9/24/2010/10:14 AM

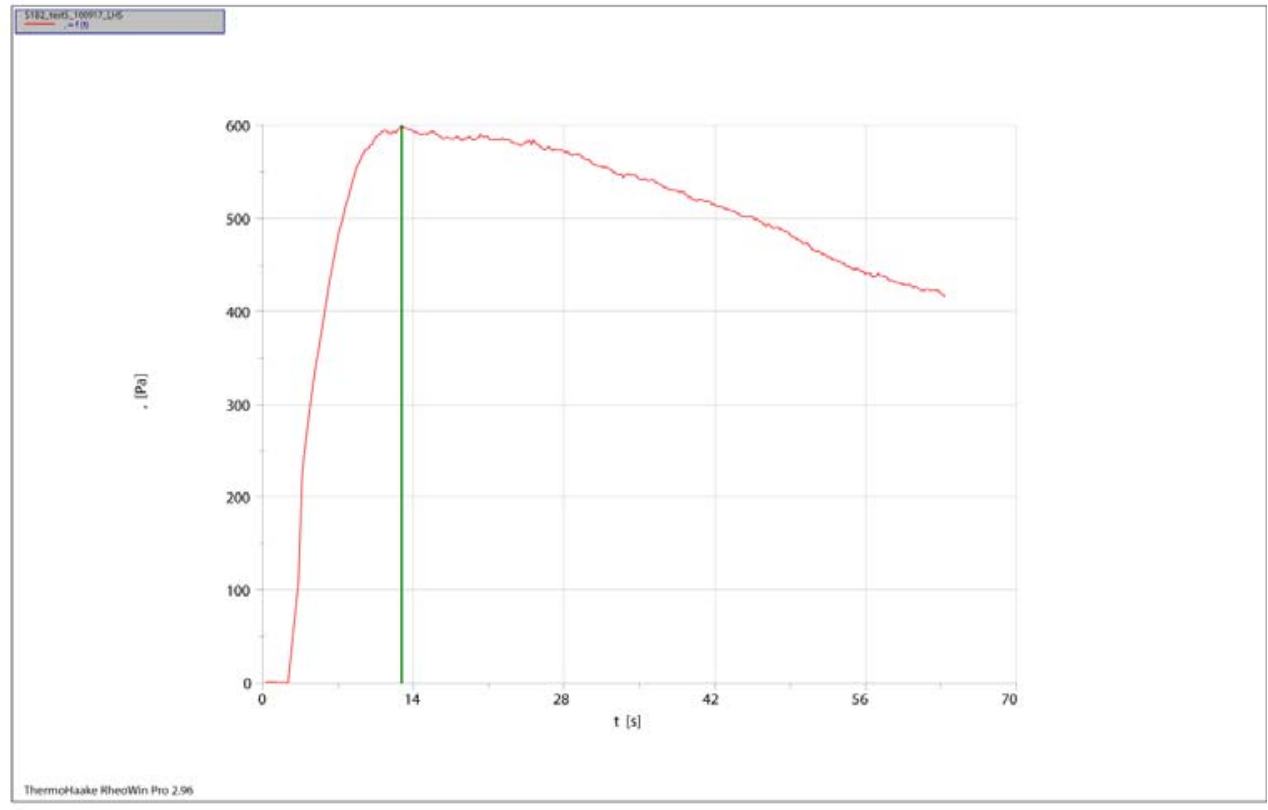

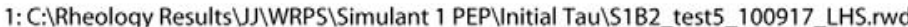

Company / Operator: PNNL / Jeromy Jenks

Date / Time / Version: 17.09.2010 / 9:29:14 AM / RheoWin Pro 296

Substance / Sample no: S1B2 / S1B2_test5_100917_LHS

Curve discussion: Greatest value $\mathrm{t}[\mathrm{s}] 12.92$, [Pa] 598.8

Figure D.22. Initial Simulant $1(67.5 \mathrm{wt} \%)$ Shear Strength (PA) as a Function of Time Measured at LHS 


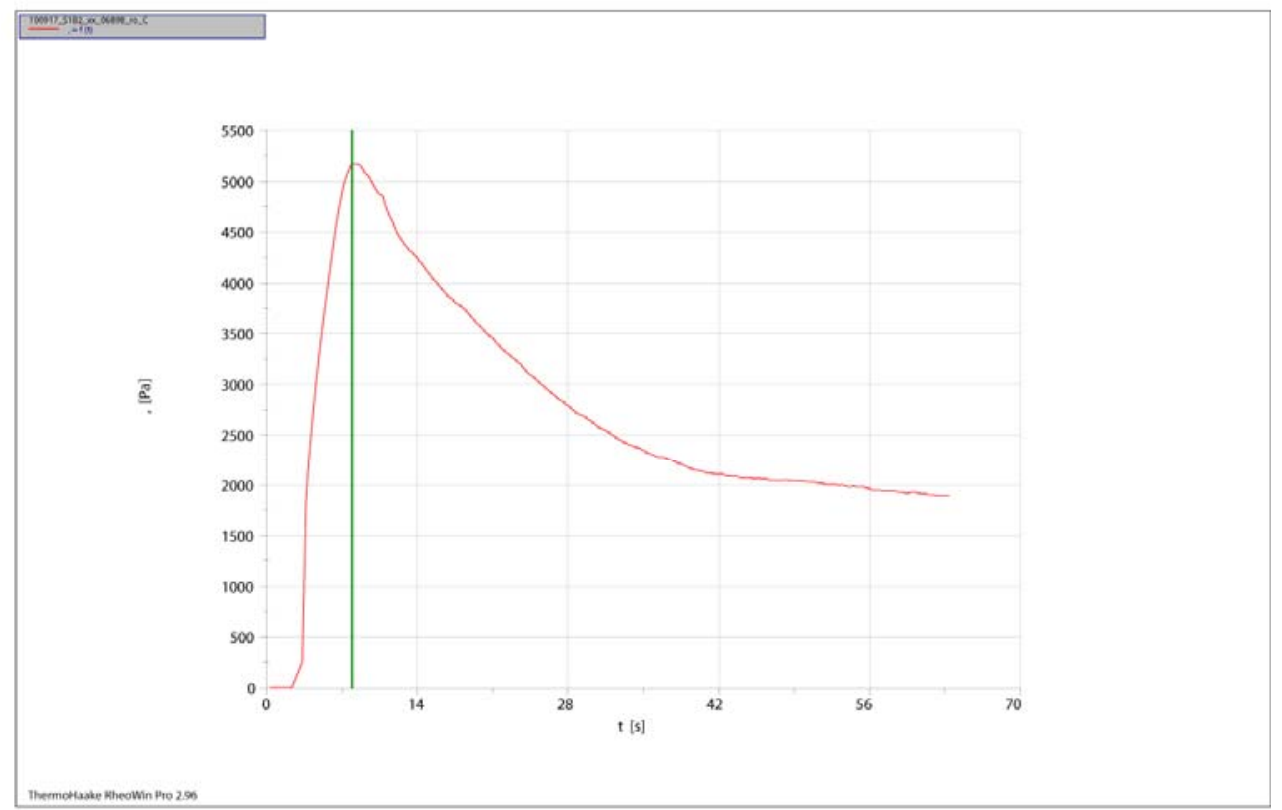

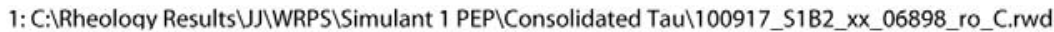

Company / Operator: PNNL / Jeromy Jenks

Date / Time / Version: 17.09.2010 / 13:08:07 PM / RheoWin Pro 296

Substance / Sample no: S1B2 / 100917_S1B2_xx_06898_ro_C

Curve discussion: Greatest value $\mathrm{t}[\mathrm{s}] 7.949$, [Pa] 5174.

Figure D.23. Consolidated Simulant 1 (71.1 wt\%) 100917 Shear Strength (PA) as a Function of Time Measured at Center

ThermoHaake RheoWin 9/24/2010/10:00 AM

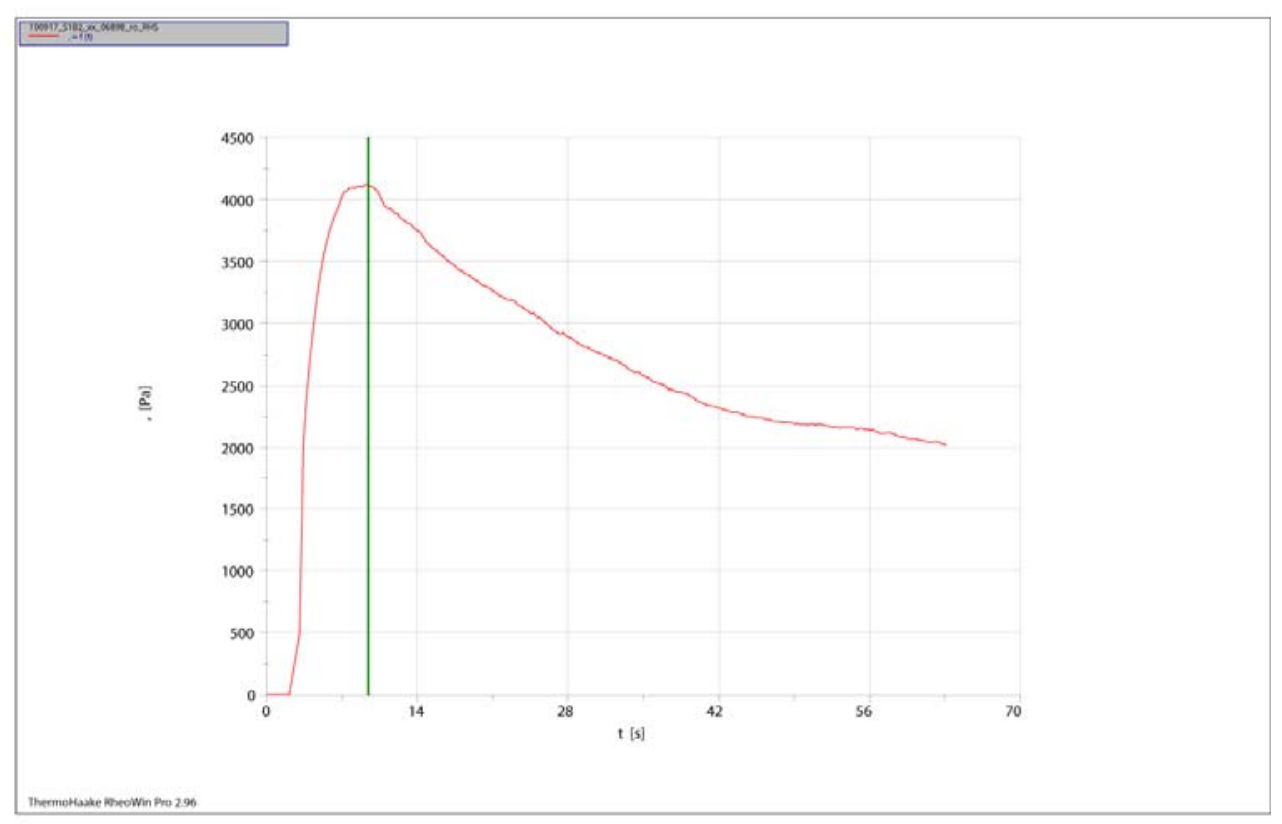

1: C:IRheoloqy Results \J\WRPSISimulant 1 PEP\Consolidated Tau 100917 S1B2_xx_06898_ro_RHS.rwd Company / Operator: PNNL / Jeromy Jenks

Date / Time / Version: 17.09.2010 / 13:11:27 PM / RheoWin Pro 296

Substance / Sample no: S1B2 / 100917 S1B2 xx 06898 ro RHS

Curve discussion: Greatest value $\mathrm{t}[\mathrm{s}] 9.460$, $[\mathrm{Pa}] 4115$.

Figure D.24. Consolidated Simulant $1(71.1 \mathrm{wt} \%) 100917$ Shear Strength (PA) as a Function of Time Measured at RHS 
ThermoHaake RheoWin 9/24/2010/9:59 AM

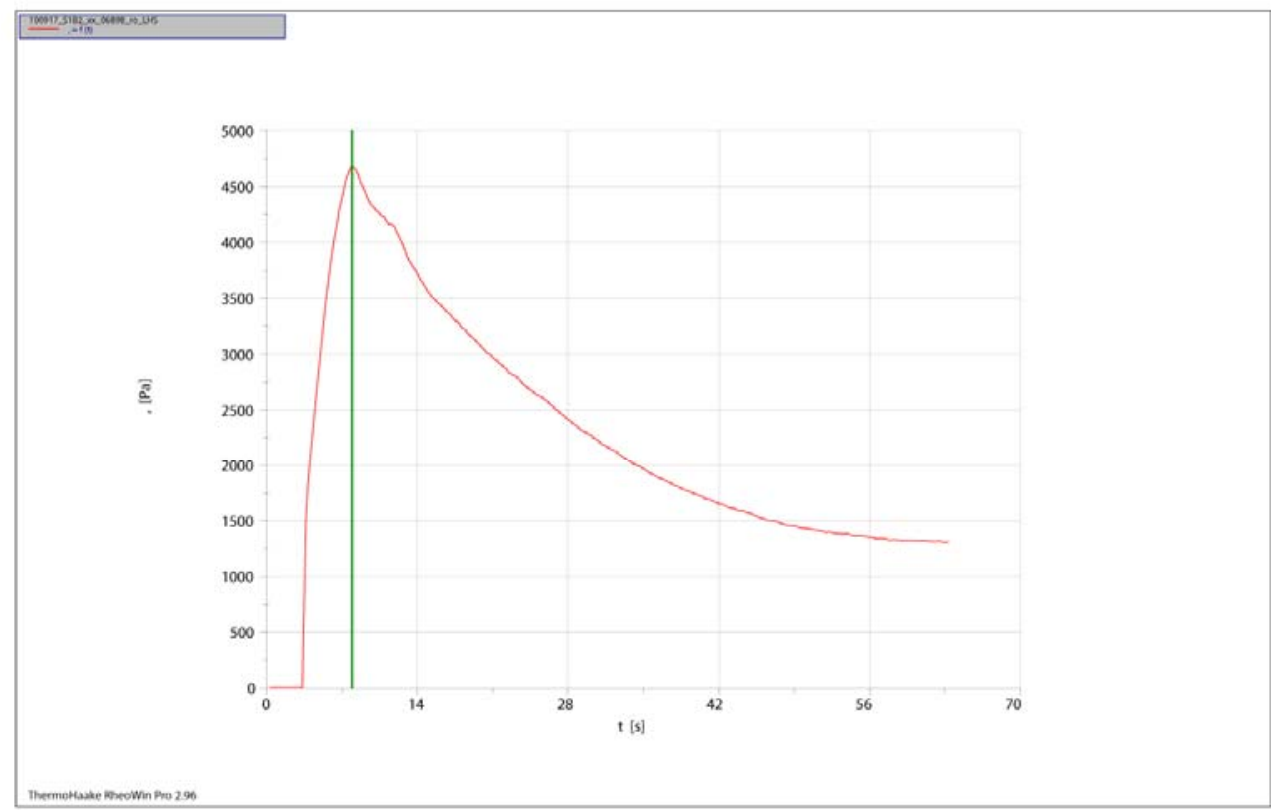

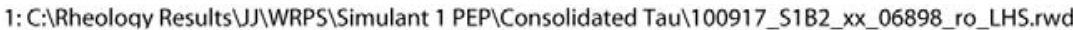

Company / Operator: PNNL / Jeromy Jenks

Date / Time / Version: 17.09.2010 / 13:14:25 PM / RheoWin Pro 296

Substance / Sample no: S1B2 / 100917_S1B2_xx_06898_ro_LHS

Curve discussion: Greatest value $\mathrm{t}[\mathrm{s}] 7.948$, [Pa] 4675.

Figure D.25. Consolidated Simulant 1 (71.1 wt\%) 100917 Shear Strength (PA) as a Function of Time Measured at LHS

ThermoHaake RheoWin 9/24/2010/10:01 AM

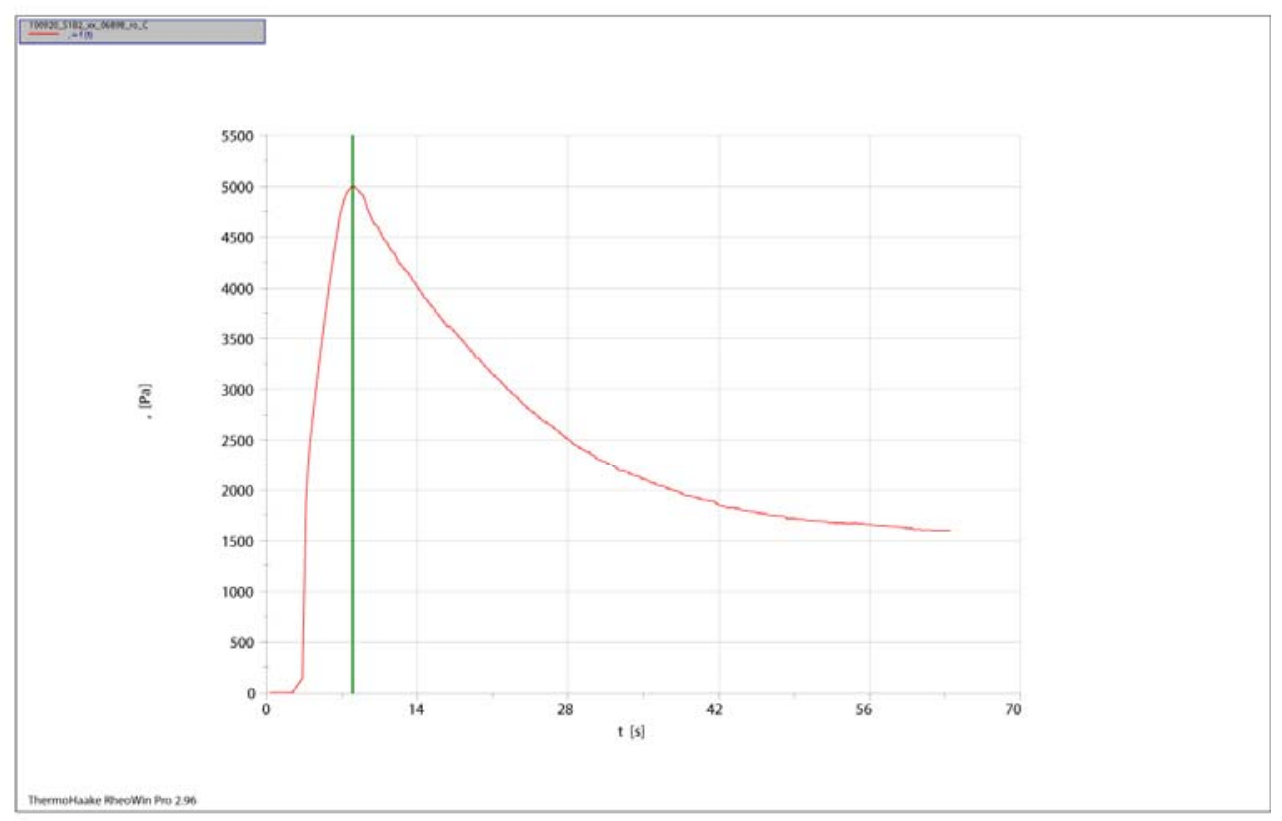

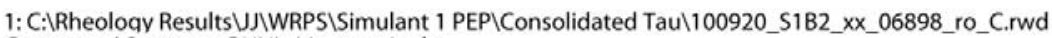
Company / Operator: PNNL / Jeromy Jenks

Date / Time / Version: 21.09.2010 / 8:56:48 AM / RheoWin Pro 296

Substance / Sample no: S1B2 / 100920 S1B2 xx 06898_ro C

Curve discussion: Greatest value $\mathrm{t}[\mathrm{s}] \mathrm{7.988}$, [ $[\mathrm{Pa}] 5001$.

Figure D.26. Consolidated Simulant 1 (70.7 wt\%) 100920 Shear Strength (PA) as a Function of Time Measured at Center 


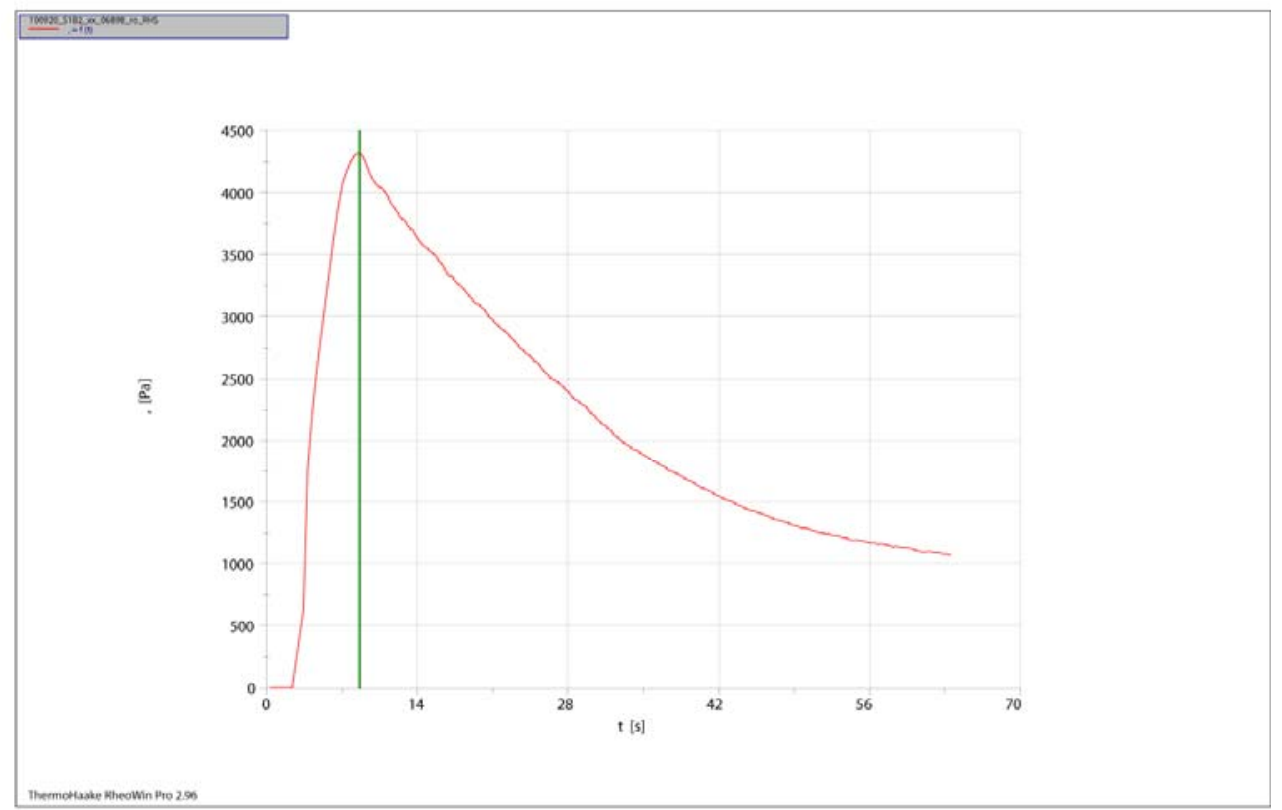

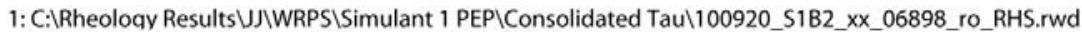
Company / Operator: PNNL / Jeromy Jenks

Date / Time / Version: 21.09.2010 / 8:48:41 AM / RheoWin Pro 296

Substance / Sample no: S1B2 / 100920_S1B2_xx_06898_ro_RHS

Curve discussion: Greatest value $\mathrm{t}[\mathrm{s}] \mathrm{8.650},[\mathrm{Pa}] 4324$.

Figure D.27. Consolidated Simulant 1(70.7 wt\% ) 100920 shear strength (PA) as a function of time Measured at RHS

ThermoHaake RheoWin 9/24/2010/10:02 AM

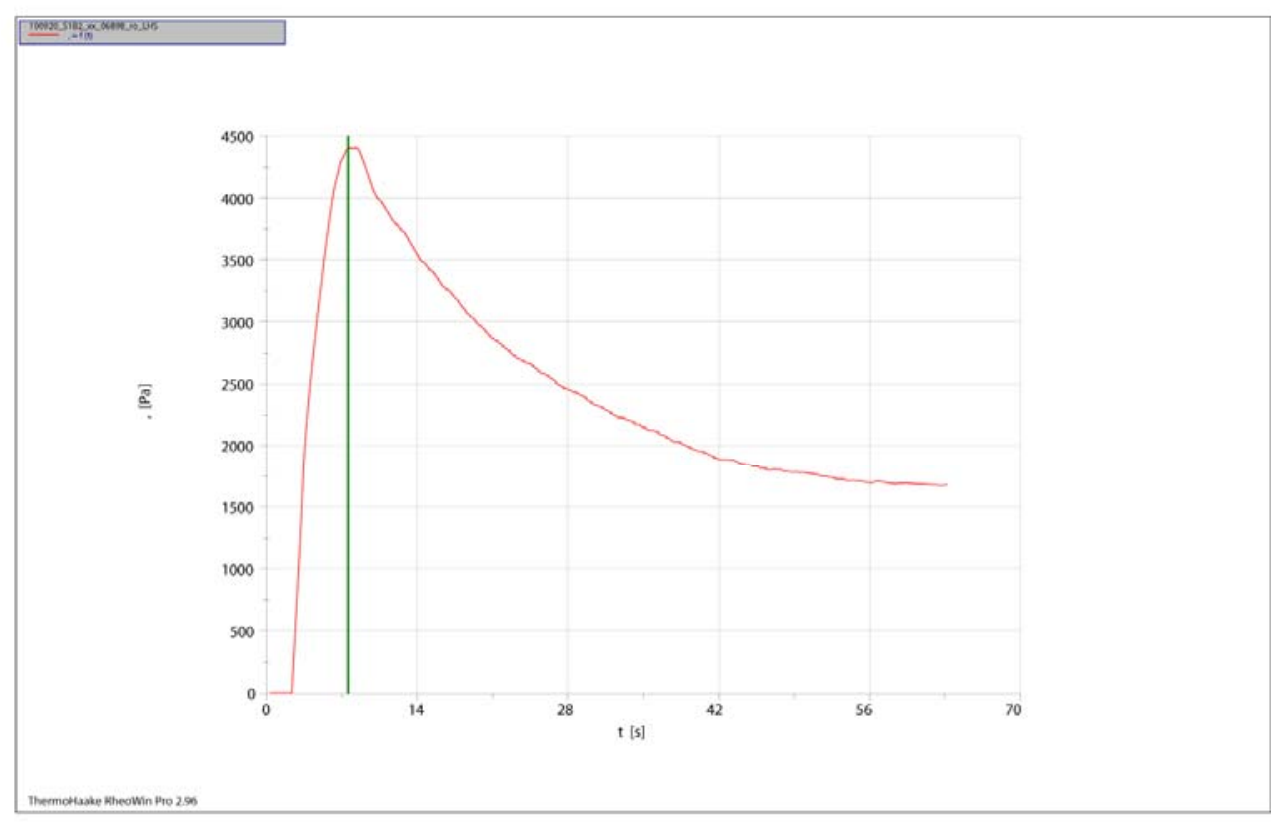

1: C:IRheoloqy Results VJ\WRPSISimulant 1 PEP\Consolidated Tau 100920 S1B2_xx_06898_ro_LHS.rwd

Company / Operator: PNNL / Jeromy Jenks

Date / Time / Version: 21.09.2010/ 8.59:54 AM/RheoWin Pro 296

Substance / Sample no: S1B2 / 100920_S1B2_xx_06898_ro_LHS

Curve discussion: Greatest value $\mathrm{t}[\mathrm{s}] \mathrm{7.568}$, [Pa] 4406.

Figure D.28. Consolidated Simulant 1(70.7 wt\% ) 100920 shear strength (PA) as a function of time Measured at LHS

D.16 


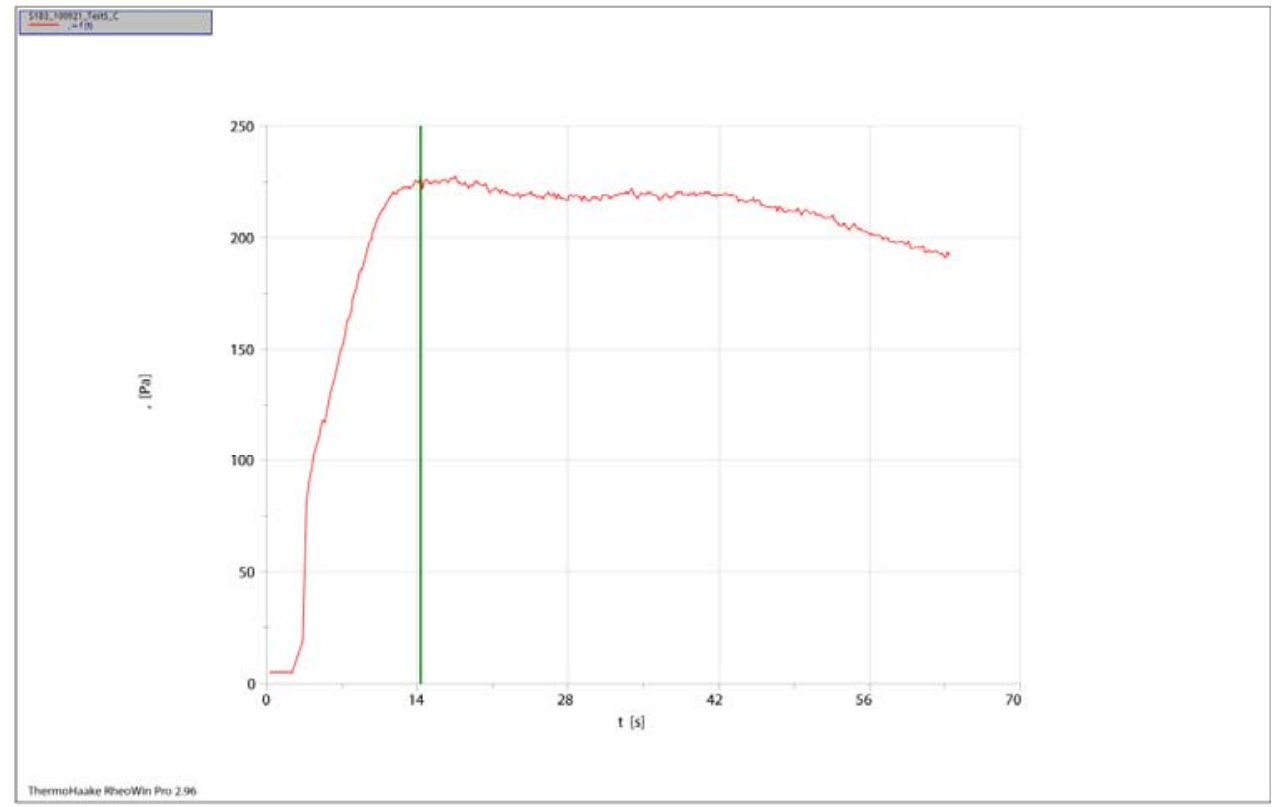

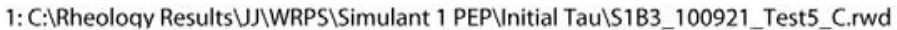
Company / Operator: PNNL / Jeromy Jenks

Date / Time / Version: 21.09.2010 / 13:02:36 PM / RheoWin Pro 296

Substance / Sample no: S1B3 / S1B3_100921_Test5_C

Curve discussion: Greatest value $\mathrm{t}[\mathrm{s}]$ 14.32, [Pa] 228.5

Figure D.29. Initial Simulant $1(66.5 \mathrm{wt} \%)$ shear strength $(\mathrm{PA})$ as a function of time Measured at Center ThermoHaake RheoWin 9/24/2010/10:17 AM

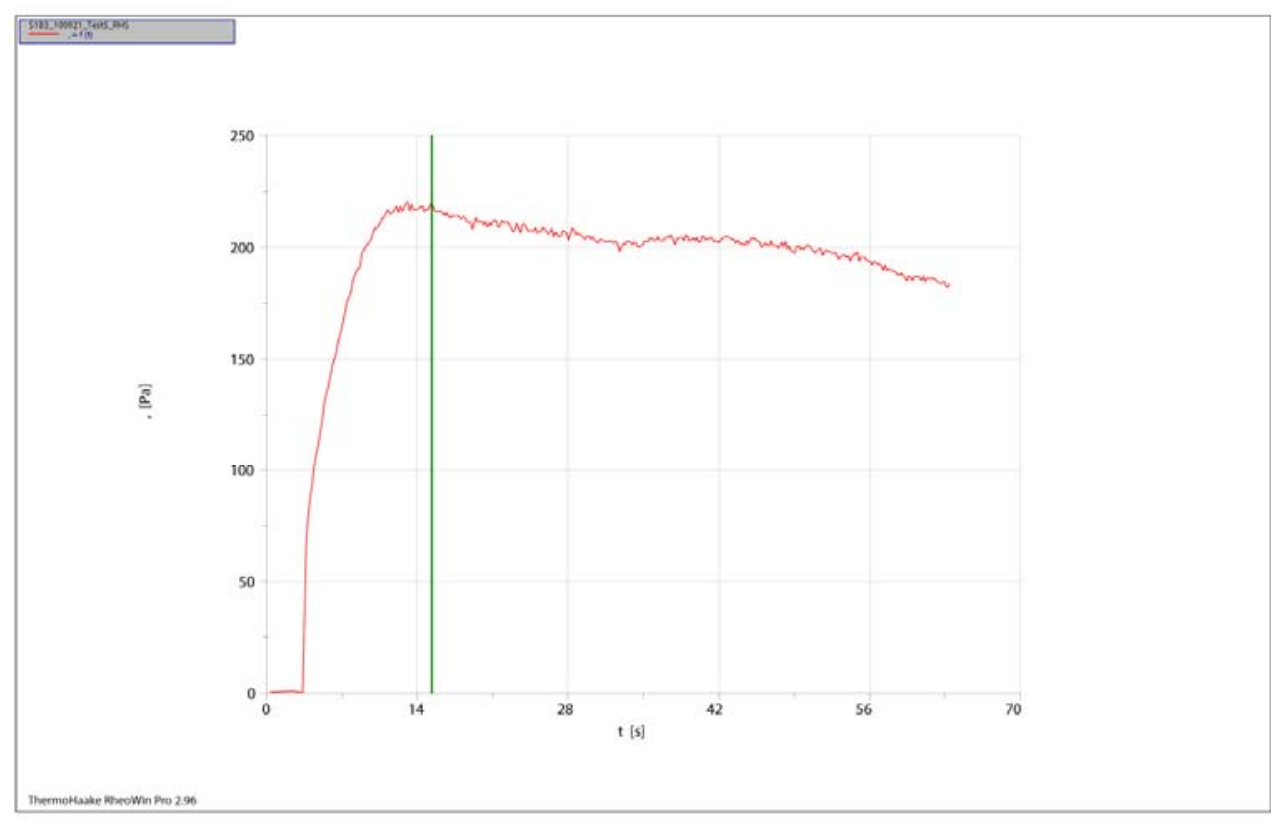

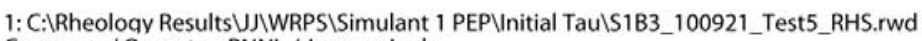
Company / Operator: PNNL / Jeromy Jenks

Date / Time / Version: 21.09.2010 / 13:06:50 PM / RheoWin Pro 296

Substance / Sample no: S1B3 / S1B3_100921_Test5 RHS

Curve discussion: Greatest value $\mathrm{t}[\mathrm{s}] 15.35$, [Pa] 220.3

Figure D.30. Initial Simulant 1(66.5 wt \% ) shear strength (PA) as a function of time Measured at RHS 


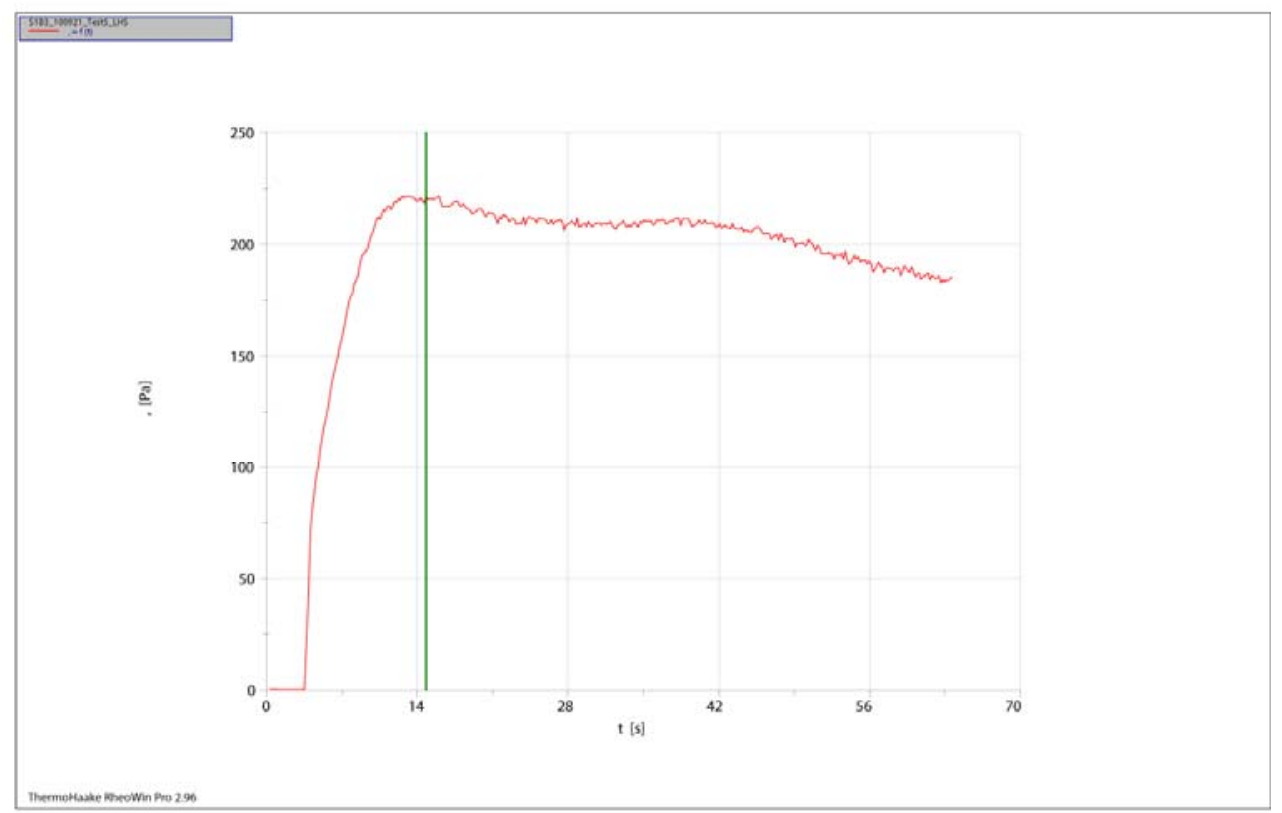

1: C:IRheology Results\JIWRPSISimulant 1 PEPVnitial TauIS1B3_100921_Test5_LHS.rwd

Company / Operator: PNNL / Jeromy Jenks

Date / Time / Version: 21.09.2010/ 13:09:35 PM / RheoWin Pro 296

Substance / Sample no: S1B3 / S1B3_100921_Test5_LHS

Curve discussion: Greatest value $\mathrm{t}[\mathrm{s}] 14.82$, [Pa] 222.0

Figure D.31. Initial Simulant $1(66.5 \mathrm{wt} \%)$ shear strength (PA) as a function of time Measured at LHS

ThermoHaake RheoWin 9/24/2010/10:04 AM

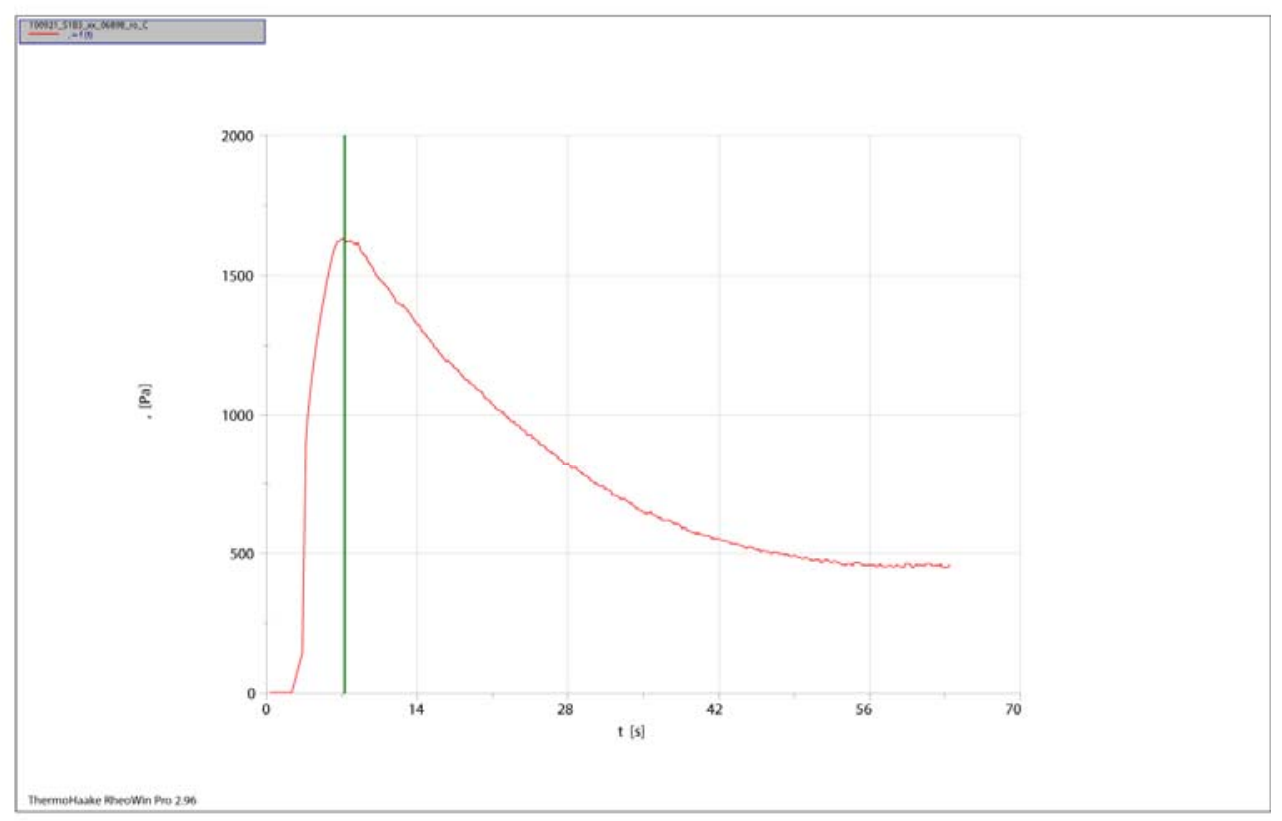

1: C:IRheoloqy Results\JWWRPSISimulant 1 PEP\Consolidated Tau 100921_S1B3_xx_06898_ro_C.rwd Company / Operator: PNNL / Jeromy Jenks

Date / Time / Version: 21.09.2010 / 16:49:59 PM / RheoWin Pro 296

Substance / Sample no: S1B3 / 100921_S1B3_xx_06898_ro_C

Curve discussion: Greatest value $\mathrm{t}$ [s] 7.257 , [Pa] 1630.

Figure D.32. Consolidated Simulant 1(69.9 wt\% ) 100921 shear strength (PA) as a function of time Measured at Center 


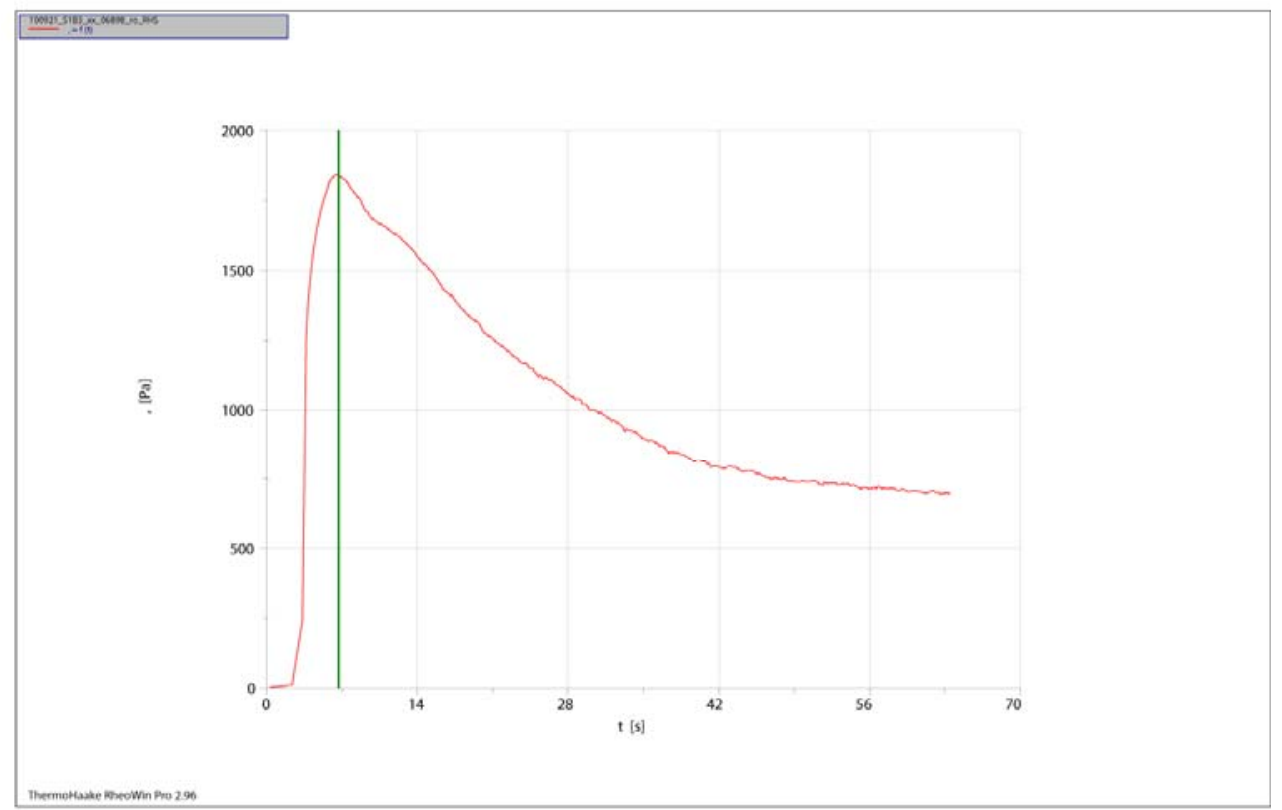

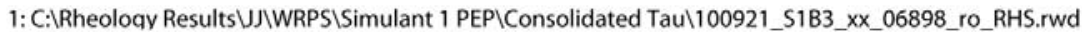
Company / Operator: PNNL / Jeromy Jenks

Date / Time / Version: 21.09.2010/ 16:44:53 PM / RheoWin Pro 296

Substance / Sample no: S1B3/100921_S1B3_xx_06898_ro_RHS

Curve discussion: Greatest value $\mathrm{t}[\mathrm{s}] 6.696$, , [Pa] 1841.

Figure D.33. Consolidated Simulant 1(69.9 wt\% ) 100921 shear strength (PA) as a function of time Measured at RHS

ThermoHaake RheoWin 9/24/2010/10:05 AM

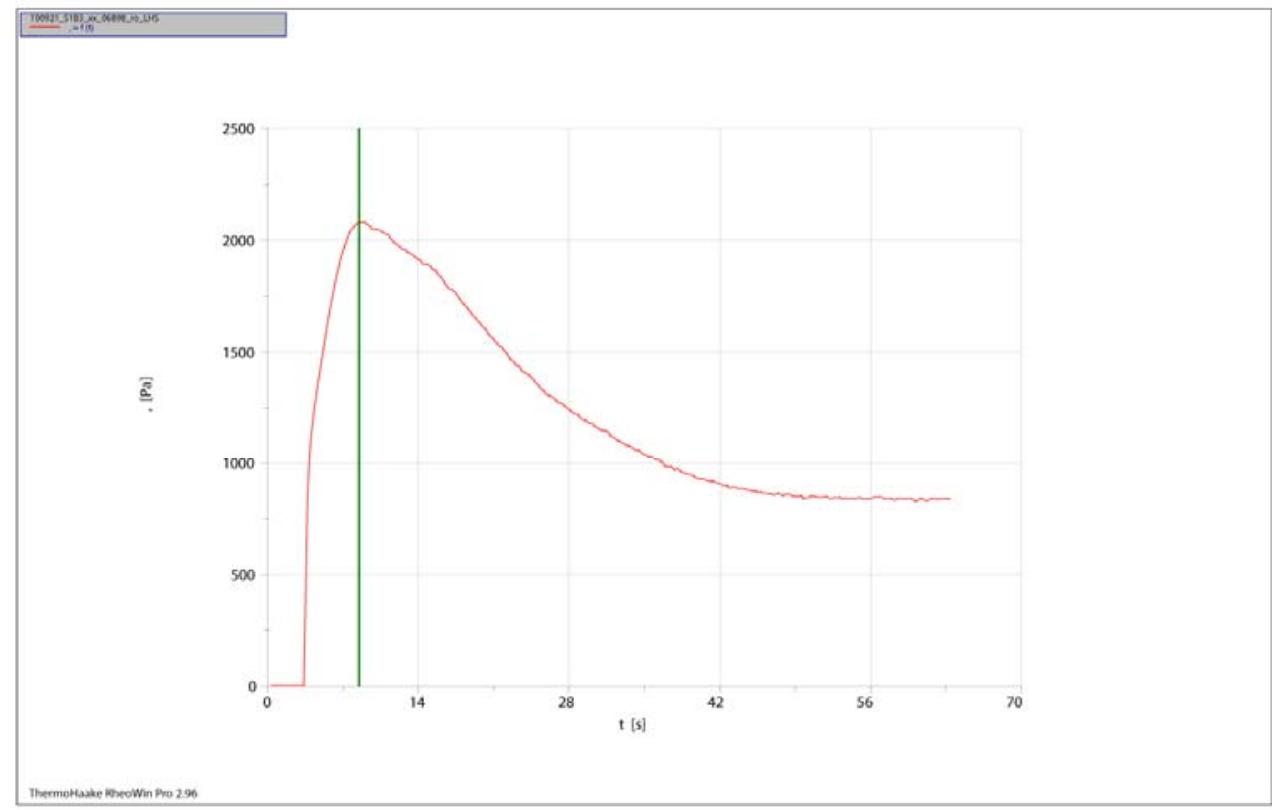

1: C:IRheoloqy Results\J\WRPSISimulant 1 PEP\Consolidated Tau\100921_S1B3 xx_06898_ro_LHS.rwd Company / Operator: PNNL / Jeromy Jenks

Date / Time / Version: 21.09.2010 / 16:53:02 PM / RheoWin Pro 296

Substance / Sample no: S1B3 / 100921_S1B3_xx_06898_ro_LHS

Curve discussion: Greatest value $\mathrm{t}[\mathrm{s}] \mathrm{8.499},[\mathrm{Pa}] 2081$.

Figure D.34. Consolidated Simulant 1(69.9 wt\% ) 100921 shear strength (PA) as a function of time Measured at LHS 


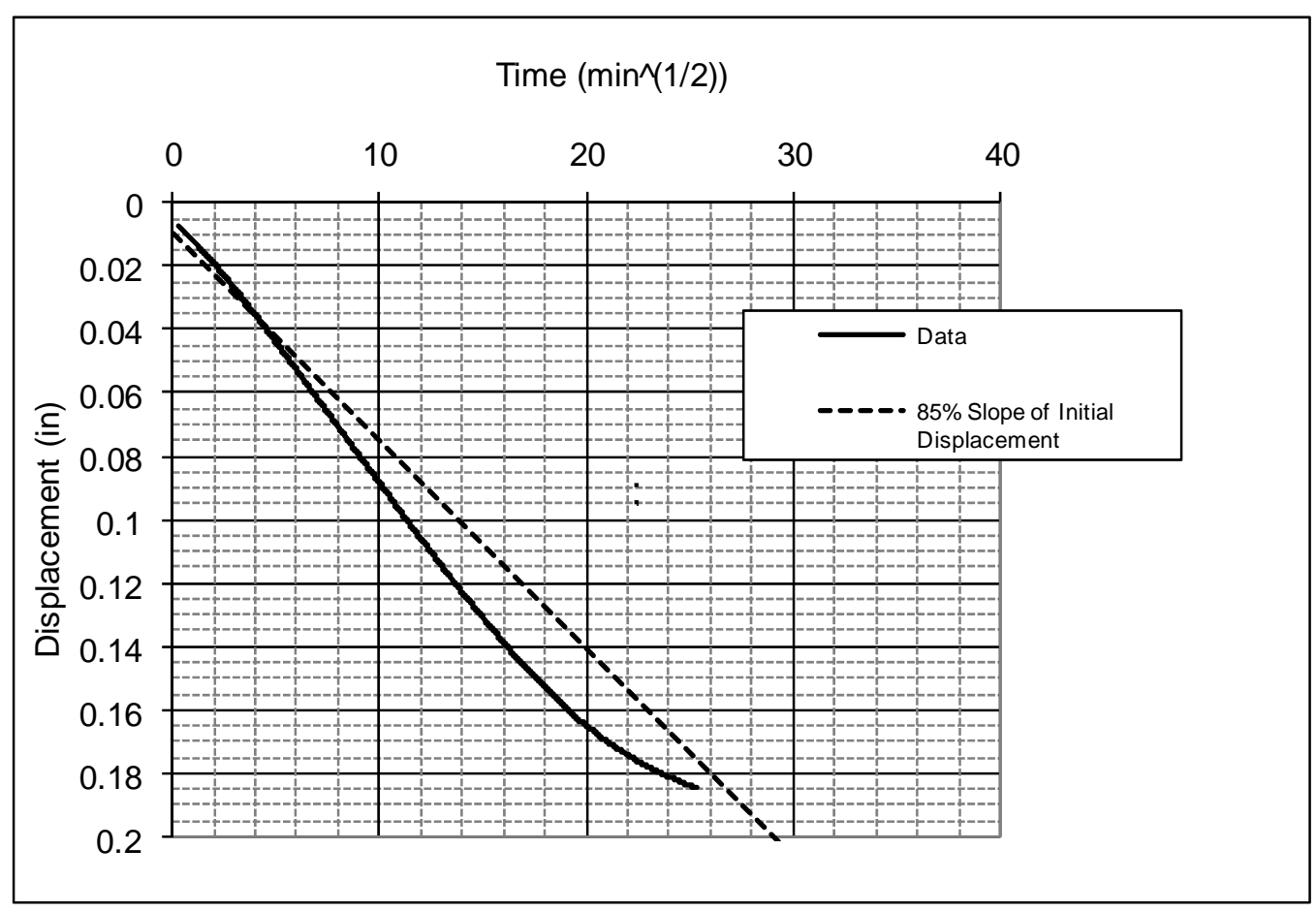

Figure D.35. Simulant 2 (42 wt\%) 100909 Displacement Versus Time ${ }^{1 / 2}$ (ASTM Standard D 2435 - 04, 12.3.2)

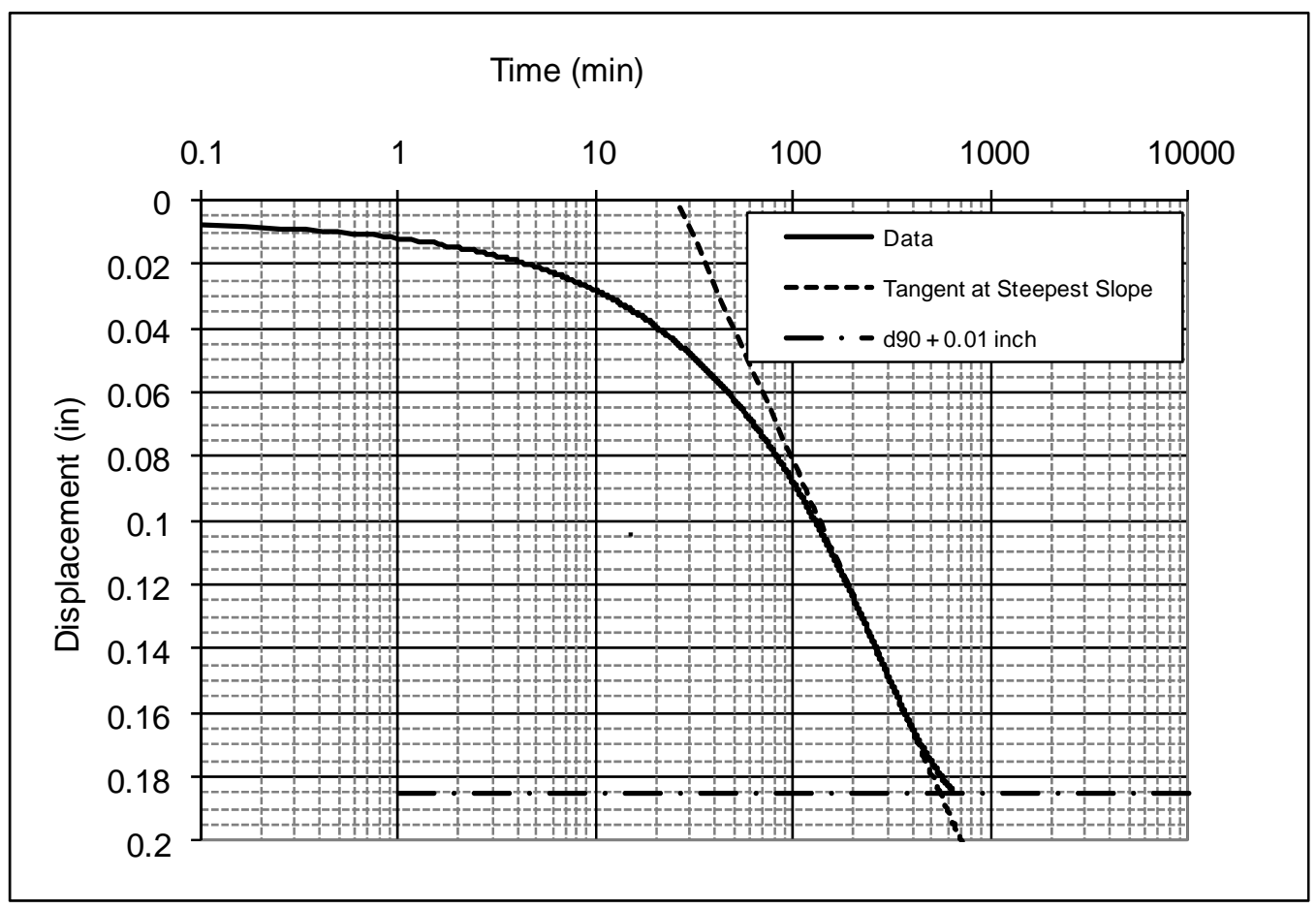

Figure D.36. Simulant 2 (42 wt\%) 100909 Displacement Versus Time ${ }^{1 / 2}$ (ASTM Standard D 2435 - 04, 12.3.1) 


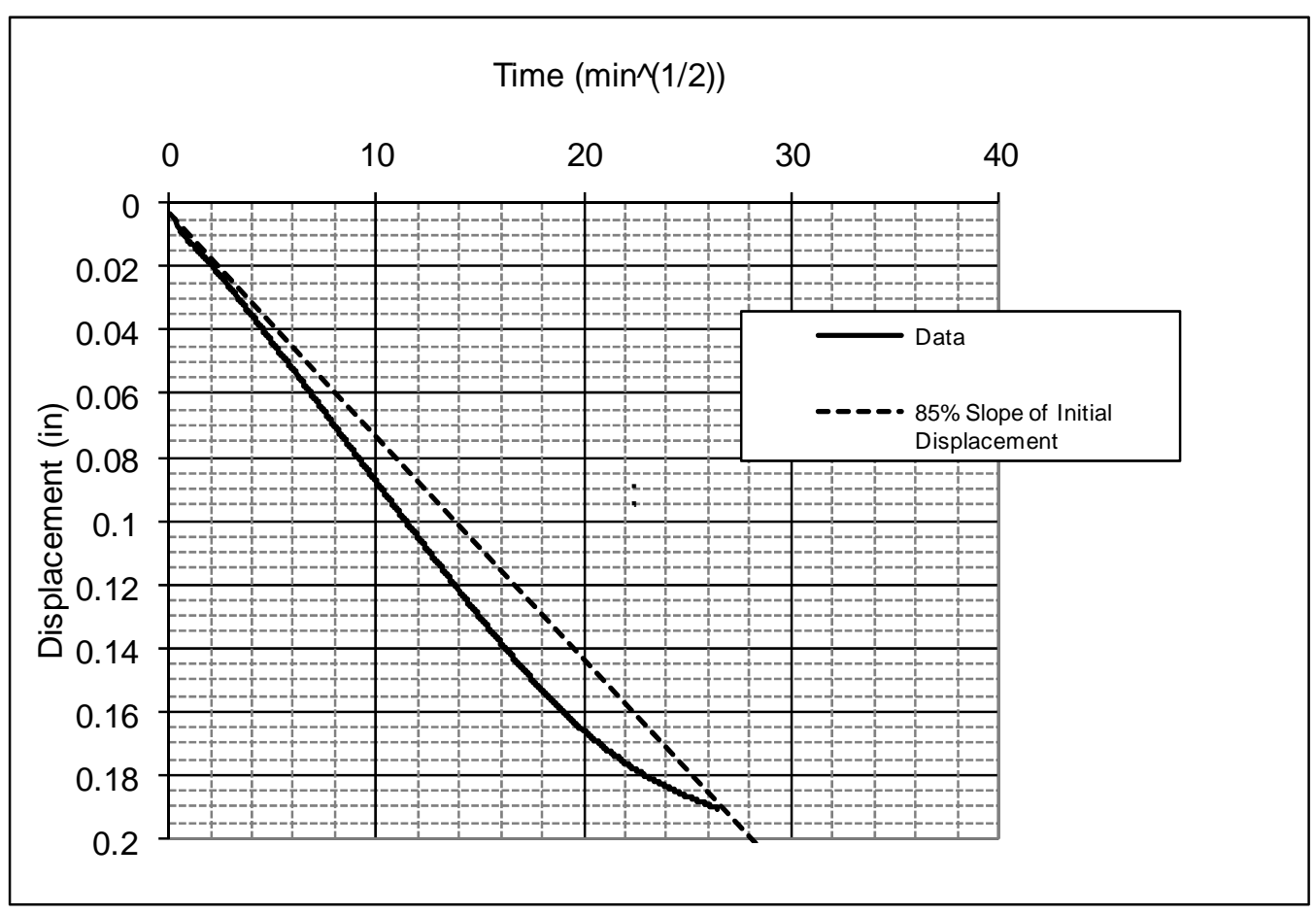

Figure D.37. Simulant 2 (42 wt\%) 100910 Displacement Versus Time ${ }^{1 / 2}$ (ASTM Standard D 2435 - 04, 12.3.2)

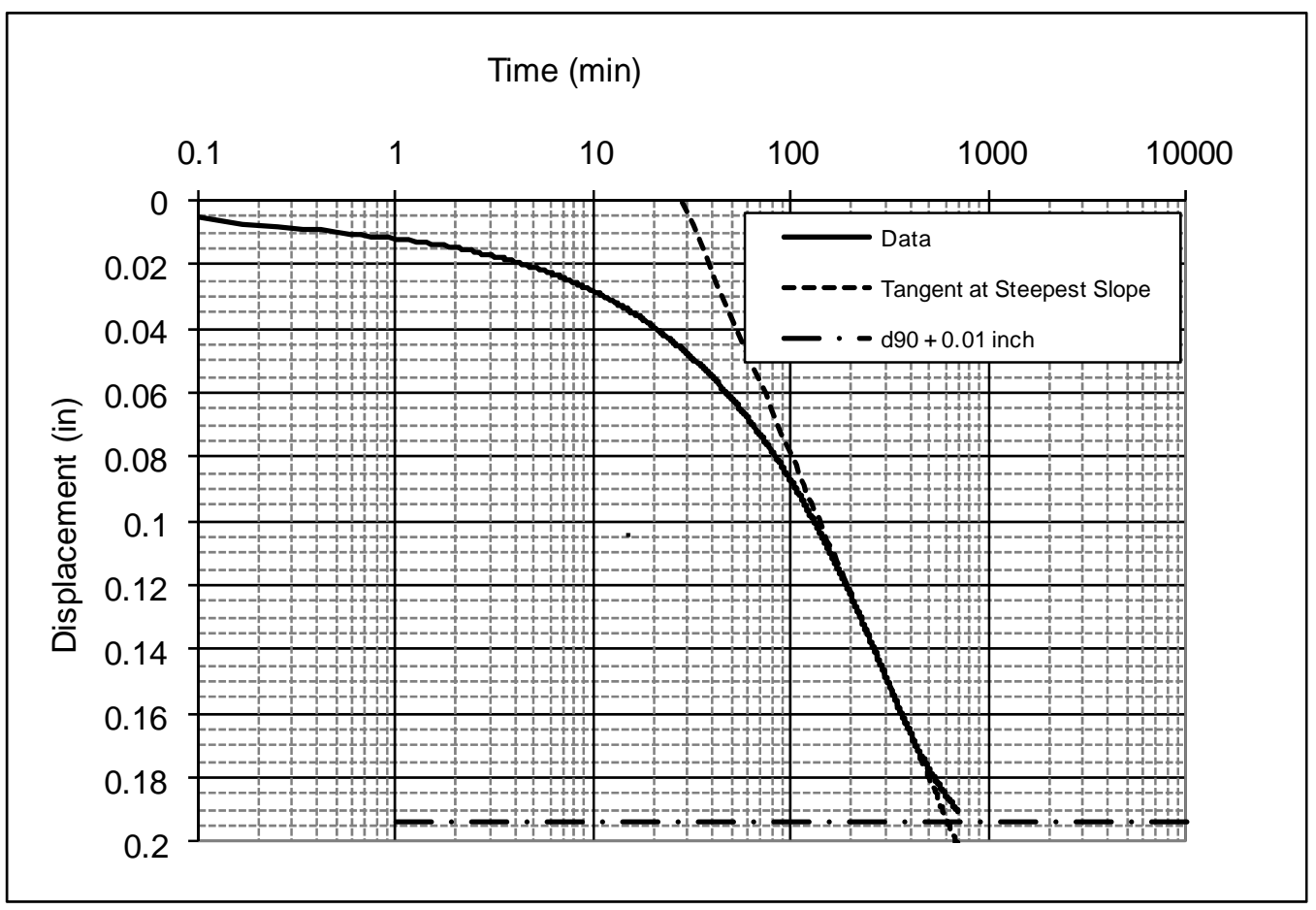

Figure D.38. Simulant 2 (42 wt\%) 100910 Displacement Versus Time ${ }^{1 / 2}$ (ASTM Standard D $2435-04$, 12.3.1) 


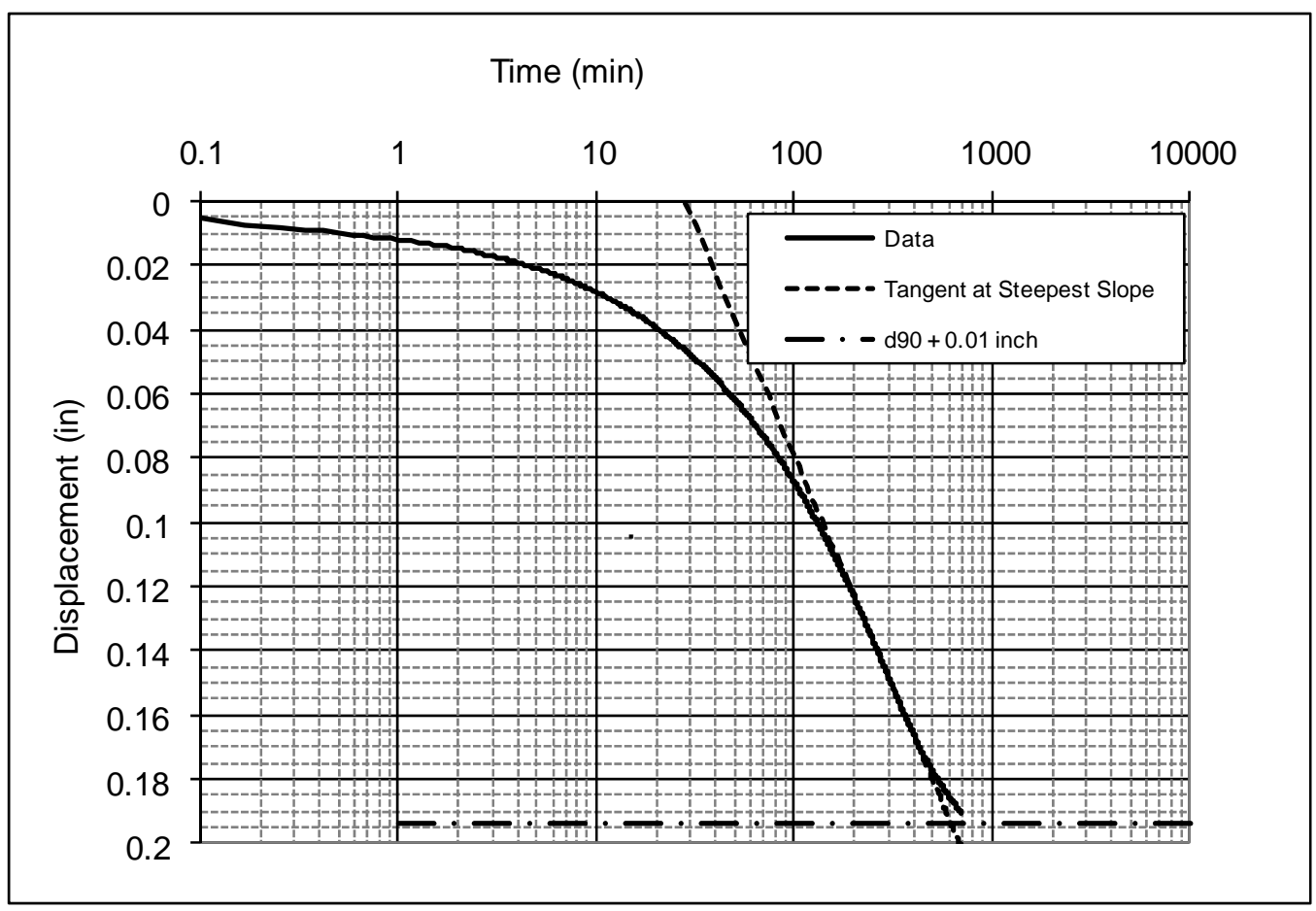

Figure D.39. Simulant 2 (42 wt\%) 100913 Displacement Versus Time ${ }^{1 / 2}$ (ASTM Standard D 2435 - 04, 12.3.2)

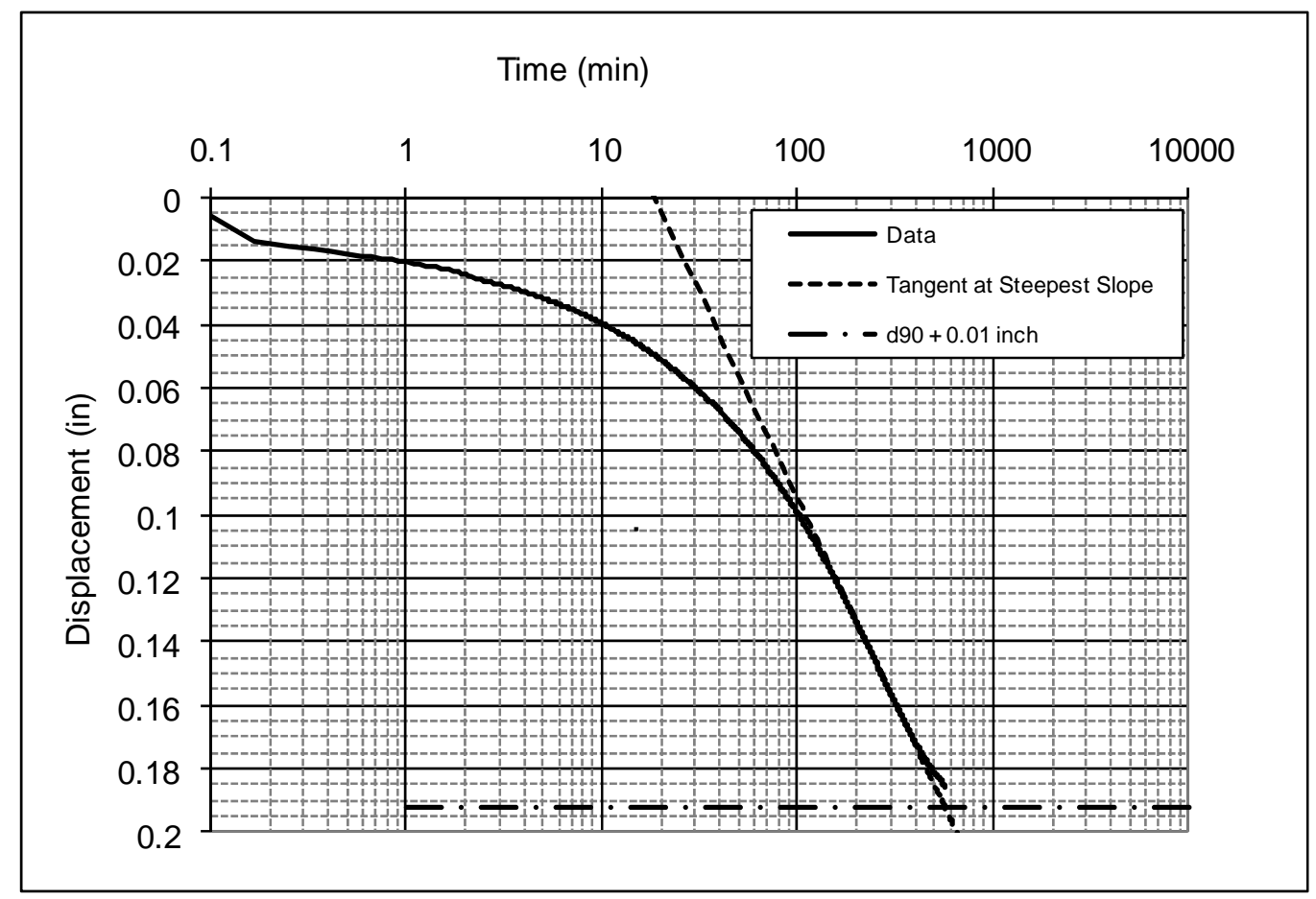

Figure D.40. Simulant 2 (42 wt\%) 100913 Displacement Versus Time ${ }^{1 / 2}$ (ASTM Standard D 2435 - 04, 12.3.1) 


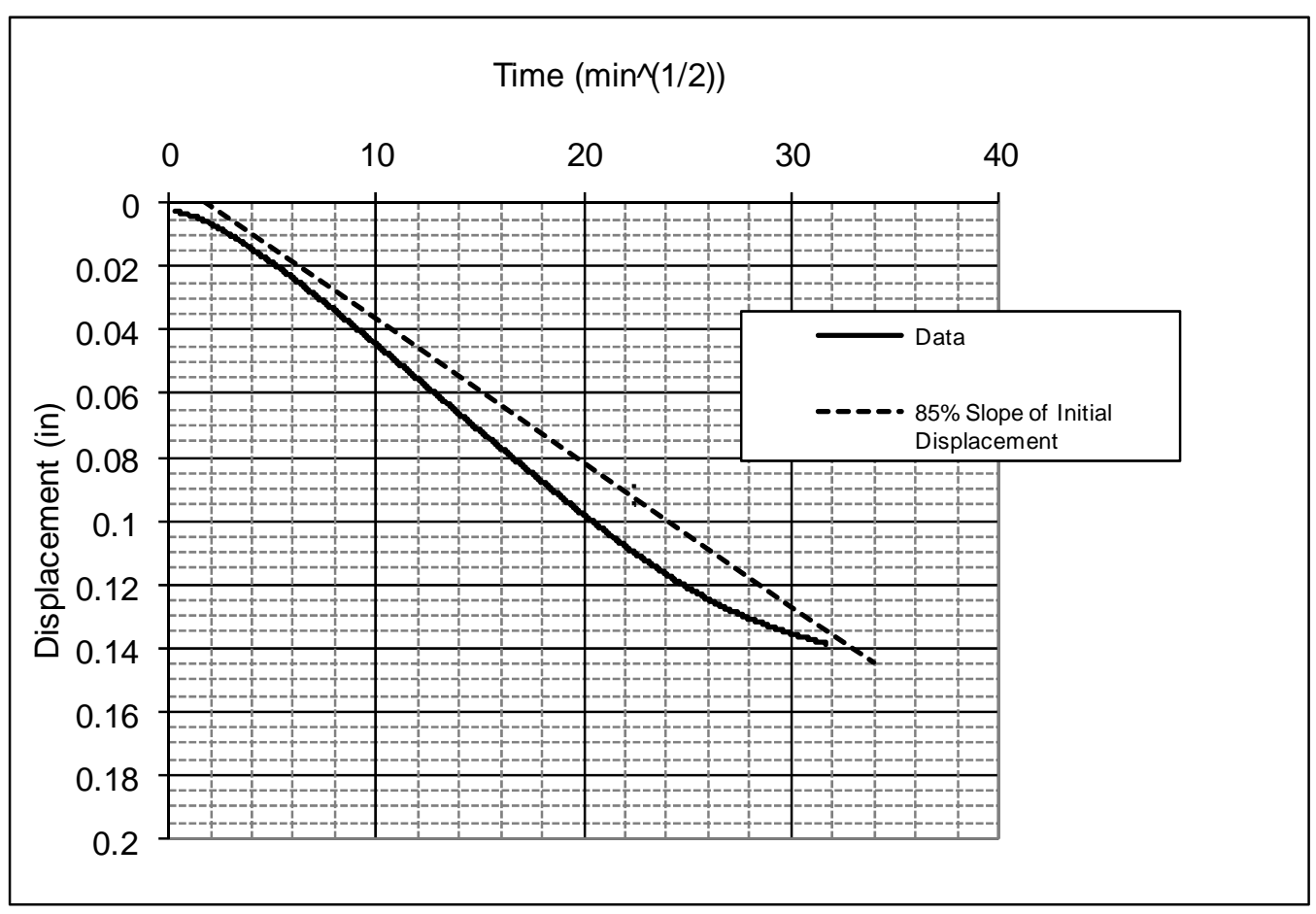

Figure D.41. Simulant 2 (40.5 wt\%) 100915 Displacement Versus Time ${ }^{1 / 2}$ (ASTM Standard D 2435 $04,12.3 .2)$

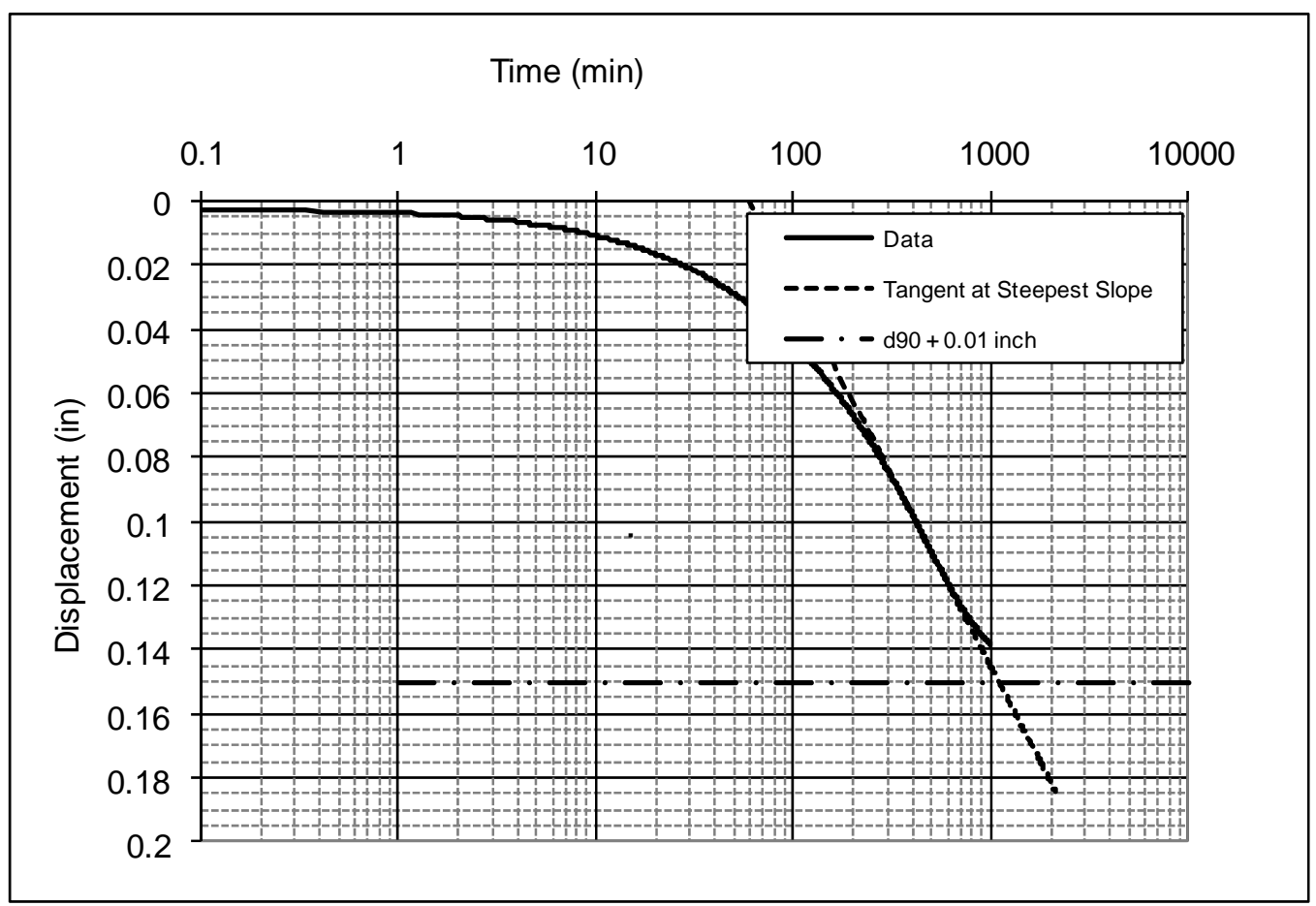

Figure D.42. Simulant 2 (40.5 wt \%) 100915 Displacement Versus Time ${ }^{1 / 2}$ (ASTM Standard D 2435 04, 12.3.1) 


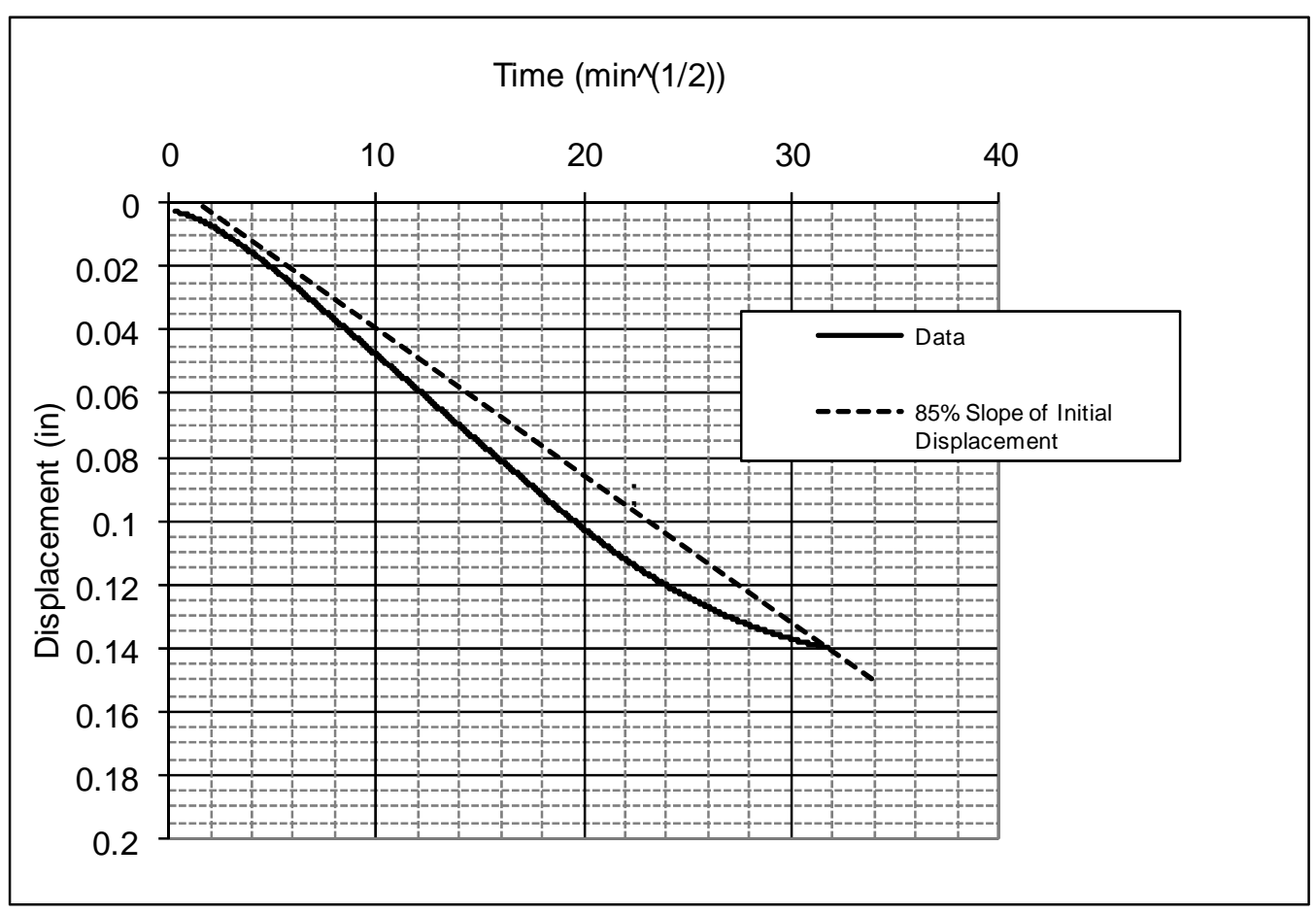

Figure D.43. Simulant 2 (40.5 wt\%) 100916 Displacement Versus Time ${ }^{1 / 2}$ (ASTM Standard D 2435 $04,12.3 .2)$

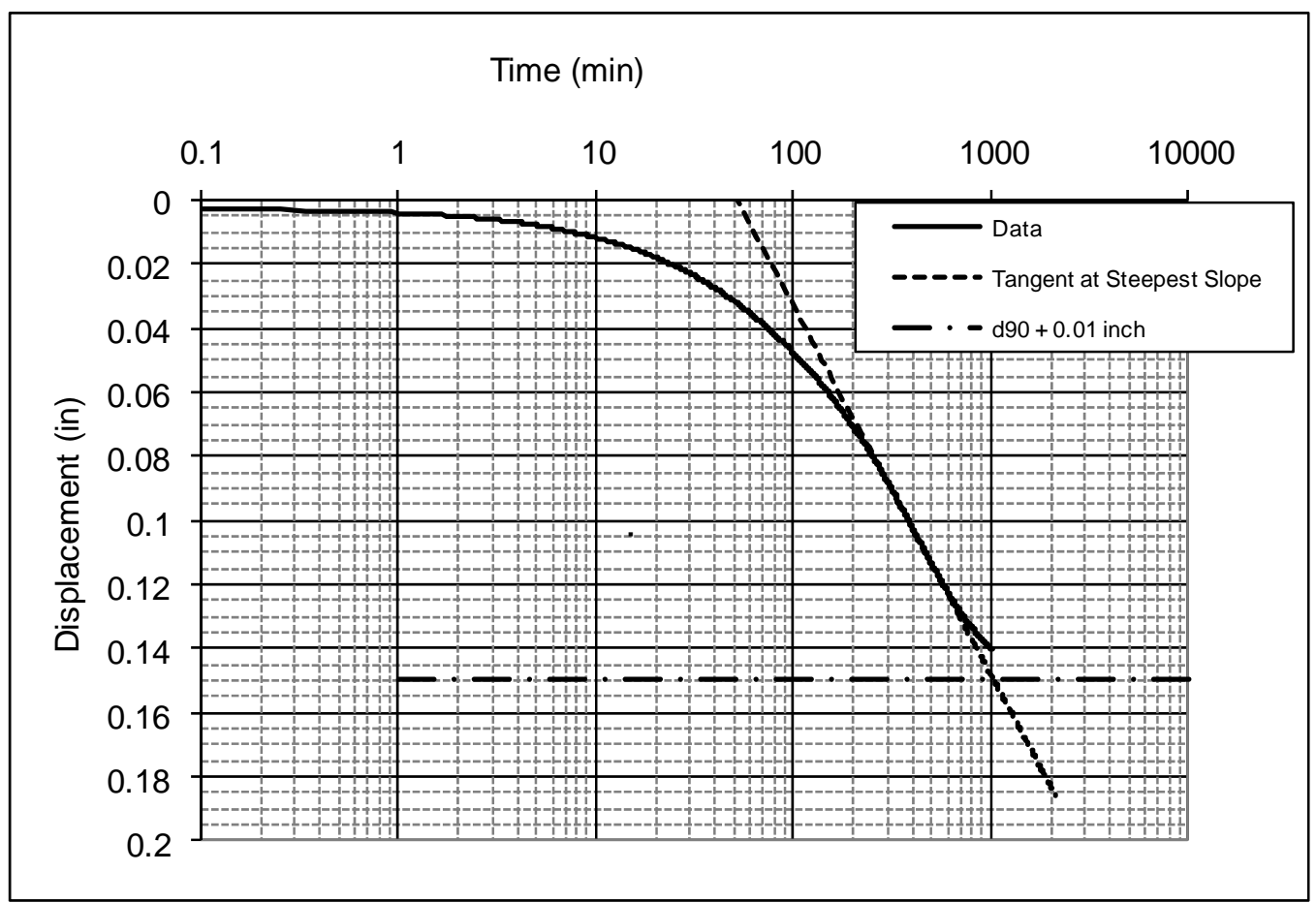

Figure D.44. Simulant 2 (40.5 wt\%) 100916 Displacement Versus Time ${ }^{1 / 2}$ (ASTM Standard D 2435 04, 12.3.1) 


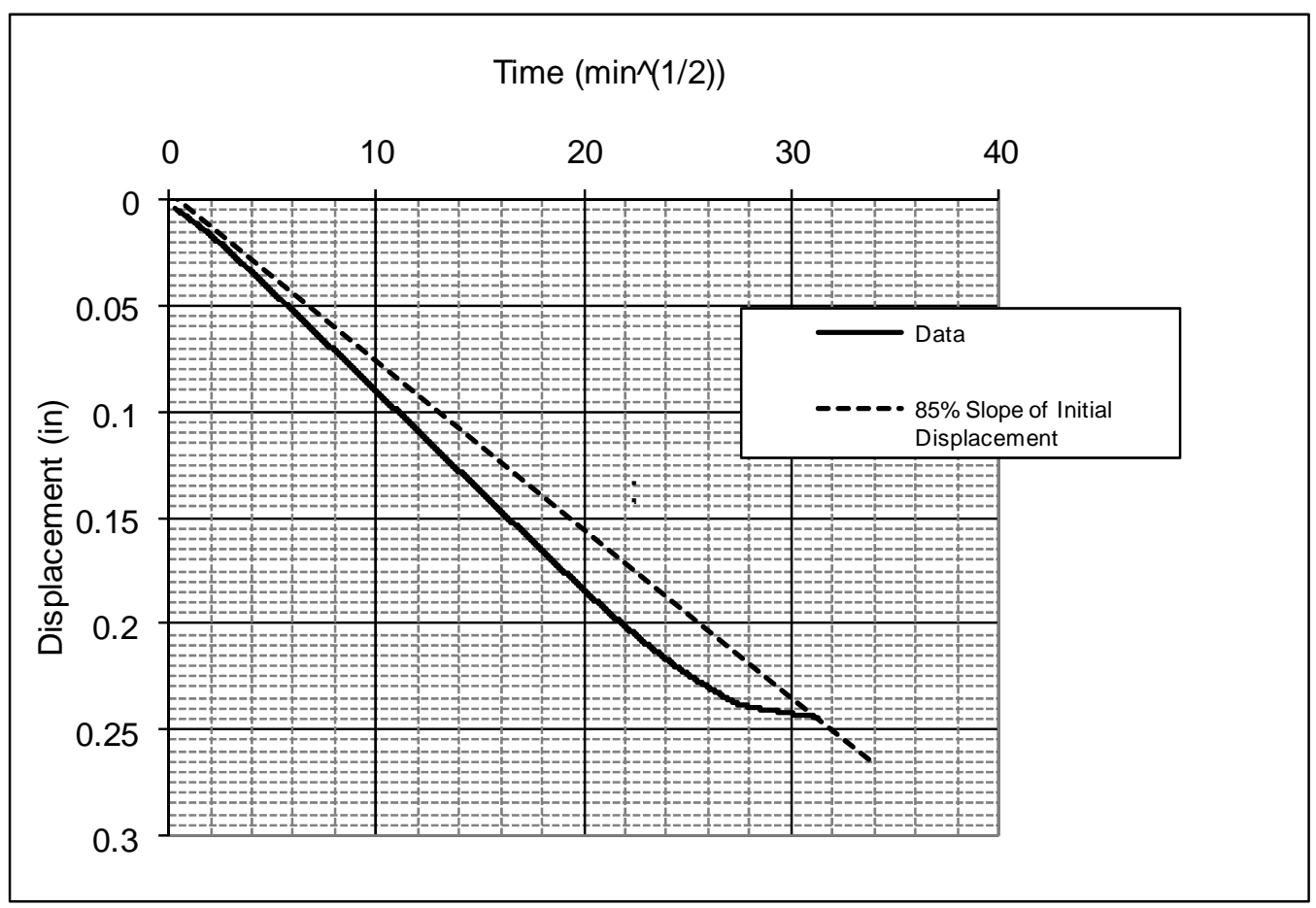

Figure D.45. Simulant 2 (36.5 wt\%) 100922 Displacement Versus Time ${ }^{1 / 2}$ (ASTM Standard D 2435 $04,12.3 .2)$

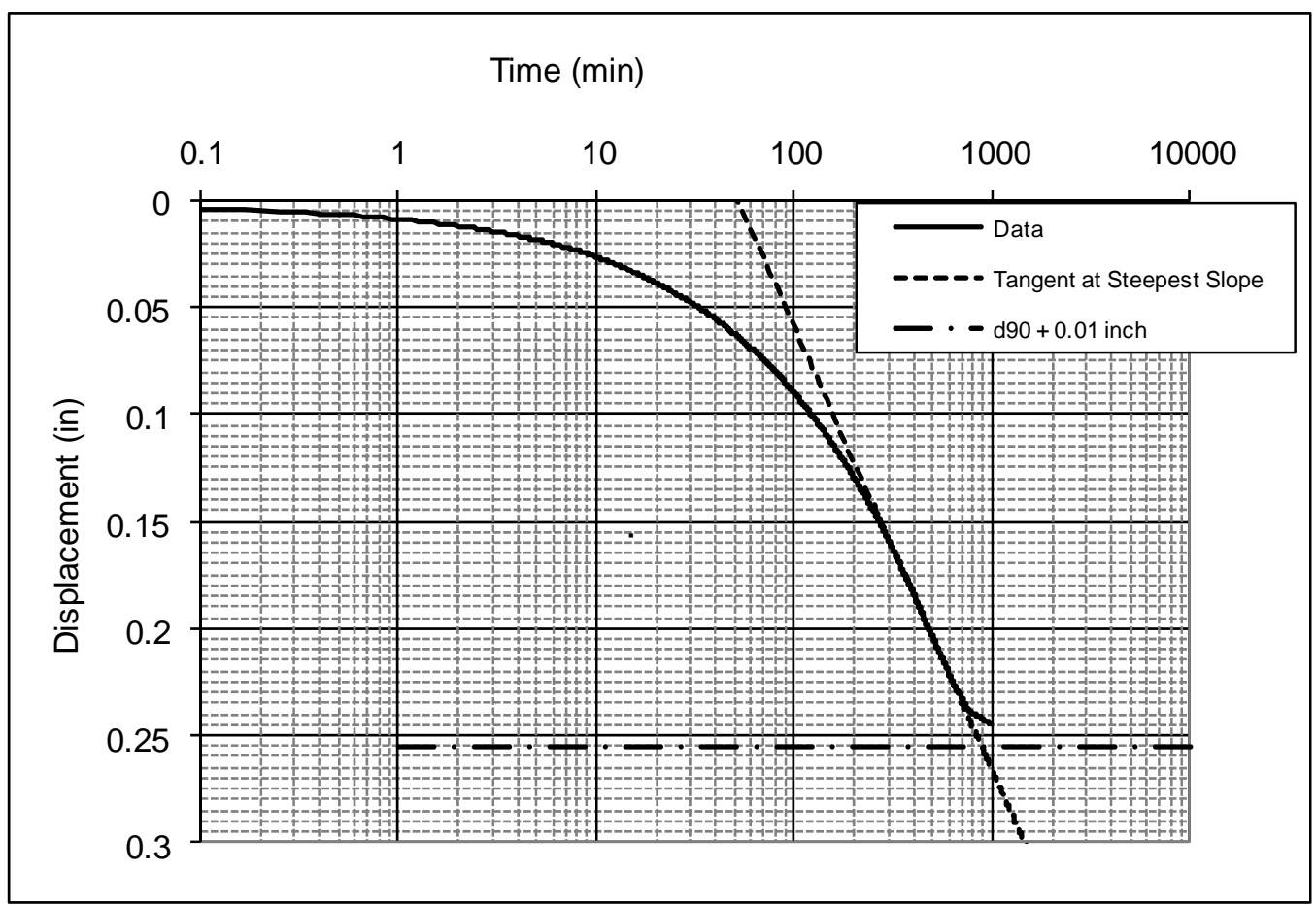

Figure D.46. Simulant 2 (36.5 wt\%) 100922 Displacement Versus Time ${ }^{1 / 2}$ (ASTM Standard D 2435 04, 12.3.1) 
ThermoHaake RheoWin 9/28/2010/8:21 AM

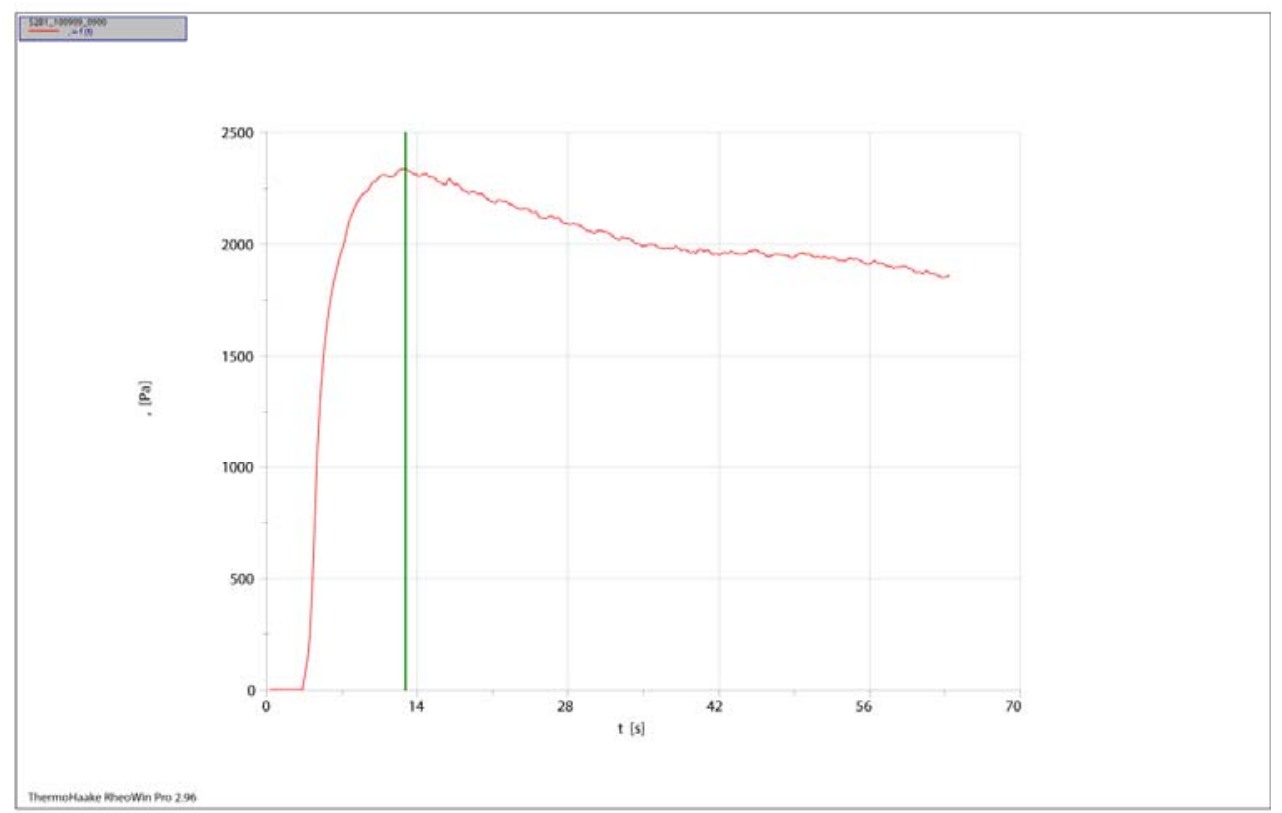

1: C:IRheoloqy Results \J\WRPSISimulant 2VInitial Tau\S2B1_100909_0900.rwd

Company / Operator: PNNL / Jeromy Jenks

Date / Time / Version: 09.09.2010 / 8.57:14 AM / RheoWin Pro 296

Substance / Sample no: S2B1 / S2B1_100909 0900

Curve discussion: Greatest value $\mathrm{t}[\mathrm{s}] 12.91$, [Pa] 2336.

Figure D.47. Initial Simulant 2(42 wt $\%$ ) shear strength (PA) as a function of time Measured at Center

ThermoHaake RheoWin 9/28/2010/8:24 AM

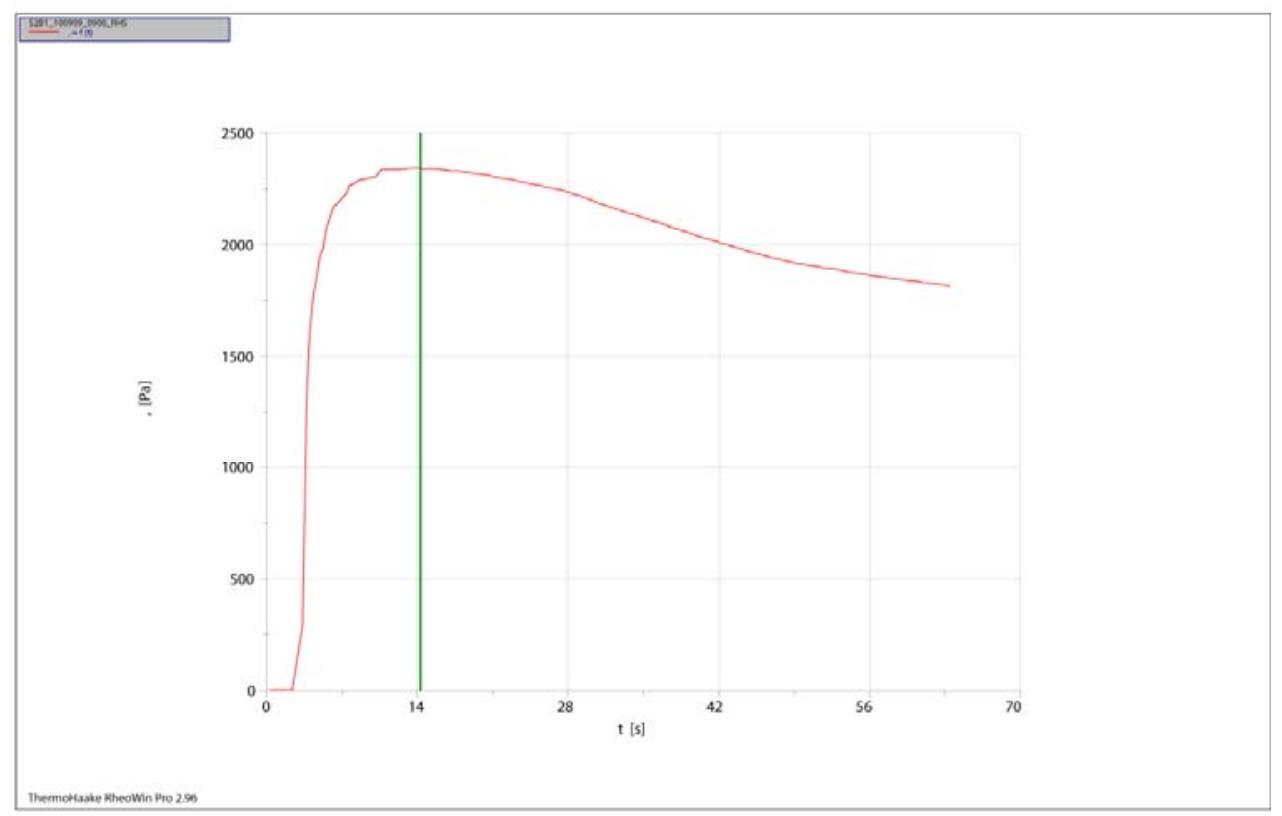

1: C:IRheoloqy Results\JWRPSISimulant 2VInitial Tau\S2B1_100909_0900_RHS.rwd

Company / Operator: PNNL / Jeromy Jenks

Date / Time / Version: 09.09.2010 / 9:00:32 AM / RheoWin Pro 296

Substance / Sample no: S2B1 / S2B1_100909_0900_RHS

Curve discussion: Greatest value $\mathrm{t}[\mathrm{s}] 14.29,[\mathrm{~Pa}] 2342$.

Figure D.48. Initial Simulant 2(42 wt \% ) shear strength (PA) as a function of time Measured at RHS 
ThermoHaake RheoWin 9/28/2010/8:22 AM

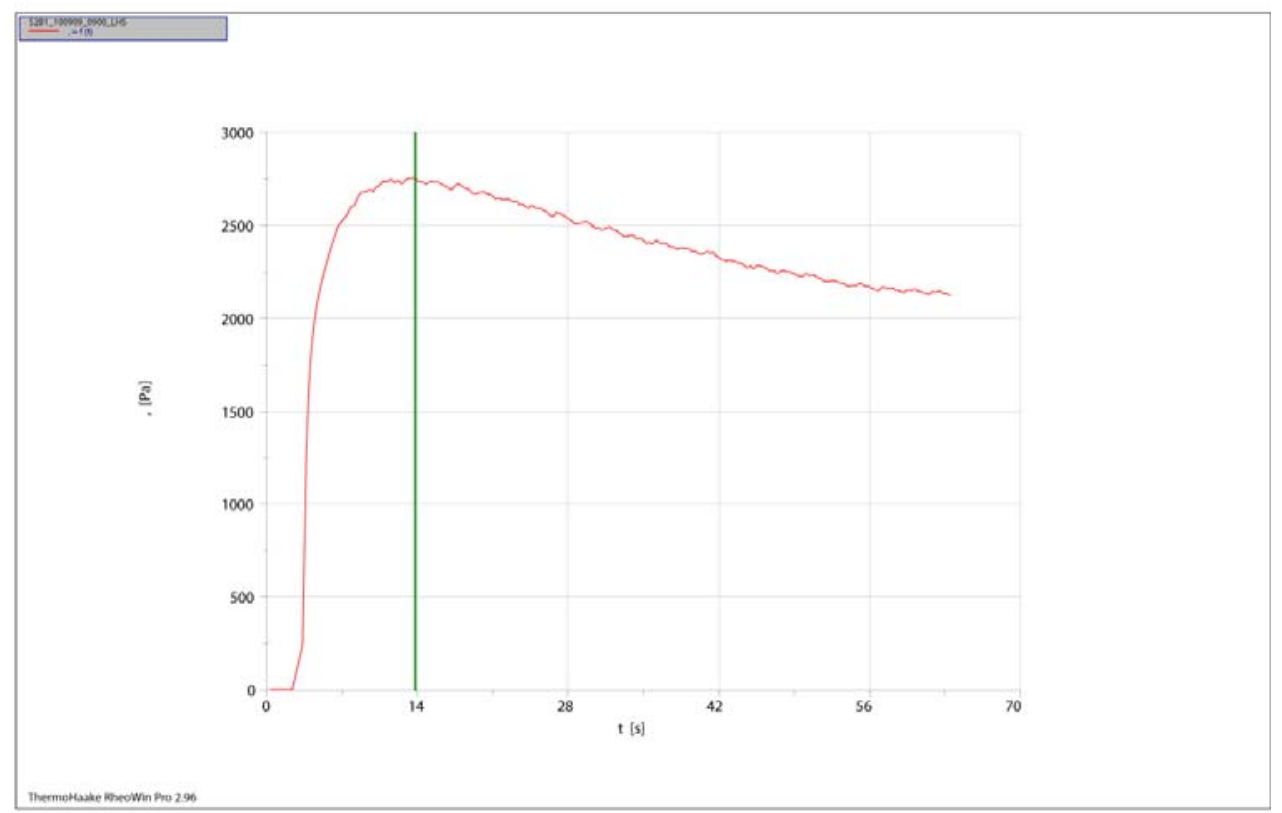

1: C:IRheoloqy Results\JWWRPSISimulant 2\Initial Tau\S2B1_100909_0900_LHS.rwd

Company / Operator: PNNL / Jeromy Jenks

Date / Time / Version: 09.09.2010/ 9:04:13 AM / RheoWin Pro 296

Substance / Sample no: S2B1 / S2B1_100909_0900_LHS

Curve discussion: Greatest value $\mathrm{t}[\mathrm{s}] 13.81,[\mathrm{~Pa}] 2 \overline{7} 57$.

Figure D.49. Initial Simulant 2(42 wt $\%)$ shear strength (PA) as a function of time Measured at LHS

ThermoHaake RheoWin 9/28/2010/8:03 AM

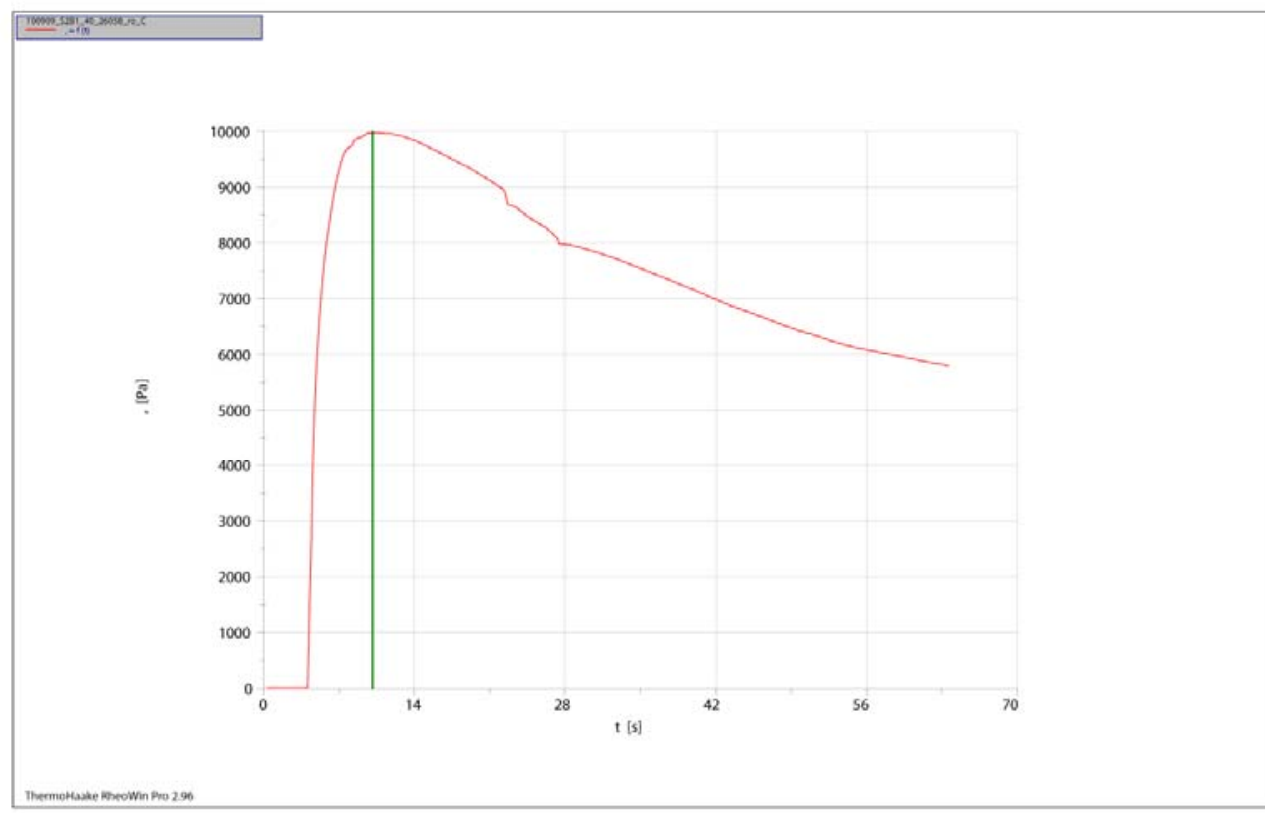

1: C: $:$ Rheoloqy Results\JWWRS\Simulant 2\Consolidated Tau\100909_S2B1_40_26058_ro_C.rwd

Company / Operator: PNNL / Jeromy Jenks

Date / Time / Version: 10.09.2010 / 11:22:29 AM / RheoWin Pro 296

Substance / Sample no: S2B1 / 100909_S2B1_40_26058_ro_C

Curve discussion: Greatest value $\mathrm{t}[\mathrm{s}] 10.13$, [Pa] 9967.

Figure D.50. Consolidated Simulant 2(45.4 wt\% ) 100909 shear strength (PA) as a function of time Measured at Center 


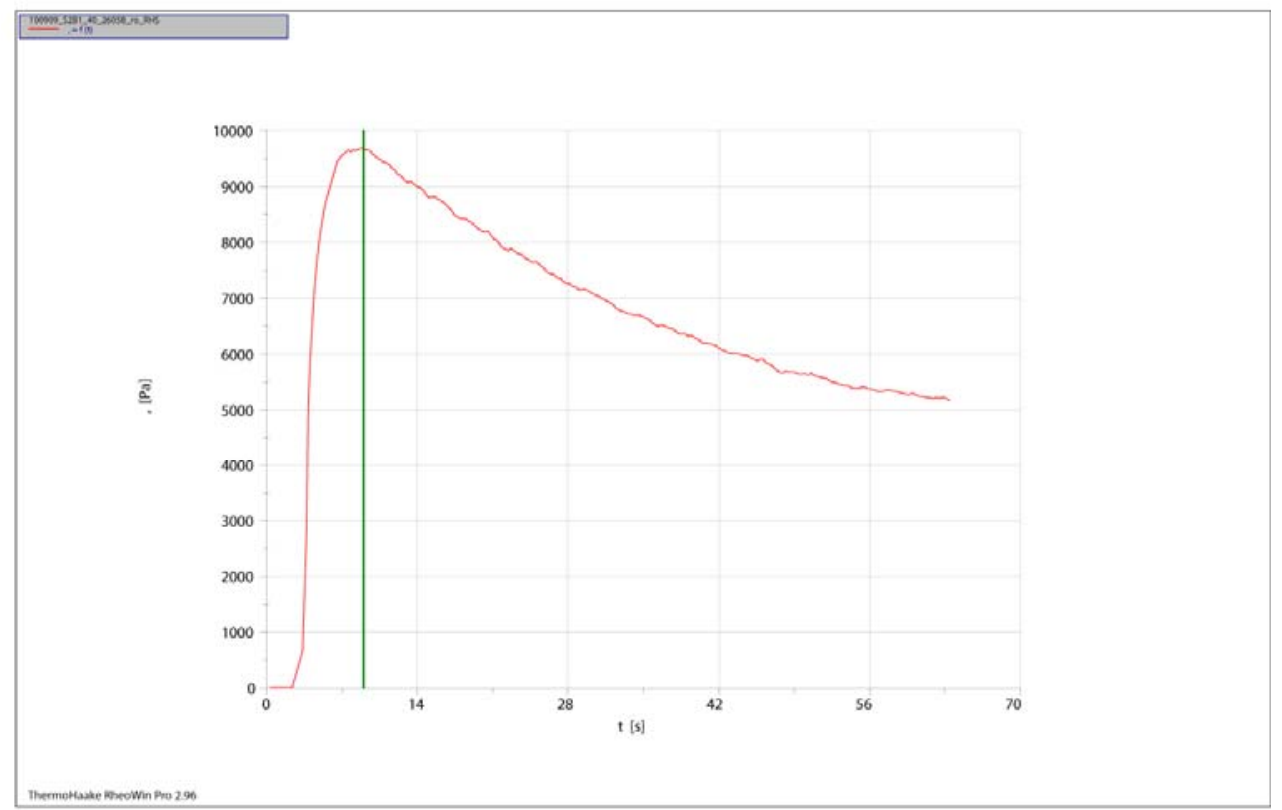

1: C:IRheoloqy Results\JWWRPSISimulant 2\Consolidated Tau\100909_S2B1_40_26058_ro_RHS.rwd

Company / Operator: PNNL / Jeromy Jenks

Date / Time / Version: 10.09.2010/11:31:00 AM / RheoWin Pro 296

Substance / Sample no: S2B1 / 100909 S2B1_40_26058_ro_RHS

Curve discussion: Greatest value $\mathrm{t}[\mathrm{s}] 9.026$, [Pa] 9689.

Figure D.51. Consolidated Simulant 2(45.4 wt\% ) 100909 shear strength (PA) as a function of time Measured at RHS

ThermoHaake RheoWin 9/28/2010/8:05 AM

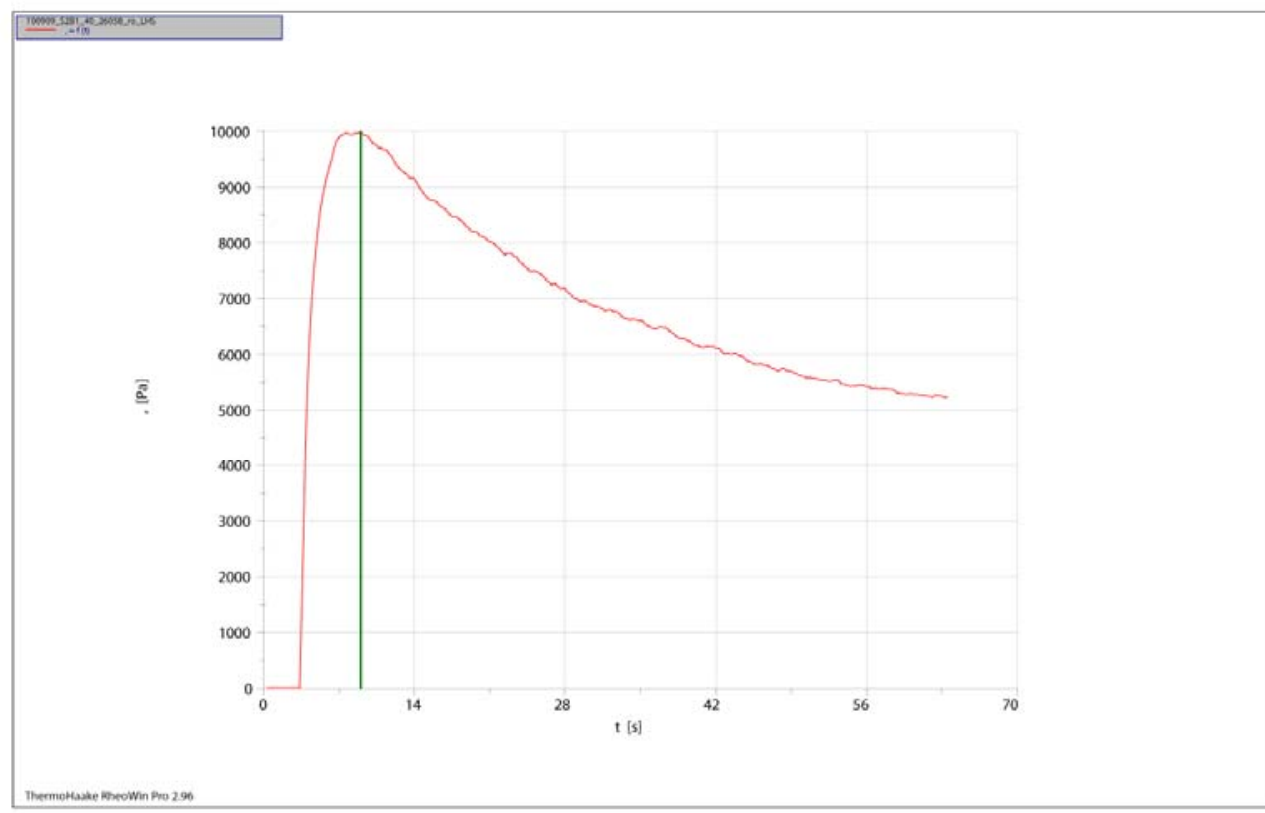

1: C:\Rheoloqy Results\J\WRPS\Simulant 2\Consolidated Tau\100909_S2B1_40_26058_ro_LHS.rwd

Company / Operator: PNNL / Jeromy Jenks

Date / Time / Version: 10.09.2010/11:35:26 AM / RheoWin Pro 296

Substance / Sample no: S2B1 / 100909_S2B1_40_26058_ro_LHS

Curve discussion: Greatest value $\mathrm{t}[\mathrm{s}] 9.040$, [Pa] 9967.

Figure D.52. Consolidated Simulant 2(45.4 wt\% ) 100909 shear strength (PA) as a function of time Measured at LHS 
ThermoHaake RheoWin 9/28/2010/8:06 AM

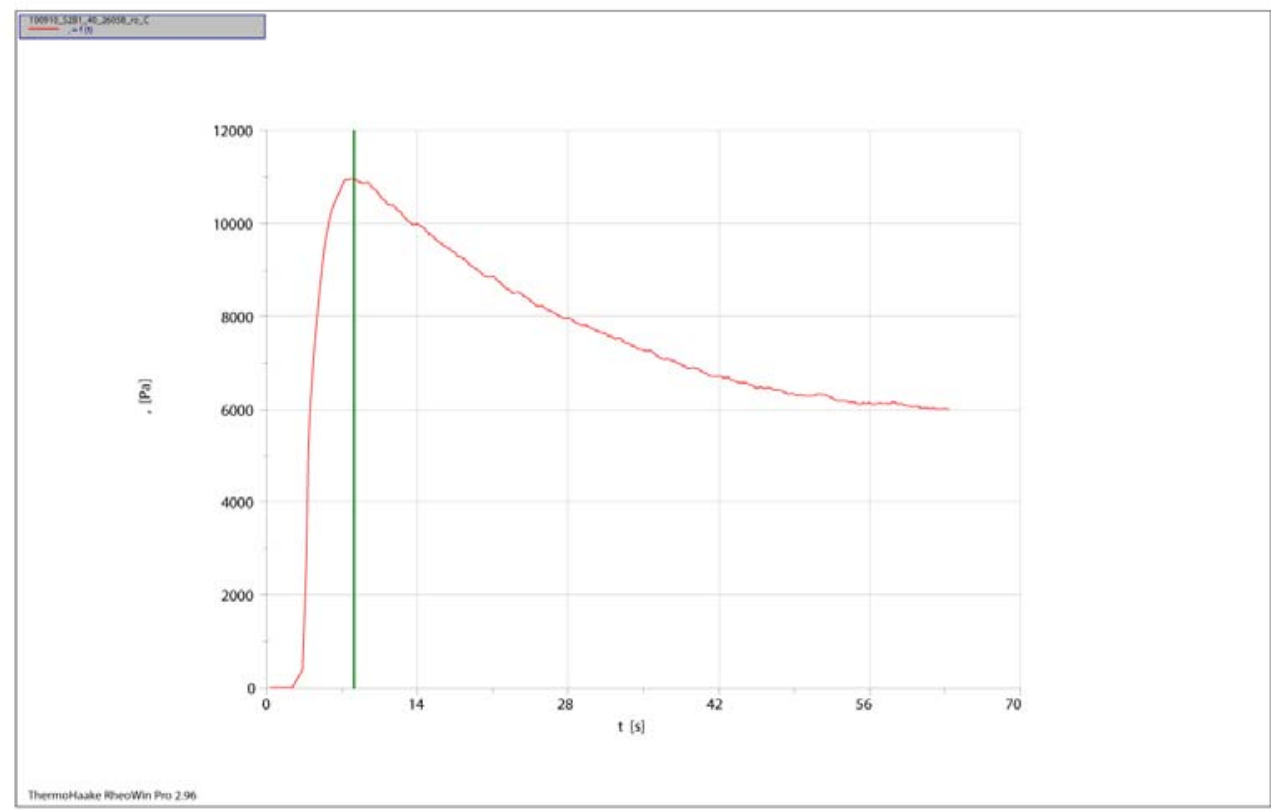

1: C:IRheoloqy Results \J\WRPS\Simulant 2\Consolidated Tau\100910_S2B1_40_26058_ro_C.rwd

Company / Operator: PNNL / Jeromy Jenks

Date / Time / Version: 14.09.2010 / 16.08.03 PM / RheoWin Pro 296

Substance / Sample no: S2B1 / 100910_S2B1_40_26058_ro_C

Curve discussion: Greatest value $\mathrm{t}[\mathrm{s}] \mathrm{8.129}$, [Pa] $1.097 \mathrm{e}+04$

Figure D.53. Consolidated Simulant 2(45.3 wt\% ) 100910 shear strength (PA) as a function of time Measured at Center

ThermoHaake RheoWin 9/28/2010/8:07 AM

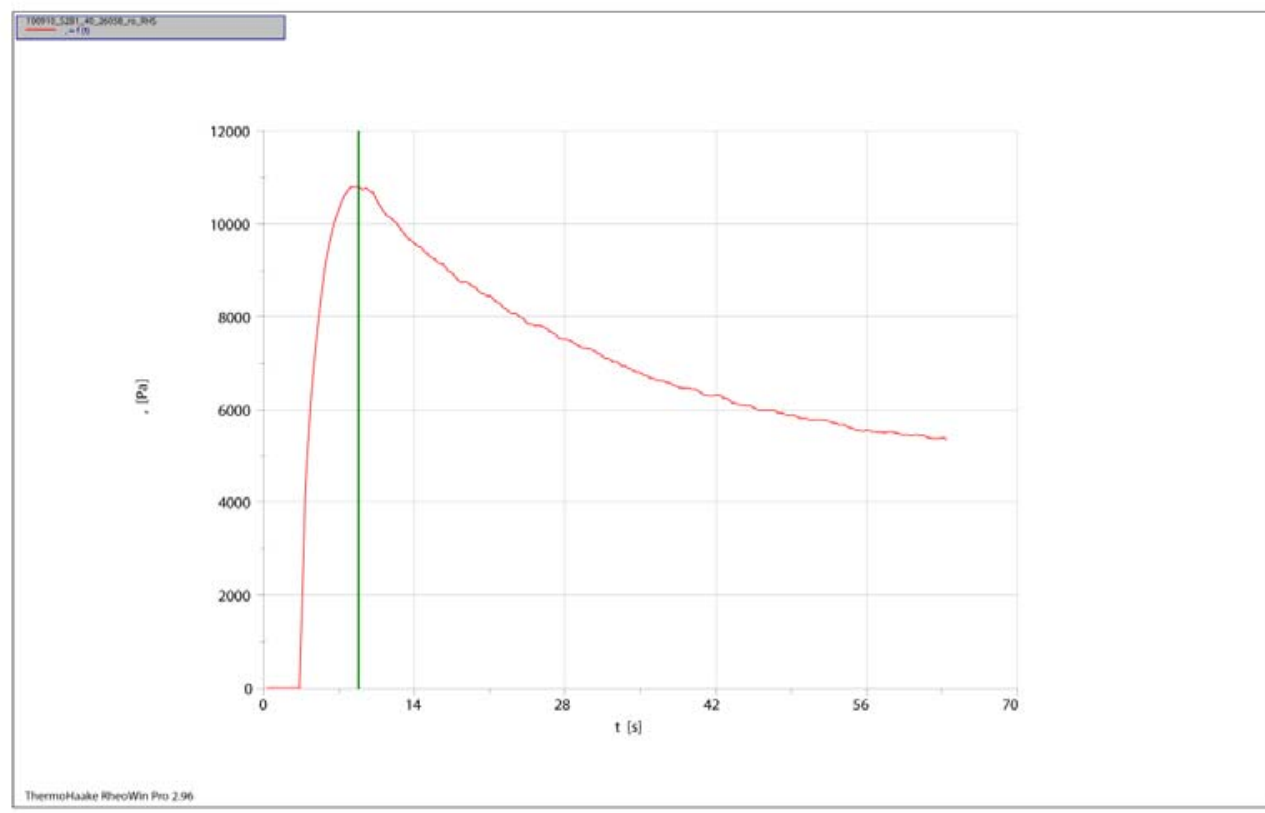

1: C:IRheoloqy Results\J\WRPS\Simulant 2\Consolidated Tau\100910_S2B1_40_26058_ro_RHS.rwd

Company / Operator: PNNL / Jeromy Jenks

Date / Time / Version: 14.09.2010 / 16:12:41 PM / RheoWin Pro 296

Substance / Sample no: S2B1 / 100910_S2B1_40_26058 ro_RHS

Curve discussion: Greatest value $\mathrm{t}[\mathrm{s}] 8.839$, [Pa] $1.081 \mathrm{e}+04$

Figure D.54. Consolidated Simulant 2(45.3 wt\% ) 100910 shear strength (PA) as a function of time Measured at RHS 
ThermoHaake RheoWin 9/28/2010/8:07 AM

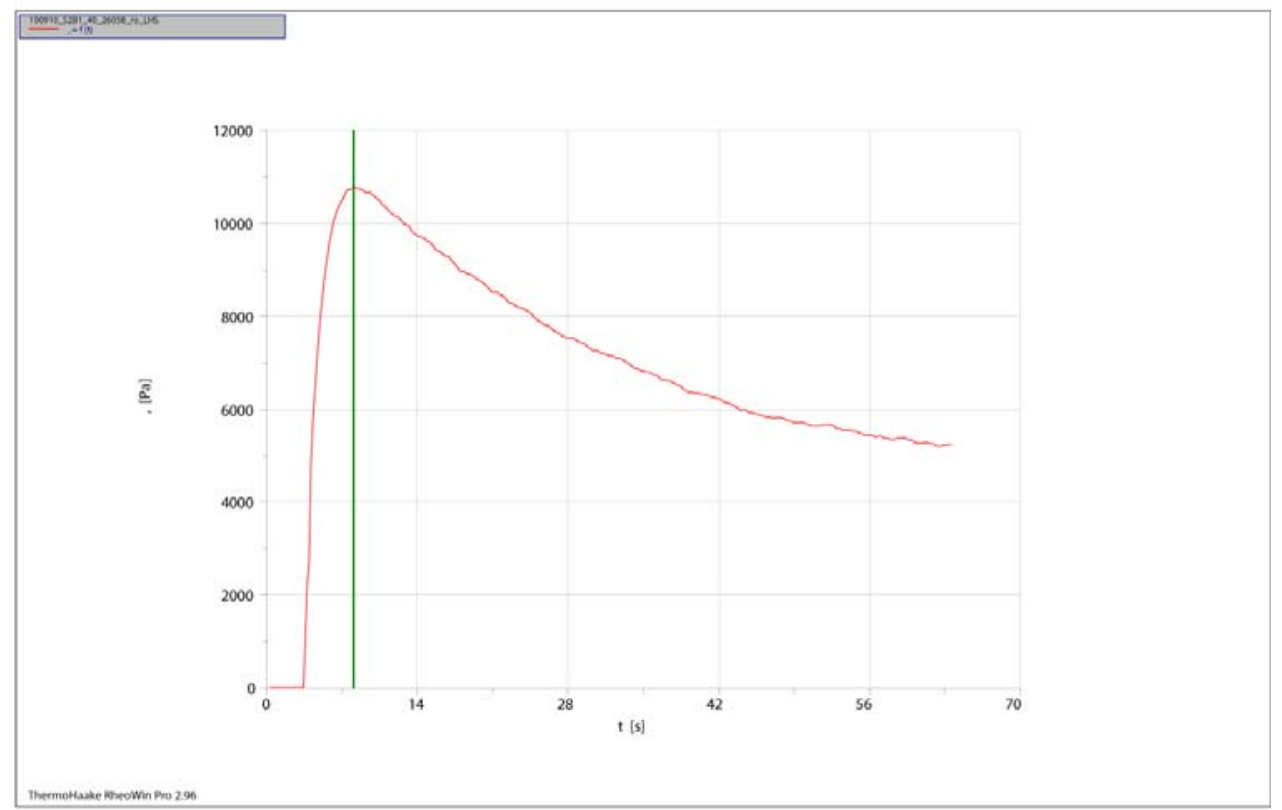

1: C:IRheoloqy Results \J\WRPS \Simulant 2\Consolidated Tau\100910_S2B1_40_26058_ro_LHS.rwd

Company / Operator: PNNL / Jeromy Jenks

Date / Time / Version: 14.09.2010 / 16:16:47 PM / RheoWin Pro 296

Substance / Sample no: S2B1 / 100910_S2B1_40_26058_ro_LHS

Curve discussion: Greatest value $\mathrm{t}[\mathrm{s}] 8.079$, [ $\mathrm{Pa}] 1.078 \mathrm{e}+04$

Figure D.55. Consolidated Simulant 2(45.3 wt\% ) 100910 shear strength (PA) as a function of time Measured at LHS

ThermoHaake RheoWin 9/28/2010/8:08 AM

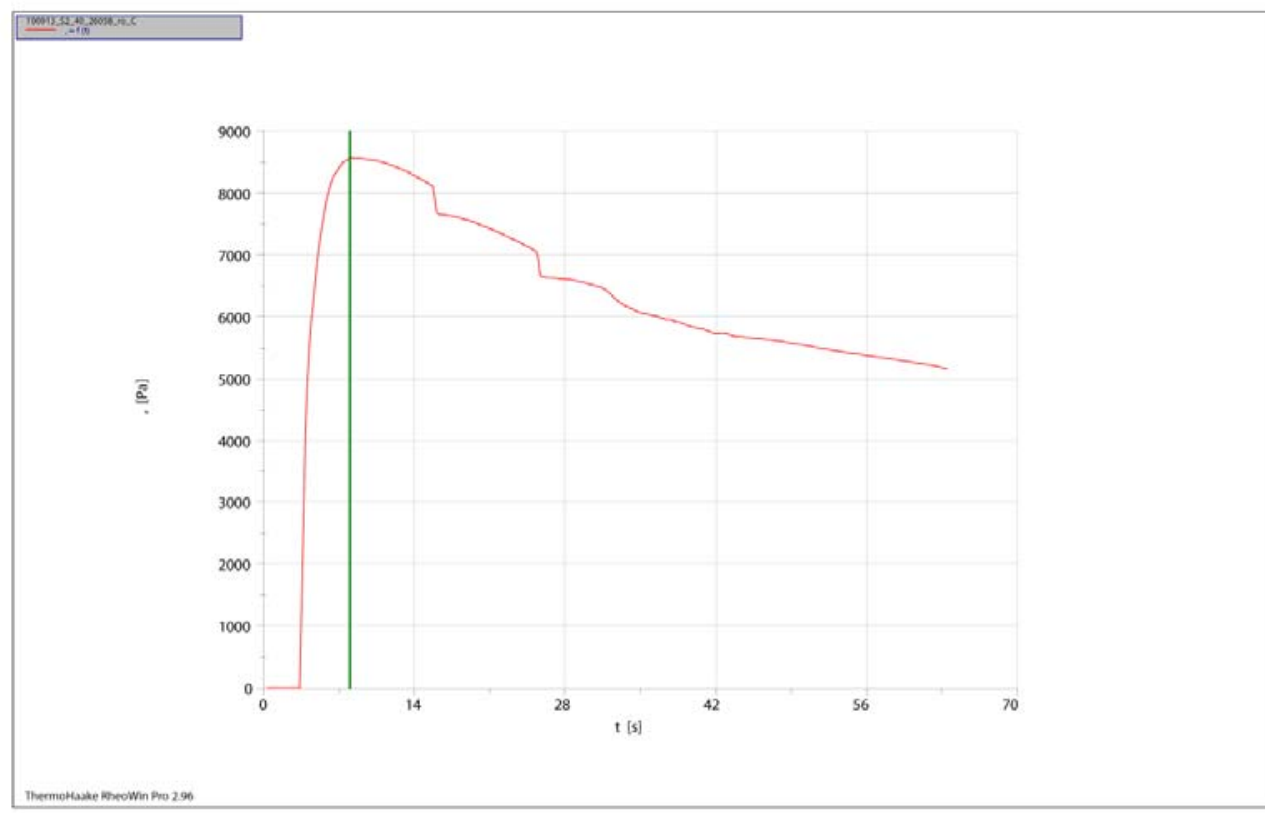

1: C:IRheoloqy Results\J\WRPS\Simulant 2\Consolidated Tau\100913_S2_40_26058 ro_C.rwd

Company / Operator: PNNL / Jeromy Jenks

Date / Time / Version: 14.09.2010 / 16:22.50 PM / RheoWin Pro 296

Substance / Sample no: S2B1 / 100913_S2_40_26058_ro_C

Curve discussion: Greatest value $\mathrm{t}[\mathrm{s}] \mathrm{8.019},[\mathrm{P} a] 856 \overline{5}$.

Figure D.56. Consolidated Simulant 2(44.8 wt\% ) 100913 shear strength (PA) as a function of time Measured at Center 


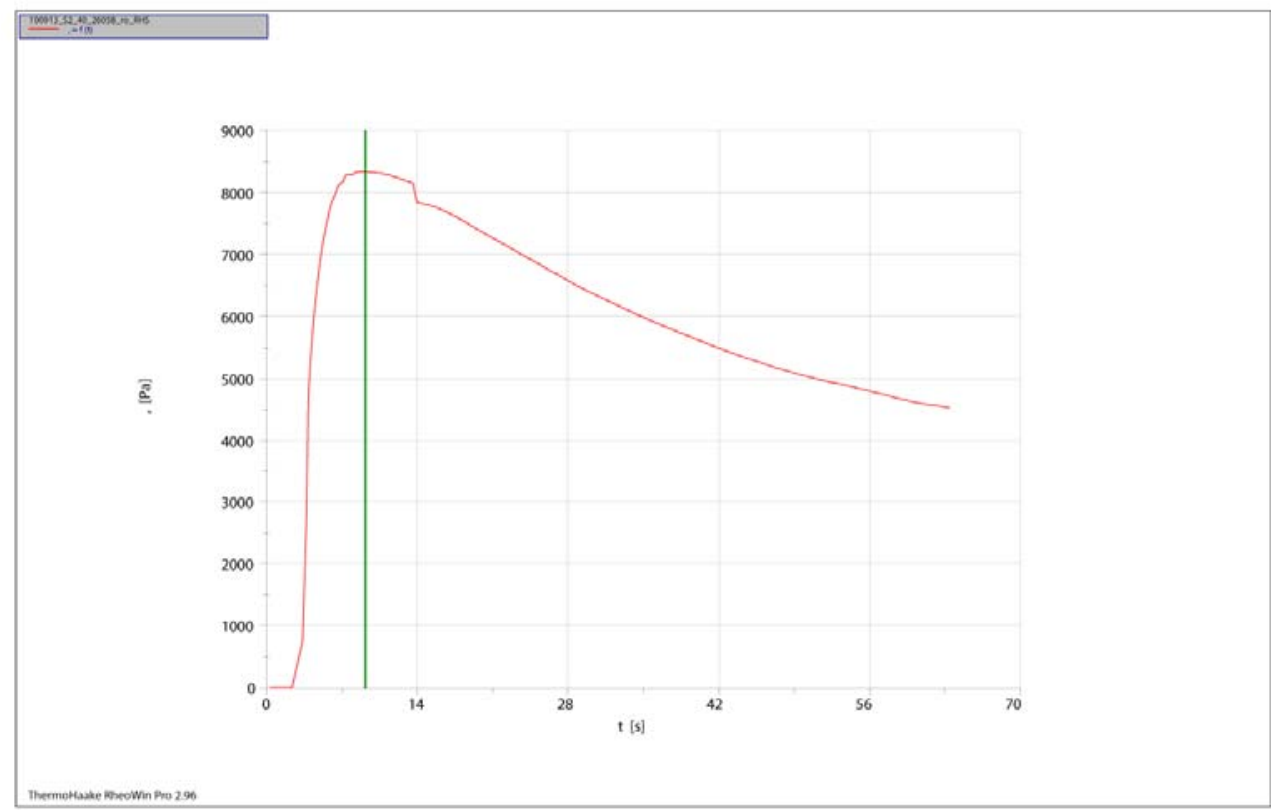

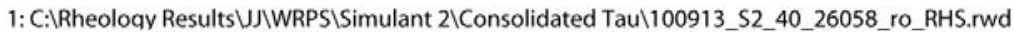

Company / Operator: PNNL / Jeromy Jenks

Date / Time / Version: 14.09.2010 / 16:26:14 PM / RheoWin Pro 296

Substance / Sample no: S2B1 / 100913_S2_40_26058_ro_RHS

Curve discussion: Greatest value $\mathrm{t}[\mathrm{s}] 9.190,[\mathrm{~Pa}] 8334$.

Figure D.57. Consolidated Simulant 2(44.8 wt\% ) 100913 shear strength (PA) as a function of time Measured at RHS

ThermoHaake RheoWin 9/28/2010/8:09 AM

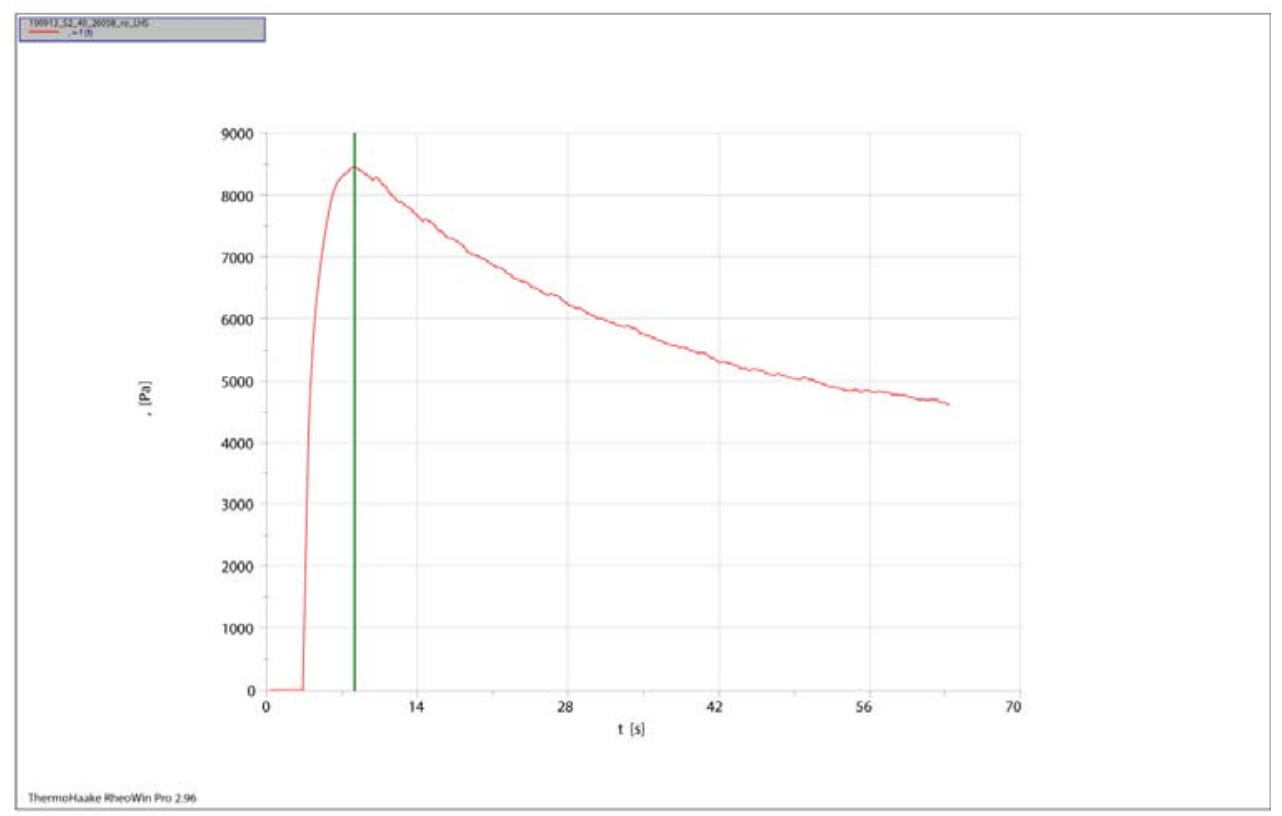

1: C:IRheoloqy Results\JWRPS\Simulant 2\Consolidated Tau\100913_S2_40_26058_ro_LHS.rwd

Company / Operator: PNNL / Jeromy Jenks

Date / Time / Version: 14.09.2010 / 16:29:18 PM / RheoWin Pro 296

Substance / Sample no: S2B1 / 100913_S2_40_26058_ro_LHS

Curve discussion: Greatest value $\mathrm{t}[\mathrm{s}] 8.189,[\mathrm{~Pa}] 846 \overline{5}$.

Figure D.58. Consolidated Simulant 2(44.8 wt\% ) 100913 shear strength (PA) as a function of time Measured at LHS 
ThermoHaake RheoWin 9/28/2010/8:18 AM

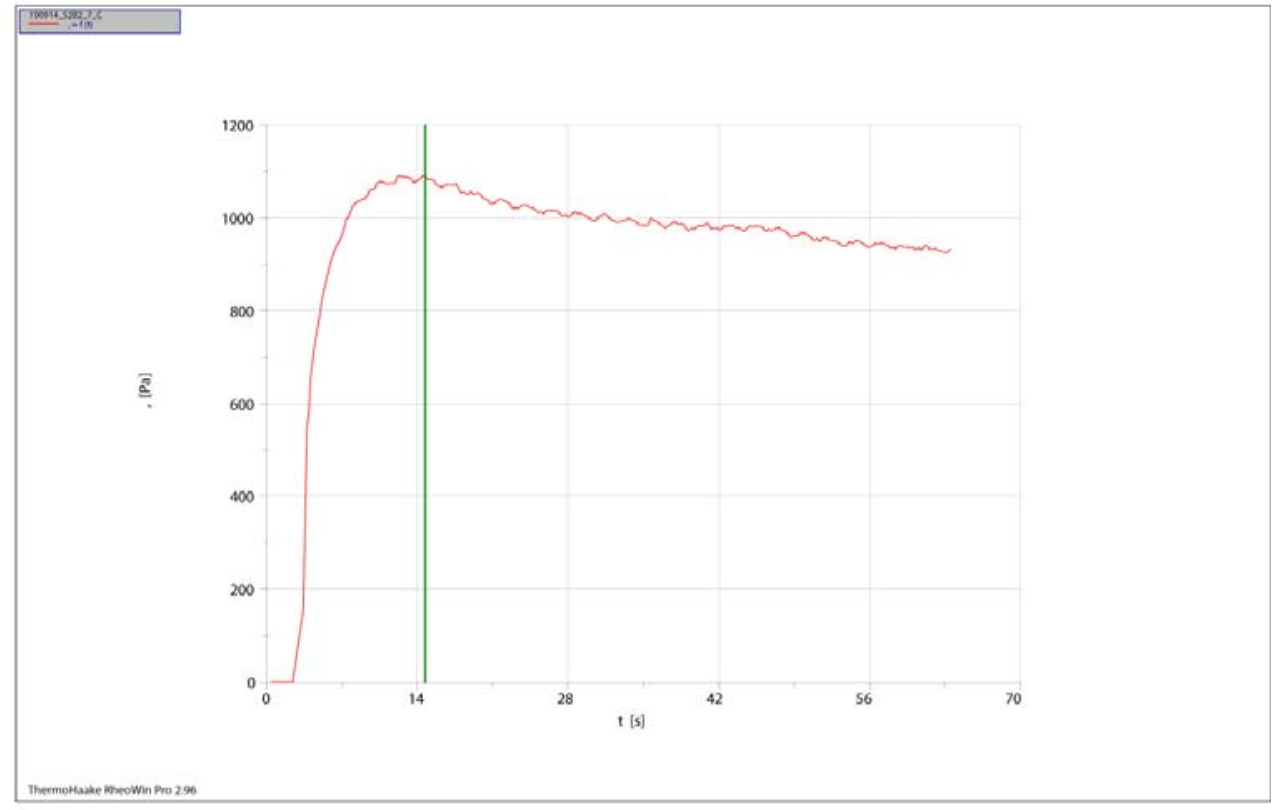

1: C:IRheoloqy Results\J\WRPSISimulant 2\Initial Tau\100914_S2B2_7_C.rwd

Company / Operator: PNNL / Jeromy Jenks

Date / Time / Version: 14.09.2010 / 22:19:33 PM / RheoWin Pro 296

Substance / Sample no: S2B2 / 100914 S2B2_7_C

Curve discussion: Greatest value $\mathrm{t}$ [s] 14.72 , [Pa] 1091.

Figure D.59. Initial Simulant $2(40.5 \mathrm{wt} \%)$ shear strength (PA) as a function of time Measured at Center

ThermoHaake RheoWin 9/28/2010/8:20 AM

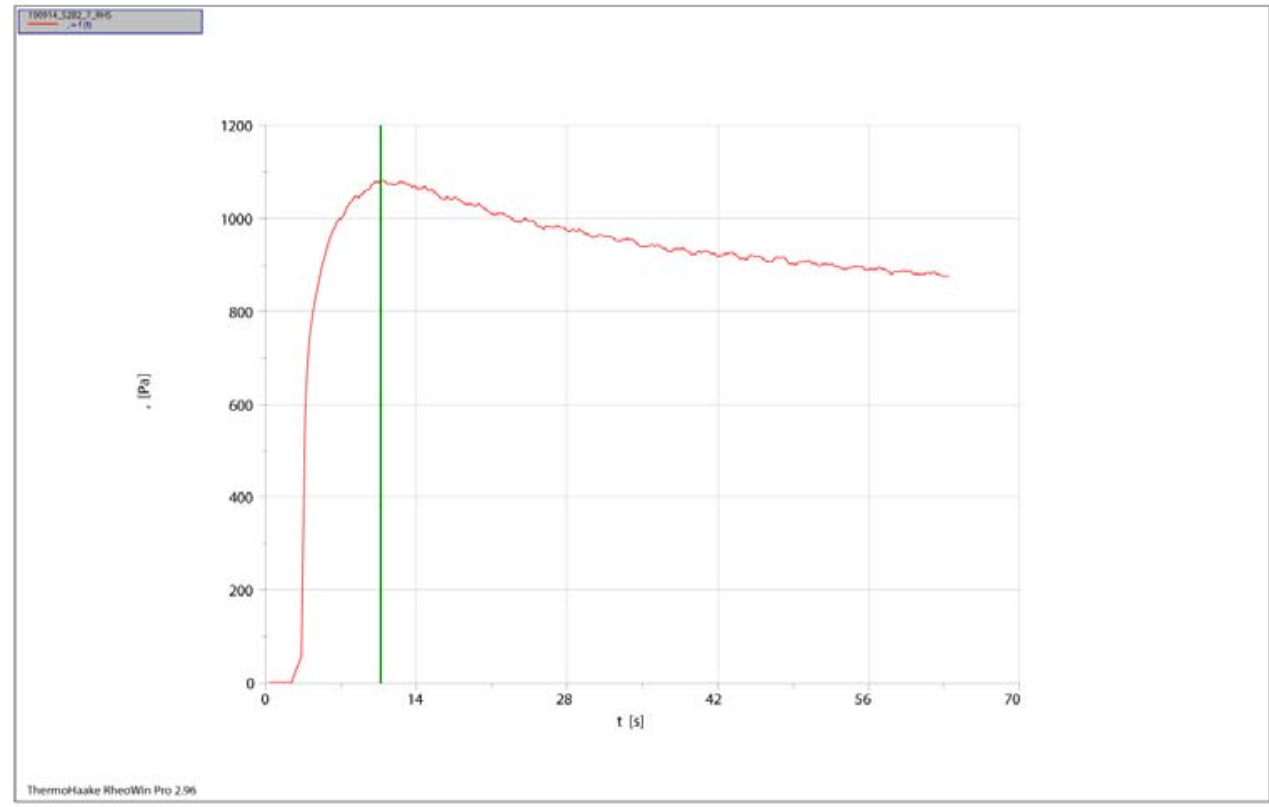

1: C:IRheoloqy Results\J\WRPS\Simulant 2\Initial Tau\100914_S2B2_7_RHS.rwd

Company / Operator: PNNL / Jeromy Jenks

Date / Time / Version: 14.09.2010 / 22:22:34 PM / RheoWin Pro 296

Substance / Sample no: S2B2 / 100914_S2B2_7_RHS

Curve discussion: Greatest value $\mathrm{t}[\mathrm{s}] 10.69,[\mathrm{~Pa}] 1083$.

Figure D.60. Initial Simulant $2(40.5 \mathrm{wt} \%)$ shear strength (PA) as a function of time Measured at RHS 
ThermoHaake RheoWin 9/28/2010/8:19 AM

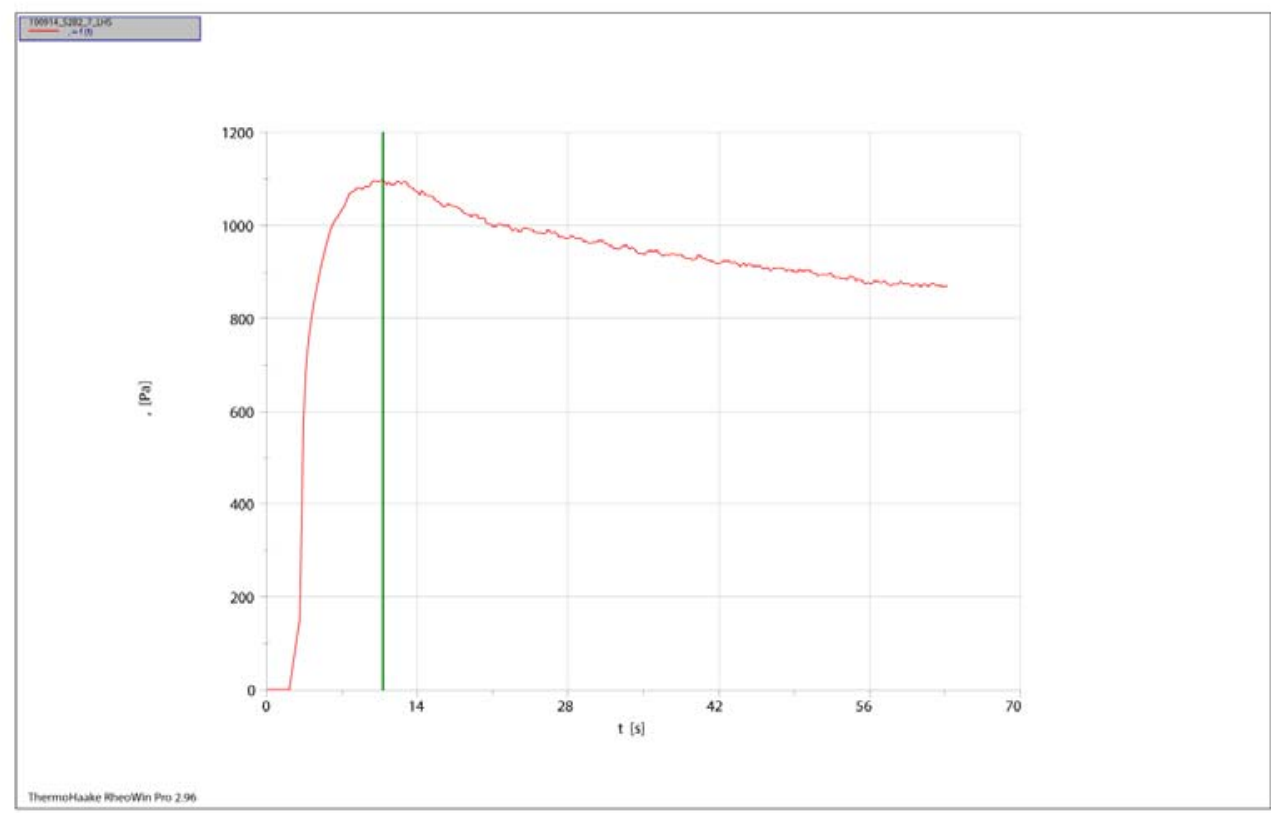

1: C:IRheoloqy Results\J\WRPS\Simulant 2\Initial Tau\100914_S2B2_7_LHS.rwd

Company / Operator: PNNL / Jeromy Jenks

Date / Time / Version: 14.09.2010 / 22:25:38 PM / RheoWin Pro 296

Substance / Sample no: S2B2 / 100914 _S2B2_7_LHS

Curve discussion: Greatest value $\mathrm{t}[\mathrm{s}] 10.81$, [Pa] 1099.

Figure D.61. Initial Simulant $2(40.5 \mathrm{wt} \%)$ shear strength (PA) as a function of time Measured at LHS

ThermoHaake RheoWin 9/28/2010/8:11 AM

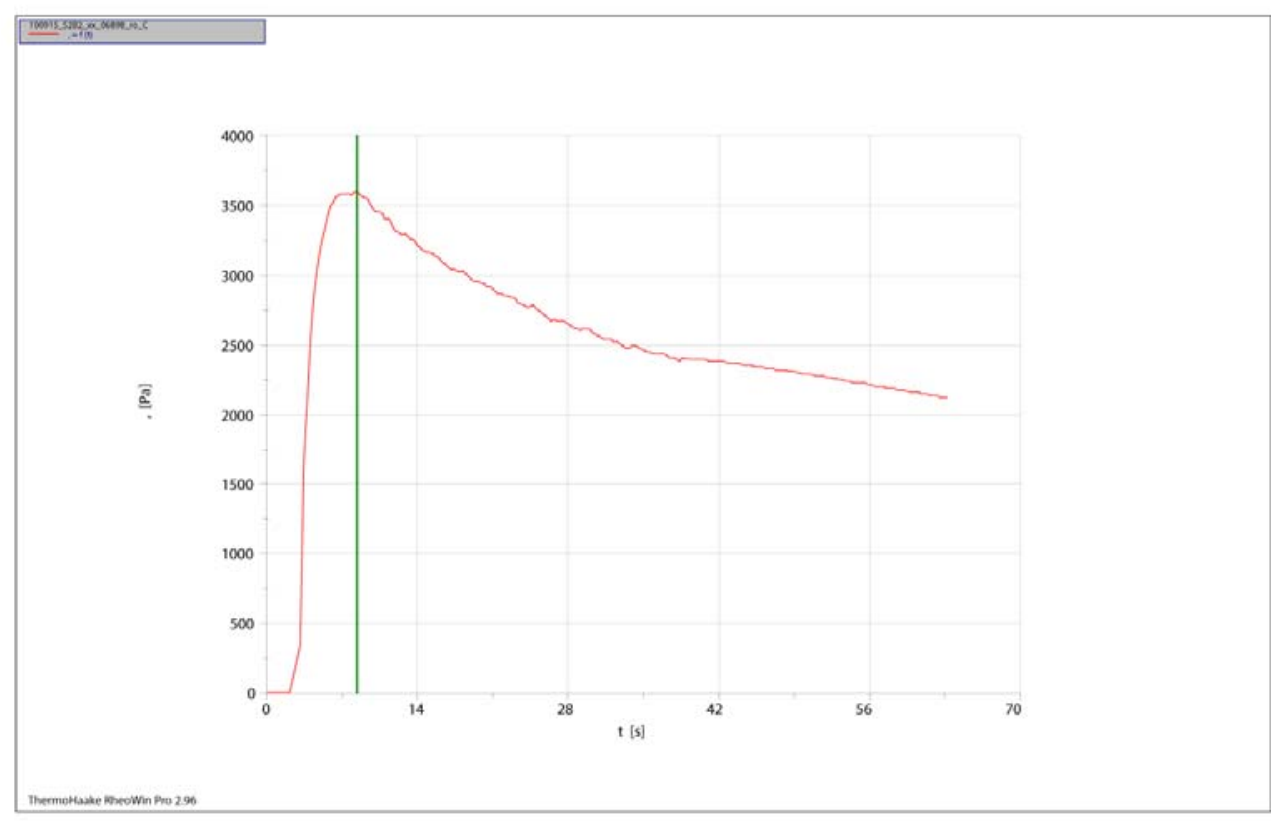

1: C:IRheoloqy Results\JWWRPS Simulant 2\Consolidated Tau\100915_S2B2_xx_06898_ro_C.rwd Company / Operator: PNNL / Jeromy Jenks

Date / Time / Version: 16.09.2010 / 10:39:55 AM / RheoWin Pro 296

Substance / Sample no: S2B2 / 100915_S2B2_xx_06898_ro_C

Curve discussion: Greatest value $\mathrm{t}[\mathrm{s}] \mathrm{8.419}$, [Pa] 3594.

Figure D.62. Consolidated Simulant $2(42.9 \mathrm{wt} \%) 100915$ shear strength (PA) as a function of time Measured at Center 
ThermoHaake RheoWin 9/28/2010/8:12 AM

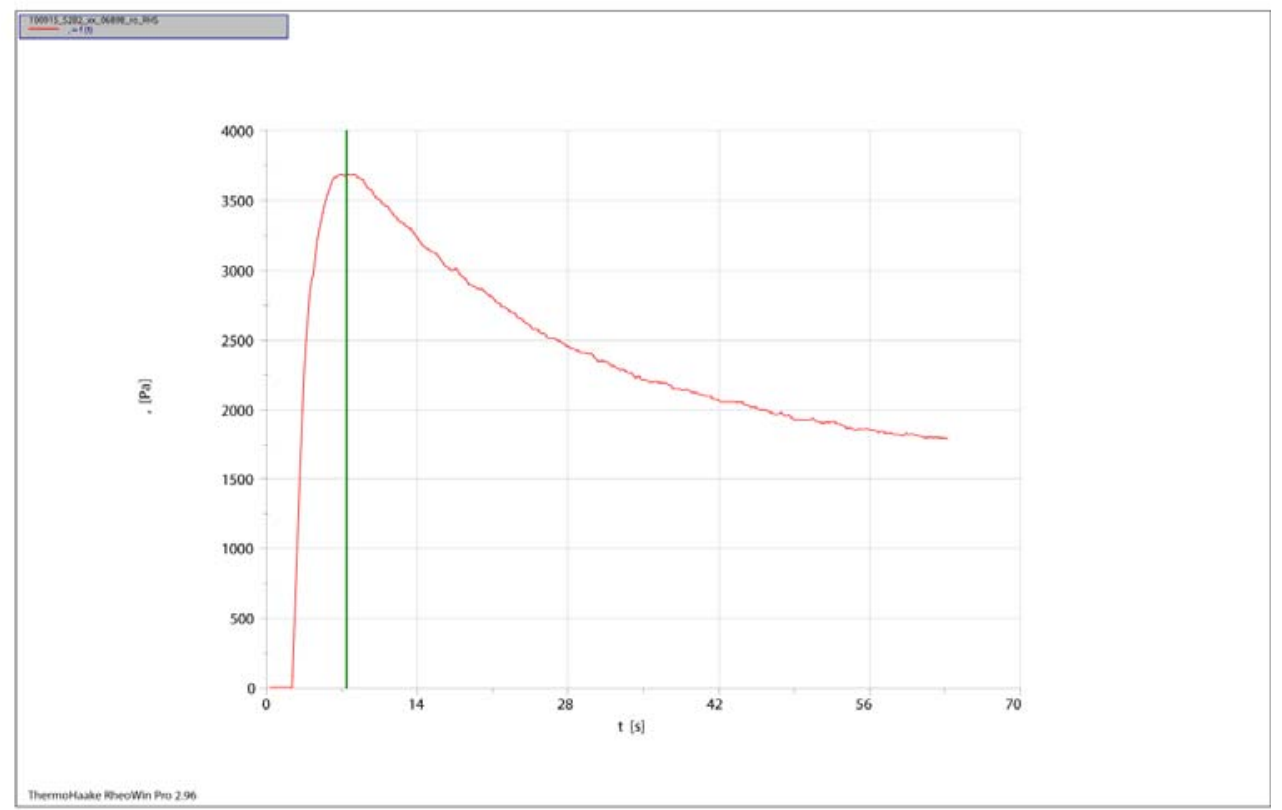

1: C:IRheoloqy Results \J\WRPS \Simulant 2\Consolidated Tau\100915_S2B2_xx_06898_ro_RHS.rwd Company / Operator: PNNL / Jeromy Jenks

Date / Time / Version: 16.09.2010/ 10:43:23 AM / RheoWin Pro 296

Substance / Sample no: S2B2 / 100915 S2B2_xx_06898_ro_RHS

Curve discussion: Greatest value $\mathrm{t}[\mathrm{s}] 7.437$, [Pa] 3690.

Figure D.63. Consolidated Simulant $2(42.9 \mathrm{wt} \%) 100915$ shear strength (PA) as a function of time Measured at RHS

ThermoHaake RheoWin 9/28/2010/8:12 AM

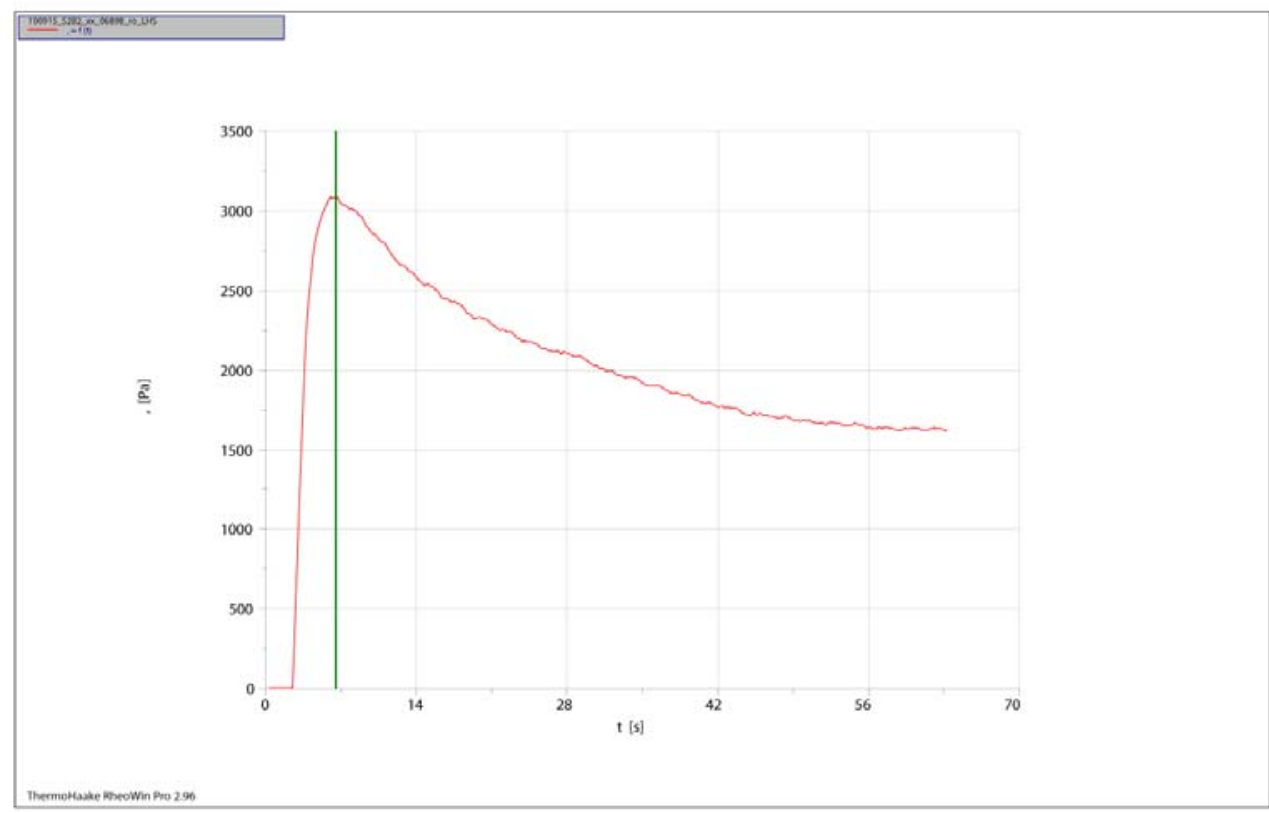

1: C:IRheoloqy Results\J\WRPS\Simulant 2\Consolidated Tau\100915 S2B2 xx 06898 ro LHS.rwd

Company / Operator: PNNL / Jeromy Jenks

Date / Time / Version: 16.09.2010 / 10:46:28 AM / RheoWin Pro 296

Substance / Sample no: S2B2 / 100915_S2B2_xx_06898_ro_LHS

Curve discussion: Greatest value $\mathrm{t}[\mathrm{s}] 6.546$, [Pa] 3086.

Figure D.64. Consolidated Simulant $2(42.9 \mathrm{wt} \%) 100915$ shear strength (PA) as a function of time Measured at LHS 
ThermoHaake RheoWin 9/28/2010/8:13 AM

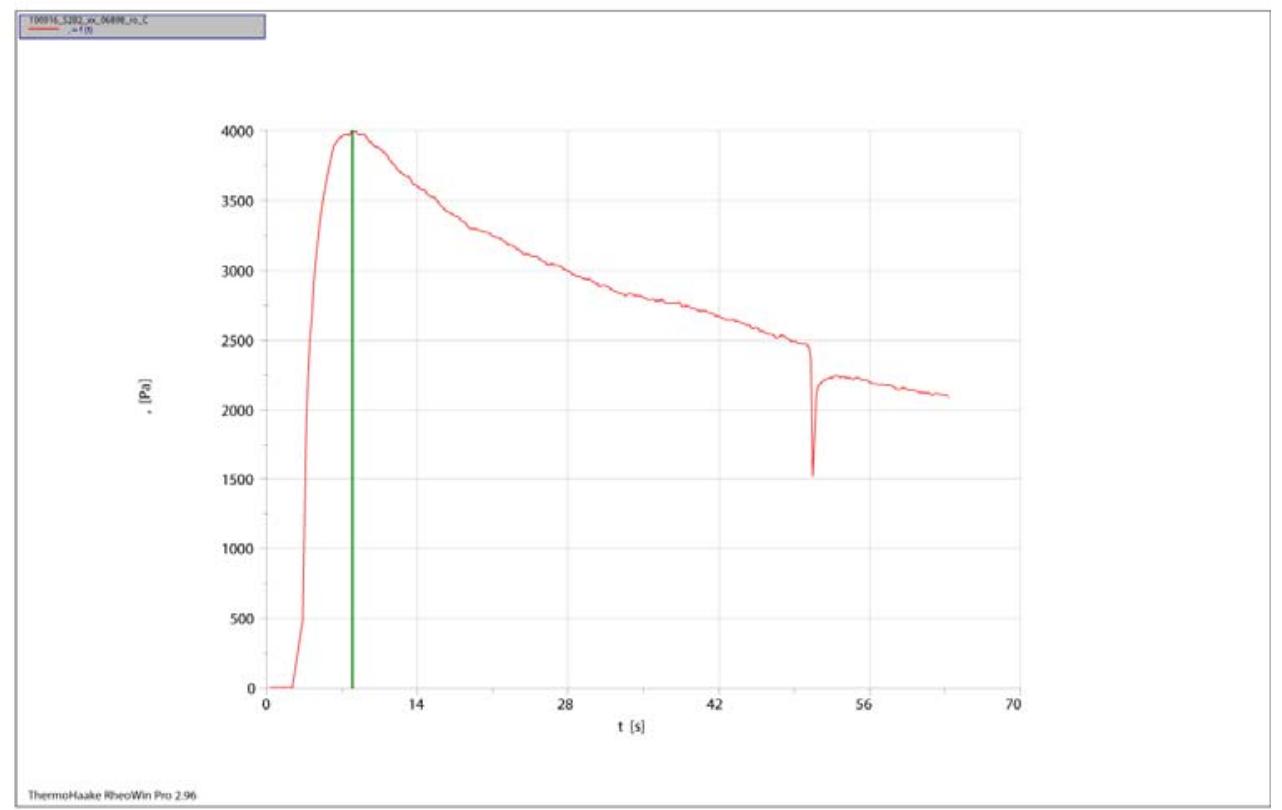

1: C:IRheoloqy Results \J\WRPS\Simulant 2\Consolidated Tau\100916_S2B2_xx_06898_ro_C.rwd

Company / Operator: PNNL / Jeromy Jenks

Date / Time / Version: 17.09.2010 / 13:26:57 PM / RheoWin Pro 296

Substance / Sample no: S2B2 / 100916 S2B2_xx_06898_ro_C

Curve discussion: Greatest value $\mathrm{t}[\mathrm{s}] 7.978,[\mathrm{~Pa}] 3998$.

Figure D.65. Consolidated Simulant $2(42.8 \mathrm{wt} \%) 100916$ shear strength (PA) as a function of time Measured at Center

ThermoHaake RheoWin 9/28/2010/8:15 AM

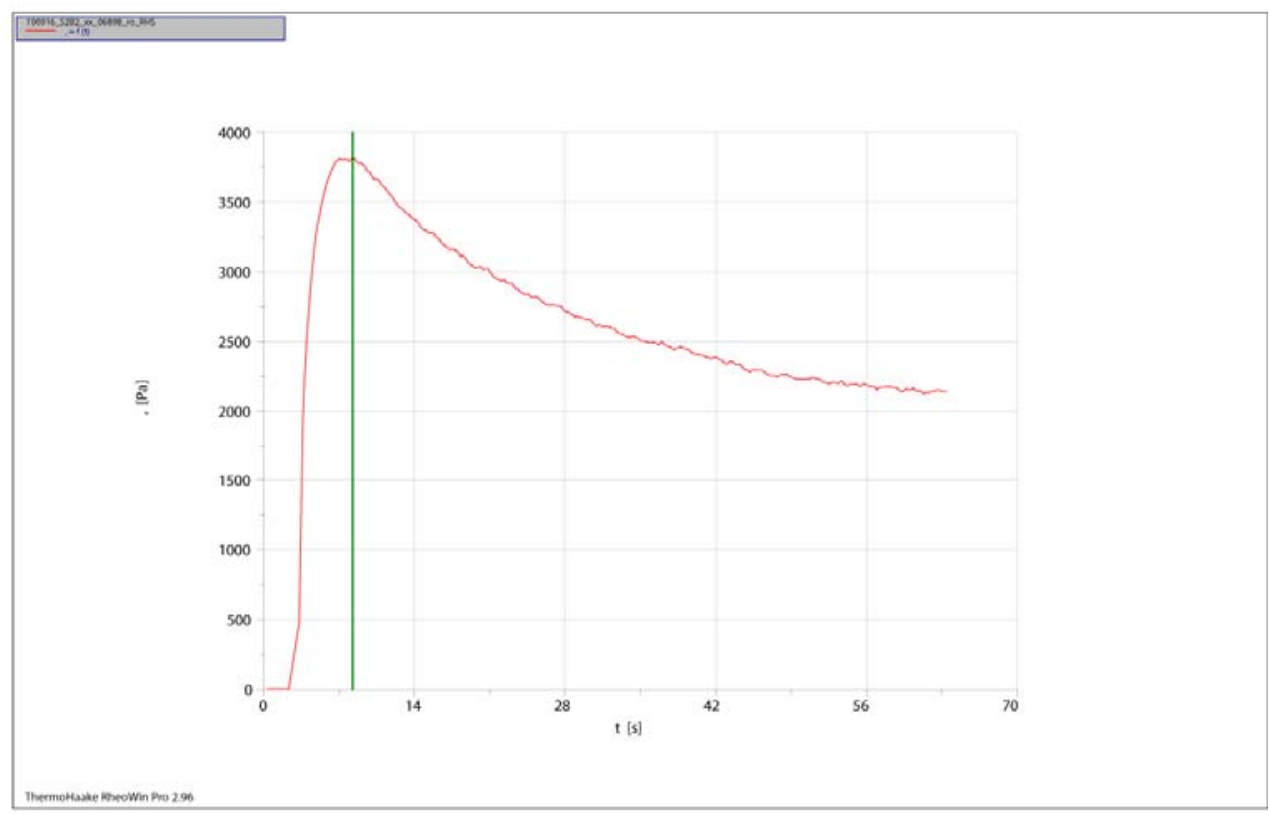

1: C:IRheoloqy Results\J\WRPS\Simulant 2\Consolidated Tau\100916 S2B2 xx 06898 ro RHS.rwd

Company / Operator: PNNL / Jeromy Jenks

Date / Time / Version: 17.09.2010/13.29:48 PM / RheoWin Pro 296

Substance / Sample no: S2B2 / 100916 S2B2_xx_06898_ro_RHS

Curve discussion: Greatest value $\mathrm{t}[\mathrm{s}] \mathrm{8.279}$, [Pa] 3816.

Figure D.66. Consolidated Simulant $2(42.8 \mathrm{wt} \%) 100916$ shear strength (PA) as a function of time Measured at RHS

D.35 
ThermoHaake RheoWin 9/28/2010/8:14 AM

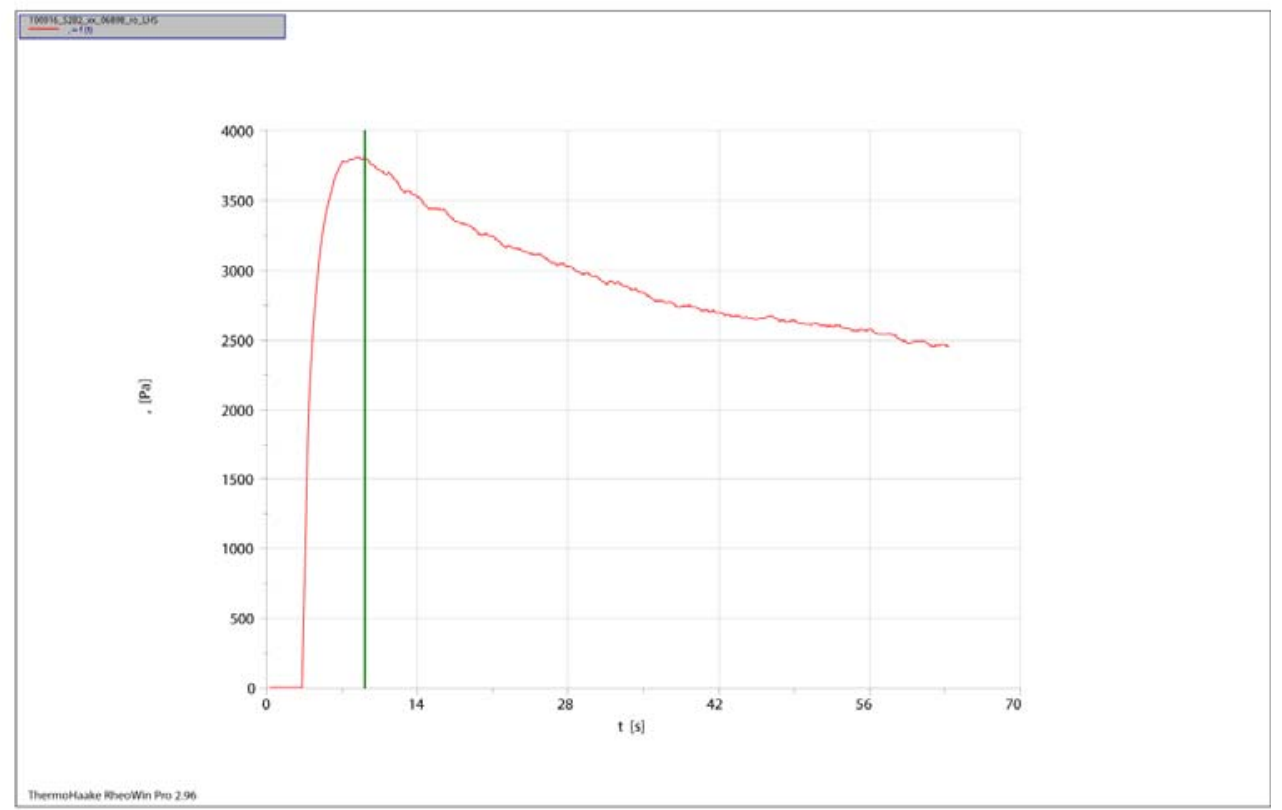

1: C:IRheoloqy Results\J\WRPS\Simulant 2\Consolidated Tau\100916_S2B2_xx_06898_ro_LHS.rwd

Company / Operator: PNNL / Jeromy Jenks

Date / Time / Version: 17.09.2010 / 13:34:07 PM / RheoWin Pro 296

Substance / Sample no: S2B2 / 100916_S2B2_xx_06898_ro_LHS

Curve discussion: Greatest value $\mathrm{t}[\mathrm{s}] \mathrm{9.120},[\mathrm{Pa}] 3807$.

Figure D.67. Consolidated Simulant $2(42.8 \mathrm{wt} \%) 100916$ shear strength (PA) as a function of time Measured at LHS

ThermoHaake RheoWin 9/28/2010/8:25 AM

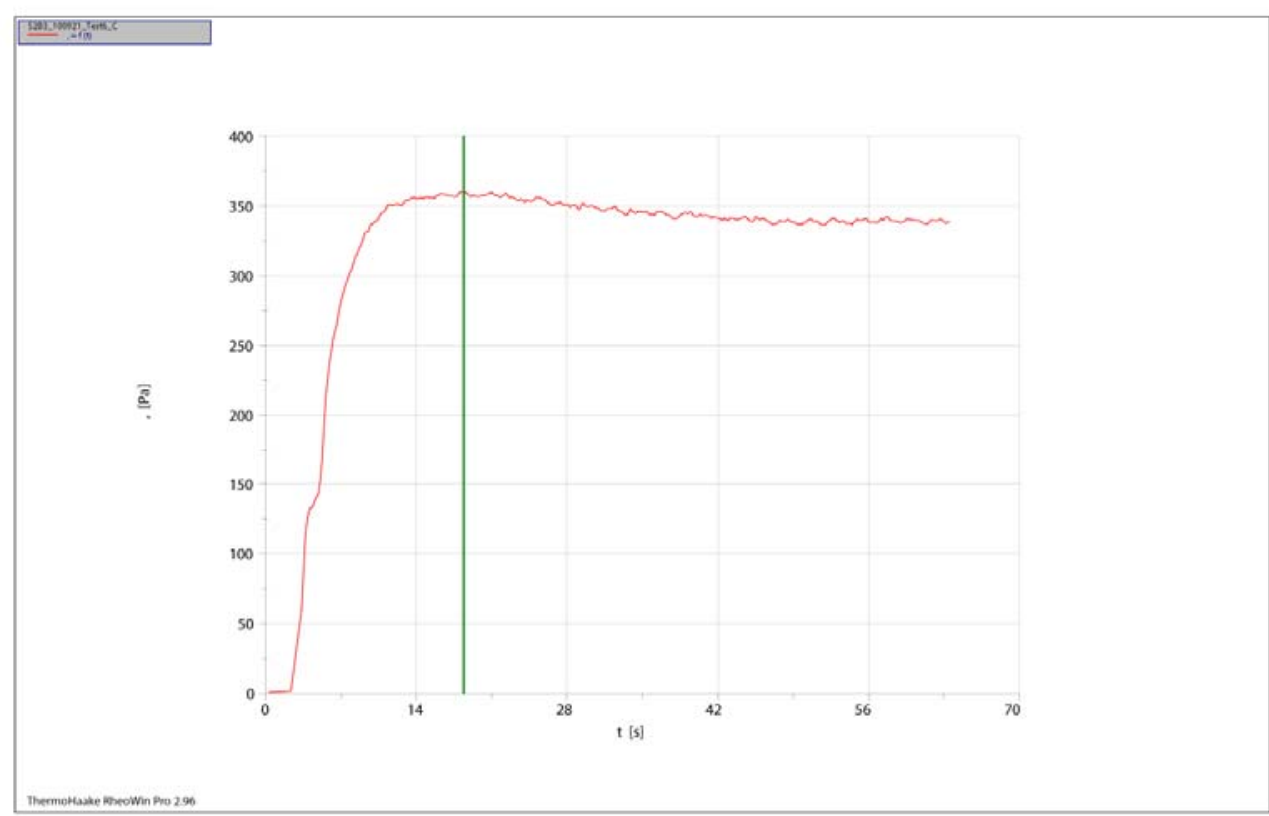

1: C:IRheoloqy Results\J\WRPS\Simulant 2\Initial Tau\S2B3_100921_Test6_C.rwd

Company / Operator: PNNL / Jeromy Jenks

Date / Time / Version: 21.09.2010 / 15:49:20 PM / RheoWin Pro 296

Substance / Sample no: S2B3 / S2B3_100921_Test6 C

Curve discussion: Greatest value $t[\mathrm{~s}] 18.42$, [Pa] 360.4

Figure D.68. Initial Simulant $2(36.5 \mathrm{wt} \%)$ shear strength (PA) as a function of time Measured at Center

D.36 


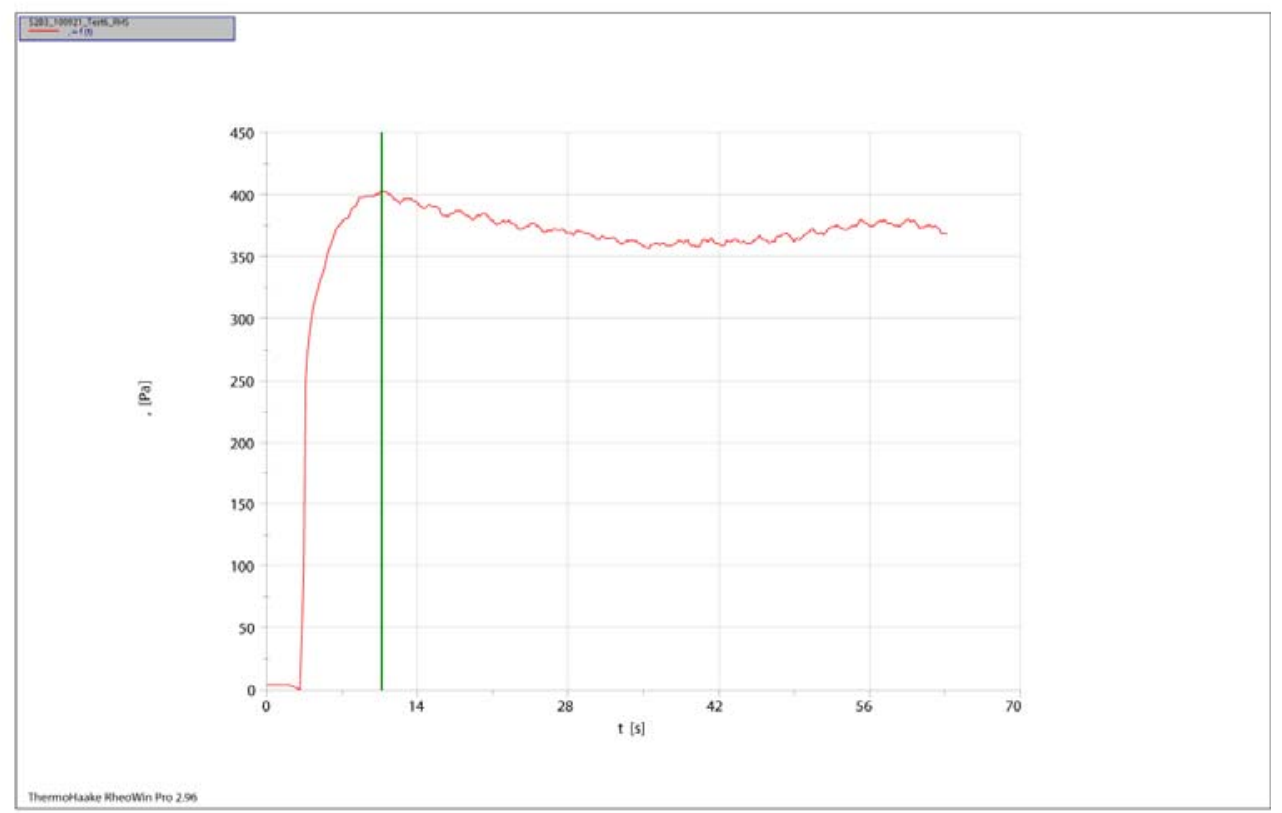

1: C:IRheoloqy Results UJ\WRPSISimulant 2\Initial Tau\S2B3_100921_Test6_RHS.rwd

Company / Operator: PNNL / Jeromy Jenks

Date / Time / Version: 21.09.2010 / 15:52:27 PM / RheoWin Pro 296

Substance / Sample no: S2B3 / S2B3_100921_Test6_RHS

Curve discussion: Greatest value $\mathrm{t}[\mathrm{s}] 10.70,[\mathrm{~Pa}] 403.5$

Figure D.69. Initial Simulant $2(36.5 \mathrm{wt} \%)$ shear strength (PA) as a function of time Measured at RHS

ThermoHaake RheoWin 9/28/2010/8:25 AM

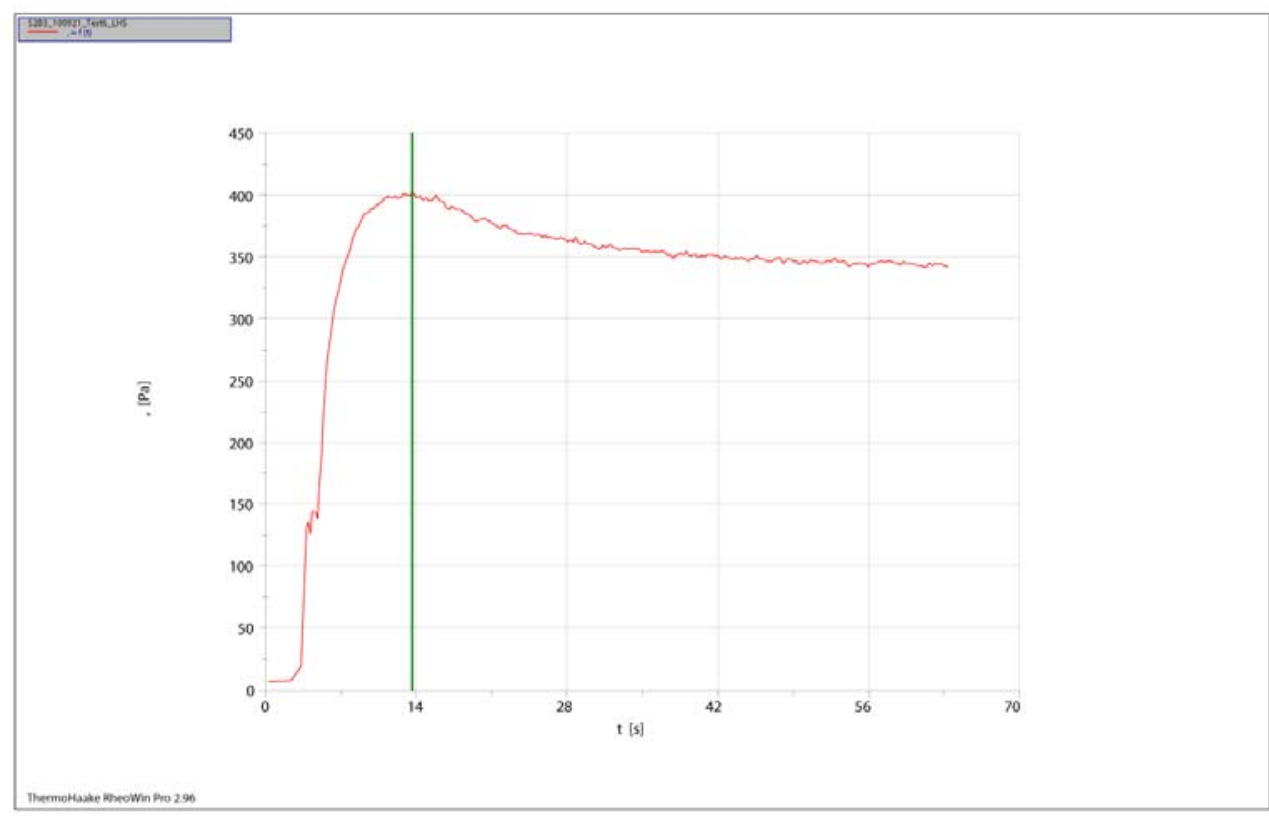

1: C:IRheoloqy Results \J\WRPS\Simulant 2\Initial Tau\S2B3_100921_Test6_LHS.rwd

Company / Operator: PNNL / Jeromy Jenks

Date / Time / Version: 21.09.2010 / 15:54:53 PM / RheoWin Pro 296

Substance / Sample no: S2B3 / S2B3_100921_Test6_LHS

Curve discussion: Greatest value $\mathrm{t}[\mathrm{s}] 13.63,[\mathrm{~Pa}] 402.2$

Figure D.70. Initial Simulant $2(36.5 \mathrm{wt} \%)$ shear strength (PA) as a function of time Measured at LHS 
ThermoHaake RheoWin 9/28/2010/8:15 AM

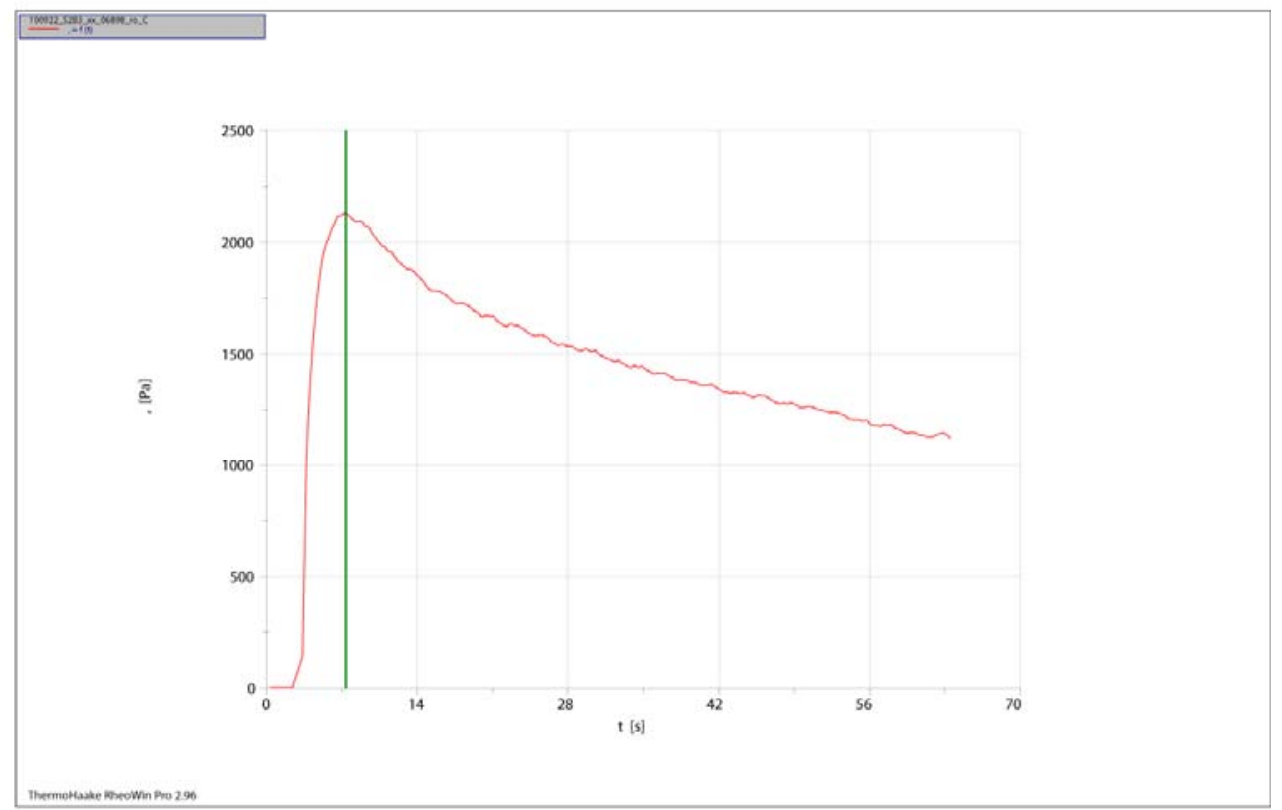

1: C:IRheoloqy Results\JWWRS \Simulant 2\Consolidated Tau\100922_S2B3_xx_06898_ro_C.rwd

Company / Operator: PNNL / Jeromy Jenks

Date / Time / Version: 23.09.2010 / 3:37:02 AM / RheoWin Pro 296

Substance / Sample no: S2B3 / 100922_S2B3_xx_06898_ro_C

Curve discussion: Greatest value $\mathrm{t}[\mathrm{s}] 7.368$, [Pa] 2130.

Figure D.71. Consolidated Simulant $2(40.3 \mathrm{wt} \%) 100922$ shear strength (PA) as a function of time Measured at Center

ThermoHaake RheoWin 9/28/2010/8:17 AM

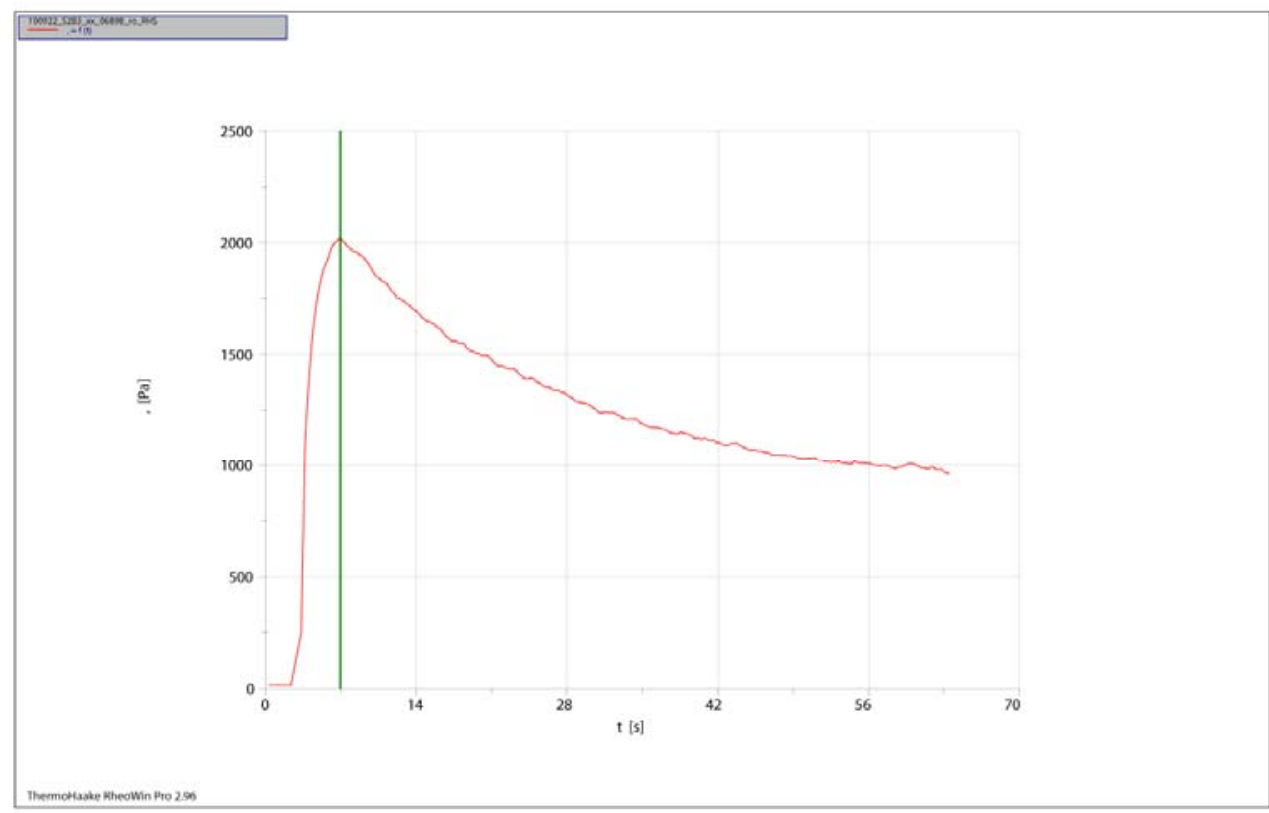

1: C:IRheoloqy Results\J\WRPS\Simulant 2\Consolidated Tau\100922_S2B3_xx_06898_ro_RHS.rwd

Company / Operator: PNNL / Jeromy Jenks

Date / Time / Version: 23.09.2010 / 3:39.59 AM / RheoWin Pro 296

Substance / Sample no: S2B3 / 100922 S2B3 xx 06898_ro_RHS

Curve discussion: Greatest value $\mathrm{t}$ [s] 6.947, [Pa] 2021.

Figure D.72. Consolidated Simulant $2(40.3 \mathrm{wt} \%) 100922$ shear strength (PA) as a function of time Measured at RHS 
ThermoHaake RheoWin 9/28/2010/8:16 AM

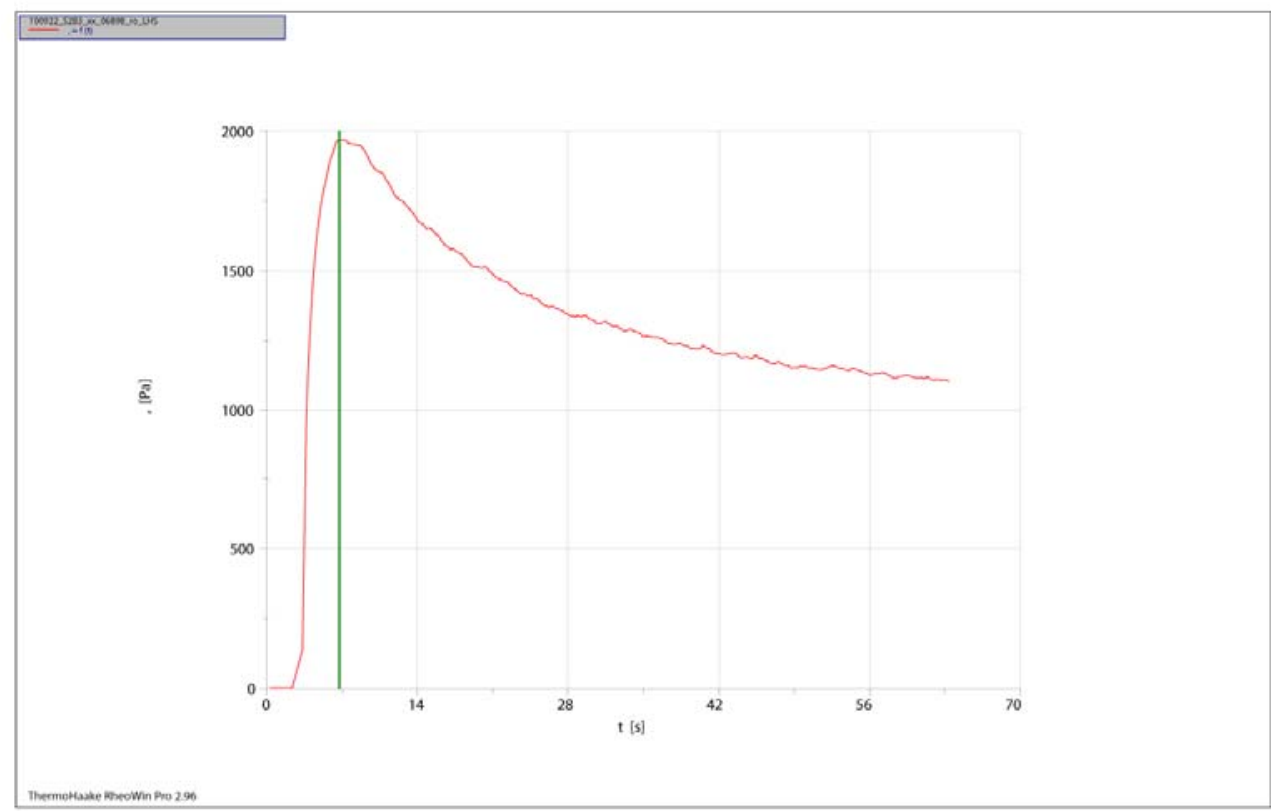

1: C:IRheoloqy Results UJ\WRPS\Simulant 2\Consolidated Tau\100922_S2B3 xx_06898_ro_LHS.rwd Company / Operator: PNNL / Jeromy Jenks

Date / Time / Version: 23.09.2010 / 3:42:54 AM / RheoWin Pro 296

Substance / Sample no: S2B3 / 100922_S2B3_xx_06898_ro_LHS

Curve discussion: Greatest value $\mathrm{t}[\mathrm{s}] 6.767,[\mathrm{~Pa}] 1967$.

Figure D.73. Consolidated Simulant $2(40.3 \mathrm{wt} \%) 100922$ shear strength (PA) as a function of time Measured at LHS 

PNNL-19829

\section{Distribution}

No. of

Copies

OFFSITE

2 P. Arduino

1321 More Hall, Box 352700

University of Washington

Seattle, WA 98195-2700
No. of

Copies

\section{ONSITE}

$7 \quad$ Pacific Northwest National Laboratory

HE Adkins

K7-15

N. Bauman

K5-16

G. Boeringa

K7-15

P. A. Gauglitz

$\mathrm{K} 7-15$

A. D. Guzman

K5-22

J. Jenks

K7-15

B. E. Wells

K7-15

Information Release (pdf)

3 WRPS

N. W. Kirch

R2-58

J. E. Meacham

R2-58

D. J. Washenfelder

R2-58

Distr. 1 




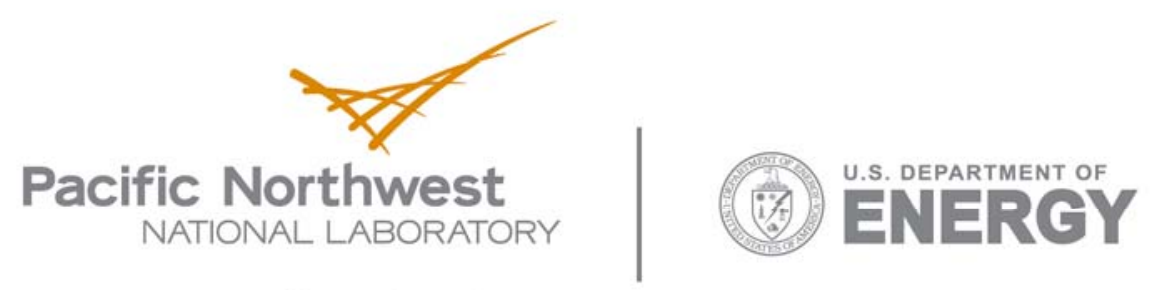

902 Battelle Boulevard

P.O. Box 999

Richland, WA 99352

1-888-375-PNNL (7665)

www.pnl.gov 